\title{
Dietary folate, genetic variation and DNA methylation in sporadic colorectal cancer
}

Citation for published version (APA):

de Vogel, S. C. (2009). Dietary folate, genetic variation and DNA methylation in sporadic colorectal cancer. [Doctoral Thesis, Maastricht University]. Maastricht University.

https://doi.org/10.26481/dis.20090618sv

Document status and date:

Published: 01/01/2009

DOI:

10.26481/dis.20090618sv

Document Version:

Publisher's PDF, also known as Version of record

\section{Please check the document version of this publication:}

- A submitted manuscript is the version of the article upon submission and before peer-review. There can be important differences between the submitted version and the official published version of record.

People interested in the research are advised to contact the author for the final version of the publication, or visit the DOI to the publisher's website.

- The final author version and the galley proof are versions of the publication after peer review.

- The final published version features the final layout of the paper including the volume, issue and page numbers.

Link to publication

\footnotetext{
General rights rights.

- You may freely distribute the URL identifying the publication in the public portal. please follow below link for the End User Agreement:

www.umlib.nl/taverne-license

Take down policy

If you believe that this document breaches copyright please contact us at:

repository@maastrichtuniversity.nl

providing details and we will investigate your claim.
}

Copyright and moral rights for the publications made accessible in the public portal are retained by the authors and/or other copyright owners and it is a condition of accessing publications that users recognise and abide by the legal requirements associated with these

- Users may download and print one copy of any publication from the public portal for the purpose of private study or research.

- You may not further distribute the material or use it for any profit-making activity or commercial gain

If the publication is distributed under the terms of Article $25 \mathrm{fa}$ of the Dutch Copyright Act, indicated by the "Taverne" license above, 


\section{Dietary folate, genetic variation and DNA methylation in sporadic colorectal cancer}


ISBN:

$978-94-9012-214-0$

Cover design: Bas Verhage

Lay-out: Yvonne Leenders

Printed by: $\quad$ Gildeprint Drukkerijen BV, Enschede

(C) 2009, S.C. de Vogel

All rights reserved. No part of this thesis may be reproduced or transmitted in any form or by any means, electronic or mechanical, including photocopying, recording or any information storage or retrieval system, without permission in writing from the author, or, when appropriate, from the publishers of the publications. 


\section{Dietary folate, genetic variation and DNA methylation in sporadic colorectal cancer}

\section{Proefschrift}

Ter verkrijging van de graad van doctor

aan de Universiteit Maastricht,

op gezag van de Rector Magnificus

Prof. Mr. G.P.M.F. Mols,

volgens het besluit van het college van Decanen,

in het openbaar te verdedigen

op donderdag 18 juni 2009 om 14:00 uur

door

Stefan Christiaan de Vogel 


\section{Promotor}

Prof. Dr. Ir. P.A. van den Brandt

\section{Copromotors}

Dr. M. van Engeland

Dr. Ir. M.P. Weijenberg

\section{Beoordelingscommissie}

Prof. Dr. F.C.S. Ramaekers (voorzitter)

Prof. Dr. Ir. E. Kampman (Wageningen Universiteit)

Dr. C.M. Ulrich (Fred Hutchinson Cancer Research Center, Seattle, USA)

Dr. J.W. Voncken

Prof. Dr. M.P.A. Zeegers

The studies described in this thesis were funded by the Dutch Cancer Society

Financial support for printing of this thesis was provided by the Stichting Nationaal Fonds tegen Kanker and the Dutch Cancer Society

The studies presented in this thesis were conducted at GROW - School for Oncology and Developmental Biology, Maastricht University, departments of Epidemiology and Pathology. 
Voor oom Fred en oma van Keeken 



\section{Contents}

Chapter 1

Introduction

Chapter 2

MGMT and MLH1 promoter methylation versus $A P C, K R A S$ and $B R A F$ gene mutations in colorectal cancer: indications for distinct pathways and sequence of events

Chapter 3

Dietary folate, methionine, riboflavin and vitamin B-6 and risk of sporadic colorectal cancer

Chapter 4

Dietary folate and $A P C$ mutations in sporadic colorectal cancer

Chapter 5

Associations of dietary methyl donor intake with MLH1 promoter hypermethylation and related molecular phenotypes in sporadic colorectal cancer

Chapter 6

Genetic variants of methyl metabolizing enzymes and epigenetic regulators: associations with promoter $\mathrm{CpG}$ island hypermethylation in colorectal cancer

Chapter 7

Dietary methyl donors, methyl metabolizing enzymes and epigenetic regulators: diet-gene interactions and promoter CpG island hypermethylation in colorectal cancer

Chapter 8

Epilogue

Summary

Samenvatting

Dankwoord 



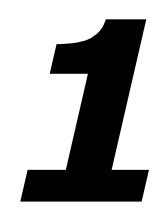

Introduction 
Adequate intake of the B-vitamin folate is important for the prevention of neural tube defects during embryonal development $(1,2)$. These observations led to a regulation in the US and Canada of mandatory fortification of flour and grains with folic acid in the year 1998, and several other countries are currently discussing whether or not to introduce nation-wide folic acid fortification. Folic acid supplementation may also prevent stroke (3). In addition, several observational studies suggested that high intake of dietary folate may protect against colorectal cancer, although results have been inconsistent $(4,5)$. One explanation for such inconsistencies may be the recently hypothesized dual role of folate in colorectal carcinogenesis, i.e. it may protect against neoplasia in normal colorectal mucosa whereas folate supplementation might enhance existing pre-malignant lesions (6). Accounting for approximately $13 \%$ of total cancer incidence, colorectal cancer is the second most common type of cancer and the second most common form of cancer death (7) in Europe, indicating the importance of studying potential determinants of the disease.

The focus of this thesis was to study associations of dietary folate and other methyl donors with overall colorectal cancer, and specifically colorectal tumors characterized by the presence or absence of gene mutations or gene promoter hypermethylation. We also studied whether genetic variants of folate metabolizing enzymes and epigenetic regulators modify these associations. In addition, we studied the occurrence of, and overlap between specific molecular characteristics in colorectal tumors.

\section{Dietary methyl donors and colorectal cancer}

\section{Folate: naturally occurring folates and folic acid}

Folate is a B-vitamin mainly present in green leafy vegetables, fruits, dairy products, meat, bread and potatoes (8). The term "folate" is used for a group of compounds with similar chemical and nutritional properties and includes folates that occur naturally in our diet, as well as folic acid which is the chemically stable synthetic form of folate used in dietary supplements and fortified foods. Naturally occurring folates predominantly exist as 5-methyl-tetrahydrofolate (5-methyl-THF), which is also the main circulating form of folate, and typically are a mixture with other tetradydrofolates such as 5,10-methylene-THF, 10-formyl-THF and other less common forms $(9,10)$. They are mostly polyglutamates and may differ in length depending on the number of attached glutamate chains. These polyglutamates first have to be hydrolyzed to monoglutamates in order to enable transport through cell membranes. Folic acid is a monoglutamate and may directly be transported through the intestinal brush border without this enzymatic conversion (6), and the bioavailability of folic acid is therefore higher compared to naturally occurring folates (11).

\section{Folate metabolism}

Folate is needed for the biosynthesis of the pyrimidine nucleoside thymidine and of purines, and thereby plays an essential role in DNA synthesis. The folate intermediate 5,10-methylene-THF serves as a methyl donor to convert deoxyuridine monophosphate (dUMP) into deoxythymidine monophosphate (dTMP) (Figure 1, Panel A). Folate deficiency may result in accumulation of dUMP, induce uracil mis-incorporation in DNA 
(instead of thymidine) and result in subsequent DNA instability, chromosomal damage and malignant transformation (12).

In addition, folate is a methyl group donor which may influence DNA methylation such as CpG island promoter hypermethylation or global hypomethylation, both of which are often observed in colorectal cancer $(13,14)$. The conversion of homocysteine into methionine, with 5-methyl-THF as a substrate, is important for the synthesis of Sadenosylmethionine, which is the universal methyl group donor needed for methylation processes (15). Since methionine itself is present in our diet, it is considered as a methyl group donor in addition to folate.

Vitamins B2, B6 and B12 are involved in folate metabolism, and may therefore modulate the bioavailability of methyl groups (15). Vitamin B2, or riboflavin, is the cofactor for methylenetetrahydrofolate reductase (MTHFR), the enzyme that reduces 5,10-methylene-THF in 5-methyl-THF. Methionine synthase (MTR) and methionine synthase reductase (MTRR) convert homocysteine into methionine, which is a vitamin B12-dependent reaction. In addition, vitamin B6 is involved in the conversion of tetrahydrofolate into 5,10-methylenetetrahydrofolate, one of the steps of the folate cycle (15).

Adequate intakes of dietary folate, methionine, vitamins B2, B6 and B12 ensure a sufficient supply of methyl groups, and may be hypothesized to prevent DNA instability and aberrant DNA methylation thereby protecting against colorectal cancer.

\section{Associations between folate, other methyl donors and colorectal cancer}

The relation between dietary folate and colorectal cancer has previously been studied in many observational studies, but results have been inconsistent. A meta-analysis estimating the aggregate effect of folate, suggested that dietary folate may have a small protective effect against colorectal cancer (an overall risk reduction of approximately $25 \%$ ), and that this effect was not present for total folate intake (i.e. including folic acid supplements) (5). However, a literature review showed that out of the 23 case-control and cohort studies conducted so far, only 10 studies suggested a protective effect of folate on colorectal cancer (4).

Relatively high methionine intake did not seem to protect against CRC (16-19). In addition, whereas a potential protective effect of vitamin B2 intake against colorectal adenomas was observed in one study (20), it was not associated with colorectal cancer $(19,21)$. Several studies demonstrated an inverse association between vitamin B6 intake or plasma levels of vitamin B6 and CRC $(18,22-26)$, although in one study, a positive association was observed between the vitamin and rectal tumors among women (17).

There may be a number of reasons for inconsistencies between observational studies, for example differences in study design, study populations and endpoints. In this respect, some of the studies had a prospective cohort design $(16,17,22-25)$, whereas others were case-control studies (18-21). Moreover, some studies were conducted among women only $(16,17,23-25)$ or in relation to colorectal adenomas (20), and there are considerable differences in the level of vitamin intake between studies. Also, particularly study populations in the US may be exposed to higher levels of folic acid intake due to the use of dietary supplements (27), and it is currently unknown if folic acid has a similar effect on colorectal carcinogenesis as compared to dietary folate. 
We aimed to investigate the associations between dietary folate, methionine, vitamin B2 and vitamin B6 in a prospective setting in the Netherlands Cohort Study on diet and cancer (NLCS) within a large group of incident colorectal cancer patients (chapter 3).

\section{Molecular pathways to colorectal cancer}

\section{Hereditary versus sporadic colorectal cancer}

Colorectal cancer may either be caused by hereditary factors, or alternatively, develop as sporadic colorectal cancer. Two well-characterized types of hereditary colorectal cancer are familial adenomatous polyposis coli (FAP) and hereditary nonpolyposis colorectal cancer (HNPCC or Lynch syndrome). Individuals with FAP have a mutation in the Adenomatous Polyposis Coli (APC) gene and typically develop multiple colorectal adenomatous polyps already in early adulthood, which are likely to result in colorectal cancer (28). FAP accounts for less than $1 \%$ of colorectal cancer cases (29). Patients with HNPCC often have germline mutations in the mismatch repair (MMR) genes $M L H 1$, MSH2 and MSH6, which have been observed in $39 \%, 42 \%$ and $18 \%$ of MMR mutation carriers among a large group of colorectal cancer patients (30). However, only $1-5 \%$ of colorectal cancer cases are estimated to develop as a result of HNPCC $(29,31,32)$. The majority of colorectal cancers occurs sporadically (from here called colorectal cancer) and will be the investigated in this thesis. In the Netherlands, almost 11000 colorectal cancer patients have been identified in the year 2005, and 4562 patients died of the disease (33).

\section{Gene mutations driving colorectal carcinogenesis}

In the early 1990s, a genetic model of the carcinogenesis of colorectal cancer was postulated by Fearon and Vogelstein (34). The authors described the sequential transformation from normal colorectal epithelium, through aberrant crypt foci, colorectal adenomas, colorectal carcinomas and finally metastasis, as a process during which accumulation of gene mutations occur which contribute to carcinogenesis. Mutations of the tumor suppressor gene $A P C$ were observed to be early events in colorectal carcinogenesis. Kirsten-ras (KRAS) oncogene mutations would be involved in the transformation from early to late adenomas, and mutations in the P53 tumor suppressor gene in the development of adenomas to carcinomas. This model was used by many scientists in the field of colorectal cancer research in the years thereafter. With new technologies that are available nowadays, it has become possible to perform whole-genome sequence analyses. When screening 18,191 genes for gene mutations, it appeared that less than 15 mutations were likely to be responsible for tumor initiation or progression, and that $A P C, K R A S$ and $P 53$ are mutated in the majority of colorectal tumors (35).

Microsatellite instability and chromosomal instability

Other mechanisms that may contribute to colorectal carcinogenesis involve either microsatellite instability (MSI), or chromosomal instability (CIN). MSI is a type of genetic instability that is characterized by length alterations within simple repeated 
microsatellite sequences (36). MSI occurs in approximately $15 \%$ of colorectal cancers and may be caused by the inactivation of mismatch repair (MMR) genes. Most sporadic MSI tumors show epigenetic silencing by promoter hypermethylation, of the MMR gene MLH1 $(37,38)$. Alternatively, CIN refers to the rate with which whole chromosomes (or large portions thereof) are gained or lost in cancers. CIN tumors therefore contain an abnormal chromosomal content and are thought to represent the remaining $85 \%$ of colorectal cancers (39).

\section{CpG island methylator phenotype (CIMP)}

In addition to genetic alterations, loss of gene function may occur through epigenetic gene silencing. DNA hypermethylation of $\mathrm{CPG}$ islands in gene promoters is a predominant epigenetic alteration that results in inactivation of transcriptional activity (13). It has been estimated that in colorectal cancer, approximately $5 \%$ of all known genes shows promoter hypermethylation and that more genes are hypermethylated than mutated, underscoring the importance of epigenetic alterations in colorectal cancer (40).

A distinct subset of colorectal cancers harbors widespread promoter hypermethylation and is referred to as the $\mathrm{CpG}$ island methylator phenotype (CIMP) $(41,42)$. Different CIMP subclasses have been proposed based on the number of methylated genes in CIMP marker panels, and their correlation with other molecular alterations in colorectal cancer (43). CIMP-high colorectal cancers are associated with MSI, BRAF mutations, wild-type $P 53$, older age, female sex and location in the proximal colon (44-46). CIMP-low tumors exhibit less extensive promoter methylation and have been associated with KRAS mutations and male sex $(47,48)$. Finally, CIMP-negative tumors have low frequencies of promoter methylation and are associated with CIN, suggesting that CIMP and CIN are two independent distinct molecular mechanisms in colorectal carcinogenesis $(49,50)$. Similar subclasses were suggested by independent research groups $(43,51)$.

However, there may be more than these three CIMP subgroups depending on the presence or absence of MSI, BRAF or KRAS mutations $(43,52)$, indicating that the classification of CIMP continues to be a subject of debate. Moreover, different panels of methylation markers have been used in the past to define CIMP (53). The clinical outcome for CIMP and related molecular characteristics may also differ. In this respect, CIMP-high and MSI were associated with a reduction of colon cancer-specific mortality, whereas BRAF mutations were associated with high mortality (54). Conversely, among patients with microsatellite stable (MSS) tumors, CIMP was associated with a shorter 5-year survival (55). Although CIMP, MSI and BRAF mutations strongly correlate, the question therefore remains whether colorectal tumors with these characteristics develop through one distinct molecular pathway.

To validate current hypotheses about molecular correlates in colorectal cancer, we studied the occurrence and overlap of the related characteristics CIMP, MLH1 hypermethylation, MSI and BRAF mutations (chapters 5 and 6 ). Since some molecular aberrations may be inversely correlated, we also investigated associations between MLH1 promoter methylation and $A P C, K R A S$ and BRAF mutations (chapter 2). In addition, we studied the associations between $M G M T$ promoter methylation and $\mathrm{G}: \mathrm{C}>\mathrm{A}: \mathrm{T}$ mutations in $K R A S$ and $A P C$, which may provide more insight in a possible sequence of events during colorectal carcinogenesis (chapter 2). 
To date, little is known about the environmental and genetic determinants of CIMP, and this question will be addressed in this thesis.

\section{Dietary methyl donors and molecular phenotypes in colorectal cancer}

\section{Folate and tumors characterized by gene mutations}

Since folate is important for nucleotide biosynthesis and DNA stability, it may be hypothesized that sufficient folate intake prevents the introduction of gene mutations. The association between dietary folate and the risk of developing tumors with gene mutations has been investigated in a limited number of studies, but with inconsistent results. Individuals with a history of colorectal adenoma and high folate intake were at reduced risk of colorectal adenoma recurrence with KRAS mutation (56). However, folate intake was not associated with colorectal cancer, with or without KRAS mutations, among individuals in two large prospective cohort studies (57). We previously observed that folate was not associated with KRAS mutations in colon cancer, but suggestions for positive and inverse associations were observed with rectal cancer risk depending on the type of KRAS mutation (58).

The association between intake of green leafy vegetables, an important source of folate, and APC mutation status in colorectal adenomas has previously been investigated (59). However, whether folate intake is associated with $A P C$ mutations in colorectal cancer has not previously been studied, and was therefore investigated in this thesis (chapter 4).

\section{Dietary methyl donors and promoter hypermethylation in colorectal cancer}

High intakes of dietary methyl donors may prevent $\mathrm{CpG}$ island promoter hypermethylation in colorectal cancer. A pilot study among 120 colorectal cancer patients previously conducted within the NLCS supported this hypothesis, since low intake of folate and methionine in combination with high alcohol intake was associated with increased promoter hypermethylation (60). However, the association in that study was weak, observed with at least one out of 6 methylated markers as an endpoint, and did not reach statistical significance. High fruit intake, a source of folate, was associated with reduced risk of colon carcinomas harboring MSI and MLH1 hypermethylation (61). High alcohol intake potentially reduces the bioavailability of folate which may affect DNA methylation in the colonic mucosa (62-64), and was associated with MSI in colorectal cancer (65). However, no associations were observed between dietary folate, vitamins B6 and B12, methionine and alcohol with CIMP in colorectal cancer in a large case-control study (65).

Conversely, it has been observed that high folate and vitamin B12 levels were associated with increased tumor methylation among colorectal cancer patients (66). Similarly, two important forms of circulating folate were associated with hypermethylation of genes in colorectal tumors (67). Moreover, in a randomized intervention trial in subjects with a history of colorectal adenoma, folate supplementation resulted in an increase of promoter hypermethylation in rectal mucosa (68). 
These observations indicate that the precise effect of dietary methyl donors is unclear and needs further investigation. Moreover, the effect of vitamin B2 on DNA methylation has not previously been investigated. Therefore, we investigate associations between dietary folate, methionine, vitamins B2 and B6 with MLH1 hypermethylation, MLH1 expression, MSI and BRAF mutations (chapter 5) and with CIMP in colorectal cancer (chapter 7).

\section{Polymorphisms in folate metabolizing enzymes and epigenetic regulators}

\section{Folate metabolizing enzymes}

The bioavailability of methyl groups depends on the activity of folate metabolizing enzymes. Single nucleotide polymorphisms in genes encoding these enzymes have been reported to alter enzymatic activity. For example, the C677T and A1298C polymorphisms in the MTHFR gene reduce enzymatic activity of the MTHFR enzyme $(69,70)$. Polymorphisms in $M T R$ and $M T R R$ were associated with lower plasma homocysteine concentrations $(71,72)$ suggesting that such genetic variants may lower catalytic activity of the MTR and MTRR enzymes.

The MTHFR C677T and A1298C polymorphisms were generally inversely associated with overall colorectal cancer in several observational studies $(73,74)$, although positive associations have been reported (75-78). In addition, individuals with these polymorphisms were more likely to develop colorectal tumors with a CpG island hypermethylation phenotype $(79,80)$ or microsatellite instability (MSI) (81). The MTR A2756G polymorphism was inversely associated with overall colorectal cancer in two studies $(82,83)$ but was not associated with CIMP (79). Though the association of $M T R R$ polymorphisms with promoter hypermethylation has not been investigated to date, it was observed that some MTRR polymorphisms may increase the risk of developing colorectal adenomas and carcinomas $(19,84,85)$.

\section{Interaction between methyl donors and folate metabolizing enzymes}

Several studies suggested an interaction between methyl donor intake and MTHFR genotypes in colorectal cancer. In this respect, an inverse association between intake of methyl donor nutrients and colorectal adenomas or colorectal cancer was more pronounced in subjects with the MTHFR 677TT genotype $(19,20,75,78,86-88)$. One study reported that a protective effect of high folate intake against colorectal adenoma was present only among individuals with MTHFR 1298AA or AC genotypes (76). However, literature on the other folate metabolizing enzymes and their potential interactions with methyl donor intake is limited. An interaction between folate and vitamin B6 and the MTRR A66G polymorphism has been suggested in one study (21).

Interestingly, folate intake or folate status and MTHFR C677T polymorphisms may also interact to affect methylation status. It has been observed that the MTHFR 677TT variant was associated with hypomethylation in blood cells of subjects with low folate status (89). Moreover, folate intake was inversely associated with MGMT hypermethylation (90) or MSI (91) in colorectal cancer among MTHFR 677TT 
homozygotes, and inversely associated with CIMP among carriers of the rare allele of MTHFR A1298C (79).

\section{DNA methyltransferases}

Whereas folate metabolizing enzymes are involved in the provision of methyl groups, DNA methyltransferases catalyze the transfer of these methyl groups from Sadenosylmethionine into CpG dinucleotides of DNA (Figure 1, Panel B). The DNA methyltransferase 3b (DNMT3b) is involved in de novo methylation (92), and several experimental studies suggested that DNMT3b depletion can reduce promoter CpG island hypermethylation (93-95). Moreover, DNMT3b expression was associated with p16 and RASSF1A promoter methylation in non-small cell lung cancer (96), and with a promoter hypermethylator phenotype in breast cancer (97).

The DNMT3b C>T (rs2424913) polymorphism was found to significantly increase enzymatic DNMT3b activity, and was associated with an increased risk of lung cancer (98), prostate cancer (99), colorectal polyps including colorectal adenomas (100) or with prognosis of head and neck cancer (101). However, the association between this polymorphism and overall colorectal cancer, or with a hypermethylation phenotype, has not previously been investigated.

\section{Histone methyltransferases}

Methylation of histones plays a critical role in maintaining epigenetic silencing by promoter hypermethylation of genes involved in colorectal cancer (102). It has been hypothesized that DNA methyltransferases such as DNMT3b, may only have an effect on the chromatin if histone tails are first methylated by histone methyltransferases (Figure 1, Panel B), and that DNA methylation may thus depend on the activity of histone methyltransferases (103).

The retinoblastoma protein $(\mathrm{Rb})$ interacting zinc finger gene (RIZ or PRDM2) is a histone methyltransferase which may act as a tumor suppressor and PRDM2 frame shift mutations have been observed in colorectal tumors with MSI (104). Polymorphisms in PRDM2 were inversely associated with lung cancer (105) but associated with increased risk of breast cancer (106). Euchromatin Histone Methyltransferase-1 (EHMT1) and -2 (EHMT2) are other histone methyltransferases, and genetic variants of these genes were modestly associated with breast cancer risk in a large case-control study (106). However, the potential impact of genetic variants of PRDM2, EHMT1 and EHMT2 have not previously been studied in relation to colorectal cancer, and is addressed in the present thesis.

The aim in this study was to determine the occurrence of polymorphisms in genes encoding folate metabolizing enzymes (MTHFR, MTR and MTRR), the DNA methyltransferase $D N M T 3 b$, and histone methyltransferases (EHMT1, EHMT2 and PRDM2). We estimated associations of these polymorphisms with overall colorectal cancer risk and with tumors with or without CIMP, MLH1 hypermethylation or MSI (chapter 6). Moreover, we investigated whether the effect of methyl donor intake on these hypermethylation-associated endpoints may be modified by genetic variants of folate metabolizing enzymes, DNA methyltransferase $3 \mathrm{~b}$ or histone methyltransferases (chapter 7). 


\section{Panel $A$}

Panel B

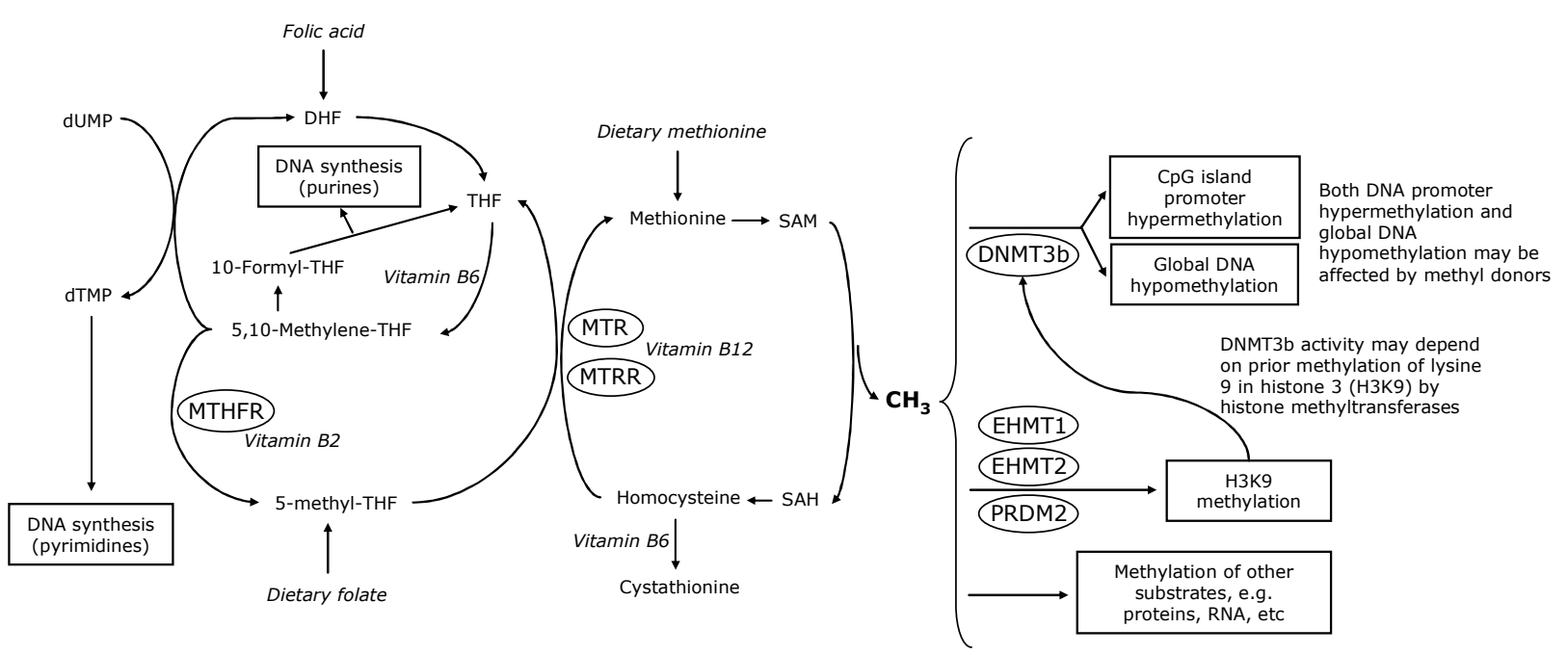

Figure 1. Folate metabolizing enzymes, DNA methyltransferases, histone methyl transferases, DNA synthesis and DNA methylation

Ovals represent the enzymes of which SNPs are investigated in this study. dUMP: deoxyuridine monophosphate, dTMP: deoxythymidine monophosphate, DHF: dihydrofolate, Th: tetrahydroflate, $F$ D. flavine adenine dinucleotide, SAM: S-adenosyl methionine, SAH: S-adenosyl homocysteine, MTHFR: methylene tetrahydrofolate reductase, MTR:

H3K9: lysine 9 of histone 3. 


\section{The Netherlands Cohort Study on diet and cancer (NLCS)}

All studies described in this thesis were conducted within the NLCS, which is a population-based prospective cohort study, initiated in 1986 (107). The NLCS includes 120,852 men and women who filled out a self-administered food frequency questionnaire at baseline to obtain dietary information and other risk factors for cancer (Figure 2). The cohort was followed-up for cancer occurrence. A subcohort of 5,000 subjects was randomly selected after baseline exposure measurement, to estimate accumulation of person-time in the cohort through biennial follow-up of vital status. Overall colorectal cancer was the endpoint in chapter 3, and could be investigated among 2,349 cases from a follow-up period of 13.3 years after baseline. Subcohort members still alive in the year 2000 were asked to collect mouth swabs, from which DNA was extracted and used for genotyping. Tumor material was collected of colorectal cancer patients identified within the first 7.3 years after baseline. In total, there were 734 patients of whom sufficient DNA could be extracted for genotyping and other molecular analyses.

\section{Outline of this thesis}

\section{A priori hypotheses}

Two hypotheses play a central role in the work presented here. Since adequate folate status is important for sufficient nucleotide synthesis and DNA stability, it may prevent the introduction of gene mutations and thereby protect against carcinogenesis. Therefore, we hypothesized that high folate intake is inversely associated with colorectal tumors harboring gene mutations.

Secondly, sufficient bioavailability of methyl groups may reduce aberrant CpG island promoter hypermethylation. We therefore hypothesized that high intakes of dietary methyl donors and of other B-vitamins involved in the folate metabolism are inversely associated with CpG island promoter hypermethylation in colorectal cancer.

Both of these hypotheses indicate that adequate intake of folate and other methyl donors may contribute to preventing colorectal cancer.

\section{Overview of research questions}

Figure 3 provides an overview of the research questions with references to chapters in which the investigated associations are reported. In chapter 2, we investigated associations between $M L H 1$ promoter methylation and $A P C, K R A S$ and $B R A F$ mutations, and between MGMT promoter methylation and G:C>A:T mutations in KRAS and APC. The associations between dietary folate, methionine, vitamin B2 and vitamin B6 with overall colorectal cancer risk are presented in chapter 3. Whether folate intake is associated with APC mutations in colorectal cancer was investigated in chapter 4 . In addition, we investigated the associations between dietary folate, methionine, vitamins B2 and B6 with MLH1 hypermethylation, MLH1 expression, MSI and BRAF mutations in chapter 5 and with CIMP in chapter 7. Chapter 6 addresses the associations between genetic variants of folate metabolizing enzymes MTHFR, MTR and MTRR, the DNA methyltransferase $3 \mathrm{~b}$ and histone methyltransferases PRDM2, EHMT1 and EHMT2 with 
overall colorectal cancer and with tumors with or without CIMP, MLH1 hypermethylation or MSI. Finally, in chapter 7 we investigated whether the effect of methyl donor intake on overall colorectal cancer and these hypermethylationassociated endpoints, may be modified by the genetic variants. 


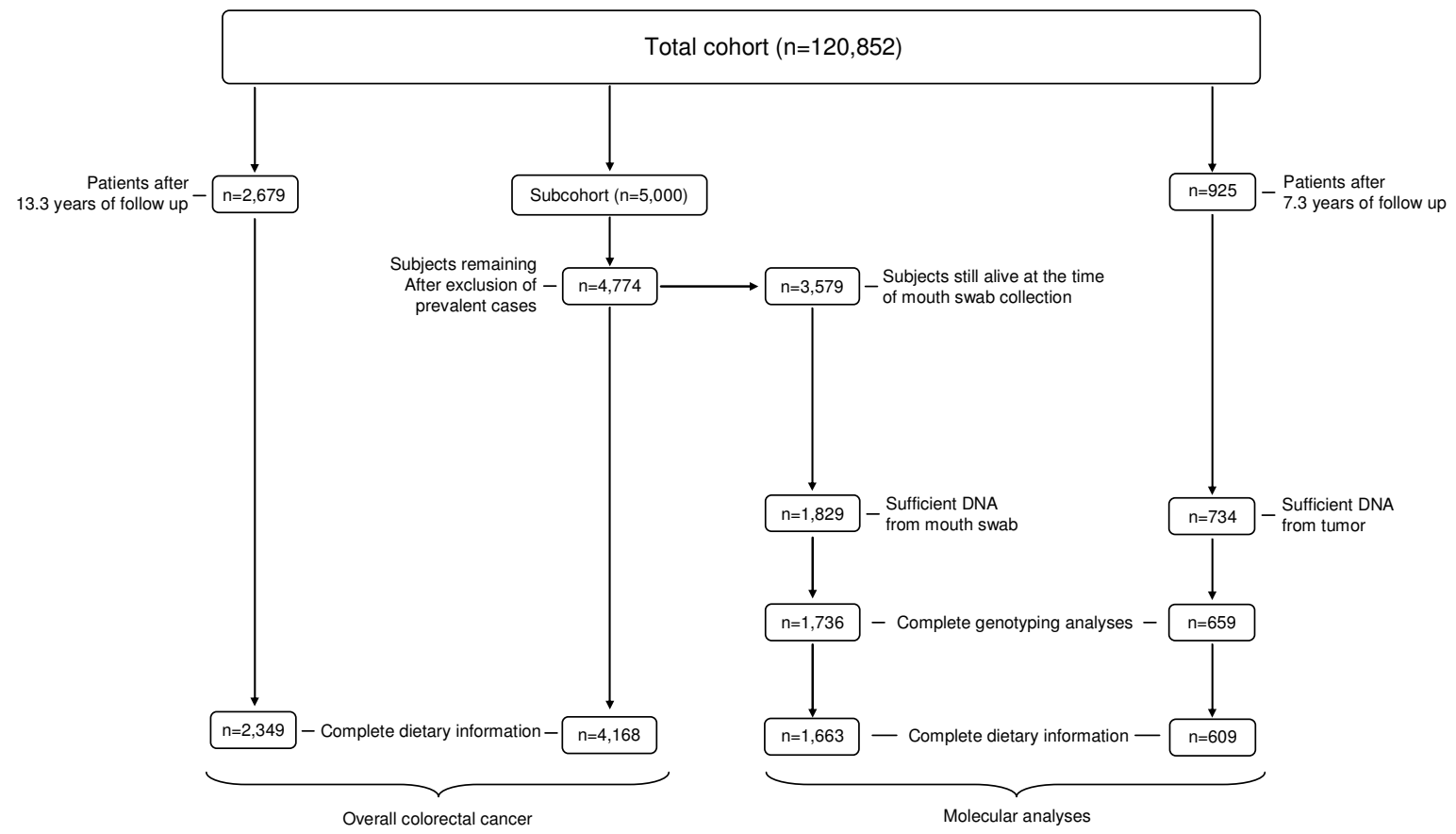

Figure 2. Subcohort members and colorectal cancer patients in the Netherlands Cohort Study on diet and cancer 


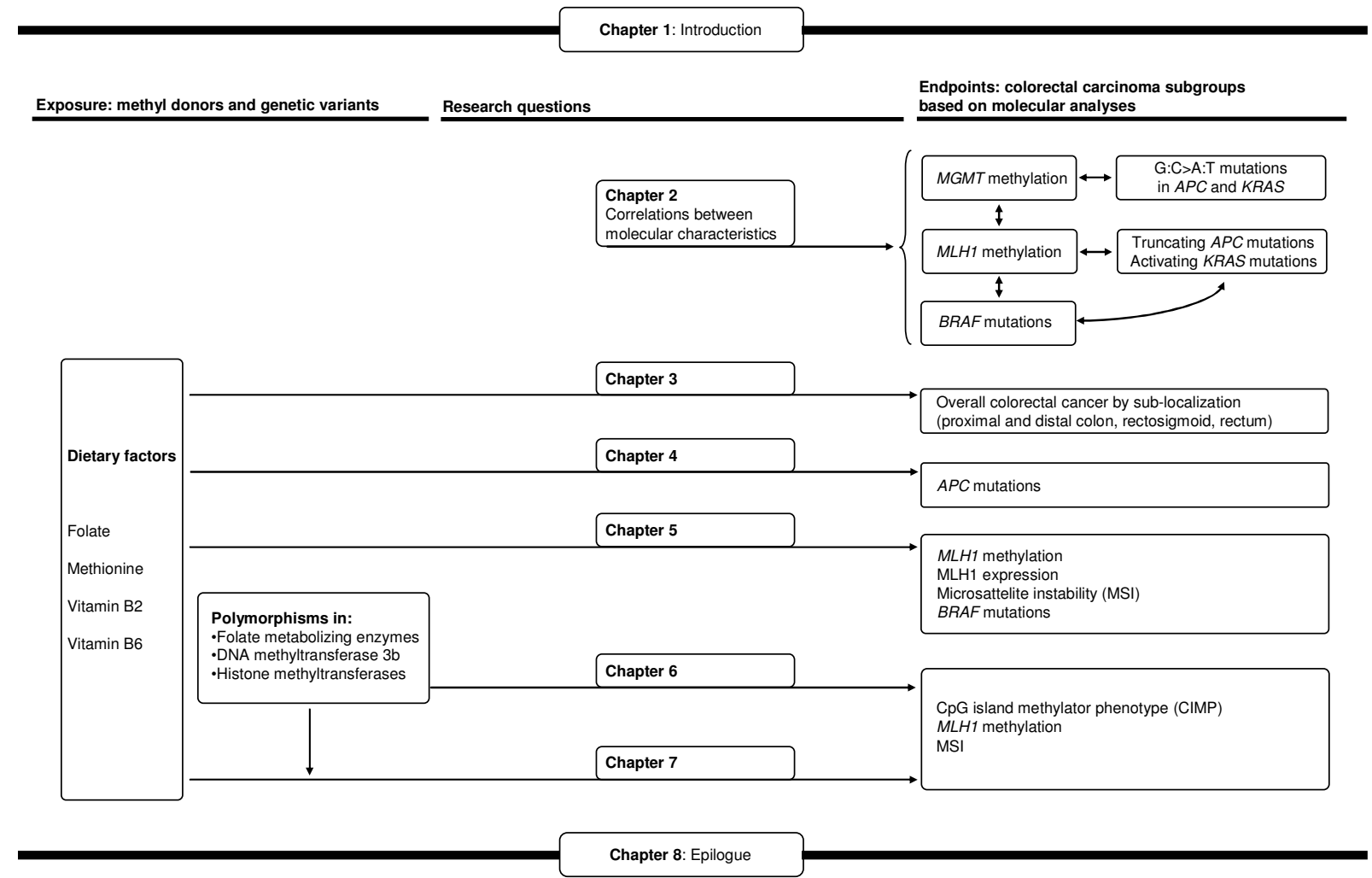

Figure 3 Overview of the research questions in the current thesis 


\section{References}

1. Prevention of neural tube defects: results of the Medical Research Council Vitamin Study. MRC Vitamin Study Research Group. Lancet 1991;338(8760):131-7.

2. Czeizel $A E$, Dudas I. Prevention of the first occurrence of neural-tube defects by periconceptional vitamin supplementation. N Engl J Med 1992;327(26):1832-5.

3. Wang X, Qin X, Demirtas H, Li J, Mao G, Huo Y, et al. Efficacy of folic acid supplementation in stroke prevention: a meta-analysis. Lancet 2007;369(9576):1876-82.

4. Bollheimer LC, Buettner R, Kullmann A, Kullmann F. Folate and its preventive potential in colorectal carcinogenesis. How strong is the biological and epidemiological evidence? Crit Rev Oncol Hematol 2005;55(1):13-36.

5. Sanjoaquin MA, Allen N, Couto E, Roddam AW, Key TJ. Folate intake and colorectal cancer risk: a meta-analytical approach. Int J Cancer 2005;113(5):825-8.

6. Kim YI. Folate and colorectal cancer: An evidence-based critical review. Mol Nutr Food Res 2007; 51(3):267-92.

7. Ferlay J, Autier $\mathrm{P}$, Boniol $\mathrm{M}$, Heanue $\mathrm{M}$, Colombet $\mathrm{M}$, Boyle $\mathrm{P}$. Estimates of the cancer incidence and mortality in Europe in 2006. Ann Oncol 2007;18(3):581-92.

8. Konings EJ, Roomans HH, Dorant E, Goldbohm RA, Saris WH, van den Brandt PA. Folate intake of the Dutch population according to newly established liquid chromatography data for foods. Am J Clin Nutr 2001;73(4):765-76.

9. Konings EJ, Goldbohm RA, Brants HA, Saris WH, van den Brandt PA. Intake of dietary folate vitamers and risk of colorectal carcinoma: results from The Netherlands Cohort Study. Cancer 2002;95(7):1421-33.

10. Scott JM. Folate and vitamin B12. Proc Nutr Soc 1999;58(2):441-8.

11. Winkels RM, Brouwer IA, Siebelink E, Katan MB, Verhoef P. Bioavailability of food folates is $80 \%$ of that of folic acid. Am J Clin Nutr 2007;85(2):465-73.

12. Duthie SJ, Narayanan S, Sharp L, Little J, Basten G, Powers H. Folate, DNA stability and colo-rectal neoplasia. Proc Nutr Soc 2004;63(4):571-8.

13. Herman JG, Baylin SB. Gene silencing in cancer in association with promoter hypermethylation. N Engl J Med 2003;349(21):2042-54.

14. Kim YI. Folate and DNA methylation: a mechanistic link between folate deficiency and colorectal cancer? Cancer Epidemiol Biomarkers Prev 2004;13(4):511-9.

15. Ulrich CM. Nutrigenetics in cancer research--folate metabolism and colorectal cancer. $J$ Nutr 2005;135(11):2698-702.

16. Flood A, Caprario L, Chaterjee N, Lacey JV, Jr., Schairer C, Schatzkin A. Folate, methionine, alcohol, and colorectal cancer in a prospective study of women in the United States. Cancer Causes Control 2002;13(6):551-61.

17. Harnack L, Jacobs DR, Jr., Nicodemus K, Lazovich D, Anderson K, Folsom AR. Relationship of folate, vitamin B-6, vitamin B-12, and methionine intake to incidence of colorectal cancers. Nutr Cancer 2002;43(2):152-8.

18. Kune G, Watson L. Colorectal cancer protective effects and the dietary micronutrients folate, methionine, vitamins B6, B12, C, E, selenium, and lycopene. Nutr Cancer 2006;56(1):11-21.

19. Le Marchand L, Donlon T, Hankin JH, Kolonel LN, Wilkens LR, Seifried A. B-vitamin intake, metabolic genes, and colorectal cancer risk (United States). Cancer Causes Control $2002 ; 13(3): 239-48$.

20. van den Donk M, Buijsse B, van den Berg SW, Ocke MC, Harryvan JL, Nagengast FM, et al. Dietary intake of folate and riboflavin, MTHFR C677T genotype, and colorectal adenoma risk: a Dutch case-control study. Cancer Epidemiol Biomarkers Prev 2005;14(6):1562-6.

21. Otani T, Iwasaki M, Hanaoka T, Kobayashi M, Ishihara J, Natsukawa $S$, et al. Folate, vitamin B6, vitamin B12, and vitamin B2 intake, genetic polymorphisms of related enzymes, and risk of colorectal cancer in a hospital-based case-control study in Japan. Nutr Cancer $2005 ; 53(1): 42-50$. 
22. Ishihara J, Otani T, Inoue M, Iwasaki M, Sasazuki S, Tsugane S. Low intake of vitamin B-6 is associated with increased risk of colorectal cancer in Japanese men. $J$ Nutr 2007;137(7):1808-14.

23. Larsson SC, Giovannucci E, Wolk A. Vitamin b6 intake, alcohol consumption, and colorectal cancer: a longitudinal population-based cohort of women. Gastroenterology $2005 ; 128(7): 1830-7$

24. Wei EK, Giovannucci E, Selhub J, Fuchs CS, Hankinson SE, Ma J. Plasma vitamin B6 and the risk of colorectal cancer and adenoma in women. J Natl Cancer Inst 2005;97(9):684-92.

25. Zhang SM, Moore SC, Lin J, Cook NR, Manson JE, Lee IM, et al. Folate, vitamin B6, multivitamin supplements, and colorectal cancer risk in women. Am J Epidemiol $2006 ; 163(2): 108-15$.

26. Weinstein SJ, Albanes D, Selhub J, Graubard B, Lim U, Taylor PR, et al. One-carbon metabolism biomarkers and risk of colon and rectal cancers. Cancer Epidemiol Biomarkers Prev 2008;17(11):3233-40.

27. Radimer K, Bindewald B, Hughes J, Ervin B, Swanson C, Picciano MF. Dietary supplement use by US adults: data from the National Health and Nutrition Examination Survey, 19992000. Am J Epidemiol 2004;160(4):339-49.

28. Kinzler KW, Vogelstein B. Lessons from hereditary colorectal cancer. Cell 1996;87(2):15970.

29. Lynch HT, de la Chapelle A. Genetic susceptibility to non-polyposis colorectal cancer. J Med Genet 1999;36(11):801-18.

30. Barnetson RA, Tenesa A, Farrington SM, Nicholl ID, Cetnarskyj R, Porteous ME, et al. Identification and survival of carriers of mutations in DNA mismatch-repair genes in colon cancer. N Engl J Med 2006;354(26):2751-63.

31. Aaltonen LA, Salovaara R, Kristo P, Canzian F, Hemminki A, Peltomaki P, et al. Incidence of hereditary nonpolyposis colorectal cancer and the feasibility of molecular screening for the disease. N Engl J Med 1998;338(21):1481-7.

32. Peel DJ, Ziogas A, Fox EA, Gildea M, Laham B, Clements E, et al. Characterization of hereditary nonpolyposis colorectal cancer families from a population-based series of cases. J Natl Cancer Inst 2000;92(18):1517-22.

33. Comprehensive Cancer Center the Netherlands: www.ikcnet.nl. Accessed in december 2008.

34. Fearon ER, Vogelstein B. A genetic model for colorectal tumorigenesis. Cell 1990;61(5):759-67.

35. Wood LD, Parsons DW, Jones S, Lin J, Sjoblom T, Leary RJ, et al. The genomic landscapes of human breast and colorectal cancers. Science 2007;318(5853):1108-13.

36. Imai $\mathrm{K}$, Yamamoto $\mathrm{H}$. Carcinogenesis and microsatellite instability: the interrelationship between genetics and epigenetics. Carcinogenesis 2008;29(4):673-80.

37. Herman JG, Umar A, Polyak K, Graff JR, Ahuja N, Issa JP, et al. Incidence and functional consequences of $h M L H 1$ promoter hypermethylation in colorectal carcinoma. Proc Natl Acad Sci U S A 1998;95(12):6870-5.

38. Kuismanen SA, Holmberg MT, Salovaara R, de la Chapelle A, Peltomaki P. Genetic and epigenetic modification of MLH1 accounts for a major share of microsatellite-unstable colorectal cancers. Am J Pathol 2000;156(5):1773-9.

39. Rajagopalan H, Lengauer C. CIN-ful cancers. Cancer Chemother Pharmacol 2004;54 Suppl 1:S65-8.

40. Schuebel KE, Chen W, Cope L, Glockner SC, Suzuki H, Yi JM, et al. Comparing the DNA hypermethylome with gene mutations in human colorectal cancer. PLoS Genet 2007;3(9):1709-23.

41. Issa JP. Opinion: CpG island methylator phenotype in cancer. Nat Rev Cancer 2004;4(12):988-93.

42. Toyota M, Ahuja N, Ohe-Toyota M, Herman JG, Baylin SB, Issa JP. CpG island methylator phenotype in colorectal cancer. Proc Natl Acad Sci U S A 1999;96(15):8681-6.

43. Ogino S, Goel A. Molecular Classification and Correlates in Colorectal Cancer. J Mol Diagn $2008 ; 10(1): 13-27$. 
44. Hawkins N, Norrie M, Cheong K, Mokany E, Ku SL, Meagher A, et al. CpG island methylation in sporadic colorectal cancers and its relationship to microsatellite instability. Gastroenterology 2002;122(5):1376-87.

45. Nosho K, Irahara N, Shima K, Kure S, Kirkner GJ, Schernhammer ES, et al. Comprehensive biostatistical analysis of CpG island methylator phenotype in colorectal cancer using a large population-based sample. PLoS ONE 2008;3(11):e3698.

46. van Rijnsoever M, Grieu F, Elsaleh H, Joseph D, Iacopetta B. Characterisation of colorectal cancers showing hypermethylation at multiple CpG islands. Gut 2002;51(6):797-802.

47. Ogino S, Kawasaki T, Kirkner GJ, Loda M, Fuchs CS. CpG island methylator phenotype-low (CIMP-low) in colorectal cancer: possible associations with male sex and KRAS mutations. $J$ Mol Diagn 2006;8(5):582-8.

48. Ogino S, Kawasaki T, Kirkner GJ, Suemoto Y, Meyerhardt JA, Fuchs CS. Molecular correlates with MGMT promoter methylation and silencing support CpG island methylator phenotypelow (CIMP-low) in colorectal cancer. Gut 2007;56(11):1564-71.

49. Cheng YW, Pincas H, Bacolod MD, Schemmann G, Giardina SF, Huang J, et al. CpG island methylator phenotype associates with low-degree chromosomal abnormalities in colorectal cancer. Clin Cancer Res 2008;14(19):6005-13.

50. Goel A, Nagasaka T, Arnold CN, Inoue T, Hamilton C, Niedzwiecki D, et al. The CpG island methylator phenotype and chromosomal instability are inversely correlated in sporadic colorectal cancer. Gastroenterology 2007;132(1):127-38.

51. Shen L, Toyota M, Kondo Y, Lin E, Zhang L, Guo Y, et al. Integrated genetic and epigenetic analysis identifies three different subclasses of colon cancer. Proc Natl Acad Sci $U S A$ 2007;104(47):18654-9.

52. Jass JR. Classification of colorectal cancer based on correlation of clinical, morphological and molecular features. Histopathology 2007;50(1):113-30.

53. Teodoridis JM, Hardie C, Brown R. CpG island methylator phenotype (CIMP) in cancer: Causes and implications. Cancer Lett 2008;268(2):177-86.

54. Ogino S, Nosho K, Kirkner GJ, Kawasaki T, Meyerhardt JA, Loda M, et al. CpG island methylator phenotype, microsatellite instability, $B R A F$ mutation and clinical outcome in colon cancer. Gut 2008.

55. Barault L, Charon-Barra C, Jooste V, de la Vega MF, Martin L, Roignot P, et al. Hypermethylator phenotype in sporadic colon cancer: study on a population-based series of 582 cases. Cancer Res 2008;68(20):8541-6.

56. Martinez ME, Maltzman T, Marshall JR, Einspahr J, Reid ME, Sampliner R, et al. Risk factors for Ki-ras protooncogene mutation in sporadic colorectal adenomas. Cancer Res 1999;59(20):5181-5.

57. Schernhammer ES, Giovannuccci E, Fuchs CS, Ogino S. A Prospective Study of Dietary Folate and Vitamin $\mathrm{B}$ and Colon Cancer According to Microsatellite Instability and KRAS Mutational Status. Cancer Epidemiol Biomarkers Prev 2008;17(10):2895-8.

58. Brink M, Weijenberg MP, de Goeij AF, Roemen GM, Lentjes MH, de Bruine AP, et al. Dietary folate intake and k-ras mutations in sporadic colon and rectal cancer in the Netherlands Cohort Study. Int J Cancer 2004.

59. Diergaarde B, Tiemersma EW, Braam H, van Muijen GN, Nagengast FM, Kok FJ, et al. Dietary factors and truncating $A P C$ mutations in sporadic colorectal adenomas. Int J Cancer 2005;113(1):126-32.

60. van Engeland M, Weijenberg MP, Roemen GM, Brink M, de Bruine AP, Goldbohm RA, et al. Effects of dietary folate and alcohol intake on promoter methylation in sporadic colorecta cancer: the Netherlands cohort study on diet and cancer. Cancer Res 2003;63(12):3133-7.

61. Diergaarde B, Braam H, van Muijen GN, Ligtenberg MJ, Kok FJ, Kampman E. Dietary factors and microsatellite instability in sporadic colon carcinomas. Cancer Epidemiol Biomarkers Prev 2003;12(11 Pt 1):1130-6.

62. Halsted $\mathrm{CH}$, Villanueva JA, Devlin AM, Chandler CJ. Metabolic interactions of alcohol and folate. J Nutr 2002;132(8 Suppl):2367S-2372S.

63. Giovannucci E. Alcohol, one-carbon metabolism, and colorectal cancer: recent insights from molecular studies. J Nutr 2004;134(9):2475S-2481S.

64. Mason JB, Choi SW. Effects of alcohol on folate metabolism: implications for carcinogenesis. Alcohol 2005;35(3):235-41. 
65. Slattery ML, Curtin K, Sweeney C, Levin TR, Potter J, Wolff RK, et al. Diet and lifestyle factor associations with CPG island methylator phenotype and BRAF mutations in colon cancer. Int J Cancer 2007;120(3):656-63.

66. Mokarram $P$, Naghibalhossaini F, Saberi Firoozi M, Hosseini SV, Izadpanah A, Salahi H, et al. Methylenetetrahydrofolate reductase C677T genotype affects promoter methylation of tumor-specific genes in sporadic colorectal cancer through an interaction with folate/vitamin B(12) status. World J Gastroenterol 2008;14(23):3662-71.

67. Kawakami K, Ruszkiewicz A, Bennett G, Moore J, Watanabe G, Iacopetta B. The folate pool in colorectal cancers is associated with DNA hypermethylation and with a polymorphism in methylenetetrahydrofolate reductase. Clin Cancer Res 2003;9(16 Pt 1):5860-5.

68. van den Donk M, Pellis L, Crott JW, van Engeland M, Friederich P, Nagengast FM, et al. Folic acid and vitamin B-12 supplementation does not favorably influence uracil incorporation and promoter methylation in rectal mucosa DNA of subjects with previous colorectal adenomas. J Nutr 2007;137(9):2114-20.

69. Frosst P, Blom HJ, Milos R, Goyette P, Sheppard CA, Matthews RG, et al. A candidate genetic risk factor for vascular disease: a common mutation in methylenetetrahydrofolate reductase. Nat Genet 1995;10(1):111-3.

70. van der Put NM, Gabreels F, Stevens EM, Smeitink JA, Trijbels FJ, Eskes TK, et al. A second common mutation in the methylenetetrahydrofolate reductase gene: an additional risk factor for neural-tube defects? Am J Hum Genet 1998;62(5):1044-51.

71. Chen J, Stampfer MJ, Ma J, Selhub J, Malinow MR, Hennekens $\mathrm{CH}$, et al. Influence of a methionine synthase (D919G) polymorphism on plasma homocysteine and folate levels and relation to risk of myocardial infarction. Atherosclerosis 2001;154(3):667-72.

72. Gaughan DJ, Kluijtmans LA, Barbaux S, McMaster D, Young IS, Yarnell JW, et al. The methionine synthase reductase (MTRR) A66G polymorphism is a novel genetic determinant of plasma homocysteine concentrations. Atherosclerosis 2001;157(2):451-6.

73. Huang Y, Han S, Li Y, Mao Y, Xie Y. Different roles of MTHFR C677T and A1298C polymorphisms in colorectal adenoma and colorectal cancer: a meta-analysis. J Hum Genet 2007;52(1):73-85.

74. Hubner RA, Houlston RS. MTHFR C677T and colorectal cancer risk: A meta-analysis of 25 populations. Int J Cancer 2007;120(5):1027-35.

75. Guerreiro CS, Carmona B, Goncalves S, Carolino E, Fidalgo P, Brito M, et al. Risk of colorectal cancer associated with the C677T polymorphism in 5,10methylenetetrahydrofolate reductase in Portuguese patients depends on the intake of methyl-donor nutrients. Am J Clin Nutr 2008;88(5):1413-8.

76. Lightfoot TJ, Barrett JH, Bishop T, Northwood EL, Smith G, Wilkie MJ, et al. Methylene tetrahydrofolate reductase genotype modifies the chemopreventive effect of folate in colorectal adenoma, but not colorectal cancer. Cancer Epidemiol Biomarkers Prev 2008;17(9):2421-30.

77. Mitrou PN, Watson MA, Loktionov AS, Cardwell C, Gunter MJ, Atkin WS, et al. MTHFR (C677T and A1298C) polymorphisms and risk of sporadic distal colorectal adenoma in the UK Flexible Sigmoidoscopy Screening Trial (United Kingdom). Cancer Causes Control $2006 ; 17(6): 793-801$.

78. Murphy G, Sansbury LB, Cross AJ, Stolzenberg-Solomon R, Laiyemo A, Albert PS, et al. Folate and MTHFR: risk of adenoma recurrence in the Polyp Prevention Trial. Cancer Causes Control 2008;19(7):751-8.

79. Curtin K, Slattery ML, Ulrich CM, Bigler J, Levin TR, Wolff RK, et al. Genetic polymorphisms in one-carbon metabolism: associations with CpG island methylator phenotype (CIMP) in colon cancer and the modifying effects of diet. Carcinogenesis 2007;28(8):1672-9.

80. Oyama K, Kawakami K, Maeda K, Ishiguro K, Watanabe G. The association between methylenetetrahydrofolate reductase polymorphism and promoter methylation in proximal colon cancer. Anticancer Res 2004;24(2B):649-54.

81. Hubner RA, Lubbe S, Chandler I, Houlston RS. MTHFR C677T has differential influence on risk of MSI and MSS colorectal cancer. Hum Mol Genet 2007;16(9):1072-7.

82. Chen J, Giovannucci E, Hankinson SE, Ma J, Willett WC, Spiegelman D, et al. A prospective study of methylenetetrahydrofolate reductase and methionine synthase gene polymorphisms, and risk of colorectal adenoma. Carcinogenesis 1998;19(12):2129-32. 
83. Ma J, Stampfer MJ, Christensen B, Giovannucci E, Hunter DJ, Chen J, et al. A polymorphism of the methionine synthase gene: association with plasma folate, vitamin B12, homocyst(e)ine, and colorectal cancer risk. Cancer Epidemiol Biomarkers Prev 1999;8(9):825-9.

84. Hazra A, Wu K, Kraft P, Fuchs CS, Giovannucci EL, Hunter DJ. Twenty-four nonsynonymous polymorphisms in the one-carbon metabolic pathway and risk of colorectal adenoma in the Nurses' Health Study. Carcinogenesis 2007;28(7):1510-9.

85. Koushik A, Kraft P, Fuchs CS, Hankinson SE, Willett WC, Giovannucci EL, et al. Nonsynonymous polymorphisms in genes in the one-carbon metabolism pathway and associations with colorectal cancer. Cancer Epidemiol Biomarkers Prev 2006;15(12):240817.

86. Chen J, Giovannucci E, Kelsey K, Rimm EB, Stampfer MJ, Colditz GA, et al. A methylenetetrahydrofolate reductase polymorphism and the risk of colorectal cancer. Cancer Res 1996;56(21):4862-4.

87. Slattery ML, Potter JD, Samowitz W, Schaffer D, Leppert M. Methylenetetrahydrofolate reductase, diet, and risk of colon cancer. Cancer Epidemiol Biomarkers Prev $1999 ; 8(6): 513-8$.

88. Ulrich CM, Kampman E, Bigler J, Schwartz SM, Chen C, Bostick R, et al. Colorecta adenomas and the C677T MTHFR polymorphism: evidence for gene-environment interaction? Cancer Epidemiol Biomarkers Prev 1999;8(8):659-68.

89. Friso S, Choi SW, Girelli D, Mason JB, Dolnikowski GG, Bagley PJ, et al. A common mutation in the 5,10-methylenetetrahydrofolate reductase gene affects genomic DNA methylation through an interaction with folate status. Proc Natl Acad Sci U S A 2002;99(8):5606-11.

90. van den Donk M, van Engeland M, Pellis L, Witteman BJ, Kok FJ, Keijer J, et al. Dietary folate intake in combination with MTHFR C677T genotype and promoter methylation of tumor suppressor and DNA repair genes in sporadic colorectal adenomas. Cancer Epidemiol Biomarkers Prev 2007;16(2):327-33.

91. Eaton AM, Sandler R, Carethers JM, Millikan RC, Galanko J, Keku TO. 5,10methylenetetrahydrofolate reductase 677 and 1298 polymorphisms, folate intake, and microsatellite instability in colon cancer. Cancer Epidemiol Biomarkers Prev 2005;14(8):2023-9.

92. Okano M, Bell DW, Haber DA, Li E. DNA methyltransferases Dnmt3a and Dnmt3b are essential for de novo methylation and mammalian development. Cell 1999;99(3):247-57.

93. Beaulieu N, Morin S, Chute IC, Robert MF, Nguyen H, MacLeod AR. An essential role for DNA methyltransferase DNMT3B in cancer cell survival. J Biol Chem 2002;277(31):2817681.

94. Jacinto FV, Ballestar E, Ropero S, Esteller M. Discovery of epigenetically silenced genes by methylated DNA immunoprecipitation in colon cancer cells. Cancer Res 2007;67(24):11481-6.

95. Wang J, Bhutani M, Pathak AK, Lang W, Ren H, Jelinek J, et al. Delta DNMT3B variants regulate DNA methylation in a promoter-specific manner. Cancer Res 2007;67(22):1064752.

96. Wang J, Walsh G, Liu DD, Lee JJ, Mao L. Expression of Delta DNMT3B variants and its association with promoter methylation of p16 and RASSF1A in primary non-small cell lung cancer. Cancer Res 2006;66(17):8361-6.

97. Roll JD, Rivenbark AG, Jones WD, Coleman WB. DNMT3b overexpression contributes to a hypermethylator phenotype in human breast cancer cell lines. Mol Cancer 2008;7:15.

98. Shen H, Wang L, Spitz MR, Hong WK, Mao L, Wei Q. A novel polymorphism in human cytosine DNA-methyltransferase-3B promoter is associated with an increased risk of lung cancer. Cancer Res 2002;62(17):4992-5.

99. Singal R, Das PM, Manoharan M, Reis IM, Schlesselman JJ. Polymorphisms in the DNA methyltransferase $3 b$ gene and prostate cancer risk. Oncol Rep 2005;14(2):569-73.

100. Jung AY, Poole EM, Bigler J, Whitton J, Potter JD, Ulrich CM. DNA methyltransferase and alcohol dehydrogenase: gene-nutrient interactions in relation to risk of colorectal polyps. Cancer Epidemiol Biomarkers Prev 2008;17(2):330-8.

101. Wang L, Rodriguez M, Kim ES, Xu Y, Bekele N, El-Naggar AK, et al. A novel C/T polymorphism in the core promoter of human de novo cytosine DNA methyltransferase $3 \mathrm{~B} 6$ is associated with prognosis in head and neck cancer. Int J Oncol 2004;25(4):993-9. 
102. Kondo $\mathrm{Y}$, Shen L, Issa JP. Critical role of histone methylation in tumor suppressor gene silencing in colorectal cancer. Mol Cell Biol 2003;23(1):206-15.

103. Tamaru H, Selker EU. A histone H3 methyltransferase controls DNA methylation in Neurospora crassa. Nature 2001;414(6861):277-83.

104. Chadwick RB, Jiang GL, Bennington GA, Yuan B, Johnson CK, Stevens MW, et al. Candidate tumor suppressor RIZ is frequently involved in colorectal carcinogenesis. Proc Natl Acad Sci U S A 2000;97(6):2662-7.

105. Yoon KA, Park S, Hwangbo B, Shin HD, Cheong HS, Shin HR, et al. Genetic polymorphisms in the Rb-binding zinc finger gene RIZ and the risk of lung cancer. Carcinogenesis 2007;28(9):1971-7.

106. Cebrian A, Pharoah PD, Ahmed S, Ropero S, Fraga MF, Smith PL, et al. Genetic variants in epigenetic genes and breast cancer risk. Carcinogenesis 2006;27(8):1661-9.

107. van den Brandt PA, Goldbohm RA, van 't Veer P, Volovics A, Hermus RJ, Sturmans F. A large-scale prospective cohort study on diet and cancer in The Netherlands. J Clin Epidemiol $1990 ; 43(3): 285-95$ 



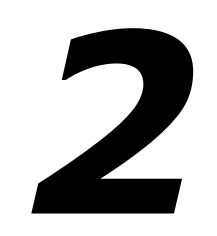

\section{MGMT and MLH1 promoter methylation versus $A P C, K R A S$ and $B R A F$ gene mutations in colorectal cancer: indications for distinct pathways and sequence of events}

Stefan de Vogel

Matty P Weijenberg

James $G$ Herman

Kim AD Wouters Anton FPM de Goeij Piet $A$ van den Brandt Adriaan $P$ de Bruïne Manon van Engeland 


\section{Abstract}

Background: To study how caretaker gene silencing relates to gatekeeper mutations in CRC, we investigated whether MGMT and MLH1 promoter hypermethylation are associated with $A P C, K R A S$ and $B R A F$ mutations among $\mathrm{n}=734 \mathrm{CRC}$ patients.

Design: We compared MGMT hypermethylation with $\mathrm{G}: \mathrm{C}>\mathrm{A}: \mathrm{T}$ mutations in $A P C$ and $K R A S$, and with the occurrence of such mutations in $\mathrm{CpG}$ or non-CpG dinucleotides in $A P C$. We also compared $M L H 1$ hypermethylation with truncating $A P C$ mutations, and activating $K R A S$ and $B R A F$ mutations.

Results: Only $10 \%$ of the tumors showed both MGMT and MLH1 hypermethylation. MGMT hypermethylation occurred more frequently in tumors with G:C>A:T KRAS mutations $(55 \%)$ compared to those without these mutations ( $38 \%, P<0.001)$. No such difference was observed for $\mathrm{G}: \mathrm{C}>\mathrm{A}: \mathrm{T}$ mutations in $A P C$, regardless of whether mutations occurred in $\mathrm{CpG}$ or non-CpG dinucleotides. $M L H 1$ hypermethylation was less common in tumors with $A P C$ mutations $(P=0.006)$ or KRAS mutations $(P=0.001)$, but was positively associated with $B R A F$ mutations $(P<0.001)$.

Conclusions: MGMT hypermethylation is associated with $\mathrm{G}: \mathrm{C}>\mathrm{A}: \mathrm{T}$ mutations in $K R A S$, but not in $A P C$, suggesting that MGMT hypermethylation may succeed APC mutations but precedes KRAS mutations in colorectal carcinogenesis. MLH1-hypermethylated tumors harbor fewer $A P C$ and KRAS mutations and more BRAF mutations, suggesting that they develop distinctly from an MGMT-methylator pathway. 


\section{Introduction}

In addition to mutations in oncogenes and tumor suppressor genes, epigenetic alterations, including aberrant methylation of DNA repair genes, play an important role in the initiation and development of cancer (1). Although aberrations in these repair genes (also referred to as caretaker genes) do not directly affect cell growth, they can result in a higher rate of mutations in oncogenes and tumor suppressor genes (called gatekeeper genes) $(2,3)$. Promoter hypermethylation inhibits the expression of DNA repair genes, occurs in early stages of cancer development and possibly even precedes somatic mutations in the initiation of colorectal cancer (CRC) (4-6). Hypermethylation of $\mathrm{O}^{6}$-methylguanine DNA methyltransferase (MGMT) for example, has been observed in normal appearing colorectal tissue adjacent to tumor tissue, which suggests that MGMT methylation may occur prior to mutations in other key genes early in the multistep process of colorectal carcinogenesis $(7,8)$. The $0^{6}-M G M T$ enzyme prevents $\mathrm{G}: \mathrm{C}>\mathrm{A}$ :T point mutations by removing alkyl adducts from the $\mathrm{O}^{6}$ position of guanine (9), and it was suggested that MGMT hypermethylation may lead to G:C>A:T mutations in KRAS and TP53 $(10,11)$ and that loss of MGMT may lead to such mutations in PIK3CA (12). Although an association of $\mathrm{G}: \mathrm{C}>\mathrm{A}: \mathrm{T}$ APC mutations with APC hypermethylation and concurrent hypermethylation of MGMT was previously suggested (13), the relation between MGMT hypermethylation exclusively and G:C>A:T mutations in the $A P C$ gene has not previously been studied.

Promoter hypermethylation of the mismatch repair gene Human Mut-L Homologue 1 (MLH1) is associated with microsatellite instability and BRAF mutations in CRC (14$18)$, and also likely to be an early event in colorectal carcinogenesis $(5,19)$. It was previously observed that microsatellite instable tumors may harbor fewer aberrations in KRAS, TP53 or APC, indicating that these tumors develop through a distinct pathway (20-23). In this respect, an interesting recent observation was that MGMT and MLH1 promoter hypermethylation were mutually exclusive (24). These results also indicate the existence of several distinct pathways in CRC, although the sample size used in that study was relatively small.

Because epigenetic silencing of caretaker genes may result in gatekeeper gene mutations, we aimed to investigate whether an association exists between MGMT hypermethylation and $\mathrm{G}: \mathrm{C}>\mathrm{A}: \mathrm{T} A P C$ mutations, and to study how this relates to the association between MGMT hypermethylation and G:C>A:T KRAS mutations. We also assessed whether $M L H 1$ promoter methylation is associated with mutations in $A P C$, $K R A S$, and $B R A F$ in a large cohort of incident sporadic CRC patients.

\section{Methods}

\section{Study population and tissue samples}

Tissue material was obtained from incident CRC patients from the Netherlands Cohort Study on diet and cancer (NLCS), which has been described in detail elsewhere (25). Briefly, this prospective cohort study was initiated in September 1986 and includes 58,279 men and 62,573 women aged 55-69 years and free of disease at baseline, who originated from 204 Dutch municipalities with computerized population registers. The 
entire cohort is monitored for cancer occurrence by annual record linkage to the Netherlands Cancer Registry (NCR, comprising nine cancer registries in The Netherlands) and to PALGA (Pathologisch Anatomisch Landelijk Geautomatiseerd Archief), a nationwide network and registry of histopathology and cytopathology reports $(26,27)$.

The PALGA database was used to identify and locate tumor tissue in Dutch pathology laboratories. CRC was classified according to disease site as follows: colon, i.e. proximal and distal colon, rectosigmoid and rectum. At baseline, all cohort members filled out a self-administered food-frequency questionnaire through which information about age, sex and family history of colorectal cancer was also obtained.

Tumor material of the CRC patients was collected after approval by the ethical review boards of Maastricht University, the NCR and PALGA. In addition, all 54 pathology laboratories in the Netherlands agreed to make relevant tissue samples available from PALGA upon request. These tissue samples were retrieved between August 1999 and December 2001, as described previously (28).

In total, 734 incident CRC patients were identified from a follow-up period of 7.3 years after baseline, of whom a PALGA report of the lesion as well as sufficient DNA was available (28).

\section{Promoter methylation analyses}

DNA methylation in the CPG islands of the MGMT and MLH1 gene promoters was determined by chemical modification of genomic DNA with sodium bisulfite and subsequent Methylation Specific PCR (MSP) as described in detail elsewhere (29). In brief, $500 \mathrm{ng}$ of DNA was denatured by $\mathrm{NaOH}$ and modified by sodium bisulfite. DNA samples were then purified using Wizard DNA purification resin (Promega), again treated with $\mathrm{NaOH}$, precipitated with ethanol and resuspended in $\mathrm{H}_{2} \mathrm{O}$.

To facilitate MSP analysis on DNA retrieved from formalin-fixed, paraffin-embedded tissue, DNA was first amplified with flanking PCR primers that amplify bisulfite modified DNA but do not preferentially amplify methylated or unmethylated DNA. The resulting fragment was used as a template for the MSP-reaction $(30,31)$.

All PCRs were performed with controls for unmethylated alleles (DNA from normal lymphocytes), methylated alleles (normal lymphocyte DNA treated in vitro with SssI methyltransferase (New England Biolabs)) and a control without DNA. Ten $\mu$ l of each MSP reaction was directly loaded onto nondenaturing $6 \%$ polyacrylamide gels, stained with ethidium bromide and visualized under UV illumination. MSP analyses were successfully performed for 693 patients for the MGMT promoter and for 686 patients for the MLH1 promoter.

\section{Gene mutation analyses}

Mutation analyses of the mutation cluster region (MCR) in APC (codons 1286-1520), was performed as described previously (32). Briefly, nested PCR was used to amplify the MCR in four overlapping DNA fragments and the purified fragments were sequenced. Two observers independently evaluated the sequence patterns and data entry. One or more fragments of the MCR could not be analyzed completely from 72 CRC patients, leaving 662 patients with complete information on APC mutation status for data analysis. Mutations that lead to the introduction of a stop codon (truncating mutations) subsequently lead to functional loss of the $A P C$ protein. Such functional $A P C$ 
mutations were observed in 37\% of CRCs (32) and are considered in the current study, as well as frameshift mutations in APC. Exon 1 (codons 12 and 13) of the KRAS oncogene was analyzed successfully for all 734 patients using nested PCR, followed by direct sequencing of purified fragments, as previously described (28).

$\mathrm{G}: \mathrm{C}>\mathrm{A}: \mathrm{T}$ mutations (being $\mathrm{G}>\mathrm{A}$ and/or $\mathrm{C}>\mathrm{T}$ mutations) in either of the two genes were also considered, irrespective of the consequence of the mutation. It is important to note that in $A P C$, these mutations may occur via two different chemical transformations depending on the orientation of the mutated cytosine or guanine. Methylated cytosines in the context of a CpG dinucleotide are prone to spontaneous deamination (33), whereas non-CpG cytosines are more likely to mutate by alkyl adduct formation (Figure 1).

We also included mutations of the BRAF gene in our study, and for this purpose, the common V600E BRAF mutation was analyzed as previously described in detail (34).

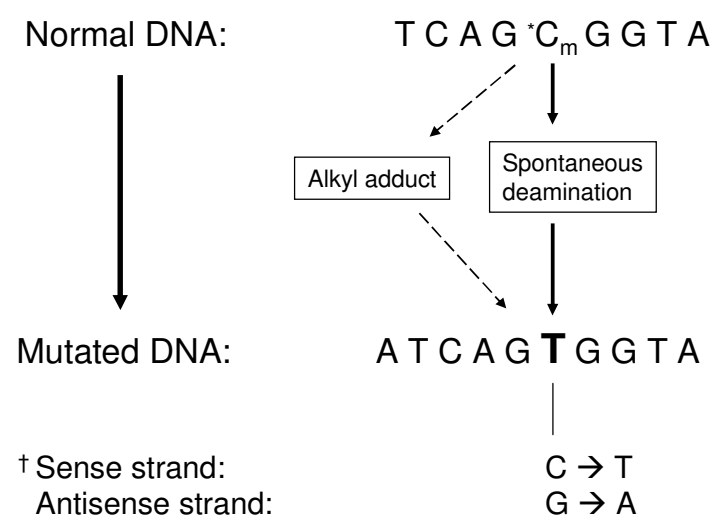

Figure 1. G:C>A:T transitions caused by deamination and possibly alkylation in CpG dinucleotides

* Methyl cytosine with neighboring guanine that mutates to thymine primarily by spontaneous deamination and possibly by alkyl adduct formation.

$\dagger \quad$ C>T mutations with corresponding $G>A$ mutations on the other DNA strand

\section{Statistical analyses}

Data analyses were conducted separately for CRCs with or without promoter hypermethylation of MGMT and MLH1. First, we evaluated the association between MGMT and MLH1 hypermethylation. Then, we compared the prevalence of MGMT hypermethylation with $\mathrm{G}: \mathrm{C}>\mathrm{A}: \mathrm{T}$ point mutations in KRAS, or in $A P C$ (irrespective of leading to a truncation or not), and with the occurrence of BRAF mutations. We also determined whether the percentage of MGMT hypermethylation differed between $\mathrm{G}: \mathrm{C}>\mathrm{A}: \mathrm{T}$ mutations in $A P C$ that occur in either $\mathrm{CpG}$ or non-CpG dinucleotides.

The prevalence of $M L H 1$ hypermethylation was compared with mutations that lead to functional alterations of $A P C, K R A S$ and $B R A F$, i.e. truncating and frameshift $A P C$ mutations, activating KRAS mutations and V600E BRAF mutations. In addition, we assessed the relation between $B R A F$ mutations and truncating $A P C$ mutations and 
activating KRAS mutations. Potential differences in prevalence or differences in patient characteristics were tested by Chi-square tests or t-tests where appropriate.

All statistical analyses were performed with the STATA statistical software package (intercooled STATA, version 9.1).

\section{Results}

Overall, hypermethylation of MGMT and MLH1 was observed in $41 \%$ and $22 \%$ of the patients respectively (Table 1 ). We observed that hypermethylation of both MGMT and MLH1 occurred in only $66(10 \%)$ of the patients with available MSP analyses. Women more often showed $M L H 1$ hypermethylation (26\%) compared to men (19\%, $P=0.03$ ), whereas no sex-difference existed for MGMT hypermethylation (Table 1). In addition, patients less frequently had a positive family history of colorectal cancer when they showed hypermethylation in MGMT or MLH1, although these differences were only borderline statistically significant. However, this difference was significant when considering patients with hypermethylation in either of the genes, since a family history of colorectal cancer was observed in $8 \%$ of the patients with MGMT and/or MLH1 methylation compared to $13 \%$ among patients showing no methylation $(P=0.03$, data not shown). Whereas MGMT hypermethylation was independent of tumor sublocalization, we observed that $M L H 1$ hypermethylation occurred more often in proximal colon tumors $(35 \%)$ compared to distal colon $(16 \%)$, rectosigmoid $(16 \%)$ and rectal tumors $(13 \%, \mathrm{p}<0.001)$. All other characteristics presented in Table 1 did not substantially differ between cases with or without MGMT and MLH1 hypermethylation.

The relation between MGMT hypermethylation and the occurrence of G:C>A:T mutations in KRAS and $A P C$ is shown in Table 2. Tumors with G:C>A:T KRAS mutations showed a higher percentage of MGMT hypermethylation (55\%) compared to those without G:C>A:T point mutations $(38 \%, P<0.001)$. The percentages of $M G M T$ hypermethylation in tumors with or without $\mathrm{G}: \mathrm{C}>\mathrm{A}: \mathrm{T}$ mutations in $A P C$ did not differ significantly. Since $\mathrm{G}: \mathrm{C}>\mathrm{A}: \mathrm{T}$ mutations in $A P C$ may also occur via spontaneous deamination when occurring in CPG dinucleotides, we stratified MGMT hypermethylation according to the orientation of these mutations. However, we then observed that the frequency of MGMT hypermethylation was similar in tumors with $\mathrm{G}: \mathrm{C}>\mathrm{A}: \mathrm{T}$ APC mutations in either $\mathrm{CpG}$ or non-CpG dinucleotides. 
Table 1. Comparison of colorectal cancer patients with or without MGMT and MLH1 promoter hypermethylation

\begin{tabular}{|c|c|c|c|c|c|c|c|c|}
\hline \multirow[b]{4}{*}{ Number of patients (\%) } & \multicolumn{8}{|c|}{ Promoter hypermethylation * } \\
\hline & \multicolumn{4}{|c|}{ MGMT } & \multicolumn{4}{|c|}{ MLH1 } \\
\hline & \multicolumn{2}{|c|}{ Methylated } & \multicolumn{2}{|c|}{ Unmethylated } & \multicolumn{2}{|c|}{ Methylated } & \multicolumn{2}{|c|}{ Unmethylated } \\
\hline & 287 & $(41 \%)$ & 406 & $(59 \%)$ & 152 & $(22 \%)$ & 534 & $(78 \%)$ \\
\hline $\begin{array}{l}\text { Age at diagnosis } \\
\text { (yr, mean (SD)) }\end{array}$ & 68.0 & $(4.3)$ & 67.9 & $(4.3)$ & 68.0 & $(4.4)$ & 68.0 & $(4.2)$ \\
\hline P-value $\ddagger$ & \multicolumn{4}{|c|}{0.64} & \multicolumn{4}{|c|}{0.76} \\
\hline \multicolumn{9}{|l|}{ Sex } \\
\hline Men & 156 & $(41 \%)$ & 229 & $(59 \%)$ & 73 & $(19 \%)$ & 309 & $(81 \%)$ \\
\hline Women & 131 & $(43 \%)$ & 177 & $(57 \%)$ & 79 & $(26 \%)$ & 225 & $(74 \%)$ \\
\hline$P$-value & \multicolumn{4}{|c|}{0.59} & \multicolumn{4}{|c|}{0.03} \\
\hline $\begin{array}{l}\text { Family history of colorectal } \\
\text { cancer }(\% \text { yes })^{\dagger}\end{array}$ & 22 & $(8 \%)$ & 47 & $(12 \%)$ & 10 & $(7 \%)$ & 62 & $(12 \%)$ \\
\hline P-value & \multicolumn{4}{|c|}{0.10} & \multicolumn{4}{|c|}{0.08} \\
\hline \multicolumn{9}{|l|}{ Tumor sub-localization ${ }^{\dagger}$} \\
\hline Proximal colon & 95 & $(41 \%)$ & 137 & $(59 \%)$ & 80 & $(35 \%)$ & 150 & $(65 \%)$ \\
\hline Distal colon & 82 & $(38 \%)$ & 132 & $(62 \%)$ & 35 & $(16 \%)$ & 178 & $(84 \%)$ \\
\hline Rectosigmoid & 37 & $(46 \%)$ & 43 & $(54 \%)$ & 12 & $(16 \%)$ & 64 & $(84 \%)$ \\
\hline Rectum & 67 & $(42 \%)$ & 92 & $(58 \%)$ & 21 & $(13 \%)$ & 138 & $(87 \%)$ \\
\hline$P$-value & \multicolumn{4}{|c|}{0.65} & \multicolumn{4}{|c|}{$<0.001$} \\
\hline \multicolumn{9}{|l|}{ Dukes' stage ${ }^{\dagger}$} \\
\hline$A$ & 84 & $(48 \%)$ & 91 & $(52 \%)$ & 36 & $(21 \%)$ & 139 & $(79 \%)$ \\
\hline B & 87 & $(39 \%)$ & 138 & $(61 \%)$ & 52 & $(23 \%)$ & 172 & $(77 \%)$ \\
\hline C & 72 & $(41 \%)$ & 105 & $(59 \%)$ & 44 & $(25 \%)$ & 133 & $(75 \%)$ \\
\hline$D$ & 32 & $(40 \%)$ & 48 & $(60 \%)$ & 14 & $(18 \%)$ & 62 & $(82 \%)$ \\
\hline$P$-value & \multicolumn{4}{|c|}{0.28} & \multicolumn{4}{|c|}{0.63} \\
\hline \multicolumn{9}{|l|}{ Differentiation ${ }^{\dagger}$} \\
\hline Good & 27 & $(40 \%)$ & 40 & $(60 \%)$ & 12 & $(18 \%)$ & 55 & $(82 \%)$ \\
\hline Moderate & 174 & $(40 \%)$ & 257 & $(60 \%)$ & 86 & $(20 \%)$ & 340 & $(80 \%)$ \\
\hline Poor & 41 & $(41 \%)$ & 58 & $(59 \%)$ & 31 & $(32 \%)$ & 67 & $(68 \%)$ \\
\hline Undifferentiated & 2 & $(29 \%)$ & 5 & $(71 \%)$ & \multirow{2}{*}{\multicolumn{4}{|c|}{$0.07^{5}$}} \\
\hline$P$-value & \multicolumn{4}{|c|}{0.93} & & & & \\
\hline
\end{tabular}

* Complete data on MGMT and MLH1 hypermethylation were available for 693 and 686 out of 734 patients, respectively. 66 patients had hypermethylation of both MGMT and MLH1

$\dagger$ Data on family history of colorectal cancer, tumor sub-localization, Dukes' stage and differentiation were unavailable for $3,9,38$ and 93 patients respectively

$\ddagger \quad$-value for the difference between the Methylated and Unmethylated groups

Table 2. MGMT Promoter hypermethylation versus G:C>A:T mutations in KRAS and APC

\begin{tabular}{|c|c|c|c|c|c|}
\hline & & \multicolumn{4}{|c|}{ MGMT promoter hypermethylation * } \\
\hline & & & nylated & Unm & \\
\hline $\mathrm{KRAS}^{\dagger}$ & $\begin{array}{l}\mathrm{G}: \mathrm{C}>\mathrm{A}: \mathrm{T} \text { mutation } \\
\text { No } \mathrm{G}: \mathrm{C}>\mathrm{A}: \mathrm{T} \text { mutation } \\
P \text {-value }\end{array}$ & $\begin{array}{l}79 \\
208\end{array}$ & $\begin{array}{l}(55 \%) \\
(38 \%)\end{array}$ & $\begin{array}{r}64 \\
342 \\
<0.001\end{array}$ & $\begin{array}{l}(45 \%) \\
(62 \%)\end{array}$ \\
\hline$A P C \ddagger$ & $\begin{array}{l}\mathrm{G}: \mathrm{C}>\mathrm{A}: \mathrm{T} \text { mutation } \S \\
\text { No G:C>A:T mutation } \\
P \text {-value }\end{array}$ & $\begin{array}{l}135 \\
127\end{array}$ & $\begin{array}{l}(41 \%) \\
(42 \%)\end{array}$ & $\begin{array}{l}198 \\
177 \\
0.75\end{array}$ & $\begin{array}{l}(59 \%) \\
(58 \%)\end{array}$ \\
\hline$A P C$ & $\begin{array}{l}\text { G:C>A:T mutation - } \mathrm{CpG} \mathbb{I},+\dagger \\
\text { G:C>A:T mutation - non-CpG }{ }^{* *},+\dagger \\
P \text {-value }\end{array}$ & $\begin{array}{l}17 \\
88\end{array}$ & $\begin{array}{l}(44 \%) \\
(39 \%)\end{array}$ & $\begin{array}{c}22 \\
135 \\
0.63\end{array}$ & $\begin{array}{l}(56 \%) \\
(61 \%)\end{array}$ \\
\hline
\end{tabular}

* Complete data on MGMT promoter hypermethylation were available for 693 out of 734 patients

$\dagger$ KRAS mutation analysis succeeded for all 734 patients

$\ddagger A P C$ mutation analyses were available for 662 out of 734 patients

$\S G>A$ with matching $C>T$ point mutation at similar loci in both DNA strands

II $\mathrm{G}: \mathrm{C}>\mathrm{A}: \mathrm{T}$ mutation in a $\mathrm{CpG}$ dinucleotide: the cytosine or guanine that mutated had a neighbouring guanine or cytosine, respectively

** G:C>A:T mutation in non-CpG dinucleotide: the cytosine or guanine that mutated did not have a neighbouring guanine or cytosine, respectively

t† 79 (21\%) of 379 patients with G:C>A:T APC mutations had more than one such a mutation that did not consistently occur in CpG or non-CpG dinucleotides 
We also assessed the relation between $M L H 1$ hypermethylation and the occurrence of truncating or frameshift $A P C$ mutations, or activating KRAS or BRAF mutations. We observed less MLH1 hypermethylation in patients with a truncating APC mutation (17\%) compared to patients without such a mutation ( $26 \%, P=0.006$, Table 3 ). A similar contrast could be observed for $A P C$ frameshift mutations, since $M L H 1$ methylation occurred in $15 \%$ of the tumors with an $A P C$ frameshift mutation, versus $25 \%$ in tumors without frameshift mutation in APC $(P=0.01)$. Less $M L H 1$ hypermethylation was also observed in patients with activating KRAS mutations compared to cases without these mutations ( $15 \%$ and $26 \%$ respectively, $P=0.001$ ). Conversely, a strong positive association was present between $M L H 1$ hypermethylation and activating $B R A F$ mutations, since $47 \%$ of the tumors with $B R A F$ mutations showed MLH1 hypermethylation compared to $17 \%$ of $M L H 1$ hypermethylation in tumors harboring wild type $B R A F(P<0.001)$.

Table 3. Promoter hypermethylation of $M L H 1$ versus mutations in APC, KRAS or BRAF

\begin{tabular}{|c|c|c|c|c|c|}
\hline \multirow{2}{*}{${ }_{A P C}$ (truncation) $^{\top}$} & \multirow[b]{3}{*}{$\begin{array}{l}\text { Mutation } \\
\text { No mutation } \\
P \text {-value }\end{array}$} & \multicolumn{4}{|c|}{ MLH1 promoter hypermethylation } \\
\hline & & \multicolumn{2}{|c|}{ Methylated } & \multirow{2}{*}{\multicolumn{2}{|c|}{$\begin{array}{cc} & \text { Unmethylated } \\
195 & (83 \%) \\
295 & (74 \%) \\
0.006 & \end{array}$}} \\
\hline$A P C$ (truncation) $^{\top}$ & & $\begin{array}{l}40 \\
106\end{array}$ & $\begin{array}{l}(17 \%) \\
(26 \%)\end{array}$ & & \\
\hline$A P C$ (frameshift mutation) & $\begin{array}{l}\text { Mutation } \\
\text { No mutation } \\
P \text {-value }\end{array}$ & $\begin{array}{l}19 \\
127\end{array}$ & $\begin{array}{l}(15 \%) \\
(25 \%)\end{array}$ & $\begin{array}{l}110 \\
375 \\
0.01\end{array}$ & $\begin{array}{l}(85 \%) \\
(75 \%)\end{array}$ \\
\hline$K R A S$ (activating mutation) ${ }^{\ddagger}$ & $\begin{array}{l}\text { Mutation } \\
\text { No mutation } \\
P \text {-value }\end{array}$ & $\begin{array}{l}40 \\
112\end{array}$ & $\begin{array}{l}(15 \%) \\
(26 \%)\end{array}$ & $\begin{array}{l}218 \\
316 \\
0.001\end{array}$ & $\begin{array}{l}(85 \%) \\
(74 \%)\end{array}$ \\
\hline$B R A F$ (activating mutation) $^{\S}$ & $\begin{array}{l}\text { Mutation } \\
\text { No mutation } \\
P \text {-value }\end{array}$ & $\begin{array}{l}51 \\
97\end{array}$ & $\begin{array}{l}(47 \%) \\
(17 \%)\end{array}$ & $\begin{array}{l}58 \\
462 \\
<0.001\end{array}$ & $\begin{array}{l}(53 \%) \\
(83 \%)\end{array}$ \\
\hline
\end{tabular}

* Complete data on MLH1 promoter hypermethylation was available for 686 out of 734 patients

$\dagger$ APC mutation analyses were available for 662 out of 734 patients

$\ddagger$ KRAS mutation analysis succeeded for all 734 patients

$\S B R A F$ mutation analysis succeeded for 697 out of 734 patients

Finally, we observed that $B R A F$ mutations were more common in tumors without $A P C$ mutations, or without KRAS mutations $(P<0.001$ for both associations respectively, Table 4). No association was observed between $B R A F$ mutations and MGMT promoter methylation (data not shown).

Table 4. Comparison of BRAF mutations with mutations in APC and KRAS

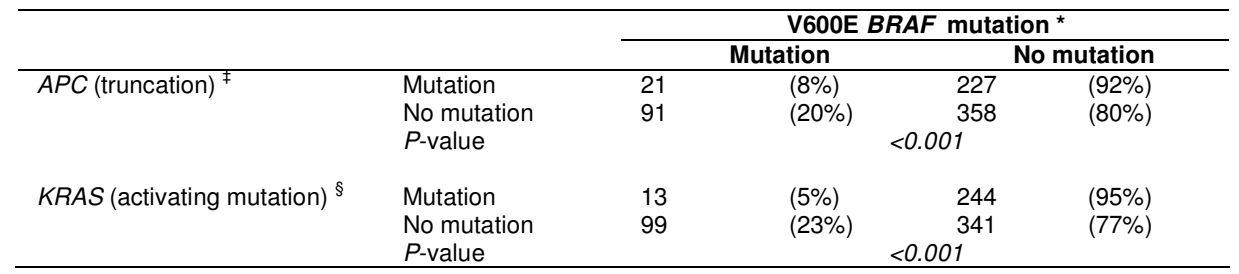

* BRAF mutation analyses were available for 697 out of 734 patients

$\dagger$ Complete data on MLH1 and MGMT promoter hypermethylation were available for 693 and 686 out of 734 patients, respectively

$\ddagger A P C$ mutation analyses were available for 662 out of 734 patients

$\S$ KRAS mutation analysis succeeded for all 734 patients 


\section{Discussion}

Here we studied the prevalence of promoter hypermethylation of the DNA repair genes MGMT and MLH1 in relation to somatic mutations in APC, KRAS and BRAF in colorectal carcinogenesis, in a large group $(n=734)$ of unselected, incident colorectal cancer patients. MGMT hypermethylation was associated with $\mathrm{G}: \mathrm{C}>\mathrm{A}: \mathrm{T}$ KRAS mutations. However, there was no association between MGMT hypermethylation and G:C>A:T mutations in $A P C$, irrespective of the occurrence of these mutations in CpG or non-CpG dinucleotides. This indicates that G:C>A:T APC mutations are independent of, and possibly occur prior to MGMT hypermethylation. Whereas there was a positive association between MLH1 hypermethylation and BRAF mutations, it was inversely associated with $A P C$ mutations and KRAS mutations.

These results support the hypothesis that MGMT hypermethylation may lead to somatic mutations in KRAS, and that functional loss of MGMT may occur early in colorectal carcinogenesis (8). This is the first study in which the association between MGMT methylation and G:C>A:T APC mutations was investigated. A possible explanation for the lack of association between these two events may be the orientation of cytosines or guanines, which may "mask" a potential association between MGMT methylation and G:C>A:T mutations. If these mutations occur in CpG dinucleotides, they may also result from spontaneous deamination (33), whereas alkyl adduct formation is more likely the primary cause in non-CpG dinucleotides. MGMT removes alkyl adducts from the $\mathrm{O}^{6}$ position of guanine, and it was previously observed that G:C>A:T mutations are repaired less effectively via MGMT when they occur in CpG dinucleotides (35). Moreover, it was also observed that MGMT hypermethylation occurred less frequently in tumors with G:C>A:T P53 mutations in CpG dinucleotides compared to such mutations in non-CpG dinucleotides (10). In order to investigate whether this difference could explain the lack of association with G:C>A:T APC mutations in our study, we stratified the analyses for those mutations occurring in CpG or non-CpG dinucleotides. However, stratification did not reveal a difference in $M G M T$ methylation between these two types of $\mathrm{G}: \mathrm{C}>\mathrm{A}: \mathrm{T} A P C$ mutations, and this therefore suggests that the association does not exist. MGMT hypermethylation in combination with hypermethylation of $A P C$ or MLH1 may be associated with G:C>A:T APC mutations (13). However, in that study the association was not studied for MGMT hypermethylation exclusively, and the conclusion was based on rather small numbers of cases. Moreover, Halford et al previously investigated the association between $\mathrm{O}^{6}$ MGMT protein expression and G:C>A:T APC mutations (36). Although the investigators demonstrated a weak association with G:C>A:T mutations in the combination of $A P C$, beta-catenin, KRAS and P53, no association was observed with G:C>A:T mutations in $A P C$ exclusively.

In view of these results, a plausible explanation is to assume that in colorectal carcinogenesis, truncating $A P C$ mutations may occur prior to epigenetic silencing of MGMT by promoter hypermethylation. Mutations in KRAS are viewed as occurring in a later stage of colorectal carcinogenesis than $A P C$ mutations, and we observed an association between MGMT hypermethylation and KRAS mutations. Esteller et al previously observed a similar association between $M G M T$ hypermethylation and $\mathrm{G}: \mathrm{C}>\mathrm{A}$ :T mutations in KRAS (11). Moreover, an association of MGMT hypermethylation with these mutations in the $P 53$ gene, which usually occur in a late stage of colorectal 
carcinogenesis (10), was observed. We propose that the sequence of events in the multi-step model of colorectal carcinogenesis as proposed by Fearon and Vogelstein (37), may include MGMT methylation as depicted in Figure 2. It should be noted, however, that the molecular endpoints studied in tumor tissue are cross-sectional data, and can therefore only provide indirect evidence for a potential sequence of events. Nevertheless, such data provide more insight in colorectal carcinogenesis, and may be an important source for new hypotheses about the possible timing of molecular events.

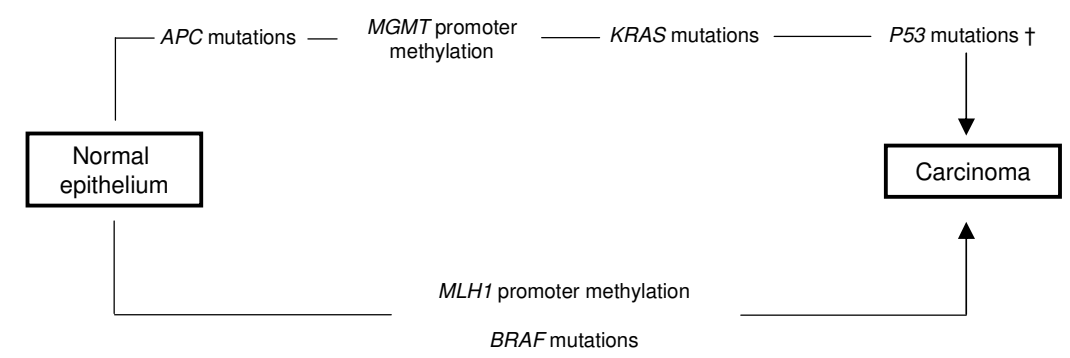

Figure 2. MGMT and MLH1 promoter methylation and mutations in APC, KRAS and BRAF in the carcinogenesis of sporadic colorectal cancer *

* Adapted from Fearon and Vogelstein, Cell 1990. Adenomas were not analyzed in the study and were therefore omitted from this model $\dagger$ P53 mutation status was not analyzed in this study

A second observation in the current study was that MLH1 hypermethylation was related to lower frequencies of somatic mutations in $A P C$ and $K R A S$, which suggests that such tumors develop through a distinct genetic pathway. This is in line with the observed high correlation between $M L H 1$ methylation and microsatellite instability in the colorectum (15-17) and its inverse relationship with mutations in other key genes involved in colorectal carcinogenesis (20-23). In addition, we have previously observed a strong positive association between $M L H 1$ methylation and MSI, and that $A P C$ and KRAS mutations are rare in MLH1 deficient tumors among CRC patients included in the current study $(18,38)$. Moreover, strong associations between $M L H 1$ hypermethylation, MSI and BRAF mutations were previously observed (14). In this respect, we demonstrated that BRAF mutated tumors were strongly associated with MLH1 hypermethylation, and moreover, that these tumors also harbored less mutations in $A P C$ and KRAS. These observations confirm previous results showing that $B R A F$ mutations were inversely associated with KRAS mutations and with $A P C$ hypermethylation $(39,40)$. On the other hand, MGMT promoter hypermethylation was not associated with $B R A F$ mutations and our results as well as observations of a smaller study (24) show that concurrent promoter hypermethylation of $M L H 1$ and MGMT is rare. We therefore suggest that these are additional indications showing that tumors with epigenetic silenced MGMT may arise through a distinct hypermethylation associated pathway.

Patients with MGMT and/or MLH1 hypermethylation less often had a positive family history of colorectal cancer but there were no age differences between patients with, or without hypermethylation. This suggests that in these tumors, exogenous factors may 
have played a larger role in colorectal carcinogenesis compared to tumors that do not develop through a hypermethylated pathway.

We conclude that MGMT inactivation by hypermethylation may cause somatic mutations in KRAS, but not in $A P C$. This suggests that in the process of colorectal carcinogenesis, MGMT hypermethylation may succeed the introduction of $A P C$ mutations, but precedes KRAS mutations. Tumors with $M L H 1$ inactivation by hypermethylation seem to develop through a distinct pathway associated with fewer $A P C$ and KRAS mutations, and this pathway is possibly distinct from an MGMTmethylator pathway. Colorectal carcinogenesis may be more susceptible to the influence of exogenous factors when hypermethylation plays an important role. 


\section{References}

1. Herman JG, Baylin SB. Gene silencing in cancer in association with promoter hypermethylation. N Engl J Med 2003;349(21):2042-54.

2. Friedberg EC. DNA damage and repair. Nature 2003;421(6921):436-40.

3. Kinzler KW, Vogelstein B. Cancer-susceptibility genes. Gatekeepers and caretakers. Nature 1997;386(6627):761, 763.

4. Derks S, Postma C, Moerkerk PT, van den Bosch SM, Carvalho B, Hermsen MA, et al. Promoter methylation precedes chromosomal alterations in colorectal cancer development. Cell Oncol 2006;28(5-6):247-57.

5. Esteller M. Epigenetic lesions causing genetic lesions in human cancer: promoter hypermethylation of DNA repair genes. Eur J Cancer 2000;36(18):2294-300.

6. Frigola J, Sole X, Paz MF, Moreno V, Esteller M, Capella G, et al. Differential DNA hypermethylation and hypomethylation signatures in colorectal cancer. Hum Mol Genet 2005;14(2):319-26.

7. Shen L, Kondo Y, Rosner GL, Xiao L, Hernandez NS, Vilaythong J, et al. MGMT promoter methylation and field defect in sporadic colorectal cancer. $J$ Natl Cancer Inst 2005;97(18):1330-8.

8. Giovannucci E, Ogino S. DNA methylation, field effects, and colorectal cancer. J Natl Cancer Inst 2005;97(18):1317-9.

9. Esteller M, Hamilton SR, Burger PC, Baylin SB, Herman JG. Inactivation of the DNA repair gene 06-methylguanine-DNA methyltransferase by promoter hypermethylation is a common event in primary human neoplasia. Cancer Res 1999;59(4):793-7.

10. Esteller M, Risques RA, Toyota M, Capella G, Moreno V, Peinado MA, et al. Promoter hypermethylation of the DNA repair gene $\mathrm{O}(6)$-methylguanine-DNA methyltransferase is associated with the presence of G:C to A:T transition mutations in p53 in human colorectal tumorigenesis. Cancer Res 2001;61(12):4689-92.

11. Esteller M, Toyota M, Sanchez-Cespedes M, Capella G, Peinado MA, Watkins DN, et al. Inactivation of the DNA repair gene 06-methylguanine-DNA methyltransferase by promoter hypermethylation is associated with $\mathrm{G}$ to A mutations in K-ras in colorectal tumorigenesis. Cancer Res 2000;60(9):2368-71.

12. Nosho K, Kawasaki T, Ohnishi M, Suemoto Y, Kirkner GJ, Zepf D, et al. PIK3CA mutation in colorectal cancer: relationship with genetic and epigenetic alterations. Neoplasia 2008;10(6):534-41.

13. Suehiro Y, Wong CW, Chirieac LR, Kondo Y, Shen L, Webb CR, et al. Epigenetic-Genetic Interactions in the APC/WNT, RAS/RAF, and P53 Pathways in Colorectal Carcinoma. Clin Cancer Res 2008;14(9):2560-9.

14. Weisenberger DJ, Siegmund KD, Campan M, Young J, Long TI, Faasse MA, et al. CpG island methylator phenotype underlies sporadic microsatellite instability and is tightly associated with BRAF mutation in colorectal cancer. Nat Genet 2006;38(7):787-93.

15. Arnold CN, Goel A, Compton C, Marcus V, Niedzwiecki D, Dowell JM, et al. Evaluation of microsatellite instability, hMLH1 expression and $h M L H 1$ promoter hypermethylation in defining the MSI phenotype of colorectal cancer. Cancer Biol Ther 2004;3(1):73-8.

16. Herman JG, Umar A, Polyak K, Graff JR, Ahuja N, Issa JP, et al. Incidence and functional consequences of $h M L H 1$ promoter hypermethylation in colorectal carcinoma. Proc Natl Acad Sci U S A 1998;95(12):6870-5.

17. Kuismanen SA, Holmberg MT, Salovaara R, de la Chapelle A, Peltomaki P. Genetic and epigenetic modification of MLH1 accounts for a major share of microsatellite-unstable colorectal cancers. Am J Pathol 2000;156(5):1773-9.

18. de Vogel S, Bongaerts BW, Wouters KA, Kester AD, Schouten LJ, de Goeij AF, et al. Associations of dietary methyl donor intake with $M L H 1$ promoter hypermethylation and related molecular phenotypes in sporadic colorectal cancer. Carcinogenesis 2008, Mar 13; doi:10.1093/carcin/bgn074.

19. Kawakami K, Ruszkiewicz A, Bennett G, Moore J, Grieu F, Watanabe G, et al. DNA hypermethylation in the normal colonic mucosa of patients with colorectal cancer. $\mathrm{Br} J$ Cancer 2006;94(4):593-8. 
20. Ogino S, Brahmandam M, Kawasaki T, Kirkner GJ, Loda M, Fuchs CS. Combined Analysis of COX-2 and p53 Expressions Reveals Synergistic Inverse Correlations with Microsatellite Instability and $\mathrm{CpG}$ Island Methylator Phenotype in Colorectal Cancer. Neoplasia 2006;8(6):458-64.

21. Salahshor S, Kressner U, Pahlman L, Glimelius B, Lindmark G, Lindblom A. Colorectal cancer with and without microsatellite instability involves different genes. Genes Chromosomes Cancer 1999;26(3):247-52.

22. Samowitz WS, Albertsen H, Herrick J, Levin TR, Sweeney C, Murtaugh MA, et al. Evaluation of a large, population-based sample supports a CpG island methylator phenotype in colon cancer. Gastroenterology 2005;129(3):837-45.

23. van Rijnsoever M, Grieu F, Elsaleh H, Joseph D, Iacopetta B. Characterisation of colorectal cancers showing hypermethylation at multiple CpG islands. Gut 2002;51(6):797-802.

24. Fox EJ, Leahy DT, Geraghty R, Mulcahy HE, Fennelly D, Hyland JM, et al. Mutually Exclusive Promoter Hypermethylation Patterns of $h M L H 1$ and O6-Methylguanine DNA Methyltransferase in Colorectal Cancer. J Mol Diagn 2006;8(1):68-75.

25. van den Brandt PA, Goldbohm RA, van 't Veer P, Volovics A, Hermus RJ, Sturmans F. A large-scale prospective cohort study on diet and cancer in The Netherlands. J Clin Epidemiol $1990 ; 43(3): 285-95$.

26. Van den Brandt PA, Schouten L, Goldbohm RA, Dorant E, Hunen PM. Development of a record linkage protocol for use in the Dutch Cancer Registry for Epidemiological Research. Int J Epidemiol 1990;19(3):553-8.

27. Casparie M, Tiebosch AT, Burger $G$, Blauwgeers $H$, van de Pol A, van Krieken JH, et al. Pathology databanking and biobanking in The Netherlands, a central role for PALGA, the nationwide histopathology and cytopathology data network and archive. Cell Oncol 2007;29(1):19-24.

28. Brink M, de Goeij AF, Weijenberg MP, Roemen GM, Lentjes MH, Pachen MM, et al. K-ras oncogene mutations in sporadic colorectal cancer in The Netherlands Cohort Study. Carcinogenesis 2003;24(4):703-10.

29. Herman JG, Graff JR, Myohanen S, Nelkin BD, Baylin SB. Methylation-specific PCR: a novel PCR assay for methylation status of CPG islands. Proc Natl Acad Sci U S A 1996;93(18):9821-6.

30. van Engeland M, Weijenberg MP, Roemen GM, Brink M, de Bruine AP, Goldbohm RA, et al. Effects of dietary folate and alcohol intake on promoter methylation in sporadic colorecta cancer: the Netherlands cohort study on diet and cancer. Cancer Res 2003;63(12):3133-7.

31. Derks $S$, Lentjes $M H$, Hellebrekers DM, de Bruine AP, Herman JG, van Engeland $M$. Methylation-specific PCR unraveled. Cell Oncol 2004;26(5-6):291-9.

32. Luchtenborg M, Weijenberg MP, Roemen GM, de Bruine AP, van den Brandt PA, Lentjes MH, et al. APC mutations in sporadic colorectal carcinomas from The Netherlands Cohort Study. Carcinogenesis 2004;25(7):1219-26.

33. Pfeifer GP. Mutagenesis at methylated $\mathrm{CpG}$ sequences. Curr Top Microbiol Immunol 2006;301:259-81.

34. Sieben NL, Roemen GM, Oosting J, Fleuren GJ, van Engeland M, Prat J. Clonal analysis favours a monoclonal origin for serous borderline tumors with peritoneal implants. J Pathol 2006;210(4):405-11.

35. Bentivegna SS, Bresnick E. Inhibition of human O6-methylguanine-DNA methyltransferase by 5-methylcytosine. Cancer Res 1994;54(2):327-9.

36. Halford S, Rowan A, Sawyer E, Talbot I, Tomlinson I. O(6)-methylguanine methyltransferase in colorectal cancers: detection of mutations, loss of expression, and weak association with G:C>A:T transitions. Gut 2005;54(6):797-802.

37. Fearon ER, Vogelstein B. A genetic model for colorectal tumorigenesis. Cell 1990;61(5):759-67.

38. Luchtenborg M, Weijenberg MP, Wark PA, Saritas AM, Roemen GM, van Muijen GN, et al. Mutations in $A P C$, CTNNB1 and $\mathrm{K}$-ras genes and expression of hMLH1 in sporadic colorectal carcinomas from the Netherlands Cohort Study. BMC Cancer 2005;5(1):160.

39. Iacopetta B, Grieu F, Li W, Ruszkiewicz A, Caruso M, Moore J, et al. APC gene methylation is inversely correlated with features of the $\mathrm{CpG}$ island methylator phenotype in colorectal cancer. Int J Cancer 2006;119(10):2272-8. 
Chapter 2

40. Ogino S, Cantor M, Kawasaki T, Brahmandam M, Kirkner GJ, Weisenberger DJ, et al. CpG island methylator phenotype (CIMP) of colorectal cancer is best characterised by quantitative DNA methylation analysis and prospective cohort studies. Gut 2006;55(7):1000-6. 


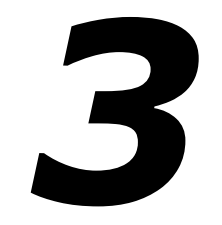

\title{
Dietary folate, methionine, riboflavin and vitamin B6 and risk of sporadic colorectal \\ cancer
}

\author{
Stefan de Vogel \\ Vasundhara Dindore \\ Manon van Engeland \\ R Alexandra Goldbohm \\ Piet A van den Brandt \\ Matty P Weijenberg
}

Journal of Nutrition 2008; 138(12):2372-8 


\section{Abstract}

Adequate intake of folate, methionine, riboflavin and vitamin B-6 may prevent aberrant DNA methylation and thereby protect against colorectal cancer (CRC). However, previous epidemiological studies investigating associations between dietary intakes of these nutrients and CRC have been inconsistent. We investigated the associations between intakes of folate, methionine, riboflavin and vitamin B-6 and CRC risk, accounting for the sub-localization of the tumor.

Within the Netherlands Cohort Study on diet and cancer ( $n=120,852), 2,349$ cases and 4,168 subcohort members were available for data analyses from a follow-up period of 13.3 y after baseline. Gender-specific adjusted incidence rate ratios (RR) were calculated over quintiles of dietary intake in case-cohort analyses.

Folate intake was not associated with CRC risk in either men or women. However, methionine was associated with decreased risk of proximal colon cancer among men $\left(R R=0.57\right.$ for highest versus lowest quintile of intake, $\left.P_{\text {trend }}=0.03\right)$ and rectal cancer among women (highest vs. lowest quintile: $R R=0.45, P_{\text {trend }}=0.05$ ). Riboflavin was nonsignificantly associated with decreased proximal colon cancer risk among women $\left(\mathrm{RR}=0.61, P_{\text {trend }}=0.07\right)$. Conversely, there was a strong positive association between vitamin B-6 and rectal cancer among women $\left(\mathrm{RR}=3.57, P_{\text {trend }}=0.01\right)$.

Our findings suggest that relatively high methionine intake may protect against proximal colon cancer in men and rectal cancer in women, but that folate may not have a protective effect. This is the second prospective cohort study in which vitamin B-6 intake was associated with increased risk of rectal tumors in women, which might suggest that this vitamin enhances rectal cancer in women. 


\section{Introduction}

It has been proposed that folate may affect colorectal carcinogenesis, because of its role in the synthesis of nucleic acid and DNA methylation (1). Folate deficiency may result in uracil mis-incorporation in DNA which possibly leads to DNA instability and gene alterations. It may also cause aberrant DNA methylation such as CpG promoter hypermethylation or global hypomethylation and which in turn may contribute to colorectal carcinogenesis. For example, hypermethylation of gene promoters is known to result in silencing of tumor suppressor genes and DNA repair genes, which in turn may enhance carcinogenesis (2). Therefore, it may be hypothesized that adequate folate levels possibly protect against CRC. However, epidemiological studies on the relation between dietary folate intake and colorectal cancer risk have not consistently shown a protective effect of high folate intake $(3,4)$. Also, it has been suggested that the effect of folate supplementation may depend on the stage of colorectal carcinogenesis, i.e. it would protect against carcinogenesis in normal colorectal tissue, but might enhance already existing lesions $(5,6)$. In this respect, the relation between dietary folate and the etiology of colorectal cancer continues to be the subject of debate.

Like folate, methionine is required for the synthesis of S-adenosylmethionine, which is the universal methyl group donor needed for methylation processes (7). Adequate intakes of folate or methionine through the diet ensure a sufficient supply of methyl groups, and it may be hypothesized that this also prevents aberrant DNA methylation. Other B-vitamins such as riboflavin and vitamin B-6 are involved in the folate-mediated 1-carbon metabolism, and may therefore modulate the bioavailability of methyl groups. Riboflavin, as flavin adenine dinucleotide (FAD), is the cofactor for methylenetetrahydrofolate reductase (MTHFR), the enzyme that influences homocysteine (tHcy) remethylation and DNA methylation. Low riboflavin status was previously observed to be associated with increased tHcy concentration, which possibly results in lower availability of methyl groups (8). In addition, vitamin B-6 is involved in the conversion of tetrahydrofolate into 5,10-methylenetetrahydrofolate, one of the steps of the folate cycle (7). On the other hand, high alcohol intake potentially reduces the bioavailability of folate and such a disruption of the one-carbon metabolism may affect DNA methylation in for example the colonic mucosa (9-11).

The associations between dietary intakes of riboflavin, vitamin B- 6 and methionine have been investigated in a number of studies. However, whereas a potential protective effect of riboflavin intake on colorectal adenomas was observed in one study (12) others have not demonstrated an association with CRC at all $(13,14)$. Similarly, relatively high methionine intake did not seem to protect against CRC $(13,15-17)$. Several studies demonstrated an inverse association between vitamin B-6 intake and CRC (17-21), although in one study, a positive association was observed between the vitamin and rectal tumors among women (16). There may be a number of reasons for these inconsistencies between studies, such as the danger of selection bias and possibly recall bias that could have played a larger role in case-control studies. In this respect, some of the studies had a prospective cohort design $(15,16,18-21)$ whereas others were case-control studies (12-14,17). Moreover, some studies were conducted among women only $(15,16,19-21)$ or in relation to colorectal adenomas (12), and there are considerable differences in the level of vitamin intake between studies. 
The relation between folate and colorectal cancer is still controversial and previous studies on associations between folate, B-vitamins and methionine with CRC show inconsistencies. This prompted us to investigate the combination of folate, riboflavin, vitamin B-6 and methionine in a prospective setting. The study was conducted among incident CRC patients and subcohort members of the Netherlands Cohort Study on diet and cancer (NLCS), which is a large population-based study with a prospective casecohort design.

\section{Subjects and methods}

\section{Study population}

The participants in this study are incident colon and rectal cancer patients and subcohort members from the NLCS, which has been described in detail elsewhere (22). Briefly, the study was initiated in September 1986 and includes 58,279 men and 62,573 women aged 55-69 y at baseline, who originated from 204 Dutch municipalities with computerized population registers. At baseline, participants completed a selfadministered food-frequency questionnaire that also provided information about age, sex and other risk factors for cancer. The entire cohort is being monitored for cancer occurrence by annual record linkage to the Netherlands Cancer Registry (NCR, nine cancer registries in The Netherlands). Accumulation of person-time in the cohort has been estimated through biennial follow-up of vital status in a subcohort of 5,000 men and women who were randomly selected after baseline exposure measurement. Cases with prevalent cancer other than non-melanoma skin cancer were excluded from this subcohort, which left 4,774 men and women eligible for analysis. CRC was classified according to disease site as follows: colon, i.e. proximal colon (ICD-O-1 codes 153.0, $153.1,153.4,153.5,153.6)$ and distal colon (153.2, 153.3, 153.7), rectosigmoid (154.0), rectum (154.1), or ICD-O-1 codes 153.8 and 153.9 if information of the disease site was not available. Follow-up information was available from a follow-up period up to 13.3 y after baseline, i.e. from September 1986 until January 2000. Within this period, 2,679 CRC patients were identified.

\section{Food frequency questionnaire}

The self-administered questionnaire was a 150-item semi-quantitative food frequency questionnaire (FFQ), which concentrated on habitual consumption of food and beverages during the year preceding the start of the study, and also contained questions about body weight and -length, smoking status, physical activity, and family history of colorectal cancer. Daily mean nutrient intakes were calculated as the cumulated product of the frequencies and portion sizes of all food items and their tabulated nutrient contents from the Dutch Food Composition Table (NEVO table, 1986) (23). The questionnaire was validated through comparison with a 9-day diet record (24), and the reproducibility was determined (25). Questionnaire data were key-entered twice for all incident cases in the cohort and for all subcohort members in a blinded manner with respect to case/subcohort status. This was done in order to minimize observer bias in coding and interpretation of the data. 
Folate data were derived from a validated liquid chromatography trienzyme method (26) used to analyze the 125 most important Dutch foods contributing to folate intake (27). Mean daily intakes of all other relevant nutrients were calculated using the computerized Dutch Food Composition Table (23). Dietary supplement data were also obtained via the food frequency questionnaire. However, the use of B-vitamin supplements was low (7\%) and folic acid was generally not included in these supplements in the Netherlands in the late 1980s. Therefore, folic acid supplement use most likely plays a very minor role in our study population, and supplement use was not further accounted for in the analyses.

\section{Statistical analyses}

Analyses were performed for all CRC cases combined and for each sub-localization, i.e. proximal colon, distal colon, rectosigmoid and rectum. Dietary factors and other baseline characteristics were evaluated for men and women separately, for subcohort members and CRC cases by calculating means and standard deviations for continuous variables and distributions of the categorical variables.

Cox proportional hazards regression models were used to estimate gender-specific multivariate-adjusted incidence rate ratios (RR) and corresponding $95 \%$ confidence intervals (CI) over quintiles of folate intake, methionine, riboflavin and B-6, using the lowest quintiles as reference. Standard errors of the RR were estimated using the robust Huber-White sandwich estimator to account for additional variance introduced by sampling from the cohort (28). Tests for dose response trends over the quintiles of intake were estimated by fitting the ordinal exposure variables as continuous variables and evaluated using the Wald test. To account for potentially non-linear effects due to skewed distributions of folate, methionine, riboflavin and vitamin B-6, we also estimated the associations between the quintile variables and CRC by replacing the quintiles with the median intakes within each quintile and compare these RR with the main analyses. The proportional hazards assumption was tested using the scaled Schoenfeld residuals (29), and by fitting the main determinants as time-dependent variables. Analyses were additionally stratified for the first and second half of the follow up time. Because undetected pre-clinical disease may have affected exposure status, we excluded the first year of follow-up in additional sub-analyses and compared these results with the analyses performed over the full 13.3 y of follow-up. In addition to gender-specific analyses, we also conducted overall analyses for men and women combined.

The dietary variables were adjusted for total energy intake by calculating nutrient residuals from the regression of nutrient intake on total energy intake, as described by Willett et al (30). Such nutrient residuals are uncorrelated with total energy intake, and the effect of the variation in nutrient intake can subsequently be estimated independently of a potential effect of energy intake. Tests for heterogeneity were performed to evaluate differences between sub-localizations of tumors, using the competing risks procedure in Stata. However, the SE for the difference of the logHR from this procedure assumes independence of both estimated $H R$, which would underestimate that SE and thus overestimate the p-values for their difference. Therefore, these $\mathrm{p}$-values and the associated confidence intervals were estimated based on a bootstrapping method that was developed for the case-cohort design (31). For each bootstrap sample, $X$ subcohort members were randomly drawn from the 
subcohort of $X$ subjects and $Y$ cases from the total of $Y$ cases outside the subcohort, both with replacement, out of the dataset of $X+Y$ observations. The logHR were obtained from this sample using Stata's competing risks procedure and recalculated for each bootstrap-replication. The confidence interval and $p$-value of the differences in hazard ratio of the subtypes were then calculated from the replicated statistics. Each bootstrap analysis was based on 1,000 replications.

First, we estimated the individual associations of dietary folate, methionine, riboflavin and vitamin B-6 with $\mathrm{CRC}$ in separate models. However, since the bioavailability of methyl groups donated by folate and methionine may be influenced by riboflavin and vitamin B-6, the effects of these nutrients may not be independent and should then be mutually adjusted for. There were no major differences between the associations of these individual models compared to the multivariate analysis including folate, methionine, riboflavin and vitamin B-6 simultaneously, and it was therefore decided to include these main determinants simultaneously in all further analyses.

The covariates considered as potential confounders were suggested risk factors of CRC and those commonly included as confounders in observational studies on the associations of B-vitamins and CRC (12-21). The covariates included were those to influence the RR of any of the main determinants considerably (by more than $5 \%$ when including the variables Body Mass Index (BMI), smoking status, energy, calcium and meat, or even more than $10 \%$ for alcohol, iron, fat, fibre). In addition, age and having a family history of CRC may be strong determinants for CRC and were therefore included as well.

We also conducted analyses using models only including the four main determinants and the variable age, and compared the results of these crude results to the multivariate-adjusted analyses. After excluding subjects with missing information on these covariates or subjects who only partly filled out the questionnaire, 4,168 subcohort members and 2,349 colorectal cancer cases remained for statistical analyses.

We determined possible interactions between dietary intakes of folate, methionine, riboflavin, vitamin B-6 and alcohol intake. This was done by first testing, in separate models, the gender specific interaction terms between folate on the one hand, with methionine, riboflavin, vitamin B-6 and alcohol on the other, for all CRC tumors combined and for each of the four sub-localizations. The Cox proportional hazard analyses without the interaction terms were subsequently stratified by low or high intake of folate, methionine, riboflavin and vitamin B-6 using the median intakes as cut-off values to define both strata within each variable. The strata used for alcohol intake were (1) abstainers, (2) subjects with intake $<30 \mathrm{~g} /$ day, and (3) subjects who consumed $\geq 30 \mathrm{~g} /$ day. All statistical analyses were performed with the Stata statistical software package (version 9.1).

\section{Results}

During a period of 13.3 y of follow up, 1,389 men and 960 women with CRC were identified who also had complete information on the co-variates used in the adjusted regression analyses. The mean intakes of the main determinants folate, methionine, riboflavin and vitamin B-6 were generally similar between subcohort members and cases in most of the subgroups among both men and women (Table 1 ). 
Table 1 Baseline dietary intake and other characteristics of subcohort members and cancer cases from the Netherlands Cohort Study on diet and cancer ${ }^{1}$

\begin{tabular}{|c|c|c|c|c|c|c|c|c|c|c|c|c|}
\hline & \multicolumn{6}{|c|}{ MEN } & \multicolumn{6}{|c|}{ WOMEN } \\
\hline & Subcohort & All tumors & $\begin{array}{c}\text { Proximal } \\
\text { colon }\end{array}$ & Distal colon & $\begin{array}{c}\text { Recto- } \\
\text { sigmoid }\end{array}$ & Rectum & Subcohort & All tumors & $\begin{array}{c}\text { Proximal } \\
\text { colon }\end{array}$ & Distal colon & $\begin{array}{l}\text { Recto- } \\
\text { sigmoid }\end{array}$ & Rectum \\
\hline \multicolumn{13}{|l|}{$\begin{array}{l}\text { Patient } \\
\text { characteristics }\end{array}$} \\
\hline$n^{2}$ & 2090 & 1389 & 382 & 467 & 141 & 360 & 2078 & 960 & 386 & 296 & 78 & 176 \\
\hline Age(y) & $61.3 \pm 4.2$ & $62.0 \pm 4.1$ & $62.5 \pm 4.0$ & $62.0 \pm 4.2$ & $62.0 \pm 3.9$ & $61.6 \pm 4.0$ & $61.4 \pm 4.3$ & $62.6 \pm 4.0$ & $62.9 \pm 4.0$ & $62.1 \pm 4.1$ & $62.8 \pm 3.6$ & $62.4 \pm 3.8$ \\
\hline $\begin{array}{l}\text { Family History of } \\
\text { CRC (\%yes) }\end{array}$ & 5.4 & 9.3 & 10.0 & 9.4 & 10.6 & 8.1 & 6.0 & 9.8 & 10.9 & 9.1 & & 9.1 \\
\hline $\begin{array}{l}\text { BMI (kg/m²) } \\
\text { Smoking Status (\%) }\end{array}$ & $24.9 \pm 2.6$ & $25.2 \pm 2.6$ & $25.1 \pm 2.6$ & $25.4 \pm 2.8$ & $25.6 \pm 2.6$ & $25.1 \pm 2.5$ & $25.0 \pm 3.5$ & $25.1 \pm 3.5$ & $25.3 \pm 3.5$ & $25.0 \pm 3.4$ & $25.1 \pm 3.2$ & $25.0 \pm 3.6$ \\
\hline Never & 12.8 & 11.0 & 11.5 & 12.0 & 9.9 & 9.4 & 57.6 & 59.8 & 61.4 & 62.1 & 51.3 & 58.5 \\
\hline Ex Smoker & 52.6 & 59.9 & 57.3 & 64.5 & 58.2 & 57.5 & 20.8 & 21.2 & 20.7 & 21.0 & 28.2 & 19.3 \\
\hline Current Smoker & 35.6 & 29.1 & 31.1 & 23.5 & 31.9 & 33.1 & 21.6 & 19.0 & 17.9 & 16.9 & 20.5 & 22.2 \\
\hline \multicolumn{13}{|l|}{ Dietary factors } \\
\hline Folate ( $\mu \mathrm{g} / \mathrm{day})$ & $224.6 \pm 66.6$ & $222.1 \pm 65.0$ & $222.0 \pm 68.1$ & $217.4 \pm 54.1$ & $227.7 \pm 80.5$ & $225.9 \pm 65.7$ & $198.5 \pm 61.1$ & $199.1 \pm 61.3$ & $196.4 \pm 58.2$ & $199.4 \pm 62.4$ & $196.5 \pm 51.7$ & $204.8 \pm 67.7$ \\
\hline Methionine (mg/d) & $1713 \pm 293$ & $1701 \pm 277$ & $1696 \pm 280$ & $1697 \pm 2.70$ & $1714 \pm 287$ & $1710 \pm 2.71$ & $1489 \pm 276$ & $1482 \pm 278$ & $1474 \pm 2.98$ & $1483 \pm 251$ & $1450 \pm 250$ & $1512 \pm 279$ \\
\hline Riboflavin (mg/d) & $1.58 \pm 0.37$ & $1.55 \pm 0.34$ & $1.56 \pm 0.35$ & $1.54 \pm 0.32$ & $1.56 \pm 0.34$ & $1.55 \pm 0.34$ & $1.45 \pm 0.34$ & $1.43 \pm 0.35$ & $1.43 \pm 0.35$ & $1.46 \pm 0.34$ & $1.33 \pm 0.30$ & $1.48 \pm 0.37$ \\
\hline Vitamin B-6 (mg/d) & $1.54 \pm 0.27$ & $1.55 \pm 0.27$ & $1.54 \pm 0.27$ & $1.53 \pm 0.27$ & $1.55 \pm 0.25$ & $1.57 \pm 0.29$ & $1.33 \pm 0.24$ & $1.33 \pm 0.24$ & $1.33 \pm 0.25$ & $1.32 \pm 0.23$ & $1.33 \pm 0.21$ & $1.36 \pm 0.25$ \\
\hline \multicolumn{13}{|l|}{ Alcohol (\%) } \\
\hline $0 \mathrm{~g} / \mathrm{d}$ & 14.6 & 12.4 & 12.0 & 14.5 & 9.9 & 11.1 & 32.3 & 33.8 & 34.7 & 33.8 & 29.5 & 34.1 \\
\hline$<30 \mathrm{~g} / \mathrm{d}$ & 70.6 & 69.7 & 74.6 & 67.5 & 73.8 & 67.2 & 64.1 & 61.4 & 59.8 & 61.8 & 61.1 & 63.1 \\
\hline$\geq 30 \mathrm{~g} / \mathrm{d}$ & 14.8 & 17.9 & 13.4 & 18.0 & 16.3 & 21.7 & 3.6 & 4.8 & 5.5 & 4.4 & 6.4 & 2.8 \\
\hline Energy (kjoules/d) & $9080 \pm 2134$ & $8949 \pm 2059$ & $8923 \pm 2006$ & $8846 \pm 2135$ & $8841 \pm 1946$ & $9149 \pm 2008$ & $7062 \pm 1659$ & $6980 \pm 1608$ & $6994 \pm 1698$ & $6933 \pm 1541$ & $7071 \pm 1944$ & $6991 \pm 1332$ \\
\hline Meat $(g / d)$ & $137 \pm 52$ & $136 \pm 49.7$ & $134 \pm 49$ & $136 \pm 49$ & $137 \pm 53$ & $137 \pm 50$ & $116 \pm 46$ & $115 \pm 45$ & $112 \pm 46$ & $115 \pm 42$ & $123 \pm 40$ & $117 \pm 47$ \\
\hline Fat $(g / d)$ & $93.9 \pm 14.2$ & $94.0 \pm 13.6$ & $95.0 \pm 12.4$ & $94.8 \pm 14.0$ & $93.7 \pm 14.3$ & $92.2 \pm 14.1$ & $74.0 \pm 10.3$ & $74.1 \pm 10.3$ & $73.6 \pm 10.8$ & $74.5 \pm 10.0$ & $75.4 \pm 8.6$ & $74.0 \pm 10.3$ \\
\hline Fiber (g/d) & $28.7 \pm 7.3$ & $28.8 \pm 7.0$ & $28.6 \pm 7.1$ & $28.4 \pm 6.6$ & $28.9 \pm 6.9$ & $29.4 \pm 7.1$ & $25.3 \pm 5.8$ & $25.1 \pm 5.9$ & $25.2 \pm 6.2$ & $24.9 \pm 5.5$ & $24.8 \pm 6.0$ & $25.4 \pm 5.8$ \\
\hline Calcium (mg/d) & $948 \pm 295$ & $932 \pm 281$ & $947 \pm 286$ & $919 \pm 267$ & $932 \pm 2.96$ & $944 \pm 287$ & $901 \pm 268$ & $896 \pm 274$ & $898 \pm 2.93$ & $909 \pm 2.54$ & $804 \pm 218$ & $913 \pm 2.81$ \\
\hline Iron (mg/d) & $13.3 \pm 2.4$ & $13.3 \pm 2.4$ & $13.2 \pm 2.26$ & $13.3 \pm 2.3$ & $13.5 \pm 2.5$ & $13.5 \pm 2.4$ & $11.7 \pm 2.0$ & $11.6 \pm 1.9$ & $11.6 \pm 2.0$ & $11.5 \pm 1.9$ & $11.6 \pm 1.8$ & $11.8 \pm 1.9$ \\
\hline Vitamin C (mg/d) & $98.6 \pm 41.6$ & $99.7 \pm 40.6$ & $98.8 \pm 40.5$ & $96.7 \pm 38.6$ & $99.5 \pm 40.3$ & $103.1 \pm 42.6$ & $108.4 \pm 42.7$ & $109.3 \pm 45.5$ & $108.0 \pm 46.1$ & $109.9 \pm 44.4$ & $110.4 \pm 36.5$ & $109.5 \pm 48.4$ \\
\hline Fruits (g/d) & $155 \pm 114$ & $160 \pm 112$ & $158 \pm 107$ & $158 \pm 107$ & $161 \pm 121$ & $166 \pm 120$ & $197 \pm 121$ & $195 \pm 83$ & $194 \pm 134$ & $195 \pm 117$ & $201 \pm 98$ & $191 \pm 123$ \\
\hline Vegetables (g/d) & $191 \pm 85$ & $192 \pm 86$ & $191 \pm 91$ & $185 \pm 76$ & $192 \pm 73$ & $205 \pm 95$ & $196 \pm 82$ & $194 \pm 83$ & $193 \pm 83$ & $191 \pm 77$ & $206 \pm 85$ & $200 \pm 88$ \\
\hline
\end{tabular}

1 Values are mean $\pm S D$ or percentages if indicated otherwise

2 Numbers of subcohort members and patients are based on complete availability of the variables presented in this table. Information about the tumor localization was unavailable for 39 men and 22 women 
Only the intakes of folate among men with a distal colon tumor and of riboflavin among women with a tumor in the rectosigmoid appeared slightly lower compared to subcohort members. The percentages of subjects with a family history of CRC were generally higher in cases than in subcohort members. There were no striking differences in any of the other variables between subcohort members and CRC patients.

We subsequently estimated multivariate adjusted incident rate ratios over quintiles of folate intake, methionine, riboflavin and vitamin B-6 for men and women.

After 13.3 y of follow-up, folate intake was not significantly associated with risk of CRC at any of the sub sites in neither men (Table 2) nor women (Table 3). Among men, methionine was associated with a decreased risk of proximal colon cancer $\left(\mathrm{RR}=0.57, \mathrm{CI}=0.28-1.18, P_{\text {trend }}=0.03\right)$, whereas among women, it was found to be inversely associated with rectal cancer $\left(\mathrm{RR}=0.45, \mathrm{CI}=0.17-1.20, P_{\text {trend }}=0.05\right)$. Among women, riboflavin tended to be inversely associated with proximal colon cancer (RR for the highest vs. the lowest quintile of intake=0.61, CI=0.35-1.06, $P_{\text {trend }}=0.07$ ). Conversely, there was a strong positive association between vitamin B- 6 and rectal cancer risk in women $\left(\mathrm{RR}=3.57, \mathrm{CI}=1.56-8.17, P_{\text {trend }}=0.01\right)$. An increased $\mathrm{RR}$ for vitamin B-6 could also be observed for all CRC tumors combined among women, although this risk was less high and not statistically significant $(R R=1.39, C I=0.92-$ 2.08, $P_{\text {trend }}=0.09$ ). When performing the analyses for men and women together, the highest quintile of vitamin B- 6 intake was also positively associated with overall CRC $\left(\mathrm{RR}=1.34, \mathrm{CI}=1.03-1.74, P_{\text {trend }}=0.02\right)$, with proximal colon cancer $(\mathrm{RR}=1.37, \mathrm{CI}=0.93-$ $\left.2.01, P_{\text {trend }}=0.05\right)$ and with rectal cancer $\left(R R=1.86, C I=1.17-2.95, P_{\text {trend }}=0.02\right.$, data not shown).

Adjustment for potential confounders only slightly aggravated the estimated associations compared to age-adjusted analyses, but did not result in different conclusions (Tables 2 and 3). There were no significant interactions between folate, methionine, riboflavin or vitamin B-6 and alcohol intake for overall CRC or for the individual sub-localizations. In addition, we did not observe consistent differences when comparing the RR between strata of low or high intakes of folate, methionine, riboflavin and vitamin B-6 or alcohol (data not shown).

Although the adjusted models did not meet the proportional hazards assumption according to the Schoenfeld residuals, fitting the main determinants as time-dependent variables showed that there was no interaction with time for these variables. Furthermore, when stratifying the analysis based on follow-up time, e.g. on the first and second half of the follow-up period, we observed no consistent differences compared to analyses on the total follow-up period. This also applied to the results when excluding the first year of follow-up. Estimating the relative risks with the median intake within quintiles only slightly changed the $P$-values for dose-response trends, and did not result in different conclusions. The tests for heterogeneity for the effects over the four subgroups of tumors were not statistically significant. 
Table 2 Associations between dietary folate, methionine, riboflavin and vitamin B-6 with colorectal cancer risk in men

\begin{tabular}{|c|c|c|c|c|c|c|c|c|c|c|c|c|}
\hline \multirow[b]{2}{*}{ Quintile ${ }^{1}$} & \multirow[b]{2}{*}{$\mathrm{PY}^{2}$} & \multicolumn{3}{|c|}{ All tumors } & \multicolumn{2}{|c|}{ Proximal colon } & \multicolumn{2}{|r|}{ Distal colon } & \multicolumn{2}{|c|}{ Rectosigmoid } & \multicolumn{2}{|r|}{ Rectum } \\
\hline & & $n^{3}$ & $\operatorname{RR}(95 \% \mathrm{Cl})^{4}$ & $\operatorname{RR}(95 \% \mathrm{Cl})^{5}$ & $n$ & $\operatorname{RR}(95 \% \mathrm{Cl})^{5}$ & $n$ & $\operatorname{RR}(95 \% \mathrm{Cl})^{5}$ & $n$ & $\operatorname{RR}(95 \% \mathrm{Cl})^{5}$ & $n$ & $\operatorname{RR}(95 \% \mathrm{Cl})^{5}$ \\
\hline \multirow{2}{*}{\multicolumn{13}{|c|}{$\begin{array}{l}\text { Folate } \\
(\mu g / d)\end{array}$}} \\
\hline$(\mu \mathrm{g} / \mathrm{d})$ & & & & & & & & & & & & \\
\hline $1(160.8)$ & 4840 & 292 & 1.00 & 1.00 & 77 & 1.00 & 111 & 1.00 & 29 & 1.00 & 65 & 1.00 \\
\hline $2(189.5)$ & 4971 & 289 & $0.93(0.74-1.17)$ & $0.90(0.71-1.13)$ & 94 & $1.14(0.80-1.61)$ & 88 & $0.69(0.50-0.97)$ & 22 & $0.67(0.37-1.22)$ & 76 & $1.05(0.72-1.55)$ \\
\hline $3(212.1)$ & 4848 & 271 & $0.88(0.70-1.13)$ & $0.85(0.66-1.09)$ & 61 & $0.77(0.51-1.16)$ & 94 & $0.72(0.50-1.04)$ & 37 & $1.18(0.67-2.08)$ & 74 & $1.03(0.68-1.55)$ \\
\hline $4(240.6)$ & 4822 & 270 & $0.89(0.69-1.14)$ & $0.86(0.66-1.11)$ & 80 & $1.02(0.68-1.51)$ & 88 & $0.69(0.47-1.01)$ & 25 & $0.78(0.40-1.50)$ & 70 & $1.00(0.64-1.56)$ \\
\hline $5(297.2)$ & 4829 & 267 & $0.93(0.71-1.20)$ & $0.87(0.65-1.15)$ & 70 & $0.97(0.62-1.52)$ & 86 & $0.71(0.46-1.08)$ & 28 & $0.83(0.41-1.66)$ & 75 & $1.01(0.64-1.60)$ \\
\hline$P_{\text {trend }}{ }^{6}$ & & & 0.43 & 0.29 & & 0.65 & & 0.16 & & 0.72 & & 0.92 \\
\hline \multicolumn{13}{|l|}{$\begin{array}{l}\text { Methionine } \\
\text { (mald) }\end{array}$} \\
\hline $1(1366)$ & 4960 & 296 & 1.00 & 1.00 & 77 & 1.00 & 104 & 1.00 & 31 & 1.00 & 72 & 1.00 \\
\hline $2(1555)$ & 4805 & 284 & $1.01(0.80-1.28)$ & $0.96(0.74-1.26)$ & 91 & $1.07(0.70-1.64)$ & 86 & $0.91(0.62-1.33)$ & 26 & $0.83(0.43-1.58)$ & 71 & $1.03(0.66-1.60)$ \\
\hline $3(1698)$ & 4971 & 277 & $0.96(0.75-1.22)$ & 0.87 (0.64-1.17) & 83 & $0.87(0.54-1.41)$ & 91 & 0.89 (0.58-1.37) & 30 & $0.81(0.37-1.74)$ & 68 & $0.98(0.60-1.61)$ \\
\hline $4(1843)$ & 4803 & 282 & $0.98(0.77-1.27)$ & $0.90(0.63-1.26)$ & 65 & $0.65(0.37-1.14)$ & 105 & $1.13(0.69-1.87)$ & 26 & $0.65(0.28-1.50)$ & 79 & $1.21(0.69-2.11)$ \\
\hline $5(2093)$ & 4772 & 250 & $0.91(0.68-1.22)$ & $0.79(0.50-1.25)$ & 66 & $0.57(0.28-1.18)$ & 81 & $1.03(0.52-2.04)$ & 28 & $0.65(0.22-1.93)$ & 70 & $1.09(0.53-2.24)$ \\
\hline$P_{\text {trend }}$ & & & 0.47 & 0.36 & & 0.03 & & 0.58 & & 0.34 & & 0.53 \\
\hline \multicolumn{13}{|l|}{$\begin{array}{l}\text { Riboflavin } \\
\text { (mg/d) }\end{array}$} \\
\hline $1(1.17)$ & 4944 & 315 & 1.00 & 1.00 & 82 & 1.00 & 93 & 1.00 & 35 & 1.00 & 89 & 1.00 \\
\hline $2(1.38)$ & 4968 & 265 & $0.82(0.66-1.03)$ & $0.83(0.65-1.05)$ & 72 & $0.82(0.56-1.20)$ & 94 & $1.13(0.80-1.60)$ & 27 & $0.68(0.38-1.20)$ & 64 & $0.67(0.45-0.99)$ \\
\hline $3(1.53)$ & 4815 & 284 & $0.91(0.72-1.15)$ & $0.92(0.71-1.19)$ & 78 & $0.91(0.61-1.35)$ & 108 & $1.44(0.98-2.11)$ & 22 & $0.56(0.29-1.08)$ & 71 & $0.73(0.48-1.11)$ \\
\hline $4(1.71)$ & 4681 & 270 & $0.90(0.70-1.16)$ & $0.93(0.69-1.24)$ & 75 & $0.96(0.60-1.52)$ & 98 & $1.47(0.95-2.29)$ & 28 & $0.74(0.38-1.43)$ & 64 & $0.65(0.40-1.03)$ \\
\hline $5(2.03)$ & 4903 & 255 & $0.83(0.63-1.08)$ & $0.86(0.60-1.22)$ & 75 & $0.91(0.53-1.58)$ & 74 & $1.22(0.71-2.08)$ & 29 & $0.72(0.30-1.74)$ & 72 & $0.66(0.38-1.14)$ \\
\hline$P_{\text {trend }}$ & & & 0.37 & 0.72 & & 0.92 & & 0.19 & & 0.52 & & 0.16 \\
\hline \multicolumn{13}{|l|}{$\begin{array}{l}\text { Vitamin B-6 } \\
(\mathrm{mg} / \mathrm{d})\end{array}$} \\
\hline $1(1.22)$ & 4838 & 257 & 1.00 & 1.00 & 70 & 1.00 & 94 & 1.00 & 25 & 1.00 & 59 & 1.00 \\
\hline $2(1.40)$ & 4766 & 272 & $1.12(0.89-1.40)$ & $1.12(0.87-1.43)$ & 77 & $1.17(0.80-1.71)$ & 93 & $1.01(0.71-1.45)$ & 26 & $1.09(0.59-2.04)$ & 69 & $1.22(0.81-1.82)$ \\
\hline $3(1.53)$ & 4959 & 283 & $1.14(0.89-1.45)$ & $1.13(0.86-1.49)$ & 82 & $1.23(0.81-1.87)$ & 93 & $0.98(0.66-1.45)$ & 26 & $1.09(0.55-2.18)$ & 78 & $1.32(0.84-2.07)$ \\
\hline $4(1.67)$ & 4884 & 302 & $1.27(0.99-1.63)$ & $1.30(0.97-1.75)$ & 76 & $1.29(0.81-2.06)$ & 103 & $1.17(0.76-1.79)$ & 37 & $1.62(0.78-3.36)$ & 76 & $1.31(0.81-2.12)$ \\
\hline $5(1.88)$ & 4863 & 275 & $1.18(0.90-1.56)$ & $1.29(0.90-1.84)$ & 77 & $1.50(0.86-2.62)$ & 84 & $1.03(0.60-1.76)$ & 27 & $1.28(0.51-3.24)$ & 78 & $1.35(0.76-2.41)$ \\
\hline$P_{\text {trend }}^{\text {ren }}$ & & & 0.14 & 0.12 & & 0.14 & & 0.87 & & 0.32 & & 0.31 \\
\hline
\end{tabular}

Quintile (median intake within quintile)

Number of accumulated Person Years (PY) within quintiles of dietary intake

Number of cases

Unadjusted Incidence Rate Ratio (RR): from a regression model including the variables folate, methionine, riboflavin, vitamin B-6 and age.

Adjusted RR. from a regression model including the variables folate, methionine, riboflavin, vitamin B-6, age, family history of colorectal cancer, BMI, smoking status and the intakes of alcohol, energy, meat, fat,

fiber, calcium and iron

6 -value for linear trend over quintiles of intake 
Table 3 Associations between dietary folate, methionine, riboflavin and vitamin B-6 with colorectal cancer risk in women

\begin{tabular}{|c|c|c|c|c|c|c|c|c|c|c|c|c|}
\hline \multirow[b]{2}{*}{ Quintile 1} & \multirow[b]{2}{*}{$\mathrm{PY}^{2}$} & \multicolumn{3}{|c|}{ All tumors } & \multicolumn{2}{|c|}{ Proximal colon } & \multicolumn{2}{|r|}{ Distal colon } & \multicolumn{2}{|c|}{ Rectosigmoid } & \multicolumn{2}{|r|}{ Rectum } \\
\hline & & $n^{3}$ & $\operatorname{RR}(95 \% \mathrm{Cl})^{4}$ & $\operatorname{RR}(95 \% \mathrm{Cl})^{5}$ & $n$ & $\operatorname{RR}(95 \% \mathrm{Cl})^{5}$ & $n$ & $\operatorname{RR}(95 \% \mathrm{Cl})^{5}$ & $n$ & $\operatorname{RR}(95 \% \mathrm{Cl})^{5}$ & $n$ & $\operatorname{RR}(95 \% \mathrm{Cl})^{5}$ \\
\hline \multicolumn{13}{|c|}{ Folate $(\mu \mathrm{g} / \mathrm{d})$} \\
\hline $1(139.0)$ & 5097 & 198 & 1.00 & 1.00 & 89 & 1.00 & 56 & 1.00 & 16 & 1.00 & 32 & 1.00 \\
\hline $2(165.6)$ & 5121 & 185 & $0.96(0.75-1.25)$ & $0.98(0.75-1.28)$ & 66 & $0.79(0.54-1.15)$ & 65 & $1.19(0.79-1.80)$ & 15 & $1.13(0.48-2.66)$ & 34 & $1.03(0.60-1.77)$ \\
\hline $3(187.5)$ & 5313 & 180 & $0.90(0.69-1.18)$ & $0.95(0.71-1.27)$ & 71 & $0.83(0.55-1.24)$ & 59 & $1.11(0.70-1.75)$ & 14 & $1.06(0.42-2.66)$ & 31 & $0.90(0.49-1.65)$ \\
\hline $4(212.9)$ & 5156 & 200 & $1.11(0.84-1.46)$ & $1.17(0.87-1.58)$ & 79 & $1.07(0.71-1.63)$ & 59 & $1.21(0.76-1.94)$ & 19 & $1.62(0.67-3.94)$ & 40 & $1.18(0.65-2.14)$ \\
\hline $5(267.3)$ & 5119 & 197 & $1.12(0.82-1.52)$ & $1.25(0.89-1.76)$ & 81 & $1.24(0.76-2.02)$ & 57 & $1.34(0.81-2.22)$ & 14 & $1.38(0.51-3.75)$ & 39 & $1.06(0.53-2.11)$ \\
\hline$P_{\text {trend }}{ }^{6}$ & & & 0.31 & 0.10 & & 0.17 & & 0.37 & & 0.28 & & 0.73 \\
\hline \multicolumn{13}{|c|}{ Methionine $(\mathrm{mg} / \mathrm{d})$} \\
\hline $1(1154)$ & 5183 & 206 & 1.00 & 1.00 & 86 & 1.00 & 59 & 1.00 & 17 & 1.00 & 38 & 1.00 \\
\hline $2(1351)$ & 5130 & 214 & $1.07(0.84-1.38)$ & $1.02(0.76-1.36)$ & 87 & $1.20(0.80-1.82)$ & 67 & $0.92(0.59-1.45)$ & 18 & $1.38(0.61-3.15)$ & 36 & $0.77(0.43-1.38)$ \\
\hline $3(1476)$ & 5081 & 164 & $0.83(0.63-1.10)$ & $0.78(0.56-1.10)$ & 68 & $1.01(0.62-1.65)$ & 53 & $0.72(0.42-1.22)$ & 13 & $1.18(0.43-3.24)$ & 29 & $0.54(0.27-1.05)$ \\
\hline $4(1617)$ & 5257 & 194 & $0.96(0.73-1.28)$ & $0.87(0.59-1.29)$ & 74 & $1.09(0.61-1.92)$ & 66 & $0.80(0.44-1.45)$ & 17 & $1.77(0.56-5.56)$ & 33 & $0.51(0.24-1.08)$ \\
\hline $5(1841)$ & 5155 & 182 & $0.88(0.65-1.21)$ & $0.76(0.46-1.26)$ & 71 & $1.07(0.51-2.22)$ & 51 & $0.53(0.24-1.19)$ & 13 & $1.91(0.52-6.92)$ & 40 & $0.45(0.17-1.20)$ \\
\hline$P_{\text {trend }}$ & & & 0.30 & 0.18 & & 0.86 & & 0.16 & & 0.31 & & 0.05 \\
\hline \multicolumn{13}{|c|}{ Riboflavin (mg/d) } \\
\hline $1(1.04)$ & 5124 & 211 & 1.00 & 1.00 & 99 & 1.00 & 51 & 1.00 & 25 & 1.00 & 33 & 1.00 \\
\hline $2(1.26)$ & 5067 & 194 & $0.91(0.71-1.17)$ & $0.89(0.68-$ & 79 & $0.74(0.51$ & 57 & $1.12(0.71$ & 17 & $0.81(0.4 C$ & 35 & $0.99(0.57-1.72)$ \\
\hline $3(1.42)$ & 5130 & 188 & $0.92(0.71-1.19)$ & $0.92(0.69-1.23)$ & 62 & $0.62(0.41-0.93)$ & 73 & $1.53(0.95-2.46)$ & 12 & $0.65(0.28-1.51)$ & 34 & $0.99(0.55-1.79)$ \\
\hline $4(1.59)$ & 5294 & 187 & $0.85(0.65-1.11)$ & $0.84(0.60-1.16)$ & 71 & $0.61(0.38-0.96)$ & 60 & $1.24(0.72-2.12)$ & 16 & $0.86(0.35-2.07)$ & 34 & $0.91(0.47-1.74)$ \\
\hline $5(1.89)$ & 5190 & 180 & $0.85(0.63-1.14)$ & $0.79(0.53-1.18)$ & 75 & $0.61(0.35-1.06)$ & 55 & $1.22(0.62-2.40)$ & 8 & $0.55(0.15-2.03)$ & 40 & $0.92(0.41-2.04)$ \\
\hline$P_{\text {trend }}$ & & & 0.26 & 0.30 & & 0.07 & & 0.40 & & 0.47 & & 0.76 \\
\hline \multicolumn{13}{|c|}{ Vitamin B-6 $(\mathrm{mg} / \mathrm{d})$} \\
\hline $1(1.05)$ & 5018 & 198 & 1.00 & 1.00 & 82 & 1.00 & 65 & 1.00 & 17 & 1.00 & 27 & 1.00 \\
\hline $2(1.21)$ & 5278 & 189 & $0.98(0.76-1.26)$ & $1.04(0.78-1.37)$ & 75 & $1.02(0.69-1.51)$ & 61 & $0.90(0.58-1.38)$ & 10 & $0.67(0.26-1.73)$ & 38 & $1.73(0.97-3.08)$ \\
\hline $3(1.32)$ & 5187 & 178 & $1.01(0.75-1.34)$ & $1.11(0.80-1.52)$ & 73 & $1.17(0.75-1.82)$ & 53 & $0.84(0.50-1.39)$ & 16 & $1.16(0.43-3.11)$ & 32 & $1.79(0.91-3.54)$ \\
\hline $4(1.44)$ & 5324 & 194 & $1.08(0.81-1.44)$ & $1.23(0.88-1.73)$ & 85 & $1.35(0.84-2.15)$ & 60 & $0.97(0.57-1.65)$ & 18 & $1.31(0.48-3.54)$ & 28 & $1.73(0.83-3.58)$ \\
\hline $5(1.63)$ & 4998 & 201 & $1.12(0.81-1.55)$ & $1.39(0.92-2.08)$ & 71 & $1.15(0.65-2.04)$ & 57 & $1.06(0.56-2.03)$ & 17 & $1.34(0.38-4.64)$ & 51 & $3.57(1.56-8.17)$ \\
\hline$P_{\text {trend }}$ & & & 0.42 & 0.09 & & 0.33 & & 0.86 & & 0.36 & & 0.01 \\
\hline
\end{tabular}

Quintile (median intake within quintile)

Number of accumulated Person Years (PY) within quintiles of dietary intake

3 Number of cases

Ratio (RR): from a regression model including the variables folate, methionine, riboflavin, vitamin B-6 and age.

Adjusted RR: from a regression model including the variables folate, methionine, riboflavin, vitamin B-6, age, family history of colorectal cancer, BMI, smoking status and the intakes of alcohol, energy, meat, fat,

$6 \quad P$-value for linear trend over quintiles of intake 


\section{Discussion}

Here, we investigated the associations between intakes of folate, methionine, riboflavin and vitamin B- 6 with CRC risk. Our results do not suggest an association between dietary folate and CRC. However, we observed inverse associations between relatively high methionine intake with proximal colon cancer in men and rectal cancer in women. Also, a modest non-significant inverse association was observed between riboflavin intake and tumors of the proximal colon in women. Conversely, a positive association between vitamin B-6 intake was observed for overall CRC, which was particularly strong for rectal cancer among women.

Previous observational studies did not consistently point to a clear inverse association between folate intake and CRC risk. Next to different sample sizes in those studies, this inconsistency may also have been caused by possible selection bias that is likely to occur in case-control studies but not in cohort studies, potential differences in the level of over- or under-estimation of dietary intake using food-frequency questionnaires, and different adjustments for confounding factors between studies (3). In addition, the inconsistencies may be due to differences between study populations and inherent variation in levels of folate intake. The intake in our study was relatively low, with the median folate intake within quintiles ranging from 160 to $299 \mu \mathrm{g} / \mathrm{day}$ among men and 137 to $270 \mu \mathrm{g}$ /day among women. However, among subjects with considerably higher levels of intake studied in prospective cohort settings, an inverse association was observed only twice $(32,33)$, whereas three other studies did not suggest this $(15,16,34)$. Moreover, a significant inverse association was observed in a cohort study among men with even lower intakes compared to men in our study (compared highest and lowest category > 249 vs. $<103 \mu \mathrm{g} /$ day) (35), indicating that high ranges of intake do not necessarily lead to reduced CRC risk. Nevertheless, in several studies the protective effect of folate was confined to either men or women, or limited to a specific study population or sub site of colorectal cancer, which makes it difficult to generalize the results and hence to be conclusive about whether dietary folate has a chemo preventive effect on CRC.

Despite the current view of the importance of folate in cancer prevention, its role in colorectal carcinogenesis is still a subject of debate. Interestingly, it was recently observed that high plasma folate levels may be associated with increased CRC risk (36), and possibly with breast cancer (37). An alternative hypothesis in this regard, is that although folate supplementation may protect against the occurrence of neoplasia in normal colorectal epithelium it might promote already existing early lesions to cancer, suggesting that the effect depends on the timing of intervention (5). It was also reported that folic acid supplementation was associated with increased risk of advanced lesions or recurrence of multiple adenomas after a follow-up of 3 to 5 y (38). Interestingly, the participants in that intervention study were people with a recent history of colorectal adenomas, and possibly, undetected neoplasms were present in these subjects which may have had a growth advantage in the presence of high concentrations of folic acid. Furthermore, after the introduction of nationwide fortification of cereals with folic acid in the United States and Canada, colorectal cancer incidence increased in these countries which may possibly be due to increased intakes folic acid (39). A potentially harmful effect of folate may also be confined to specific subgroups of cancers based on their molecular characteristics. In this respect, we 
previously observed positive associations between folate intake and colorectal carcinomas harboring mutations in the key genes $A P C$ or $B R A F$ among men $(40,41)$, indicating that folate may result in a growth advantage of such tumors.

Regarding methionine, we observed that relatively high intake may be inversely associated with proximal colon cancer in men and rectal cancer in women. Previous studies examining the role of methionine intake did not demonstrate an individual inverse association with colorectal cancer risk (13,15-17), but one study showed that low methionine in combination with low folate and high alcohol intake may lead to increased CRC risk (34). Although we did not observe an interaction between folate and methionine, our findings suggest that methionine, as a methyl donor, may be more effective in preventing CRC than folate in some of the colorectal sub-localizations. We also found a weak inverse association between riboflavin and proximal colon cancer only in women, whereas in men riboflavin was unrelated to colorectal cancer. Riboflavin is a co-factor for MTHFR, and a low intake of the vitamin may reduce the metabolic activity of this enzyme and thereby contribute to colorectal carcinogenesis (8). In addition, the $677 \mathrm{C}>\mathrm{T}$ polymorphism in MTHFR may also affect enzymatic activity, and the occurrence of this polymorphism was associated with reduced CRC risk among subjects with adequate folate status (42). It is worthwhile to further explore potential effect modification by such polymorphisms, however, as of today this information is not yet available for our cohort members.

The reason why an effect of methionine or riboflavin would be site or genderspecific remains unclear. Possibly, the development of tumors harboring promoter hypermethylation, which were observed more often in the proximal colon and among women $(41,43,44)$, is more sensitive to these nutrients. We do not have information on global hypomethylation status; however, it is unknown whether the level of global DNA hypomethylation may differ between tumors in different sub localisations of the colorectum or between men and women.

A remarkable finding in our study was the strong positive association between vitamin B-6 intake and rectal cancer in women, with the RR strongly increased in the highest quintile of intake. Also, when analyzing men and women and all colorectal tumors combined, we observed a modest positive association with the RR increasing evenly over quintiles of intake, suggesting a linear dose-response effect. Meat intake appeared to be the main contributor of vitamin B-6 intake (men 23.8\%, women $24.4 \%$ ) and could therefore have accounted for the positive association of vitamin B6, because meat may also be a risk factor for CRC. However, all analyses were adjusted for meat intake. Interestingly, a positive association with rectal cancer in women has previously been observed in the IOWA women's health population based cohort study (IWHS) (16), while the range of intake among women in that study was considerably higher compared to our study. Notwithstanding this difference, these observations suggest that vitamin B-6 may indeed be associated with increased CRC risk. Although these are observations based on subgroups of patients, and thus caution should be taken in interpreting such findings, these are two prospective cohort studies showing a positive association between vitamin B- 6 and rectal cancer. Moreover, we have previously observed that a positive association between vitamin B- 6 intake and CRC was most pronounced among individuals with tumors harboring human mut-L homologue 1 (MLH1) promoter hypermethylation (41). In view of this finding, we hypothesize that relatively high vitamin B-6 intake may increase promoter 
hypermethylation and thereby enhances the development of tumors with a methylation-associated phenotype. However, because an inverse association between the vitamin and $\mathrm{CRC}$ has been suggested in a number of previous prospective cohort studies (18-21), the role of vitamin B-6 clearly needs further attention. In future research, the role of vitamin B-6 in a hypermethylation-associated pathway should be studied and preferably be investigated in even larger cohort studies.

The current study was a population-based prospective cohort design with a long follow-up period. The large number of incident CRC patients is likely to have minimized the probability of reporting results based on chance alone. It is also unlikely that selection bias has occurred, because the follow up of cases and subcohort members was almost complete. Recall bias was probably low, certainly if compared with retrospective case-control designs, although measurement error is unavoidable with self administered food frequency questionnaires and may still have biased results to some extent. After a validation study however, it was concluded that the questionnaire is sufficiently able to rank subjects according to dietary intake (24) suggesting reasonably adequate validity of the single baseline measurement. Furthermore, potential pre-clinical disease is not likely to have affected exposure status, since the results did not substantially change after excluding the first year of follow-up.

This study could not account for potential changes in dietary habits over time, since there have been no follow-up measurements of dietary intake. We do nonetheless have information on the reproducibility of the baseline FFQ, which was determined from five annually repeated measurements in independent random samples from the cohort. The average decline of the correlation between follow up measures was only minimal indicating that the ability of the baseline FFQ to rank subjects according to dietary intake is maintained relatively well over a period of at least five years (25). Moreover, subjects aged 55-69 years at baseline and these elderly people tend to have a more stable dietary habits compared to younger individuals (22). Although follow up was longer than five years, for these reasons, we consider that potential changes in dietary intake over time have presumably not influenced the estimated associations to a great extent.

In conclusion, the current large prospective cohort study suggests that dietary folate does not protect against CRC in this Dutch population, and that methionine may reduce colorectal cancer risk of the proximal colon in men and rectum among women. Riboflavin also tended to reduce the risk of proximal colon tumors in women. Our study is the second cohort study to show a positive association between vitamin B-6 and rectal cancer among women, which is interesting considering a possible similarity with the recent insight in a potentially harmful effect of high folate levels in colorectal carcinogenesis. However, we underscore the need for larger studies or meta-analyses and to further investigate the role of these nutrients in colorectal cancer development. 


\section{References}

1. Kim YI. Folate and DNA methylation: a mechanistic link between folate deficiency and colorectal cancer? Cancer Epidemiol Biomarkers Prev 2004;13(4):511-9.

2. Herman JG, Baylin SB. Gene silencing in cancer in association with promoter hypermethylation. N Engl J Med 2003;349(21):2042-54.

3. Bollheimer LC, Buettner R, Kullmann A, Kullmann F. Folate and its preventive potential in colorectal carcinogenesis. How strong is the biological and epidemiological evidence? Crit Rev Oncol Hematol 2005;55(1):13-36.

4. Sanjoaquin MA, Allen N, Couto E, Roddam AW, Key TJ. Folate intake and colorectal cancer risk: a meta-analytical approach. Int J Cancer 2005;113(5):825-8.

5. Kim YI. Folate and colorectal cancer: An evidence-based critical review. Mol Nutr Food Res 2007;51(3):267-92.

6. Ulrich CM, Potter JD. Folate and cancer--timing is everything. Jama 2007;297(21):2408-9.

7. Ulrich CM. Nutrigenetics in cancer research--folate metabolism and colorectal cancer. 3 Nutr 2005;135(11):2698-702.

8. Moat SJ, Ashfield-Watt PA, Powers HJ, Newcombe RG, McDowell IF. Effect of riboflavin status on the homocysteine-lowering effect of folate in relation to the MTHFR (C677T) genotype. Clin Chem 2003;49(2):295-302.

9. Halsted $\mathrm{CH}$, Villanueva JA, Devlin AM, Chandler CJ. Metabolic interactions of alcohol and folate. J Nutr 2002;132(8 Suppl):2367S-2372S.

10. Giovannucci E. Alcohol, one-carbon metabolism, and colorectal cancer: recent insights from molecular studies. J Nutr 2004;134(9):2475S-2481S.

11. Mason JB, Choi SW. Effects of alcohol on folate metabolism: implications for carcinogenesis. Alcohol 2005;35(3):235-41.

12. van den Donk M, Buijsse B, van den Berg SW, Ocke MC, Harryvan JL, Nagengast FM, et al. Dietary intake of folate and riboflavin, MTHFR C677T genotype, and colorectal adenoma risk: a Dutch case-control study. Cancer Epidemiol Biomarkers Prev 2005;14(6):1562-6.

13. Le Marchand L, Donlon T, Hankin JH, Kolonel LN, Wilkens LR, Seifried A. B-vitamin intake, metabolic genes, and colorectal cancer risk (United States). Cancer Causes Control 2002;13(3):239-48.

14. Otani T, Iwasaki M, Hanaoka T, Kobayashi M, Ishihara J, Natsukawa S, et al. Folate, vitamin B6, vitamin B12, and vitamin B2 intake, genetic polymorphisms of related enzymes, and risk of colorectal cancer in a hospital-based case-control study in Japan. Nutr Cancer 2005;53(1):42-50.

15. Flood A, Caprario L, Chaterjee N, Lacey JV, Jr., Schairer C, Schatzkin A. Folate, methionine, alcohol, and colorectal cancer in a prospective study of women in the United States. Cancer Causes Control 2002;13(6):551-61

16. Harnack L, Jacobs DR, Jr., Nicodemus K, Lazovich D, Anderson K, Folsom AR. Relationship of folate, vitamin B-6, vitamin B-12, and methionine intake to incidence of colorectal cancers. Nutr Cancer 2002;43(2):152-8.

17. Kune G, Watson L. Colorectal cancer protective effects and the dietary micronutrients folate, methionine, vitamins B6, B12, C, E, selenium, and lycopene. Nutr Cancer 2006;56(1):11-21.

18. Ishihara J, Otani T, Inoue M, Iwasaki M, Sasazuki S, Tsugane S. Low intake of vitamin B-6 is associated with increased risk of colorectal cancer in Japanese men. J Nutr 2007;137(7):1808-14.

19. Larsson SC, Giovannucci E, Wolk A. Vitamin b6 intake, alcohol consumption, and colorectal cancer: a longitudinal population-based cohort of women. Gastroenterology 2005;128(7):1830-7.

20. Wei EK, Giovannucci E, Selhub J, Fuchs CS, Hankinson SE, Ma J. Plasma vitamin B6 and the risk of colorectal cancer and adenoma in women. J Natl Cancer Inst 2005;97(9):684-92.

21. Zhang SM, Moore SC, Lin J, Cook NR, Manson JE, Lee IM, et al. Folate, vitamin B6, multivitamin supplements, and colorectal cancer risk in women. Am J Epidemiol $2006 ; 163(2): 108-15$ 
22. van den Brandt PA, Goldbohm RA, van 't Veer P, Volovics A, Hermus RJ, Sturmans F. A large-scale prospective cohort study on diet and cancer in The Netherlands. J Clin Epidemiol $1990 ; 43(3): 285-95$.

23. Nevo table. Dutch food composition table 1986-1987, The Hague, The Netherlands: Voorlichtingsbureau voor de voeding, 1986. 1986.

24. Goldbohm RA, van den Brandt PA, Brants HA, van't Veer P, Al M, Sturmans F, et al. Validation of a dietary questionnaire used in a large-scale prospective cohort study on diet and cancer. Eur J Clin Nutr 1994;48(4):253-65.

25. Goldbohm RA, van 't Veer P, van den Brandt PA, van 't Hof MA, Brants HA, Sturmans F, et al. Reproducibility of a food frequency questionnaire and stability of dietary habits determined from five annually repeated measurements. Eur J Clin Nutr 1995;49(6):420-9.

26. Konings EJ. A validated liquid chromatographic method for determining folates in vegetables, milk powder, liver, and flour. J AOAC Int 1999;82(1):119-27.

27. Konings EJ, Roomans HH, Dorant E, Goldbohm RA, Saris WH, van den Brandt PA. Folate intake of the Dutch population according to newly established liquid chromatography data for foods. Am J Clin Nutr 2001;73(4):765-76.

28. Lin D, Wei L. The robust inference for the Cox Proportional Hazards Model. JASA 1989;84(408):1074-1078.

29. Schoenfeld D. Partial residuals for the proportional hazards regression models. Biometrika 1982;69(1):239-241

30. Willett W, Stampfer MJ. Total energy intake: implications for epidemiologic analyses. Am J Epidemiol 1986;124(1):17-27.

31. Wacholder S, Gail MH, Pee D, Brookmeyer R. Alternative variance and efficiency calculations for the case-cohort design. Biometrika 1989;76(1):117-23.

32. Giovannucci E, Stampfer MJ, Colditz GA, Hunter DJ, Fuchs C, Rosner BA, et al. Multivitamin use, folate, and colon cancer in women in the Nurses' Health Study. Ann Intern Med $1998 ; 129(7): 517-24$.

33. Terry $P$, Jain $M$, Miller AB, Howe GR, Rohan TE. Dietary intake of folic acid and colorectal cancer risk in a cohort of women. Int J Cancer 2002;97(6):864-7.

34. Giovannucci E, Rimm EB, Ascherio A, Stampfer MJ, Colditz GA, Willett WC. Alcohol, lowmethionine--low-folate diets, and risk of colon cancer in men. $J$ Natl Cancer Inst $1995 ; 87(4): 265-73$.

35. Su LJ, Arab L. Nutritional status of folate and colon cancer risk: evidence from NHANES I epidemiologic follow-up study. Ann Epidemiol 2001;11(1):65-72.

36. Van Guelpen B, Hultdin J, Johansson I, Hallmans G, Stenling R, Riboli E, et al. Low folate levels may protect against colorectal cancer. Gut 2006;55(10):1461-6.

37. Lin J, Lee IM, Cook NR, Selhub J, Manson JE, Buring JE, et al. Plasma folate, vitamin B-6, vitamin B-12, and risk of breast cancer in women. Am J Clin Nutr 2008;87(3):734-43.

38. Cole BF, Baron JA, Sandler RS, Haile RW, Ahnen DJ, Bresalier RS, et al. Folic acid for the prevention of colorectal adenomas: a randomized clinical trial. Jama 2007;297(21):2351-9.

39. Mason JB, Dickstein A, Jacques PF, Haggarty P, Selhub J, Dallal G, et al. A temporal association between folic acid fortification and an increase in colorectal cancer rates may be illuminating important biological principles: a hypothesis. Cancer Epidemiol Biomarkers Prev 2007;16(7):1325-9.

40. de Vogel S, van Engeland M, Luchtenborg M, de Bruine AP, Roemen GM, Lentjes MH, et al. Dietary folate and APC mutations in sporadic colorectal cancer. J Nutr 2006;136(12):301521.

41. de Vogel S, Bongaerts BW, Wouters KA, Kester AD, Schouten LJ, de Goeij AF, et al. Associations of dietary methyl donor intake with MLH1 promoter hypermethylation and related molecular phenotypes in sporadic colorectal cancer. Carcinogenesis 2008, Mar 13; doi: $10.1093 /$ carcin/bgn074

42. Sharp L, Little J. Polymorphisms in Genes Involved in Folate Metabolism and Colorecta Neoplasia: A HuGE Review. Am J Epidemiol 2004;159(5):423-43.

43. Hawkins N, Norrie M, Cheong K, Mokany E, Ku SL, Meagher A, et al. CpG island methylation in sporadic colorectal cancers and its relationship to microsatellite instability. Gastroenterology 2002;122(5):1376-87.

44. van Rijnsoever M, Grieu F, Elsaleh H, Joseph D, Iacopetta B. Characterisation of colorectal cancers showing hypermethylation at multiple CpG islands. Gut 2002;51(6):797-802. 



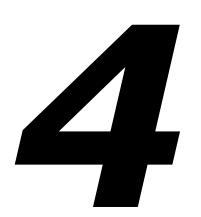

\title{
Dietary folate and $A P C$ mutations in sporadic colorectal cancer
}

\author{
Stefan de Vogel \\ Manon van Engeland \\ Margreet Lüchtenborg \\ Adriaan $P$ de Bruïne \\ Guido MJM Roemen \\ Marjolein HFM Lentjes \\ R Alexandra Goldbohm \\ Piet A van den Brandt \\ Anton FPM de Goeij \\ Matty $P$ Weijenberg
}

Journal of Nutrition 2006; 136(12):3015-21 


\begin{abstract}
Folate deficiency has been associated with colorectal cancer risk, and may be involved in colorectal carcinogenesis through increased chromosome instability, gene mutations and aberrant DNA methylation. Within the Netherlands Cohort Study on diet and cancer, we investigated associations between dietary folate intake and colorectal cancer risk with $\left(A P C^{+}\right)$and without $\left(A P C^{-}\right)$truncating $A P C$ mutations, accounting for hMLH1 expression and $K$-ras mutations. In total, 528 cases and 4,200 subcohort members were available for data analyses out of the study cohort $(n=120,852)$ from a follow-up period between 2.3 and 7.3 years after baseline. Adjusted gender-specific incidence rate ratios (RR) over tertiles of folate intake were calculated in case-cohort analyses for colon and rectal cancer. Although relatively high folate intake was not associated with overall colorectal cancer risk, it reduced the risk of $A P C$ colon tumors in men $\left(R R=0.58,95 \% C I=0.32-1.05, P_{\text {trend }}=0.06\right.$ for the highest versus the lowest tertile of folate intake). In contrast, it was positively associated with $A P C^{+}$colon tumors in men (highest vs. lowest tertile: $\mathrm{RR}=2.77, \mathrm{CI}=1.29-5.95, P_{\text {trend }}=0.008$ ), and even stronger when additional lack of hMLH1 expression and $K$-ras mutations were excluded $\left(R R=3.99, C I=1.43-11.14, P_{\text {trend }}=0.007\right)$. Such positive associations were not observed among women, neither was folate intake associated with rectal cancer when APC mutation status was accounted for. Relatively high folate consumption reduced the risk of $A P C^{-}$colon tumors, but folate intake was positively associated with $A P C^{+}$colon tumors among men. These opposite results may indicate that folate enhances colorectal carcinogenesis through a distinct $A P C$ mutated pathway.
\end{abstract}




\section{Introduction}

Folate deficiency is hypothesized to increase the risk of colorectal carcinogenesis through various mechanisms (1). It can cause uracil misincorporation in DNA, which in turn may lead to DNA strand breaks and chromosome instability. In addition, a low folate status can cause global DNA hypomethylation and hypermethylation of promoter regions, which may impair the expression of tumor suppressor genes and DNA repair genes (1). Considering these mechanisms it could be expected that sufficient intake of dietary folate protects against colorectal cancer. Epidemiological studies on the relation between dietary folate intake and colorectal cancer risk however, have not consistently shown a protective effect of high folate intake $(2,3)$. This inconsistency may partly be explained by the possible dual role of folate in carcinogenesis, that is, folate would prevent carcinogenesis in normal healthy tissue but may promote growth of existing tumors (4). In addition, accounting for molecular events underlying the carcinogenic process may further clarify the effect of folate intake on colorectal carcinogenesis, but this was not addressed in most of these epidemiological studies.

A well-characterized molecular alteration in colorectal carcinogenesis is the occurrence of mutations in the adenomatous polyposis coli $(A P C)$ gene. Somatic mutations in this tumor suppressor gene were found mainly in its mutation cluster region in a significant proportion of sporadic colorectal carcinomas, varying from $34 \%$ to more than $80 \%(5-8)$. This underscores the importance of APC gene mutations in sporadic colorectal carcinogenesis. In an earlier study in colorectal cancer patients (8) we found that $37 \%$ of the patients had tumors harboring an APC mutation resulting in a stop codon, which leads to a truncated and therefore inactive $A P C$ protein. In addition, Diergaarde et al (9) found an indication for a positive association between folate intake and colorectal adenomas, but the associations did not differ between adenomas with or without truncating $A P C$ mutations. In another study, Diergaarde observed a differential association between consumption of green leafy vegetables, an important source of dietary folate, and the risk of carcinomas with or without truncating $A P C$ mutations (10).

The exact mechanism through which folate may alter $A P C$ functionality remains unclear however. Possibly, there is an indirect effect of decreased activity of the DNA repair gene $0^{6}$-methylguanine DNA methyltransferase $\left(O^{6}-M G M T\right)$ which was found to be associated with hypermethylation of its promoter region (11). Consequently, this can lead to an increased risk of tumors with $\mathrm{G}: \mathrm{C}>\mathrm{A}: \mathrm{T}$ mutations in other key-genes, like $A P C$, involved in colorectal cancer $(12,13)$.

Several studies have suggested that colorectal tumors may arise through distinct pathways based on specific molecular alterations. In this respect, it has been reported that mutations in $A P C$ and $K$-ras occur less often in tumors with microsatellite instability (MSI) compared to microsatellite stable ones (14-17). MSI is known to be strongly associated with the lack of expression of the DNA mismatch repair gene $h M L H 1(18,19)$. Tumors harboring this type of instability occur predominantly in the proximal colon, are often poorly differentiated, and are more frequently present in women at older age $(14,20)$. Furthermore, exogenous factors such as smoking behavior $(21,22)$ and dietary factors $(7,23-25)$ may be differentially associated with the risk of cancer development in MSI and non-MSI tumors. In addition, differential associations were also observed between folate intake and mutations in $K$-ras (26-29). 
Therefore, it is important to account for potential aberrations in $K$-ras and $h M L H 1$ and for differences in tumor location and sex when assessing the potential effect of dietary folate on colorectal cancer risk and APC mutations.

In view of these findings, this study aimed to investigate the associations between folate intake and the risk of colon and rectal cancer, with and without truncating $A P C$ mutations. It was also assessed whether these associations were independent of $K$-ras mutations and hMLH1 expression. The study was conducted within the framework of the Netherlands Cohort Study on diet and cancer (NLCS), of which the study population consumed relatively low levels of dietary folate compared to some other Western countries, since folic acid fortification is not allowed in the Netherlands.

\section{Subjects and methods}

\section{Study population}

The participants in this study are incident colon and rectal cancer patients and subcohort members from the Netherlands Cohort Study (NLCS), which has been described in detail elsewhere (30). Briefly, the study was initiated in 1986 and includes 58,279 men and 62,573 women aged 55-69 years at baseline, who originated from 204 Dutch municipalities with computerized population registers. Numbers of subcohort members and cases are displayed in a flow chart (Figure 1). At baseline, participants completed a self-administered food-frequency questionnaire that also contained questions about other risk factors for cancer. The entire cohort is being monitored for cancer occurrence by annual record linkage to the Netherlands Cancer Registry (NCR, nine cancer registries in The Netherlands) and to PALGA, a nationwide network and registry of histopathology and cytopathology reports (31). Accumulation of person-time in the cohort has been estimated through biennial vital status follow-up of a subcohort of 5,000 men and women who were randomly selected after baseline exposure measurement. Cases with prevalent cancer other than non-melanoma skin cancer were excluded from this subcohort, which left 4,774 men and women eligible for analysis.

The PALGA registry was not yet implemented in some of the municipalities included in the study in 1986, but reached full coverage by the end of 1988 . Incomplete coverage may introduce selection bias, and also possible preclinical disease may have affected exposure status. For these reasons we excluded the first 2.3 years of followup from the analyses. 101 subcohort members were either deceased or diagnosed with cancer other than non-melanoma skin cancer within this period, leaving 4,673 men and women for analysis. From 1989 to 1994, 925 incident cases were identified with histologically confirmed colorectal cancer of whom 815 could also be linked to a PALGA report of the lesion. The PALGA database was used to identify and locate tumor tissue in Dutch pathology laboratories. Colorectal cancer was classified according to disease site as follows: colon, i.e. proximal colon (ICD-O-1 codes 153.0, 153.1, 153.4, 153.5, 153.6) and distal colon (153.2, 153.3, 153.7, 153.8 153.9), rectosigmoid (ICD-O-1 code 154.0) and rectum (ICD-O-1 code 154.1). Information about age at baseline, sex and family history of colorectal cancer (at baseline) was retrieved from the NLCS database. 


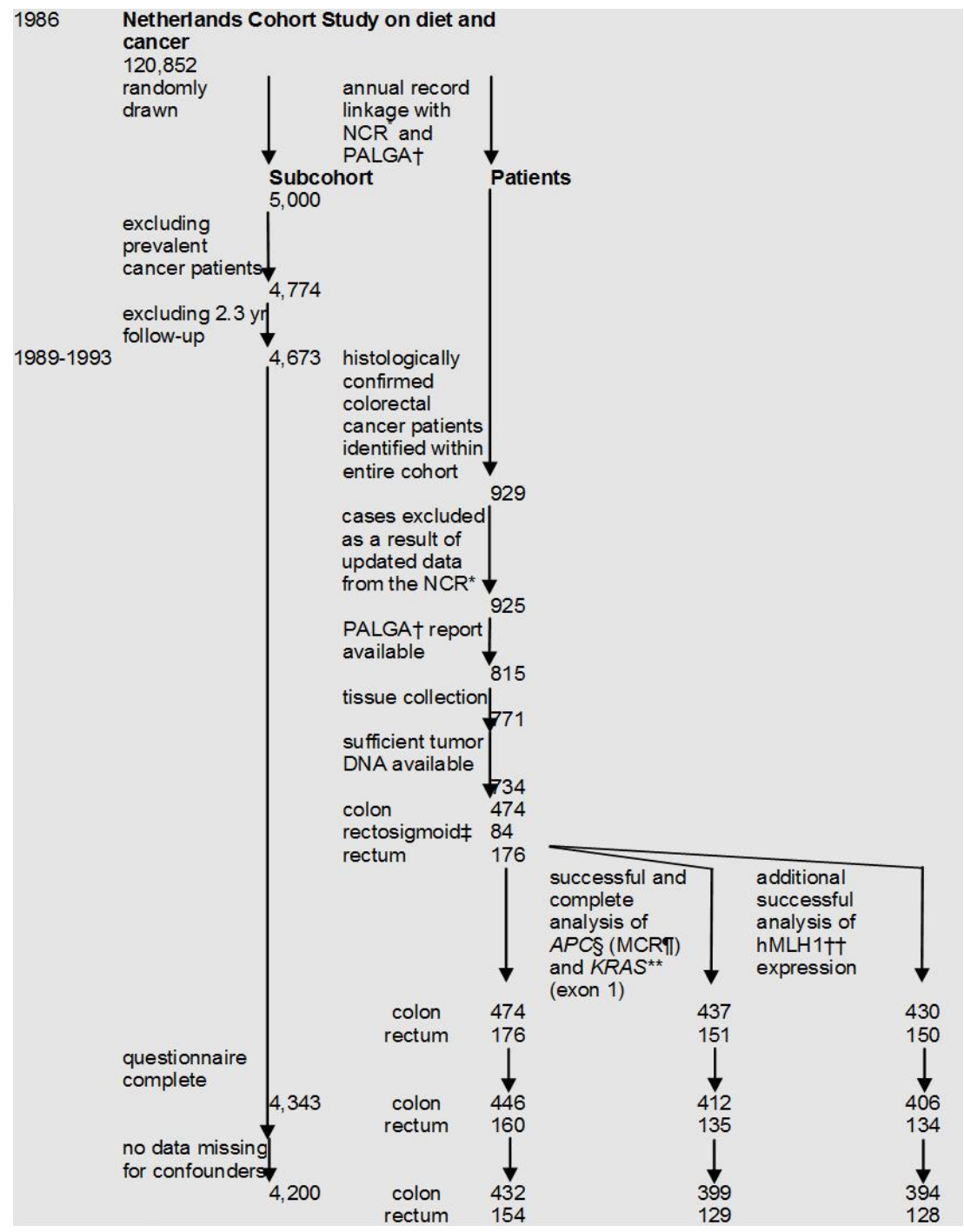

Figure 1. Flow diagram of subjects on whom the analyses were based

* Netherlands Cancer Registry

$\dagger$ Pathologisch Anatomisch Landelijk Geautomatiseerd Archief

$\ddagger$ Patients with rectosigmoid tumors were not included in the analyses

$\S$ Adenomatous polyposis coli

I Mutation cluster region

** Kirsten ras

†† human mut-L homologue 1

\section{Tissue samples}

Tumor material of the colorectal cancer patients was collected after approval by the ethical review boards of Maastricht University, the NCR and PALGA (32). In addition, all pathology laboratories in the Netherlands agreed to make relevant tissue samples 
available from PALGA upon request. From the 815 tissue samples that were scattered over 54 pathology laboratories in the Netherlands, 734 samples (90\%) could be traced and were retrieved between August 1999 and December 2001.

\section{Gene mutation analyses}

Genomic DNA was isolated from the paraffin sections after macrodissection of tumor cells as described previously (32). Gene mutation analyses of the mutation cluster region in APC (codons 1286-1520), was performed as previously described (8). Briefly, nested PCR was used to amplify the mutation cluster region in four overlapping DNA fragments and the purified fragments were sequenced. Two observers independently evaluated the sequence patterns and data entry. From 72 colorectal cancer patients, one or more fragments of the APC gene could not be analyzed completely, leaving 662 patients for data analysis.

The exon 1 fragment of the $K$-ras oncogene, spanning codons 8-29, was analyzed successfully of all 734 patients using nested PCR, followed by direct sequencing of purified fragments as described (32).

\section{hMLH1 expression analysis}

Immunohistochemical analyses were performed and scored on $4 \mu \mathrm{m}$ sections of formalin-fixed, paraffin-embedded cancer tissue and adjacent normal tissue using a monoclonal antibody against hMLH1, as previously described (7). Two investigators reviewed the immunohistochemical staining profiles independently and discrepancies were re-examined and discussed with a pathologist until consensus was reached. hMLH1 expression status was determined successfully in 721 (98\%) of the 734 patients.

\section{Food frequency questionnaire}

The self-administered questionnaire was a 150-item semi-quantitative food frequency questionnaire, which concentrated on habitual consumption of food and beverages during the year preceding the start of the study, and also contained questions about body weight and -length, smoking status, physical activity, and family history of colorectal cancer. Daily mean nutrient intakes were calculated as the cumulated product of the frequencies and portion sizes of all food items and their tabulated nutrient contents from the Dutch Food Composition Table (NEVO table, 1986) (33). The questionnaire was validated through comparison with a 9-day diet record (34). Questionnaire data were key-entered twice for all incident cases in the cohort and for all subcohort members in a blinded manner with respect to case/subcohort status. This was done in order to minimize observer bias in coding and interpretation of the data.

Folate data were derived from a validated liquid chromatography trienzyme method (35) used to analyze the 125 most important Dutch foods contributing to folate intake (36). Mean daily intakes of all other relevant nutrients were calculated using the computerized Dutch Food Composition Table (33). Dietary supplement data were also obtained via the food frequency questionnaire. However, the use of B-vitamins and/or multivitamin supplements was low ( $7 \%$ and $4 \%$ respectively), and folic acid was generally not included in supplements in the Netherlands in the late 1980s. Therefore, folic acid supplement use probably plays a very minor role in our study population, and 
dietary supplement use was not further accounted for in the analyses. Cases and subcohort members with incomplete or inconsistent dietary data were excluded from analyses $(27,34)$. Hence, 446 colon cancer cases, 160 rectal cancer cases, 76 rectosigmoid cancer cases, and 4,343 subcohort members remained.

\section{Statistical analyses}

Data analyses were conducted overall, as well as stratified for men and women, and for colon and rectal tumors with and without truncating $A P C$ mutations, described here as $A P C^{+}$tumors and $A P C^{-}$tumors respectively. The group of cases without truncating $A P C$ mutations consists of cases with tumors containing a wild-type $A P C$ gene $(28 \%)$, a missense mutation $(29 \%)$, or a silent mutation $(6 \%)$. Since the number of patients with a rectosigmoid tumor was too small for adequate stratified analyses, we included these patients only when assessing associations for all colorectal tumors combined. Furthermore, the rectosigmoid is regarded as a clinically applied term rather than an anatomically defined transitional zone between the colon and rectum (32).

The analyses were repeated for tumors with APC mutations, with exclusion of those tumors that also contained activating $K$-ras mutations and were hMLH1 deficient. Out of 125 truncating APC colon tumors, 64 (49\%) exclusively contained a truncating $A P C$ mutation. In order to investigate the effect of folate on specific point mutations, analyses were conducted for tumors with $\mathrm{G}: \mathrm{C}>\mathrm{A}: \mathrm{T}$ mutations in $A P C$, irrespective of the presence of truncating $A P C$ mutations or other gene defects.

Intake of dietary folate and other baseline characteristics were evaluated for subcohort members and colon and rectal cancer cases with or without APC mutations, by calculating mean and standard deviation of the continuous variables folate intake ( $\mu \mathrm{g} /$ day), age (years), body mass index $\left(\mathrm{BMI}, \mathrm{kg} / \mathrm{m}^{2}\right)$, energy $(\mathrm{kJ} /$ day), alcohol (g/day), total fat (g/day), fiber (g/day), vitamin C (mg/day), vitamin B-2 (mg/day), vitamin B-6 (mg/day), iron ( $\mathrm{mg} /$ day) and methionine $(\mathrm{mg} /$ day), as well as distributions of the variables family history of colorectal cancer (yes/no), smoking status (never/ex/current smoker), and physical activity in leisure time $(<30,30-60,60-90$, $>90 \mathrm{~min} /$ day). Differences in mean values or distributions of variables between groups of cases with and without truncating $A P C$ mutations were tested with the Student ttest, the Mann-Whitney-U-test, or the Chi-square test where appropriate.

Cox proportional hazards regression models were used to estimate age-adjusted and multivariate-adjusted gender specific incidence rate ratios (RR) and corresponding $95 \%$ confidence intervals (CI) of colon and rectal cancer for tertiles of folate intake. In addition, associations were estimated for tumors with or without truncating APC mutations. Standard errors of the RRs were estimated using the robust Huber-White sandwich estimator to account for additional variance introduced by sampling from the cohort (37). The proportional hazards assumption was tested using the scaled Schoenfeld residuals (38). Tests for dose response trends over the different tertiles of folate intake were estimated by fitting the ordinal exposure variables as continuous variables and evaluated using the Wald test.

The covariates included in the multivariate analyses were those found to significantly contribute to the multivariate model $(P \leq 0.05)$ for colon and/or rectal cancer, or to influence the RR by more than 10 percent. This applied for the variables age, family history of colorectal cancer, BMI, energy, fiber, vitamin C, vitamin B-2, vitamin B-6, iron and methionine. After excluding subjects with missing information on 
one or more of these covariates 4,200 subcohort members remained for statistical analyses, as well as 399 colon- and 129 rectal cancer cases with complete APC and $K$ ras mutation analyses, and 394 colon- and 128 rectal cancer cases with additional complete hMLH1 expression analyses.

Several factors were previously found to be associated with colorectal cancer risk, or capable to modify the association between dietary folate and colorectal cancer risk, i.e. smoking $(22,39,40)$, alcohol $(41,42)$, vitamins B-2 and B-6 $(43,44)$, and iron intake (45). We therefore determined possible effect modification of these factors, as well as for sex, by testing for interaction and by stratified analyses.

All statistical analyses were performed with the STATA statistical software package (intercooled STATA, version 9.1).

\section{Results}

We first explored mean dietary intakes and other characteristics measured at baseline for cancer cases and subcohort members. Folate intake among males with $\mathrm{APC}^{+}$colon tumors was higher compared to males with APC colon tumors (Table 1). Furthermore, we observed that intakes of vitamin B-2 and iron were significantly higher among men with $A P C^{+}$colon tumors compared to men with $A P C$ colon tumors. All other characteristics presented in Table 1 did not differ substantially between tumors with and without truncating APC mutations.

In order to further investigate the associations between folate intake, colon cancer risk and $A P C$ mutation status, we have calculated relative risks for men and women (Table 2). Folate intake was not associated with overall colon cancer risk in either men or women. However, it reduced the risk of $A P C$ colon tumors in men (RR 0.58, CI 0.32-1.05 for the highest versus the lowest tertile of folate intake; $P_{\text {trend }}=0.06$ ). In contrast, there was a strong positive association between dietary folate and $A P C^{+}$colon tumors in men (RR 2.77, CI 1.29-5.95, $P_{\text {trend }}=0.008$ ), whereas no association could be observed in women with this type of colon tumors. When calculating associations between folate intake and cancer risk for $A P C^{+}$colon tumors without an additional mutated $K$-ras gene and with hMLH1 expression, the positive association appeared even stronger in men (RR 3.99, CI 1.43-11.14, $P_{\text {trend }}=0.007$ ) but not in women. Although not statistically significant, high folate intake reduced the risk of colon tumors in women harboring G:C>A:T point mutations in the APC gene (RR 0.45, CI 0.18-1.14; $\left.P_{\text {trend }}=0.10\right)$. This was not observed in men. 
Table 1 Baseline dietary intake and other characteristics of cancer cases and subcohort members from the Netherlands Cohort Study on die and cancer in $1986^{1}$

\begin{tabular}{|c|c|c|c|c|c|c|c|c|c|c|}
\hline \multirow{3}{*}{ Characteristic } & \multicolumn{5}{|c|}{ Men } & \multicolumn{5}{|c|}{ Women } \\
\hline & \multirow[t]{2}{*}{ Subcohort } & \multicolumn{2}{|c|}{ Colon } & \multicolumn{2}{|c|}{ Rectum } & \multirow[t]{2}{*}{ Subcohort } & \multicolumn{2}{|c|}{ Colon } & \multicolumn{2}{|c|}{ Rectum } \\
\hline & & $A P C-{ }^{2}$ & $A P C+3$ & APC- & $A P C+$ & & APC- & APC+ & APC- & APC+ \\
\hline $\mathrm{N}$ & 2040 & 143 & 70 & 46 & 38 & 2136 & 131 & 55 & 26 & 19 \\
\hline Folate( $\mu \mathrm{g} /$ day) & $224.9 \pm 75.2$ & $215.8 \pm 65.6$ & $247.9 \pm 67.9^{6}$ & $221.6 \pm 52.1$ & $218.1 \pm 69.8$ & $198.7 \pm 67.2$ & $186.7 \pm 69.2$ & $195.2 \pm 56.9$ & $218.5 \pm 94.8$ & $211.0 \pm 56.9$ \\
\hline Age(y) & $61.3 \pm 4.2$ & $63.0 \pm 4.3$ & $62.7 \pm 3.9$ & $62.2 \pm 4.7$ & $62.4 \pm 3.6$ & $61.4 \pm 4.3$ & $63.3 \pm 3.9$ & $62.7 \pm 4.2$ & $62.2 \pm 4.0$ & $62.9 \pm 3.3$ \\
\hline Family History (\% yes) & & & & & 15.8 & & & 12.7 & 15.4 & \\
\hline BMI $\left(\mathrm{kg} / \mathrm{m}^{2}\right)$ & $25.0 \pm 2.6$ & $25.5 \pm 2.9$ & $25.7 \pm 2.9$ & $25.2 \pm 2.6$ & $24.8 \pm 2.7$ & $25.1 \pm 3.56$ & $25.4 \pm 3.7$ & $25.9 \pm 3.2$ & $25.4 \pm 3.9$ & $25.7 \pm 3.0$ \\
\hline \multicolumn{11}{|l|}{ Smoking Status (\%) } \\
\hline Never & 12.8 & 11.9 & 8.6 & 8.7 & 13.2 & 58.2 & 61.8 & 74.6 & 57.7 & 73.7 \\
\hline Ex Smoker & 51.7 & 65.7 & 64.3 & 56.5 & 52.6 & 20.6 & 24.4 & 16.4 & 30.8 & 10.5 \\
\hline Current Smoker & 35.5 & 22.4 & 27.1 & 34.8 & 34.2 & 21.2 & 13.7 & 9.1 & 11.5 & 15.8 \\
\hline \multicolumn{11}{|l|}{ Physical Activity $(\%)^{4}$} \\
\hline$<30 \mathrm{~min} / \mathrm{day}$ & 17.7 & 9.9 & 20.3 & 13.3 & 15.8 & 24.3 & 28.7 & 33.3 & 23.1 & 47.4 \\
\hline 30-60 min/day & 30.5 & 35.5 & 30.4 & 20.0 & 36.8 & 31.3 & 31.0 & 27.8 & 42.3 & 21.1 \\
\hline 60-90 min/day & 18.8 & 22.0 & 14.5 & 22.2 & 13.2 & 22.7 & 21.7 & 20.4 & 23.1 & 26.3 \\
\hline$>90 \mathrm{~min} / \mathrm{day}$ & 32.0 & 32.6 & 34.8 & 44.4 & 34.2 & 21.7 & 18.6 & 18.5 & 11.5 & 5.3 \\
\hline \multicolumn{11}{|l|}{ Dietary Factors } \\
\hline Energy (kjoules/day) & $9084 \pm 2134$ & $8815 \pm 1698$ & $9183 \pm 2166$ & $9204 \pm 1769$ & $8875 \pm 1604$ & $7044 \pm 1656$ & $6785 \pm 1492$ & $7239 \pm 2003$ & $7071 \pm 1415$ & $7592 \pm 1296$ \\
\hline Alcohol (g/day) ${ }^{5}$ & $14.9 \pm 16.8$ & $15.3 \pm 15.9$ & $16.8 \pm 18.8$ & $15.2 \pm 17.1$ & $18.6 \pm 19.4$ & $5.8 \pm 9.5$ & $6.2 \pm 12.2$ & $3.9 \pm 9.2$ & $6.8 \pm 7.9$ & $5.8 \pm 11.2$ \\
\hline Fat (g/day) & $94.3 \pm 28.4$ & $92.0 \pm 23.5$ & $94.1 \pm 28.8$ & $93.0 \pm 24.5$ & $89.7 \pm 25.4$ & $73.9 \pm 22.7$ & $71.5 \pm 21.9$ & $77.1 \pm 25.8$ & $74.3 \pm 22.2$ & $83.5 \pm 18.8$ \\
\hline Fiber (g/day) & $28.7 \pm 8.7$ & $28.9 \pm 7.7$ & $30.3 \pm 7.9$ & $30.0 \pm 7.7$ & $29.1 \pm 10.2$ & $25.3 \pm 7.0$ & $24.2 \pm 7.5$ & $24.8 \pm 7.2$ & $24.6 \pm 4.0$ & $26.3 \pm 5.3$ \\
\hline Vitamin C (mg/day) & $98.8 \pm 42.9$ & $102.3 \pm 42.9$ & $111.6 \pm 42.9$ & $113.9 \pm 51.9$ & $98.7 \pm 48.0$ & $108.6 \pm 44.5$ & $101.9 \pm 48.8$ & $105.6 \pm 43.1$ & $114.8 \pm 34.0$ & $117.5 \pm 52.2$ \\
\hline Vitamin B-2 (mg/day) & $1.58 \pm 0.45$ & $1.53 \pm 0.39$ & $1.65 \pm 0.44^{6}$ & $1.53 \pm 0.35$ & $1.49 \pm 0.34$ & $1.45 \pm 0.41$ & $1.37 \pm 0.34$ & $1.46 \pm 0.44$ & $1.53 \pm 0.48$ & $1.53 \pm 0.29$ \\
\hline Vitamin B-6 (mg/day) & $1.54 \pm 0.38$ & $1.54 \pm 0.35$ & $1.62 \pm 0.37$ & $1.58 \pm 0.35$ & $1.46 \pm 0.40$ & $1.33 \pm 0.32$ & $1.28 \pm 0.30$ & $1.37 \pm 0.37$ & $1.34 \pm 0.27$ & $1.45 \pm 0.32$ \\
\hline Iron (mg/day) & $13.2 \pm 3.3$ & $13.3 \pm 3.0$ & $14.5 \pm 2.8^{6}$ & $13.6 \pm 2.6$ & $13.5 \pm 3.3$ & $11.7 \pm 2.7$ & $11.3 \pm 2.4$ & $11.3 \pm 2.5$ & $11.5 \pm 2.1$ & $12.1 \pm 2.1$ \\
\hline Methionine (mg/day) & $1716 \pm 417$ & $1694 \pm 366$ & $1736 \pm 387$ & $1658 \pm 298$ & $1598 \pm 408$ & $1492 \pm 366$ & $1442 \pm 304$ & $1537 \pm 447$ & $1140 \pm 337$ & $1613 \pm 290$ \\
\hline
\end{tabular}

1 Values are means \pm SD, except for Family History (\% yes), Smoking Status (\%) and Physical Activity (\%)

Values are means $\pm S D$, except for Family
Tumors without a truncating $A P C$ mutation

Tumors with a truncating APC mutation

Information on physical activity was not available for 43 subcohort members, for 6 colon cancer cases and for 1 rectal cancer case.

6 Informalion on alcohol intake was not avallable for 117 subcohort members, for 4 colon cancer cases and for 4 rectal cancer cases. 
Table 2 Incidence Rate Ratios (RR) and $95 \% \mathrm{Cl}$ for colon cancer patients according to tertiles of folate intake

\begin{tabular}{|c|c|c|c|c|c|c|}
\hline \multirow[b]{2}{*}{ Tertiles of folate intake ${ }^{1}$} & \multicolumn{3}{|c|}{ MEN } & \multicolumn{3}{|c|}{ WOMEN } \\
\hline & $\mathbf{N}^{2}$ & $\mathrm{RR}^{3}$ & $95 \% \mathrm{Cl}$ & $\mathbf{N}^{2}$ & $\mathbf{R R}^{3}$ & $95 \% \mathrm{Cl}$ \\
\hline \multicolumn{7}{|l|}{ Colon carcinoma, all tumors } \\
\hline 1 & 74 & 1.00 & & 74 & 1.00 & \\
\hline 2 & 56 & 0.69 & $0.46-1.02$ & 64 & 0.94 & $0.61-1.44$ \\
\hline 3 & 83 & 0.96 & $0.61-1.54$ & 48 & 0.82 & $0.45-1.49$ \\
\hline$P$-value for linear trend & & 0.84 & & & 0.53 & \\
\hline \multicolumn{7}{|l|}{ Colon carcinoma, APC- 4} \\
\hline 1 & 60 & 1.00 & & 56 & 1.00 & \\
\hline 2 & 39 & 0.56 & $0.35-0.88$ & 42 & 0.85 & $0.52-1.39$ \\
\hline 3 & 44 & 0.58 & $0.32-1.05$ & 33 & 0.79 & $0.40-1.54$ \\
\hline$P$-value for linear trend & & 0.06 & & & 0.47 & \\
\hline \multicolumn{7}{|l|}{ Colon carcinoma, $A P C+5$} \\
\hline 1 & 14 & 1.00 & & 18 & 1.00 & \\
\hline 2 & 17 & 1.20 & $0.56-2.55$ & 22 & 1.21 & $0.54-2.70$ \\
\hline 3 & 39 & 2.77 & $1.29-5.95$ & 15 & 0.91 & $0.27-3.06$ \\
\hline$P$-value for linear trend & & 0.008 & & & 0.91 & \\
\hline \multicolumn{7}{|c|}{ Colon carcinoma, APC+, K-ras -, hMLH1+ 6} \\
\hline 1 & 7 & 1.00 & & 11 & 1.00 & \\
\hline 2 & 10 & 1.58 & $0.57-4.35$ & 7 & 0.67 & $0.18-2.48$ \\
\hline 3 & 22 & 3.99 & $1.43-11.14$ & 7 & 0.77 & $0.13-4.57$ \\
\hline$P$-value for linear trend & & 0.007 & & & 0.75 & \\
\hline \multicolumn{7}{|c|}{ Colon carcinoma, $G: C>A: T$ point mutations in $A P C$} \\
\hline 1 & 40 & 1.00 & & 39 & 1.00 & \\
\hline 2 & 32 & 0.66 & $0.39-1.12$ & 34 & 0.78 & $0.41-1.49$ \\
\hline 3 & 48 & 0.86 & $0.46-1.61$ & 20 & 0.45 & $0.18-1.14$ \\
\hline$P$-value for linear trend & & 0.63 & & & 0.10 & \\
\hline
\end{tabular}

1 Median intakes of folate within tertiles of folate are $162.7,211.4,279.9 \mu \mathrm{g} /$ day for men, and $142.5,186.8,248.0 \mu \mathrm{g} /$ day for women

2 Number of person years among subcohort members for the first, second and third tertile of folate intake is 3243,3282 and 3293 for men, and 3457,3512 and 3526 for women respectively

3 RR adjusted for age, family history, BMI, iron, fiber, energy, vitamin B-2, vitamin B-6, vitamin C and methionine

4 Colon tumors without a truncating APC mutation.

5 Colon tumors with a truncating $A P C$ mutation.

6 Colon tumors with a truncating APC mutation, no K-ras mutation and with hMLH1 expression.

Relative risks were also calculated for tumor sub-localizations within the colon. However, it appeared that folate intake was neither associated with proximal and distal colon cancer risk, nor did these relative risks substantially differ from overall colon cancer risk. Accounting for APC mutations in these subgroups did not reveal any differential results (data not shown).

Regarding rectal cancer, we observed that intake of dietary folate was neither associated with overall cancer risk, nor with rectal cancer with or without APC truncating mutations in either men or women (see Table 3). However, when conducting the analyses for $A P C^{+}$tumors without a $K$-ras mutation and with hMHL1 expression, folate was again positively associated with rectal cancer risk among men (RR 3.69, CI 0.97-13.98; $P_{\text {trend }}=0.06$ ). 
Table 3 Incidence Rate Ratios (RR) and $95 \% \mathrm{Cl}$ for rectal cancer patients according to tertiles of folate intake

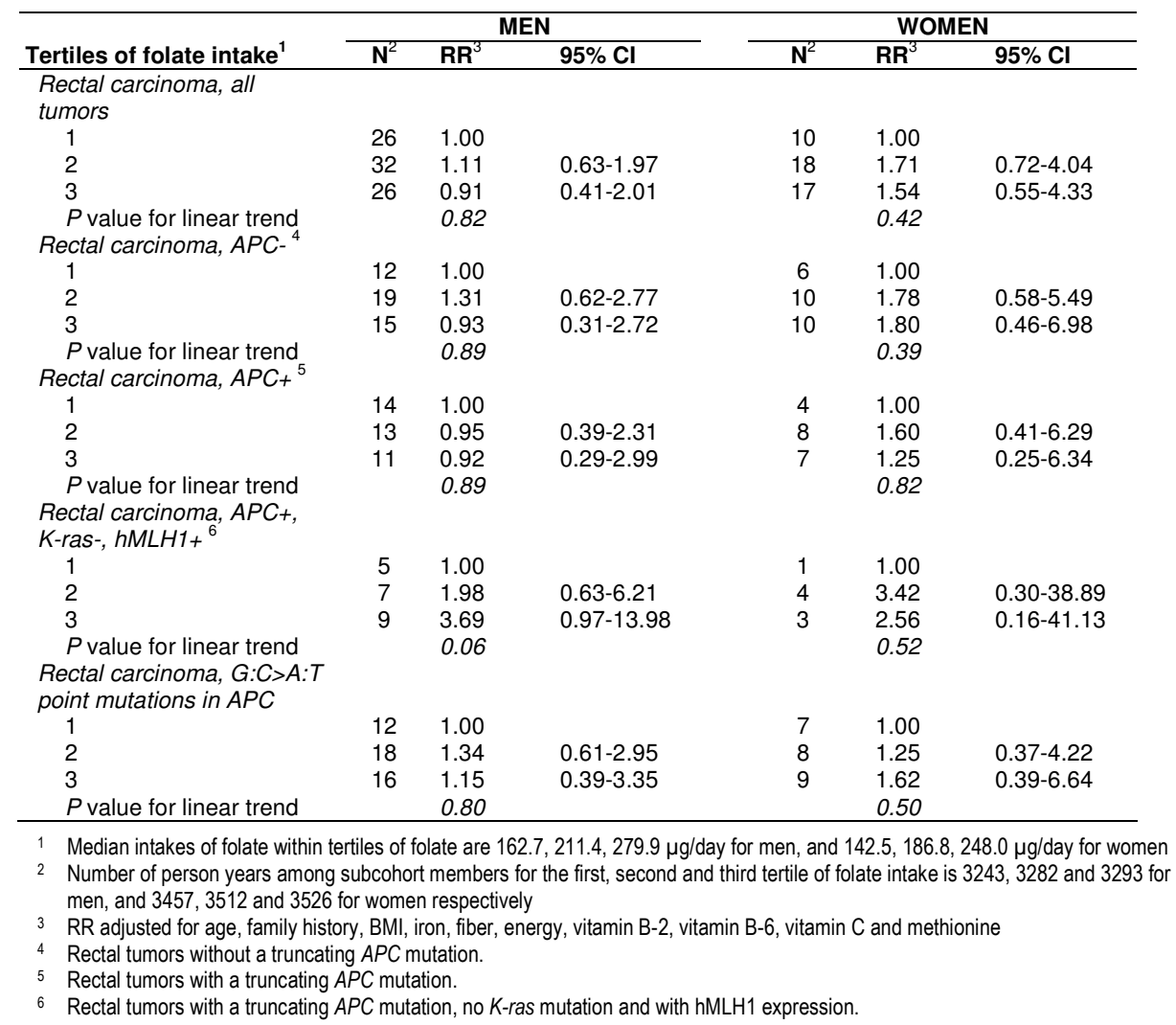

In addition, we assessed possible associations for all colorectal cancer cases combined, for each of the endpoints considered in this study. Folate intake was also positively associated with $A P C^{+}$colorectal tumors without a $K$-ras mutation and with hMHL1 expression (RR 1.86, CI 0.97-3.55), again being most pronounced among men (RR 3.40, CI 1.54-7.50), although the interaction with sex was not statistically significant. Significant interactions were observed between folate intake and sex in the associations with overall colon cancer risk $(P=0.03)$, and $A P C^{+}$colon tumors $(P=$ $0.01)$. None of the other interactions tested were statistically significant, nor did the remaining stratified analyses reveal any different relative risks compared to the overall groups. 


\section{Discussion}

In this study we investigated the associations between folate intake and colorectal carcinoma risk with and without truncating $A P C$ mutations. We observed that folate intake in the second and highest tertile reduced the risk of $A P C^{-}$colon tumors among men, while folate intake was positively associated with $A P C^{+}$colon tumors in men. It is striking that this positive association among men was even stronger for $A P C^{+}$colon tumors, and appeared in rectal tumors, when tumors with additional aberrations in $K$ ras and with hMLH1 expression were excluded.

The relation between folate and $A P C$ mutations has been investigated only once before in colorectal adenomas by Diergaarde et al (9), but in contrast to our study, no differences were observed between the $A P C^{-}$and $A P C^{+}$endpoints. Reasons for this discrepancy might be that adenomas were studied instead of carcinomas, and that a case-control design was used with selected cases versus a case-cohort design with incident cases in our study. Furthermore, in the study of Diergaarde et al (9), the analyses were not stratified for gender, which may have attenuated potential associations in men. On the other hand, the ranges of dietary folate intake within the tertiles of intake were comparable to those in our study population. In another study by Diergaarde et al (10), intake of green leafy vegetables - an important source of dietary folate - was inversely associated with $A P C^{-}$colon carcinomas. Although the association with folate intake was not calculated separately in that study, the results suggest a similarity with the inverse association between folate and $A P C^{-}$colon carcinomas in our study. However, the reason why the protective influence of folate is confined to these tumors remains unclear and needs further investigation.

After determining potential interactions it was found that sex significantly modified the effect of folate intake on overall colon cancer risk, as well as on $A P C^{+}$colon tumors. For this reason, we presented the data for men and women separately in spite of the drawbacks of thereby creating smaller subgroups and less precise estimations. In order to minimize the potential danger of reporting chance findings however, we also conducted analyses for all colorectal tumors combined with and without stratifying for sex. We then observed that folate intake was again positively associated with $\mathrm{APC}^{+}$ colorectal tumors without a $K$-ras mutation and with hMHL1 expression, and that this effect was only present among men.

Although one could argue that the number of cases in some subgroups should preferably have been higher, we emphasize that the selection of patients in this study was based on the availability of a tissue sample with sufficient extracted DNA as well as the completeness of analyses of the $K$-ras and APC genes and hMLH1 expression. This led to a reduction of the number of cases that could be included in the analyses. However, a tissue sample as well as a sufficient amount of DNA was available for no less than $90 \%$ of the patients. Moreover, the overlap of available molecular analyses was high $(89 \%)$. Finally, it is important to realize that the characteristics of these patients with regard to age, sex, family history of colorectal cancer, smoking behavior and dietary factors neither differed from the 815 patients initially identified, nor from the 734 patients with sufficient tumor DNA. It is therefore unlikely that bias has occurred due to selection of patients.

High folate intake resulted in an increased risk of $\mathrm{APC}^{+}$colon tumors among men. However, this was not expected given the hypothesis that folate prevents DNA 
damage. Since it is reasonable to assume that aberrations in other key genes in colorectal carcinogenesis may also be associated with folate intake, we included $K$-ras mutation status and hMLH1 expression in our analyses in order to exclude their potential underlying influence. The observations that $A P C$ and $K$-ras mutations may be inversely associated with microsatellite instability (14-17), and with hMLH1 expression $(18,19)$, are an important reasons to do so. APC mutated colon tumors without additional $K$-ras mutation and with hMLH1 expression were even more strongly positively associated with folate intake in men, and the positive association also appeared for this type of rectal tumors among men. Interestingly, it has been suggested that folic acid supplementation might have a cancer-promoting effect in people with already existing, undiagnosed pre-malignant or malignant lesions $(4,46)$. $A P C$ mutations are known to play an important role in both tumor initiation as well as in later stages of colorectal cancer development (47). The development of lesions containing early $A P C$ mutations is possibly more sensitive to a high folate intake, that is, the protective influence of dietary folate on cancer progression might be decreased after an $A P C$ mutation has occurred compared to tumors that were initiated otherwise.

Other recent studies confirm that multiple alternative genetic pathways to colorectal cancer may exist, since it was found that only a very small number of colorectal tumors ( 5 to $6 \%$ ) harbored mutations in all three key genes $K$-ras, $A P C$ and TP53 $(48,49)$. We observed strong positive associations for tumors containing exclusively $A P C$ mutations in men only. This may indicate that folate potentially mediates an $A P C$ mutated pathway in the colon and rectum in men, but that its effect differs between men and women. However, the reasons for these differences are unknown, and clearly other studies are warranted to confirm or reject this.

The relative risks of tumors harboring $\mathrm{G}: \mathrm{C}>\mathrm{A}: \mathrm{T}$ point mutations in $A P C$ were slightly decreased among women with colon tumors. Decreased activity of the DNA repair gene $O^{6}-M G M T$ by epigenetic hypermethylation might be an indirect mechanism through which folate intake modifies colorectal cancer risk (11). The $0^{6}$-MGMT protein removes adducts from the $O^{6}$ position of guanine in DNA (12), which in turn prevents G:C>A:T point mutations. Previously, we reported that $O^{6}-M G M T$ promoter hypermethylation may partly be due to a low folate status (50). It has also been reported that that $O^{6}-M G M T$ hypermethylation is associated with $\mathrm{G}: \mathrm{C}>\mathrm{A}: \mathrm{T}$ mutations in $K$-ras and TP53 $(12,13,27)$. However, others did not observe an association between $O^{6}$-MGMT expression and G:C>A:T mutations in the APC gene alone (51). Further research is therefore needed to investigate whether $A P C$ mutations might occur via decreased $O^{6}-M G M T$ functionality.

A potential protective effect of folate intake on colorectal cancer risk has been demonstrated only in 10 out of 23 epidemiological studies conducted to investigate this association (2). In addition, we have observed higher risks of colorectal cancer in some subgroups, even though intakes of dietary folate in our study population were relatively low compared to some other Western countries. This raises the question whether high folate intake should be a reason for concern in terms of colorectal cancer risk, particularly in view of differences in recommended dietary intakes between countries and the mandatory fortification of cereals with folic acid in the United States and Canada. It is therefore of crucial importance to gain more insight in the role that dietary folate plays in colorectal carcinogenesis with genetic aberrations like truncating $A P C$ mutations in future studies. 
In conclusion, the results of this study indicate that an inverse association between relatively high folate consumption and carcinogenesis is limited to $A P C^{-}$colon tumors, especially in men. Combined with the higher relative risks of $A P C^{+}$colon and rectal tumors without additional aberrations in two other key genes involved in colorectal cancer in men, these findings may indicate that folate intake exerts an effect on specific genetic pathways, i.e. an APC mutated pathway. Tumors that arise through distinct genetic pathways on the basis of specific genetic aberrations, such as truncating $A P C$ mutations, possibly have a unique etiology and folate may have a different effect on these pathways in men and women. 


\section{References}

1. Kim YI. Folate and DNA methylation: a mechanistic link between folate deficiency and colorectal cancer? Cancer Epidemiol Biomarkers Prev 2004;13(4):511-9.

2. Bollheimer LC, Buettner R, Kullmann A, Kullmann F. Folate and its preventive potential in colorectal carcinogenesis. How strong is the biological and epidemiological evidence? Crit Rev Oncol Hematol 2005;55(1):13-36.

3. Sanjoaquin MA, Allen N, Couto E, Roddam AW, Key TJ. Folate intake and colorectal cancer risk: a meta-analytical approach. Int J Cancer 2005;113(5):825-8.

4. Ulrich CM, Potter JD. Folate supplementation: too much of a good thing? Cancer Epidemiol Biomarkers Prev 2006;15(2):189-93.

5. Miyoshi $Y$, Nagase $H$, Ando $H$, Horii A, Ichii $S$, Nakatsuru $S$, et al. Somatic mutations of the $A P C$ gene in colorectal tumors: mutation cluster region in the $A P C$ gene. Hum Mol Genet $1992 ; 1(4): 229-33$.

6. Powell SM, Zilz N, Beazer-Barclay Y, Bryan TM, Hamilton SR, Thibodeau SN, et al. APC mutations occur early during colorectal tumorigenesis. Nature 1992;359(6392):235-7.

7. Diergaarde B, Braam H, van Muijen GN, Ligtenberg MJ, Kok FJ, Kampman E. Dietary factors and microsatellite instability in sporadic colon carcinomas. Cancer Epidemiol Biomarkers Prev 2003;12(11 Pt 1):1130-6.

8. Luchtenborg M, Weijenberg MP, Roemen GM, de Bruine AP, van den Brandt PA, Lentjes MH, et al. $A P C$ mutations in sporadic colorectal carcinomas from The Netherlands Cohort Study. Carcinogenesis 2004;25(7):1219-26.

9. Diergaarde B, Tiemersma EW, Braam H, van Muijen GN, Nagengast FM, Kok FJ, et al. Dietary factors and truncating $A P C$ mutations in sporadic colorectal adenomas. Int $\mathrm{J}$ Cancer $2005 ; 113(1): 126-32$

10. Diergaarde B, van Geloof WL, van Muijen GN, Kok FJ, Kampman E. Dietary factors and the occurrence of truncating $A P C$ mutations in sporadic colon carcinomas: a Dutch populationbased study. Carcinogenesis 2003;24(2):283-90.

11. Esteller M, Hamilton SR, Burger PC, Baylin SB, Herman JG. Inactivation of the DNA repair gene 06-methylguanine-DNA methyltransferase by promoter hypermethylation is a common event in primary human neoplasia. Cancer Res 1999;59(4):793-7.

12. Esteller M, Toyota M, Sanchez-Cespedes M, Capella G, Peinado MA, Watkins DN, et al. Inactivation of the DNA repair gene O6-methylguanine-DNA methyltransferase by promoter hypermethylation is associated with $\mathrm{G}$ to $\mathrm{A}$ mutations in $\mathrm{K}$-ras in colorectal tumorigenesis. Cancer Res 2000;60(9):2368-71.

13. Esteller M, Risques RA, Toyota M, Capella G, Moreno V, Peinado MA, et al. Promoter hypermethylation of the DNA repair gene $\mathrm{O}(6)$-methylguanine-DNA methyltransferase is associated with the presence of G:C to A:T transition mutations in p53 in human colorectal tumorigenesis. Cancer Res 2001;61(12):4689-92.

14. Luchtenborg M, Weijenberg MP, Wark PA, Saritas AM, Roemen GM, van Muijen GN, et al. Mutations in APC, CTNNB1 and K-ras genes and expression of hMLH1 in sporadic colorectal carcinomas from the Netherlands Cohort Study. BMC Cancer 2005;5(1):160.

15. Olschwang $S$, Hamelin R, Laurent-Puig P, Thuille B, De Rycke $Y, L i ~ Y J$, et al. Alternative genetic pathways in colorectal carcinogenesis. Proc Natl Acad Sci U S A 1997;94(22):12122-7.

16. Salahshor S, Kressner U, Pahlman L, Glimelius B, Lindmark G, Lindblom A. Colorectal cancer with and without microsatellite instability involves different genes. Genes Chromosomes Cancer 1999;26(3):247-52.

17. Samowitz WS, Holden JA, Curtin K, Edwards SL, Walker AR, Lin HA, et al. Inverse relationship between microsatellite instability and $\mathrm{K}$-ras and $\mathrm{p} 53$ gene alterations in colon cancer. Am J Pathol 2001;158(4):1517-24.

18. Rajagopalan H, Lengauer C. CIN-ful cancers. Cancer Chemother Pharmacol 2004.

19. Kuismanen SA, Holmberg MT, Salovaara R, de la Chapelle A, Peltomaki P. Genetic and epigenetic modification of MLH1 accounts for a major share of microsatellite-unstable colorectal cancers. Am J Pathol 2000;156(5):1773-9. 
20. Breivik J, Lothe RA, Meling GI, Rognum TO, Borresen-Dale AL, Gaudernack G. Different genetic pathways to proximal and distal colorectal cancer influenced by sex-related factors. Int J Cancer 1997;74(6):664-9.

21. Slattery ML, Curtin K, Anderson K, Ma KN, Ballard L, Edwards S, et al. Associations between cigarette smoking, lifestyle factors, and microsatellite instability in colon tumors. J Natl Cancer Inst 2000;92(22):1831-6.

22. Luchtenborg M, Weijenberg MP, Kampman E, van Muijen GN, Roemen GM, Zeegers MP, et al. Cigarette smoking and colorectal cancer: $A P C$ mutations, hMLH1 expression, and GSTM1 and GSTT1 polymorphisms. Am J Epidemiol 2005;161(9):806-15.

23. Slattery ML, Anderson K, Curtin K, Ma KN, Schaffer D, Samowitz W. Dietary intake and microsatellite instability in colon tumors. Int J Cancer 2001;93(4):601-7.

24. Wark PA, Weijenberg MP, van 't Veer P, van Wijhe G, Luchtenborg M, van Muijen GN, et al. Fruits, vegetables, and hMLH1 protein-deficient and -proficient colon cancer: The Netherlands cohort study. Cancer Epidemiol Biomarkers Prev 2005;14(7):1619-25.

25. Luchtenborg M, Weijenberg MP, de Goeij AF, Wark PA, Brink M, Roemen GM, et al. Meat and Fish Consumption, APCGene Mutations and hMLH1 Expression in Colon and Rectal Cancer: a Prospective Cohort Study (The Netherlands). Cancer Causes Control 2005;16(9):1041-54.

26. Bautista D, Obrador A, Moreno V, Cabeza E, Canet R, Benito E, et al. Ki-ras mutation modifies the protective effect of dietary monounsaturated fat and calcium on sporadic colorectal cancer. Cancer Epidemiol Biomarkers Prev 1997;6(1):57-61.

27. Brink M, Weijenberg MP, de Goeij AF, Roemen GM, Lentjes MH, de Bruine AP, et al. Dietary folate intake and k-ras mutations in sporadic colon and rectal cancer in the Netherlands Cohort Study. Int J Cancer 2004.

28. Martinez ME, Maltzman T, Marshall JR, Einspahr J, Reid ME, Sampliner R, et al. Risk factors for Ki-ras protooncogene mutation in sporadic colorectal adenomas. Cancer Res 1999;59(20):5181-5.

29. Slattery ML, Curtin K, Anderson K, Ma KN, Edwards S, Leppert M, et al. Associations between dietary intake and Ki-ras mutations in colon tumors: a population-based study. Cancer Res 2000;60(24):6935-41.

30. van den Brandt PA, Goldbohm RA, van 't Veer P, Volovics A, Hermus RJ, Sturmans F. A large-scale prospective cohort study on diet and cancer in The Netherlands. J Clin Epidemiol $1990 ; 43(3): 285-95$.

31. Van den Brandt PA, Schouten $\sqcup$, Goldbohm RA, Dorant E, Hunen PM. Development of a record linkage protocol for use in the Dutch Cancer Registry for Epidemiological Research. Int J Epidemiol 1990;19(3):553-8.

32. Brink M, de Goeij AF, Weijenberg MP, Roemen GM, Lentjes MH, Pachen MM, et al. K-ras oncogene mutations in sporadic colorectal cancer in The Netherlands Cohort Study. Carcinogenesis 2003;24(4):703-10.

33. Nevo table. Dutch food composition table 1986-1987, The Hague, The Netherlands: Voorlichtingsbureau voor de voeding, 1986. 1986.

34. Goldbohm RA, van den Brandt PA, Brants HA, van't Veer P, Al M, Sturmans F, et al. Validation of a dietary questionnaire used in a large-scale prospective cohort study on diet and cancer. Eur J Clin Nutr 1994;48(4):253-65.

35. Konings EJ. A validated liquid chromatographic method for determining folates in vegetables, milk powder, liver, and flour. J AOAC Int 1999;82(1):119-27.

36. Konings EJ, Roomans HH, Dorant E, Goldbohm RA, Saris WH, van den Brandt PA. Folate intake of the Dutch population according to newly established liquid chromatography data for foods. Am J Clin Nutr 2001;73(4):765-76.

37. Lin DY WL. The robust inference for the Cox Proportional Hazards Model. JASA 1989;84(408):1074-1078.

38. Schoenfeld D. Partial residuals for the proportional hazards regression models. Biometrika 1982;69(1):239-241.

39. Diergaarde B, Vrieling A, van Kraats AA, van Muijen GN, Kok FJ, Kampman E. Cigarette smoking and genetic alterations in sporadic colon carcinomas. Carcinogenesis $2003 ; 24(3): 565-71$. 
40. Larsson SC, Giovannucci E, Wolk A. A prospective study of dietary folate intake and risk of colorectal cancer: modification by caffeine intake and cigarette smoking. Cancer Epidemiol Biomarkers Prev 2005;14(3):740-3.

41. Halsted $\mathrm{CH}$, Villanueva JA, Devlin AM, Chandler $\mathrm{C}$. Metabolic interactions of alcohol and folate. J Nutr 2002;132(8 Suppl):2367S-2372S.

42. Wei EK, Giovannucci E, Wu K, Rosner B, Fuchs CS, Willett WC, et al. Comparison of risk factors for colon and rectal cancer. Int J Cancer 2004;108(3):433-42.

43. van den Donk M, Buijsse B, van den Berg SW, Ocke MC, Harryvan JL, Nagengast FM, et al. Dietary intake of folate and riboflavin, MTHFR C677T genotype, and colorectal adenoma risk: a Dutch case-control study. Cancer Epidemiol Biomarkers Prev 2005;14(6):1562-6.

44. Larsson SC, Giovannucci E, Wolk A. Vitamin b6 intake, alcohol consumption, and colorectal cancer: a longitudinal population-based cohort of women. Gastroenterology $2005 ; 128(7): 1830-7$.

45. Chan AT, Ma J, Tranah GJ, Giovannucci EL, Rifai N, Hunter DJ, et al. Hemochromatosis gene mutations, body iron stores, dietary iron, and risk of colorectal adenoma in women. J Natl Cancer Inst 2005;97(12):917-26.

46. Kim YI. Will mandatory folic acid fortification prevent or promote cancer? Am J Clin Nutr 2004;80(5):1123-8.

47. Fodde R. The APC gene in colorectal cancer. Eur J Cancer 2002;38(7):867-71.

48. Smith G, Carey FA, Beattie J, Wilkie MJ, Lightfoot TJ, Coxhead J, et al. Mutations in APC, Kirsten-ras, and p53--alternative genetic pathways to colorectal cancer. Proc Natl Acad Sci U S A 2002;99(14):9433-8.

49. Chiang JM, Wu Chou YH, Ma SC, Chen JR. Influence of age on adenomatous polyposis coli and p53 mutation frequency in sporadic colorectal cancer-rarity of co-occurrence of mutations in APC, K-ras, and p53 genes. Virchows Arch 2004;445(5):465-71.

50. van Engeland M, Weijenberg MP, Roemen GM, Brink M, de Bruine AP, Goldbohm RA, et al. Effects of dietary folate and alcohol intake on promoter methylation in sporadic colorectal cancer: the Netherlands cohort study on diet and cancer. Cancer Res 2003;63(12):3133-7.

51. Halford S, Rowan A, Sawyer E, Talbot I, Tomlinson I. O(6)-methylguanine methyltransferase in colorectal cancers: detection of mutations, loss of expression, and weak association with G:C>A:T transitions. Gut 2005;54(6):797-802. 



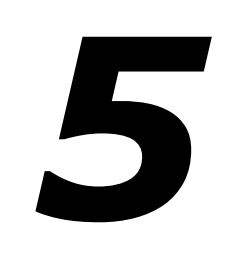

\title{
Associations of dietary methyl donor intake with MLH1 promoter hypermethylation and related molecular phenotypes in sporadic colorectal cancer
}

\author{
Stefan de Vogel \\ Brenda WC Bongaerts \\ Kim AD Wouters \\ Arnold DM Kester \\ Leo J Schouten \\ Anton FPM de Goeij \\ Adriaan $P$ de Bruïne \\ R Alexandra Goldbohm \\ Piet $A$ van den Brandt \\ Manon van Engeland \\ Matty $P$ Weijenberg
}




\section{Abstract}

Intake of dietary factors that serve as methyl group donors may influence promoter hypermethylation in colorectal carcinogenesis. We investigated whether dietary folate, vitamins B2 and B6, methionine and alcohol were associated with MLH1 hypermethylation, and the related molecular phenotypes of MLH1 protein expression, microsatellite instability (MSI) and BRAF mutations in patients with colorectal carcinomas.

Within the Netherlands Cohort Study on diet and cancer $(n=120,852), 648$ cases (367 men and 281 women) and 4,059 subcohort members were available for data analyses from a follow-up period between 2.3 and 7.3 years after baseline. Genderspecific adjusted incidence rate ratios (RR) were calculated over categories of dietary intake in case-cohort analyses.

The intakes of folate, vitamin B2, methionine and alcohol were not associated with risk of tumors showing MLH1 hypermethylation, those lacking MLH1 protein expression, or with MSI. Among men, we observed strong positive associations between folate and $B R A F$-mutated tumors $(R R=3.04$, for the highest versus lowest tertile of intake, $P_{\text {trend }}=0.03$ ), and between vitamin B6 and tumors showing $M L H 1$ hypermethylation (highest vs. lowest tertile: $\mathrm{RR}=3.23, P_{\text {trend }}=0.03$ ). Among women, the relative risks of tumors with $B R A F$ mutations or $M L H 1$ hypermethylation were also increased in the highest tertiles of folate and vitamin B6 intake respectively, but these did not reach statistical significance.

The positive associations between folate intake and tumors harboring $B R A F$ mutations and between vitamin B6 intake and those showing MLH1 hypermethylation were most pronounced among men, and may suggest that these vitamins enhance $\mathrm{CRC}$ risk through genetic as well as epigenetic aberrations. 


\section{Introduction}

It has been hypothesized that two forms of genetic instability may contribute to the carcinogenesis of sporadic colorectal cancer (CRC). While microsatellite instability (MSI) occurs in approximately $15 \%$ of the sporadic CRCs, chromosomal instability (CIN) would account for the remaining $85 \%$ (1). Sporadic tumors with MSI present a distinct molecular phenotype and may develop predominantly as a consequence of hypermethylation of the mismatch repair gene Mut-L Homologue 1 (MLH1) (2-4). Furthermore, mutations in the BRAF oncogene are strongly associated with $M L H 1$ promoter methylation and MSI (5), and are an additional type of molecular alteration characterizing this phenotype.

Dietary factors that serve as methyl group donors, such as folate and methionine, potentially have an effect at the level of DNA methylation. A low folate status may decrease genomic DNA methylation, which in turn presumably contributes to the process of carcinogenesis (6). A specific form of aberrant methylation that is frequently observed in carcinogenesis involves CpG island promoter hypermethylation of for example DNA repair genes (7). It may be hypothesized that deficient status or low intake of methyl donors could also lead to increased frequencies of this type of aberrant DNA methylation. In this respect, in a pilot study ( $n=122$ patients), we previously observed a weak association between relatively low folate intake in combination with high alcohol consumption, and increased promoter hypermethylation of at least one out of six of the studied colorectal cancer genes (8). Conversely, it was recently suggested that folate supplementation of $4.6 \mathrm{mg} / \mathrm{day}$ in combination with vitamin B12 during 6 months may be associated with increased levels of promoter hypermethylation in colorectal mucosa, although this association was borderline significant (9). These results seem contradictive and it is obviously important to further study the potential effect of relatively high methyl donor intake on the occurrence of promoter hypermethylation.

Other dietary factors, such as vitamins B2 and B6, are also involved in the folatemediated one-carbon metabolism (Figure 1). These vitamins may therefore modulate the bioavailability of methyl groups and thereby DNA methylation as well (10). Flavin adenine dinucleotide (FAD), a metabolite of vitamin B2, is the cofactor for methylenetetrahydrofolate reductase (MTHFR), the enzyme that converts 5,10-methylenetetrahydrofolate into 5-methyl-tetrahydrofolate and thereby enhances DNA methylation. Low vitamin B2 status was previously observed to be associated with increased tHcy concentration, which possibly results in lower availability of methyl groups needed for DNA methylation (11). Interestingly, it was suggested that patients with the MTHFR C677T and A1298C polymorphisms, that are associated with lower activity of this enzyme, tended to have a higher level of $M L H 1$ promoter methylation in colon carcinomas (12). Subjects with the homozygous MTHFR 677TT variant also had lower serum folate levels (13), and may be at increased risk of developing tumors harboring MSI $(13,14)$. Vitamin B6 is involved in the conversion of tetrahydrofolate into 5,10 -methylenetetrahydrofolate, which is one of the steps of the folate cycle and therefore essential for the subsequent supply of methyl groups.

Conversely, high alcohol intake reduces the bioavailability of folate and such a disruption of the one-carbon metabolism may affect DNA methylation in for example 
the colonic mucosa $(15,16)$. Long term alcohol consumption may also result in an increased risk of tumors harboring MSI $(17,18)$.

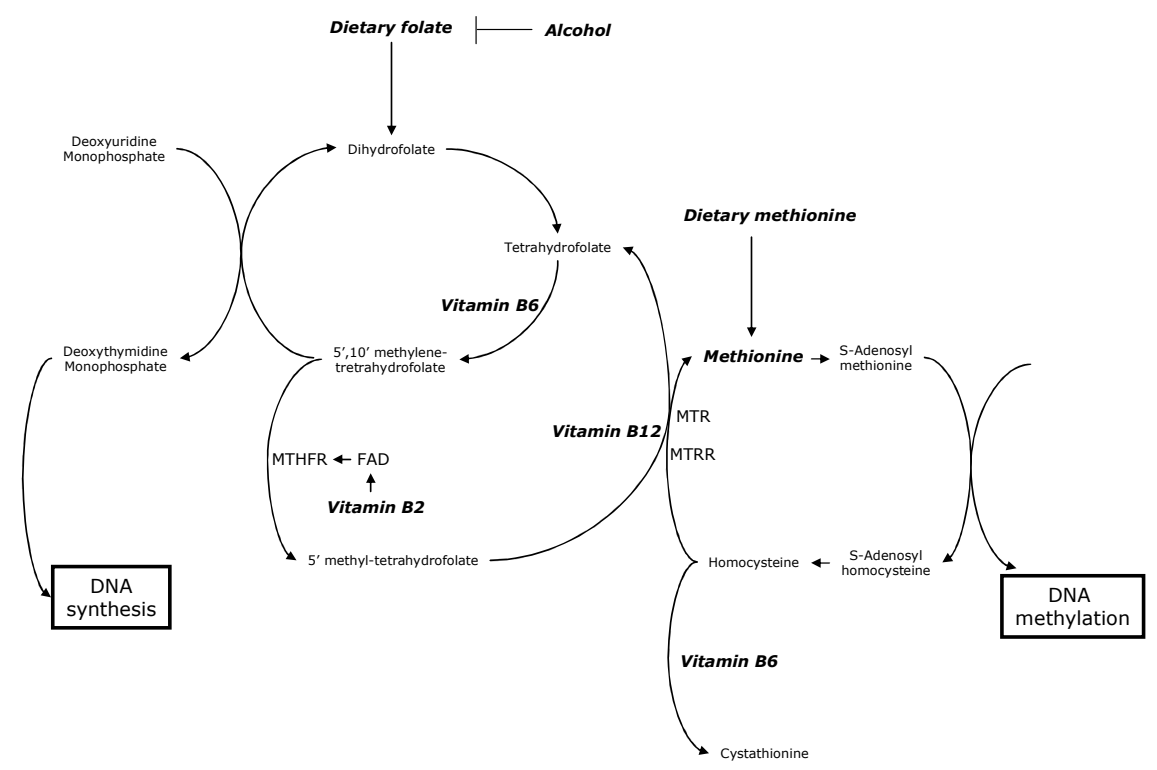

Figure 1 The role of folate, methionine, vitamins B2 and B6, and alcohol in the synthesis and methylation of DNA.

Dietary factors are displayed in Italics. Methyl donors are folate and methionine; factors that may modulate the bioavailability of methyl groups are vitamin B2, vitamin B6 and alcohol. FAD: flavine adenine dinucleotide, MTHFR: methylene tetrahydrofolate reductase, MTR: methionine synthase; MTRR: methionine synthase reductase.

Since folate plays an important role in both DNA synthesis and -methylation, one would expect that adequate folate status or sufficient folate intake can also reduce the risk of tumors harboring gene mutations. Opposite to this however, we have previously observed that men in the third tertile of folate intake may be at increased risk of CRCs with truncating $A P C$ mutations (19). The relation between diet and $B R A F$ mutations has been studied, but no associations were observed with folate, vitamins B6 and B12, and methionine (20).

Here, we investigate associations between dietary folate, vitamin B2, vitamin B6, methionine and alcohol in relation to MLH1 promoter methylation and the associated molecular characteristics of absence of MLH1 protein expression, MSI and BRAF mutations in CRCs. This allows us to establish which of these endpoints associated with the MSI phenotype is most sensitive to dietary exposure, and whether the effect of methyl donor intake through folate and methionine may be modulated by vitamins $\mathrm{B} 2$ and B6, or alcohol. We also describe the occurrence and overlap between MLH1 promoter methylation, MLH1 protein expression, MSI and BRAF mutations. This study is carried out within the Netherlands Cohort Study on diet and cancer (NLCS), among a large group of unselected CRC patients. 


\section{Subjects and methods}

\section{Study population}

The participants in this study are incident colon and rectal cancer patients and subcohort members from the Netherlands Cohort Study (NLCS), which has been described in detail elsewhere (21). Briefly, the study was initiated in 1986 and includes 58,279 men and 62,573 women aged 55-69 years at baseline, who originated from 204 Dutch municipalities with computerized population registers. At baseline, participants completed a self-administered food-frequency questionnaire that also provided information about age, sex and other risk factors for cancer. The entire cohort is being monitored for cancer occurrence by annual record linkage to the Netherlands Cancer Registry (NCR, nine cancer registries in The Netherlands) and to PALGA (Pathologisch Anatomisch Landelijk Geautomatiseerd Archief), a nationwide network and registry of histopathology and cytopathology reports (22). Accumulation of persontime in the cohort has been estimated through biennial vital status follow-up of a subcohort of 5,000 men and women who were randomly selected after baseline exposure measurement. Cases with prevalent cancer other than non-melanoma skin cancer were excluded from this subcohort, which left 4,774 men and women eligible for analysis.

In 1986, the PALGA registry was not yet implemented in some of the municipalities included in the study, but reached full coverage by the end of 1988 . Incomplete coverage may introduce selection bias, and in addition, possible preclinical disease may have affected exposure status. For these reasons we excluded the first 2.3 years of follow-up from the analyses. A total of 101 subcohort members were either deceased or diagnosed with cancer other than non-melanoma skin cancer within this period, leaving 4,673 men and women for analysis. From 1989 to 1994, 925 incident cases were identified with histologically confirmed CRC of whom 815 could also be linked to a PALGA report of the lesion. The PALGA database was used to identify and locate tumor tissue in Dutch pathology laboratories. CRC was classified according to disease site as follows: colon, i.e. proximal colon (ICD-O-1 codes 153.0, 153.1, 153.4, 153.5, 153.6) and distal colon $(153.2,153.3,153.7)$, rectosigmoid (154.0), rectum (154.1), or ICDO-1 codes 153.8 and 153.9 if information of the disease site was not available.

\section{Tissue samples}

Tumor material of the colorectal cancer patients was collected after approval by the ethical review boards of Maastricht University, the NCR and PALGA (23). In addition, all pathology laboratories in the Netherlands agreed to make relevant tissue samples available from PALGA upon request. Of the 815 tissue samples that were scattered over 54 pathology laboratories in the Netherlands, 734 samples (90\%) could be traced and were retrieved between August 1999 and December 2001 (23).

\section{MLH1 promoter methylation}

DNA methylation in the CPG islands of the MLH1 gene was determined by chemical modification of genomic DNA with sodium bisulfite and subsequent Methylation Specific PCR (MSP, described in detail elsewhere (24)). In brief, 500 ng of DNA was denatured 
by $\mathrm{NaOH}$ and modified by sodium bisulfite. DNA samples were then purified using Wizard DNA purification resin (Promega), again treated with $\mathrm{NaOH}$, precipitated with ethanol and resuspended in $\mathrm{H}_{2} \mathrm{O}$.

To facilitate MSP analysis on DNA retrieved from formalin-fixed, paraffin-embedded tissue, DNA was first amplified with flanking PCR primers (described in ref (8)) that amplify bisulfite modified DNA but do not preferentially amplify methylated or unmethylated DNA. The resulting fragment was used as a template for the MSPreaction $(8,25)$.

All PCRs were performed with controls for unmethylated alleles (DNA from normal lymphocytes), methylated alleles (normal lymphocyte DNA treated in vitro with SssI methyltransferase (New England Biolabs)) and a control without DNA. Ten $\mu$ of each MSP reaction was directly loaded onto nondenaturing $6 \%$ polyacrylamide gels, stained with ethidium bromide and visualized under UV illumination. MSP analyses of MLH1 were successfully performed for 686 (93\%) out of 734 patients. Reproducibility was high, with duplo anlyses performed on a random subset of 72 samples yielding the same result in $89 \%$ of the cases.

\section{MLH1 protein expression status}

Immunohistochemical analyses were performed and scored on $4 \mu \mathrm{m}$ sections of formalin-fixed, paraffin-embedded cancer tissue and adjacent normal tissue using a monoclonal antibody against MLH1, as previously described (17). Staining was evaluated with normal cells as internal control. Two investigators reviewed the immunohistochemical staining profiles independently and discrepancies were reexamined and discussed with a pathologist until consensus was reached. MLH1 protein expression status was determined successfully in 721 (98\%) of the 734 patients.

\section{Microsatellite instability}

Microsatellite instability (MSI) was determined by a pentaplex PCR, using the MSI markers BAT-26, BAT-25, NR-21, NR-22 and NR-24, as described in detail by Suraweera et al (26). MSI analyses were successful on 662 (90\%) out of the 734 available samples. The reproducibility was $100 \%$, since all of the 53 duplo analyses had identical results.

\section{BRAF mutations}

The common V600E BRAF mutation in exon 15 was analyzed by a semi-nested PCR and subsequent RFLP analyses as previously described (27). BRAF mutation status could be analyzed successfully in 697 (95\%) out of 734 tissue samples. The analyses could be reproduced in a satisfactory $88 \%$ of the additional duplo analyses on 33 randomly drawn samples.

\section{Food frequency questionnaire}

The self-administered questionnaire was a 150 -item semi-quantitative food frequency questionnaire (FFQ), which concentrated on habitual consumption of food and beverages during the year preceding the start of the study, and also contained questions about body weight and -length, smoking status, physical activity, and family history of colorectal cancer. Daily mean nutrient intakes were calculated as the 
cumulated product of the frequencies and portion sizes of all food items and their tabulated nutrient contents from the Dutch Food Composition Table (NEVO table, 1986 (28)). The validity and reproducibility of the FFQ were determined $(29,30)$. Questionnaire data were key-entered twice for all incident cases in the cohort and for all subcohort members in a blinded manner with respect to case/subcohort status. This was done in order to minimize observer bias in coding and interpretation of the data.

Folate data were derived from a validated liquid chromatography trienzyme method (31) used to analyze the 125 most important Dutch foods contributing to folate intake (32). Mean daily intakes of all other relevant nutrients were calculated using the computerized Dutch Food Composition Table (28). Dietary supplement data were also obtained via the food frequency questionnaire. However, the use of B-vitamin supplements was low (7\%) and folic acid was generally not included in these supplements in the Netherlands in the late 1980s. Therefore, folic acid supplement use most likely plays a very minor role in our study population, and supplement use was not further accounted for in the analyses.

\section{Statistical analyses}

The occurrence and relative overlap of $M L H 1$ hypermethylation with any of the three other characteristics - absence of MLH1 protein expression, MSI, and BRAF mutations were calculated and tested with Chi-square tests. Dietary factors and other baseline characteristics were summarized for men and women separately, for subcohort members and colorectal cancer cases by calculating means and standard deviations for continuous variables and distributions of the categorical variables. Differences in dietary folate, vitamins B2 and B6, methionine and alcohol intake were tested between CRC cases and the non-cases in the subcohort using Student t-tests or Chi-square tests where appropriate. This comparison was also made for the four other molecular characteristics.

Cox proportional hazards regression models were used to estimate multivariateadjusted incidence rate ratios (RR) and corresponding $95 \%$ confidence intervals (CI) over tertiles of folate intake, vitamin B2, vitamin B6 and methionine, and over categories of alcohol intake, using the lowest intake categories as reference. Standard errors (SE) of the RRs were estimated using the robust Huber-White sandwich estimator to account for additional variance introduced by sampling from the cohort (33). The proportional hazards assumption was tested using the scaled Schoenfeld residuals (34). Tests for dose response trends over the different categories of intake were estimated by fitting the ordinal exposure variables as continuous variables and evaluated using the Wald test. For each endpoint, a model was used that included all of these 5 dietary variables. Folate, vitamins B2 and B6, and methionine were adjusted for total energy intake by calculating nutrient residuals from the regression of nutrient intake on total energy intake, as described by Willet et al (35). These nutrient residuals are uncorrelated with total energy intake, and the effect of the variation in nutrient intake can subsequently be estimated independently of a potential effect of energy intake. The RRs were calculated for all colorectal tumors, for tumors with MLH1 hypermethylation, absence of MLH1 protein expression, MSI, or BRAF mutations. Because tumors presenting MSI usually occur more frequently among women, and may have a different etiology than in men, we have chosen to present gender-specific results. In addition to these analyses, we also performed overall analyses for men and 
women combined in order to create larger subgroups and thereby to reduce the probability of reporting chance findings.

Tests for heterogeneity were performed to evaluate differences between subtypes of tumors (e.g. MLH1 methylated versus unmethylated), using the competing risks procedure in Stata. However, the SE for the difference of the logHRs from this procedure assumes independence of both estimated HRs, which would underestimate that SE and thus overestimate the $p$-values for their difference. Therefore, these $p$ values and the associated confidence intervals were estimated based on a bootstrapping method that was developed for the case-cohort design (36). For each bootstrap sample, $X$ subcohort members were randomly drawn from the subcohort of $X$ subjects and $Y$ cases from the total of $Y$ cases outside the subcohort, both with replacement, out of the dataset of $X+Y$ observations. The logHRs were obtained from this sample using Stata's competing risks procedure and recalculated for each bootstrap-replication. The confidence interval and $p$-value of the differences in hazard ratio of the subtypes were then calculated from the replicated statistics. Each bootstrap analysis was based on 1,000 replications.

The covariates included in the multivariate analyses were those found to influence the RR by more than 10 percent, or those observed to be associated with CRC in previous studies. This applied for the variables age, family history of CRC, smoking, Body Mass Index (BMI), and dietary intakes of energy, meat, fat, fiber, vitamin C, iron and calcium. After excluding subjects with missing information on these covariates or subjects who only partly filled out the questionnaire, 4,059 subcohort members remained for statistical analyses as well as 648 CRC cases, irrespective of the available molecular analyses.

We determined possible interactions between dietary intakes of methyl donors (folate and methionine) and the potentially "modulating" factors vitamin B2, vitamin B6 and alcohol, for each of the individual endpoints. This was done by first testing, in separate models, the gender-specific interaction terms between folate and methionine, with vitamin B2, vitamin B6 and alcohol, i.e. folate*methionine, folate*B2, folate*B6, folate*alcohol, methionine*B2, methionine*B6 and methionine*alcohol. The Cox proportional hazard analyses without the interaction terms were subsequently stratified by low or high intake of folate, vitamins B2 and B6, and methionine using the median intakes as cut-off values to define both strata within each variable. The strata used for alcohol intake were 1: abstainers, 2: subjects with intake $<30 \mathrm{~g} / \mathrm{day}$, and 3 : subjects who consumed $\geq 30 \mathrm{~g} /$ day.

All statistical analyses were performed with the Stata statistical software package (version 9.1).

\section{Results}

Among the CRC patients in our study, we first assessed the occurrence of $M L H 1$ hypermethylation, MLH1 protein expression, MSI, and BRAF mutations. The analyses of these four characteristics were complete of 648 patients. The frequencies and percentages, as well as the overlap between these molecular phenotypes are shown in Table 1 and Figure 2. 
Table 1 Frequencies of molecular phenotypes and overlap of $M L H 1$ promoter methylation with MLH1 expression, MSI and BRAF mutations

\begin{tabular}{|c|c|c|c|c|c|c|c|c|}
\hline & \multirow{2}{*}{\multicolumn{3}{|c|}{ Frequency of molecular phenotype }} & \multicolumn{4}{|c|}{ MLH1 promoter methylation } & \multirow[b]{3}{*}{$P$-value } \\
\hline & & & & \multicolumn{2}{|c|}{ Methylated } & \multicolumn{2}{|c|}{ Unmethylated } & \\
\hline & & $\mathbf{N}$ & $(\%)$ & $\mathbf{N}^{*}$ & $(\%)$ & $\mathbf{N}^{*}$ & $(\%)$ & \\
\hline \multirow[t]{2}{*}{ MLH1 methylation } & Methylated & 152 & $(22.1 \%)$ & - & - & - & - & \\
\hline & Unmethylated & 534 & $(77.9 \%)$ & - & - & - & - & - \\
\hline \multirow[t]{2}{*}{ MLH1 expression } & No & 61 & $(8.5 \%)$ & 41 & $(74.6 \%)$ & 14 & $(25.4 \%)$ & \\
\hline & Yes & 660 & $(91.5 \%)$ & 97 & $(17.3 \%)$ & 463 & $(82.7 \%)$ & $<0.001$ \\
\hline \multirow[t]{2}{*}{ MSI } & Present & 84 & $(12.7 \%)$ & 50 & $(65.8 \%)$ & 26 & $(34.2 \%)$ & \\
\hline & Absent & 578 & $(87.3 \%)$ & 88 & $(16.3 \%)$ & 452 & $(83.7 \%)$ & $<0.001$ \\
\hline \multirow[t]{2}{*}{ BRAF } & Mutation & 112 & $(16.1 \%)$ & 48 & $(47.5 \%)$ & 53 & $(52.5 \%)$ & \\
\hline & Wild Type & 585 & $(83.9 \%)$ & 90 & $(17.5 \%)$ & 425 & $(82.5 \%)$ & $<0.001$ \\
\hline
\end{tabular}

* Numbers and percentages are based on tumors with complete analyses of all four molecular characteristics

(tumors of 648 cases in total)

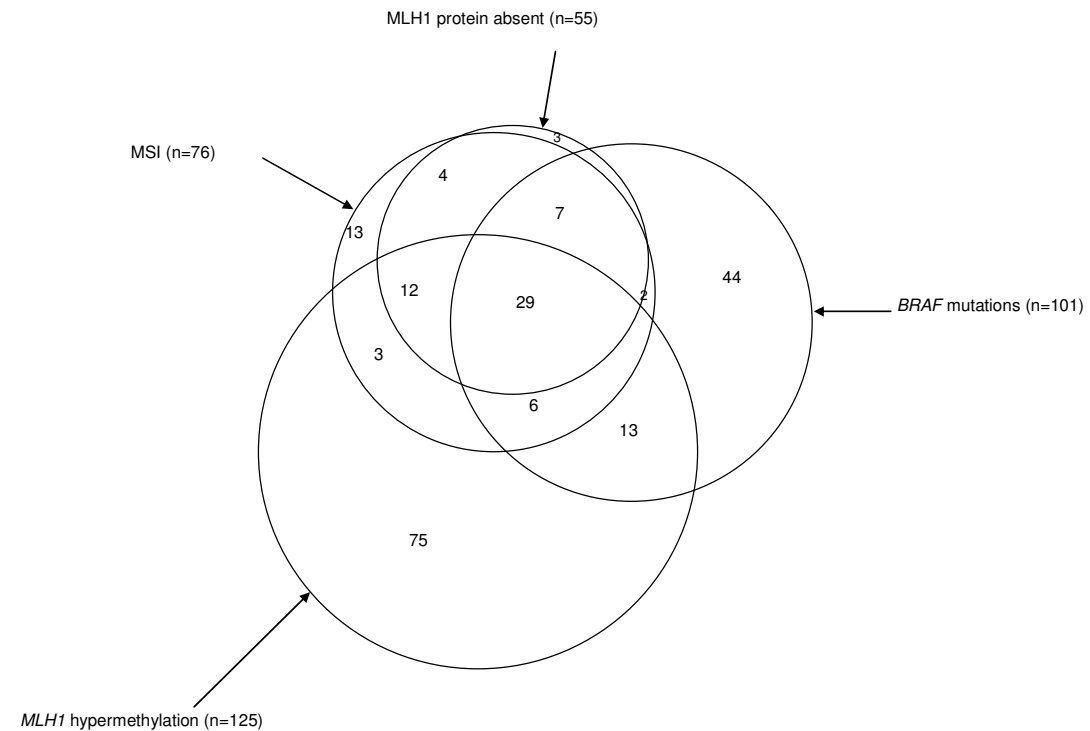

Figure 2 Overlap between MLH1 hypermethylation, absence of MLH1 protein expression, MSI and BRAF mutations in tumors showing at least one of these four aberrations.

In total, there were $\mathrm{n}=238$ tumors harboring at least one aberration. Numbers are based on tumors with complete analyses of all four molecular characteristics (tumors of $n=648$ cases in total). The sizes of the different areas in this figure do not exactly reflect the numbers of the applicable subsets.

In $152(22.1 \%)$ of the patients with successful MLH1 MSP analyses promoter methylation of this gene was found. The percentages of tumors that lacked the MLH1 protein, those with MSI as determined by the MSI pentaplex assay, or those harboring BRAF mutations were $8.5 \%, 12.7 \%$ and $16.1 \%$ respectively. Although the associations between $M L H 1$ hypermethylation and the three other aberrations individually were 
highly significant (all Chi-square tests had $P$-values $<0.001$ ), the overlap between the four molecular phenotypes, which was based on patients with all molecular analyses available, was not complete. The highest relative overlap was observed with MLH1 protein expression since out of the 55 tumors lacking the MLH1 protein, 41 (74.6\%) also showed MLH1 hypermethylation. The overlap between MSI and MLH1 hypermethylation was lower, with $50(65.8 \%)$ out of 76 tumors harboring MSI also having MLH1 hypermethylation. The lowest percentage of overlap was observed between BRAF mutations and MLH1 hypermethylation, as $48(47.5 \%)$ out of 101 BRAFmutated tumors had a hypermethylated $M L H 1$ gene.

We then explored dietary intakes and other baseline characteristics of subcohort members and cancer cases with MLH1 promoter methylation, absence of MLH1 protein expression, MSI, or BRAF mutations among men and women (Table 2). The percentage of male patients with a family history of colorectal cancer was substantially lower among men with a hypermethylated MLH1 gene, as compared to all CRC tumors combined in men. It was also clear that tumors with $M L H 1$ hypermethylation, without MLH1 protein expression, with MSI or BRAF mutations all occurred more often in the proximal colon if compared to the total group of tumors in both men and women. The intakes of folate, vitamin B2, vitamin B6, methionine and alcohol were similar among cases in the different subgroups compared to subcohort members.

We subsequently estimated the associations between intakes of folate, vitamins B2 and B6, methionine and alcohol on the one hand, with colorectal carcinoma risk with or without MLH1 hypermethylation, absence of MLH1 protein expression, MSI or BRAF mutations on the other. Among men, folate intake was not associated with overall colorectal cancer, with tumors showing MLH1 hypermethylation, lacking MLH1 protein expression or with MSI. However, it was positively associated with colorectal tumors harboring $B R A F$ mutations in men $\left(\mathrm{RR}=3.04, \mathrm{CI}=1.13-8.20, P_{\text {trend }}=0.03\right.$ for the highest versus the lowest tertile of intake, Table 3 ). Conversely, there was an inverse association between methionine intake and risk of $B R A F$ mutated tumors (highest vs. lowest tertile: $\mathrm{RR}=0.28, \mathrm{CI}=0.09-0.86, P_{\text {trend }}=0.02$ ). Both vitamin $\mathrm{B} 2$ and alcohol were not associated with any of the endpoints studied in men. However, dietary intake of vitamin B6 was positively associated with overall colorectal cancer in men $(R R=1.54$, $\mathrm{CI}=1.01-2.36, P_{\text {trend }}=0.06$ for the highest versus the lowest tertile of intake). The association between vitamin B6 and tumors with $M L H 1$ hypermethylation in men was even stronger $\left(\mathrm{RR}=3.23, \mathrm{CI}=1.15-9.06, P_{\text {trend }}=0.03\right)$.

Among women, dietary intakes of folate, vitamin B2, vitamin B6, methionine and alcohol were not associated with overall colorectal cancer or any of the endpoints studied (Table 4). Although the RRs of tumors with BRAF mutations and those with MLH1 hypermethylation were also increased in the highest tertiles of folate and vitamin B6 intake respectively, these associations were not statistically significant among women. 
Methyl donor intake and MLH1 hypermethylation in colorectal cancer

Table 2 Baseline dietary intake (mean \pm SD) and other characteristics of cancer cases and subcohort members from the Netherlands Cohort Study on diet and cancer

\begin{tabular}{|c|c|c|c|c|c|c|c|c|c|c|c|c|}
\hline & \multicolumn{6}{|c|}{ MEN } & \multicolumn{6}{|c|}{ WOMEN } \\
\hline & Sub-cohort & All tumors & $\begin{array}{l}\text { MLH1 } \\
\text { Methylation }\end{array}$ & $\begin{array}{l}\text { No MLH1 } \\
\text { protein }\end{array}$ & MSI & $\begin{array}{l}\text { BRAF } \\
\text { Mutation }\end{array}$ & Subcohort & All tumors & $\begin{array}{l}\text { MLH1 } \\
\text { Methylation }\end{array}$ & $\begin{array}{l}\text { No MLH1 } \\
\text { protein }\end{array}$ & MSI & $\begin{array}{l}\text { BRAF } \\
\text { Mutation }\end{array}$ \\
\hline \multicolumn{13}{|l|}{ Patient characteristics } \\
\hline $\mathrm{N}^{*}$ & 2017 & 367 & 65 & 24 & 38 & 49 & 2042 & 281 & 73 & & & \\
\hline Age(y) & $61.3 \pm 4.2$ & $62.7 \pm 4.1$ & $62.5 \pm 4.1$ & $63.4 \pm 4.4$ & $62.9 \pm 4.6$ & $62.1 \pm 4.2$ & $61.3 \pm 4.3$ & $62.9 \pm 3.9$ & $62.5 \pm 4.4$ & $62.7 \pm 4.6$ & $63.6 \pm 4.3$ & $62.9 \pm 4.0$ \\
\hline $\begin{array}{l}\text { Family History of CRC } \\
(\% \text { yes) }\end{array}$ & 5.5 & 12.0 & 4.6 & 9.4 & 7.9 & 8.2 & 5.9 & 10.0 & 9.6 & 9.4 & 7.9 & 11.5 \\
\hline \multicolumn{13}{|l|}{$\begin{array}{l}\text { Tumor } \\
\text { sublocalisation (\%) }\end{array}$} \\
\hline Proximal & - & 29.0 & 52.4 & 83.3 & 73.7 & 62.5 & - & 39.9 & 57.8 & 84.4 & 89.2 & 68.6 \\
\hline Distal & - & 33.2 & 22.2 & 8.3 & 18.4 & 14.6 & - & 30.2 & 25.4 & 15.6 & 10.8 & 19.6 \\
\hline Rectosigmoid & - & 10.5 & 9.5 & 8.3 & 7.9 & 2.1 & - & 11.5 & 7.0 & 0 & 0 & 2.0 \\
\hline Rectum & - & 27.3 & 15.9 & 0 & 0 & 20.8 & - & 18.4 & 9.8 & 0 & 0 & \\
\hline Smoking Status (\%) & $25.0 \pm 2.6$ & $25.4 \pm 2.7$ & $25.6 \pm 2.5$ & $25.7 \pm 2.5$ & $25.3 \pm 2.3$ & $25.2 \pm 2.4$ & $25.0 \pm 3.6$ & $25.6 \pm 3.6$ & $25.2 \pm 3.4$ & $25.5 \pm 4.0$ & $25.9 \pm 4.2$ & $25.6 \pm 3.5$ \\
\hline Never & 12.9 & 9.8 & 7.7 & 4.2 & 7.9 & 14.3 & 57.6 & 61.6 & 61.6 & 53.1 & 55.3 & 55.8 \\
\hline Ex Smoker & 51.7 & 63.2 & 61.5 & 50.0 & 60.5 & 53.1 & 20.8 & 22.4 & 21.9 & 25.0 & 18.4 & 32.7 \\
\hline Current Smoker & 35.4 & 27.0 & 30.8 & 45.8 & 31.6 & 32.6 & 21.6 & 16.0 & 16.4 & 21.9 & 26.3 & 11.5 \\
\hline \multicolumn{13}{|l|}{ Dietary factors } \\
\hline Energy (kjoules/day) & $9091 \pm 21.37$ & $8909 \pm 1866$ & $8911 \pm 1715$ & $8674 \pm 1412$ & $9211 \pm 1863$ & $8969 \pm 1410$ & $7062 \pm 1655$ & $6997 \pm 1695$ & $6774 \pm 1741$ & $6685 \pm 1381$ & $6851 \pm 1516$ & $6675 \pm 1373$ \\
\hline Folate ( $\mu g /$ day) & $225.0 \pm 75.3$ & $225.5 \pm 75.4$ & $225.0 \pm 73.9$ & $209.5 \pm 50.3$ & $228.4 \pm 89.1$ & $233.5 \pm 81.3$ & $198.8 \pm 67.6$ & $197.6 \pm 70.5$ & $187.1 \pm 64.5$ & $198.4 \pm 101.9$ & $191.8 \pm 97.3$ & $190.8 \pm 81.9$ \\
\hline Vitamin B2 (mg/day) & $1.58 \pm 0.37$ & $1.57 \pm 0.35$ & $1.62 \pm 0.38$ & $1.70 \pm 0.38$ & $1.65 \pm 0.39$ & $1.59 \pm 0.36$ & $1.45 \pm 0.35$ & $1.44 \pm 0.34$ & $1.37 \pm 0.31$ & $1.42 \pm 0.35$ & $1.38 \pm 0.33$ & $1.39 \pm 0.31$ \\
\hline Vitamin B6 (mg/day) & $1.54 \pm 0.27$ & $1.56 \pm 0.27$ & $1.58 \pm 0.28$ & $1.56 \pm 0.22$ & $1.52 \pm 0.26$ & $1.56 \pm 0.25$ & $1.33 \pm 0.24$ & $1.34 \pm 0.23$ & $1.31 \pm 0.22$ & $1.33 \pm 0.31$ & $1.32 \pm 0.31$ & $1.33 \pm 0.27$ \\
\hline Methionine (mg/day) & $1713 \pm 293$ & $1701 \pm 284$ & $1693 \pm 274$ & $1729 \pm 252$ & $1676 \pm 266.2$ & $1699 \pm 2.68$ & $1491 \pm 276$ & $1492 \pm 271$ & $1436 \pm 254$ & $1451 \pm 263$ & $1452 \pm 261$ & $1487 \pm 243$ \\
\hline \multicolumn{13}{|l|}{ Alcohol (\%) } \\
\hline 0 g/day & 14.3 & 13.4 & 12.3 & 25 & 15.8 & 10.2 & 32.3 & 36.7 & 31.5 & 34.4 & 34.2 & 36.5 \\
\hline$<30$ g/day & 71 & 69.2 & 72.3 & 66.7 & 73.7 & 75.5 & 64.3 & 58.7 & 61.6 & 56.2 & 57.9 & 55.8 \\
\hline$\geq 30$ g/day & 14.6 & 17.4 & 15.4 & 8.3 & 10.5 & 14.3 & 3.4 & 4.6 & 6.9 & 9.4 & 7.9 & 7.7 \\
\hline Meat (g/day) & $137.3 \pm 52.2$ & $132.2 \pm 47.3$ & $132.1 \pm 45.6$ & $128.5 \pm 41.6$ & $125.0 \pm 42.5$ & $135.1 \pm 44.4$ & $116.1 \pm 46.0$ & $118.2 \pm 42.8$ & $113.0 \pm 43.3$ & $116 \pm 42.5$ & $117.3 \pm 40.5$ & $116.6 \pm 48.1$ \\
\hline Fat (g/day) & $94.0 \pm 14.2$ & $93.5 \pm 12.8$ & $96.8 \pm 12.0$ & $99.0 \pm 12.0$ & $95.0 \pm 11.7$ & $95.3 \pm 10.3$ & $74.0 \pm 10.3$ & $74.9 \pm 10.5$ & $74.8 \pm 10.6$ & $73.2 \pm 11.9$ & $74.8 \pm 12.5$ & $74.1 \pm 11.6$ \\
\hline Fiber (g/day) & $28.7 \pm 7.3$ & $29.6 \pm 6.7$ & $29.4 \pm 7.0$ & $28.6 \pm 5.9$ & $28.8 \pm 8.0$ & $29.2 \pm 7.3$ & $25.3 \pm 5.8$ & $24.8 \pm 5.6$ & $25.4 \pm 6.5$ & $24.9 \pm 6.8$ & $24.7 \pm 7.2$ & $24.6 \pm 5.8$ \\
\hline Vitamin C (mg/day) & $98.8 \pm 41.6$ & $106.8 \pm 44.9$ & $102.6 \pm 45.9$ & $95.2 \pm 30.2$ & $95.8 \pm 42.5$ & $105.4 \pm 46.3$ & $108.4 \pm 42.7$ & $107.0 \pm 43.2$ & $102.6 \pm 45.0$ & $103.7 \pm 47.0$ & $99.0 \pm 42.4$ & $102.0 \pm 44.2$ \\
\hline Iron (mg/day) & $13.2 \pm 2.4$ & $13.7 \pm 2.4$ & $13.6 \pm 2.5$ & $13.4 \pm 1.7$ & $13.4 \pm 2.3$ & $13.7 \pm 2.6$ & $11.7 \pm 2.0$ & $11.6 \pm 2.0$ & $11.6 \pm 1.9$ & $11.6 \pm 1.9$ & $11.5 \pm 2.0$ & $11.7 \pm 1.6$ \\
\hline Calcium (mg/day) & $947 \pm 293$ & $943 \pm 281$ & $964 \pm 279$ & $1048 \pm 364$ & $1006 \pm 344$ & $950 \pm 306$ & $903 \pm 268$ & $899 \pm 256$ & $839 \pm 216$ & $860 \pm 243$ & $863 \pm 245$ & $858 \pm 233$ \\
\hline
\end{tabular}

Numbers of subcohort members and patients are based on complete availability of dietary information and/or complete analyses of MLH1 methylation, MLH1 expression, MSI and BRAF mutations 
Table 3 Associations between dietary factors and MLH1 hypermethylation, absence of the MLH1 protein, MSI and BRAF mutations in colorectal tumors among men

\begin{tabular}{|c|c|c|c|c|c|c|c|c|c|c|c|c|c|c|c|c|}
\hline \multirow[b]{2}{*}{$\begin{array}{l}\text { Tertile (median within } \\
\text { tertile) }\end{array}$} & \multirow[b]{2}{*}{$P Y *$} & \multicolumn{3}{|c|}{ Overall } & \multicolumn{3}{|c|}{ MLH1 hypermethylation } & \multicolumn{3}{|c|}{ No MLH1 protein } & \multicolumn{3}{|c|}{ MSI } & \multicolumn{3}{|c|}{ BRAF mutations } \\
\hline & & $\mathbf{N}^{\dagger}$ & $\mathrm{RR}^{\ddagger}$ & $95 \% \mathrm{Cl} \S$ & $\mathrm{N}$ & RR & $95 \% \mathrm{Cl}$ & $\mathbf{N}$ & RR & $95 \% \mathrm{Cl}$ & $\mathbf{N}$ & RR & $95 \% \mathrm{Cl}$ & $\mathrm{N}$ & RR & $95 \% \mathrm{Cl}$ \\
\hline \multicolumn{17}{|l|}{ Folate $(\mu \mathrm{g} / \mathrm{day})$} \\
\hline $1(163.2)$ & 3207 & 125 & 1.00 & & 24 & 1.00 & & 8 & 1.00 & & 13 & 1.00 & & 10 & 1.00 & \\
\hline $2(211.6)$ & 3248 & 110 & 0.79 & $0.57-1.08$ & 18 & 0.66 & $0.31-1.40$ & 10 & 1.42 & $0.51-3.99$ & 14 & 1.02 & $0.42-2.51$ & 19 & 2.33 & $1.07-5.06$ \\
\hline $3(279.9)$ & 3258 & 132 & 0.97 & $0.65-1.44$ & 23 & 0.88 & $0.36-2.14$ & 6 & 1.00 & $0.20-5.10$ & 11 & 0.78 & $0.23-2.67$ & 20 & 3.04 & $1.13-8.20$ \\
\hline$P$-value for linear trend & & & 0.88 & & & 0.83 & & & 0.95 & & & 0.66 & & & 0.03 & \\
\hline \multicolumn{17}{|l|}{ Vitamin B2 (mg/day) } \\
\hline $1(1.26)$ & 3282 & 126 & 1.00 & & 20 & 1.00 & & 6 & 1.00 & & 11 & 1.00 & & 16 & 1.00 & \\
\hline $2(1.53)$ & 3259 & 128 & 0.95 & $0.70-1.31$ & 24 & 1.19 & $0.56-2.55$ & 8 & 1.15 & $0.35-3.75$ & 11 & 1.04 & $0.42-2.57$ & 16 & 0.80 & $0.36-1.76$ \\
\hline $3(1.90)$ & 3172 & 113 & 0.80 & $0.53-1.21$ & 21 & 0.93 & $0.35-2.46$ & 10 & 1.13 & $0.24-5.31$ & 16 & 1.59 & $0.56-4.53$ & 17 & 0.79 & $0.28-2.24$ \\
\hline$P$-value for linear trend & & & 0.32 & & & 0.92 & & & 0.88 & & & 0.39 & & & 0.67 & \\
\hline \multicolumn{17}{|l|}{ Vitamin B6 (mg/day) } \\
\hline $1(1.29)$ & 3242 & 104 & 1.00 & & 15 & 1.00 & & 7 & 1.00 & & 14 & 1.00 & & 16 & 1.00 & \\
\hline $2(1.53)$ & 3258 & 128 & 1.32 & $0.94-1.85$ & 25 & 2.26 & $1.02-5.04$ & 8 & 1.53 & $0.47-4.99$ & 11 & 1.09 & $0.42-2.81$ & 16 & 0.94 & $0.42-2.09$ \\
\hline $3(1.79)$ & 3212 & 135 & 1.54 & $1.01-2.36$ & 25 & 3.23 & $1.15-9.06$ & 9 & 2.49 & $0.57-10.86$ & 13 & 1.82 & $0.57-5.80$ & 17 & 1.04 & $0.35-3.08$ \\
\hline$P$-value for linear trend & & & 0.06 & & & 0.03 & & & 0.24 & & & 0.31 & & & 0.89 & \\
\hline \multicolumn{17}{|l|}{ Methionine (mg/day) } \\
\hline $1(1445)$ & 3243 & 127 & 1.00 & & 26 & 1.00 & & 8 & 1.00 & & 15 & 1.00 & & 19 & 1.00 & \\
\hline $2(1697)$ & 3290 & 127 & 0.98 & $0.69-1.40$ & 18 & 0.46 & $0.22-0.99$ & 8 & 0.51 & $0.16-1.56$ & 13 & 0.65 & $0.26-1.64$ & 17 & 0.60 & $0.27-1.34$ \\
\hline $3(1986)$ & 3180 & 113 & 0.93 & $0.56-1.52$ & 21 & 0.42 & $0.14-1.25$ & 8 & 0.25 & $0.03-1.90$ & 10 & 0.35 & $0.07-1.83$ & 13 & 0.28 & $0.09-0.86$ \\
\hline$P$-value for linear trend & & & 0.77 & & & 0.12 & & & 0.17 & & & 0.20 & & & 0.02 & \\
\hline \multicolumn{17}{|l|}{ Alcohol } \\
\hline 0 g/day (0) & 1370 & 49 & 1.00 & & 8 & 1.00 & & 6 & 1.00 & & 6 & 1.00 & & 5 & 1.00 & \\
\hline$<30$ g/day (6.7) & 6907 & 254 & 1.05 & $0.74-1.50$ & 47 & 1.14 & $0.54-2.41$ & 16 & 0.60 & $0.19-1.88$ & 28 & 1.02 & $0.39-2.67$ & 37 & 1.52 & $0.57-4.05$ \\
\hline$\geq 30$ g/day $(40.6)$ & 1437 & 64 & 1.25 & $0.78-2.00$ & 10 & 1.61 & $0.61-4.21$ & 2 & 0.54 & $0.09-3.17$ & 4 & 0.74 & $0.19-2.89$ & 7 & 1.40 & $0.39-4.94$ \\
\hline$P$-value for linear trend & & & 0.36 & & & 0.36 & & & 0.42 & & & 0.68 & & & 0.57 & \\
\hline
\end{tabular}

* Number of accumulated Person Years (PY) within categories of dietary intake

Number of cases within categories of dietary intake

F Incidence Rate Ratio (RR) from a Cox regression model including the variables folate, vitamins B2 and B6, methionine and alcohol. Adjusted for age, family history of colorectal cancer, smoking behavior, BMI energy, meat, total fat, fiber, vitamin c, total iron and calcium

\& $95 \%$ Confidence Interval (Cl) 
Methyl donor intake and MLH1 hypermethylation in colorectal cancer

Table 4 Associations between dietary factors and MLH1 hypermethylation, absence of the MLH1 protein, MSI and BRAF mutations in colorectal tumors among women

\begin{tabular}{|c|c|c|c|c|c|c|c|c|c|c|c|c|c|c|c|c|}
\hline \multirow[b]{2}{*}{ Tertile (median within tertile) } & \multirow[b]{2}{*}{$P Y *$} & \multicolumn{3}{|c|}{ Overall } & \multicolumn{3}{|c|}{ MLH1 hypermethylation } & \multicolumn{3}{|c|}{ No MLH1 protein } & \multicolumn{3}{|c|}{ MSI } & \multicolumn{3}{|c|}{ BRAF mutations } \\
\hline & & $\mathbf{N}^{\dagger}$ & $\mathrm{RR}^{\ddagger}$ & $95 \% \mathrm{Cl} \S$ & $\mathrm{N}$ & $\mathrm{RR}$ & $95 \% \mathrm{Cl}$ & $\mathbf{N}$ & RR & $95 \% \mathrm{Cl}$ & $\mathrm{N}$ & RR & $95 \% \mathrm{Cl}$ & $\mathrm{N}$ & RR & $95 \% \mathrm{Cl}$ \\
\hline \multicolumn{17}{|l|}{ Folate ( $\mu$ g/day) } \\
\hline $1(142.4)$ & 3295 & 98 & 1.00 & & 31 & 1.00 & & 12 & 1.00 & & 16 & 1.00 & & 20 & 1.00 & \\
\hline $2(186.6)$ & 3384 & 99 & 1.02 & $0.72-1.47$ & 22 & 0.79 & $0.39-1.58$ & 11 & 1.27 & $0.50-3.19$ & 13 & 0.93 & $0.37-2.34$ & 17 & 1.23 & $0.58-2.61$ \\
\hline $3(247.9)$ & 3359 & 84 & 0.92 & $0.57-1.48$ & 20 & 0.88 & $0.33-2.32$ & 9 & 1.22 & $0.31-4.74$ & 9 & 0.72 & $0.19-2.72$ & 15 & 1.42 & $0.51-3.95$ \\
\hline$P$-value for linear trend & & & 0.76 & & & 0.76 & & & 0.68 & & & 0.67 & & & 0.47 & \\
\hline \multicolumn{17}{|l|}{ Vitamin B2 (mg/day) } \\
\hline $1(1.12)$ & 3324 & 97 & 1.00 & & 32 & 1.00 & & 14 & 1.00 & & 16 & 1.00 & & 22 & 1.00 & \\
\hline $2(1.42)$ & 3358 & 90 & 0.99 & $0.69-1.41$ & 22 & 0.84 & $0.45-1.56$ & 7 & 0.66 & $0.22-1.99$ & 10 & 0.85 & $0.34-2.13$ & 14 & 0.75 & $0.33-1.71$ \\
\hline $3(1.76)$ & 3356 & 94 & 1.08 & $0.68-1.71$ & 19 & 0.94 & $0.39-2.26$ & 11 & 1.18 & $0.31-4.48$ & 12 & 1.26 & $0.37-4.23$ & 16 & 0.93 & $0.30-2.91$ \\
\hline$P$-value for linear trend & & & 0.95 & & & 0.78 & & & 0.94 & & & 0.92 & & & 0.68 & \\
\hline \multicolumn{17}{|l|}{ Vitamin B6 (mg/day) } \\
\hline $1(1.12)$ & 3330 & 90 & 1.00 & & 23 & 1.00 & & 13 & 1.00 & & 15 & 1.00 & & 21 & 1.00 & \\
\hline $2(1.32)$ & 3416 & 92 & 1.16 & $0.80-1.69$ & 26 & 1.39 & $0.70-2.75$ & 7 & 0.57 & $0.17-1.86$ & 10 & 0.78 & $0.28-2.18$ & 12 & 0.56 & $0.23-1.34$ \\
\hline $3(1.54)$ & 3292 & 99 & 1.45 & $0.93-2.28$ & 24 & 1.61 & $0.70-3.71$ & 12 & 0.93 & $0.29-3.01$ & 13 & 1.10 & $0.36-3.39$ & 19 & 0.97 & $0.39-2.46$ \\
\hline$P$-value for linear trend & & & 0.11 & & & 0.27 & & & 0.88 & & & 0.89 & & & 0.96 & \\
\hline \multicolumn{17}{|l|}{ Methionine (mg/day) } \\
\hline $1(1232)$ & 3370 & 96 & 1.00 & & 28 & 1.00 & & 13 & 1.00 & & 15 & 1.00 & & 17 & 1.00 & \\
\hline $2(1476)$ & 3331 & 85 & 0.83 & $0.56-1.22$ & 25 & 1.08 & $0.51-2.30$ & 7 & 0.69 & $0.21-2.30$ & 9 & 0.69 & $0.24-2.00$ & 16 & 1.44 & $0.59-3.49$ \\
\hline $3(1738)$ & 3338 & 100 & 0.89 & $0.53-1.51$ & 20 & 1.13 & $0.39-2.29$ & 12 & 1.19 & $0.34-4.13$ & 14 & 1.15 & $0.33-4.01$ & 19 & 2.06 & $0.67-6.32$ \\
\hline$P$-value for linear trend & & & 0.64 & & & 0.83 & & & 0.89 & & & 0.88 & & & 0.23 & \\
\hline \multicolumn{17}{|l|}{ Alcohol } \\
\hline 0 g/day (0) & 3210 & 103 & 1.00 & & 23 & 1.00 & & 11 & 1.00 & & 13 & 1.00 & & 19 & 1.00 & \\
\hline$<30$ g/day (3.9) & 6478 & 165 & 0.82 & $0.62-1.10$ & 45 & 1.10 & $0.62-1.94$ & 18 & 0.93 & $0.41-2.11$ & 22 & 1.02 & $0.48-2.17$ & 29 & 0.77 & $0.41-1.47$ \\
\hline$\geq 30$ g/day (36.8) & 351 & 13 & 1.58 & $0.78-3.20$ & 5 & 3.81 & 1.27-11.47 & 3 & 3.38 & $0.97-11.87$ & 3 & 3.96 & $1.09-4.40$ & 4 & 2.54 & $0.70-9.19$ \\
\hline$P$-value for linear trend & & & 0.54 & & & 0.29 & & & 0.64 & & & 0.53 & & & 0.99 & \\
\hline \multicolumn{17}{|c|}{ Number of accumulated Person Years (PY) within categories of dietary intake } \\
\hline $\begin{array}{l}\text { Number of cases } \\
\text { Incidence Rate R } \\
\text { cancer, smoking }\end{array}$ & & & & & & & and & & & & & & & & & orectal \\
\hline
\end{tabular}


Increased relative risks could be observed in the highest category of alcohol intake for most of the endpoints, however, trends were not statistically significant and the numbers of cases in the highest category were low for both men and women.

When performing overall analyses for men and women together (data not shown), we observed that, although borderline significant, the highest tertile of folate intake was associated with colorectal tumors harboring $B R A F$ mutations $(R R=1.85, C I=0.92-$ 3.73, $\left.P_{\text {trend }}=0.08\right)$. There clearly were positive associations between vitamin B6 intake and overall $\mathrm{CRC}\left(\mathrm{RR}=1.51, \mathrm{CI}=1.11-2.04, P_{\text {trend }}=0.01\right)$ and risk of tumors with $M L H 1$ promoter methylation $\left(\mathrm{RR}=2.32, \quad \mathrm{CI}=1.21-4.43, \quad P_{\text {trend }}=0.01\right)$. The tests for heterogeneity did not show significant differences between tumors with or without MLH1 hypermethylation, MLH1 protein expression, MSI or BRAF mutations (data not shown).

After testing potential interactions, it appeared that there was no interaction between folate and methionine, vitamin B2 or alcohol in either men or women. However, among men we observed an interaction between folate and vitamin B6 for overall CRC. In this respect, stratified analyses revealed that relatively high vitamin B6 intake was associated with an increased risk of overall CRC among men who had a folate intake in the category above the median $\left(\mathrm{RR}=1.96, \mathrm{CI}=1.06-3.60, P_{\text {trend }}=0.02\right.$ for the highest vs. lowest tertile of B6 intake, data not shown), whereas the RR was not increased among subjects with folate intake below the median of the distribution $\left(P_{\text {interaction }}=0.06\right)$. Similarly, men having tumors with $M L H 1$ hypermethylation also had higher RRs in the $3^{\text {rd }}$ tertile of vitamin B6 intake in the subgroup of high folate intake $\left(\mathrm{RR}=3.36, \mathrm{CI}=0.81-13.93, P_{\text {trend }}=0.08\right.$, data not shown), which was not observed among men with low folate intake. However, the interaction term for this endpoint was not statistically significant. Among women, an interaction between vitamin B6 and folate was not observed, though it was present for men and women combined for overall CRC ( $P_{\text {interaction}=0.07)}$. We observed no interactions between methionine and any of the other dietary variables under study.

\section{Discussion}

In this study we investigated the associations between dietary folate, vitamins B2 and B6, methionine, alcohol and colorectal cancer risk while accounting for $M L H 1$ promoter methylation, MLH1 protein expression, MSI and BRAF mutations. It was observed that the highest tertiles of folate, vitamins B2, B6 and methionine, and low alcohol intake were not associated with decreased colorectal cancer risk, irrespective of the presence of $M L H 1$ hypermethylation, the MLH1 protein or MSI. On the other hand, we observed a positive association between dietary folate and BRAF mutations in men. Moreover, vitamin B6 increased overall CRC risk, and especially MLH1-hypermethylated tumors among men.

We studied four different aberrations that have previously been suggested to be associated with the MSI pathway. Despite the strong and statistically significant correlations between these characteristics, they were not always concurrently present in tumors. Whereas the percentages of overlap between absence of MLH1 protein expression and MLH1 methylation, and between MSI and MLH1 methylation were relatively high $(74.6 \%$ and $65.8 \%$ respectively), less than half of the tumors with $B R A F$ 
mutations (47.5\%) appeared to have MLH1 methylation. In this respect, it is appreciated that individual techniques were used for each endpoint, each having specific sensitivities, which may partly account for the observed incomplete overlap. However, an additional, even more obvious reason may lie in potential differences in tumor biology. For example, within the subset of sporadic CRCs showing MSI, there may be differences in the frequency of $M L H 1$ hypermethylation depending on the localization of the tumor. In this respect, MLH1 hypermethylation was observed less frequently in distal sporadic CRCs with MSI compared to proximal MSI cancers, suggesting that an epigenetic pathway has played a smaller role in the development of distal MSI cancers (37). Next to MLH1 hypermethylation, MLH1 mutations may result in loss of the MLH1 protein as well. Although such mutations are mainly observed in tumors of HNPCC patients with MSI (38), it has been suggested that they may also occur in sporadic colorectal carcinomas, and that MSI may be present concurrently (39). The occurrence of $M L H 1$ hypermethylation, lack of MLH1 protein expression or $B R A F$ mutations may apparently differ among tumors that develop through the MSI pathway. In addition to the observed incomplete overlap in our study, this is an important reason to study these molecular phenotypes separately in relation to methyl donor intake. From our results, it appeared that the endpoint of MSI is least related to the intake of the studied methyl donors, but that there rather may be an effect on methylation and mutations which are associated with MSI. Moreover, the relation between folate intake and MSI in colorectal cancer was previously investigated (18), but no association was observed in that particular study.

Promoter hypermethylation and global hypomethylation are alternative types of aberrant methylation, and it has been suggested that both of these patterns may contribute separately to the process of colorectal carcinogenesis $(40,41)$. Moreover, they may also specifically affect DNA stability, given the observed strong associations between promoter hypermethylation and MSI and between global hypomethylation and CIN in colorectal carcinomas $(42,43)$. However, the relative contribution of methyl donor intake to either hypermethylation or hypomethylation is unknown. Promoter hypermethylation may occur in normal colorectal mucosa of patients with hyperplastic polyposis (44) or colorectal cancer (45), suggesting that dietary methyl donors may play a role in the prevention or initiation of neoplastic formation. Moreover, folic acid supplementation may decrease global hypomethylation in the normal-appearing colonic mucosa of patients with adenomas (46). Furthermore, in a pilot study we previously observed an indication for an inverse association between relatively high folate intake in combination with low alcohol intake and promoter methylation in colorectal tumors (8). However, this association was only weak, and the conclusion in this study was based on an outcome measure defined as hypermethylation of at least one out of six genes. Others observed positive associations between high alcohol consumption and risk of MSI-H tumors $(17,18,20)$, indicating that disruption of the folate metabolism may lead to colorectal cancer, possibly partly through increasing promoter hypermethylation.

Although the above suggests a protective effect of adequate folate status or intake on aberrant methylation, it has been hypothesized that its actual influence may also differ depending on the stage of tumor development in colorectal carcinogenesis. Whereas folate deficiency might increase the risk of neoplastic transformation of normal tissue by inducing genomic hypomethylation, it may have an inhibitory effect 
on progression of neoplasms to cancer. Conversely, folate supplementation may prevent aberrant DNA methylation in normal tissue, but could promote established lesions by increasing promoter hypermethylation (47). Results of a recent study suggest that folic acid and vitamin B12 supplementation in subjects with a history of colorectal adenoma may indeed increase promoter hypermethylation, although this association was statistically borderline significant (9). Moreover, folic acid supplementation was associated with increased risk of advanced lesions or recurrence of multiple adenomas in patients with available follow-up information (48). Interestingly, the participants in that study also had a recent history of colorectal adenomas, and possibly, undetected neoplasms were present in these subjects which may have had a growth advantage in the presence of high concentrations of folic acid. However, one might wonder whether intake of dietary folate has a similar effect as supplementation with folic acid. Nevertheless, our data revealed the strongest increased risk among patients in the highest tertile of vitamin B6 intake of tumors with MLH1 hypermethylation, suggesting that vitamin B6 may have had a tumor-promoting effect by increasing promoter methylation. We also observed that the increased RRs in the highest tertiles of vitamin B6 of overall CRC and tumors harboring MLH1 hypermethylation were present only among men who also had a relatively high folate intake. The latter association suggests that the transfer of methyl donors provided by folate may at least partly depend on the availability of vitamin B6 as a "modulating" factor, and that the combination of relatively high vitamin B6 and folate intake may increase promoter methylation and thereby enhance the development of tumors with a methylation-associated phenotype. Our results therefore contribute to the hypothesis that relatively high methyl donor intake potentially increases aberrant promoter hypermethylation rather than preventing it.

Several other studies showed inverse associations between vitamin B6 intake and CRC risk. However, in these studies, the levels of vitamin B6 intake were generally higher, and the distributions sometimes even lie largely above the median intake of the highest tertile of the Dutch population included in our study (49-52). One could hypothesize that, if vitamin B6 is protective above a certain threshold of intake, this may have been a reason why we did not observe an inverse association. However, vitamin B6 was also associated with decreased CRC risk in a recent study in a Japanese population, in which intake of vitamin B6 was comparable to that in our study (53). There is one study that has previously demonstrated a positive association between vitamin B6 intake and CRC risk, among women who had a much higher vitamin B6 intake than in our study population (54). Apparently, a potential positive association between vitamin B6 and colorectal cancer should be taken into account and obviously needs further attention in future studies.

Another interesting finding in our study is the positive association between dietary folate and BRAF mutations among men, which was not expected considering the importance of folate for nucleotide synthesis. We have previously observed that folate may increase the risk of tumors harboring truncating $A P C$ mutations in men (19). BRAF and $A P C$ mutations are inversely correlated in this study population, which was also the case in a previous study (55), indicating that relatively high folate intake may give a growth advantage to mutated tumors independent of the type of mutation. Moreover, folate was not associated with MLH1 hypermethylation in men, suggesting that it exerts a specific effect on tumors with gene mutations. 
A limitation of our study is that some of the molecular subgroups present relatively small numbers of cases, and the possibility that some of the gender-specific results are partly based on chance can therefore not be excluded. However, overall analyses, with subgroups then containing substantial numbers of cases (at least 30) within tertiles of intake, showed similar positive associations of folate with BRAF mutations and of vitamin B6 with MLH1 hypermethylation. Furthermore, residual confounding may have been present for the associations observed, although methyl donor intake was comparable between molecular subgroups and associations were further adjusted for a number of potential confounders or known risk factors of CRC. We consider it unlikely that changes in dietary intake over time have influenced disease outcome, since the reproducibility of the baseline FFQ over a period of 5 years was relatively high (30) and the follow-up of 7.3 years was only 2.3 years longer in the current study.

In this Dutch population, relatively high intakes of folate, vitamins B2 and B6 and methionine, or low alcohol intake were not associated with a decreased risk of CRC, or with tumors harboring MLH1 hypermethylation, lack of MLH1 protein expression or with MSI. The occurrence of MSI does not seem to be sensitive to methyl donor intake; however, folate increased the risk of $B R A F$ mutations whereas vitamin $B 6$ increased the risk of tumors with $M L H 1$ hypermethylation among men. This may indicate that dietary folate and vitamin B6 have different effects, but may both enhance colorectal carcinogenesis by exerting an effect on genetic or epigenetic alterations. 


\section{References}

1. Rajagopalan H, Lengauer C. CIN-ful cancers. Cancer Chemother Pharmacol 2004;54 Suppl 1:S65-8.

2. Arnold CN, Goel A, Compton C, Marcus V, Niedzwiecki D, Dowell JM, et al. Evaluation of microsatellite instability, hMLH1 expression and $h M L H 1$ promoter hypermethylation in defining the MSI phenotype of colorectal cancer. Cancer Biol Ther 2004;3(1):73-8.

3. Herman JG, Umar A, Polyak K, Graff JR, Ahuja N, Issa JP, et al. Incidence and functional consequences of $h M L H 1$ promoter hypermethylation in colorectal carcinoma. Proc Natl Acad Sci U S A 1998;95(12):6870-5.

4. Kuismanen SA, Holmberg MT, Salovaara R, de la Chapelle A, Peltomaki P. Genetic and epigenetic modification of MLH1 accounts for a major share of microsatellite-unstable colorectal cancers. Am J Pathol 2000;156(5):1773-9.

5. Deng G, Bell I, Crawley S, Gum J, Terdiman JP, Allen BA, et al. BRAF mutation is frequently present in sporadic colorectal cancer with methylated $h M L H 1$, but not in hereditary nonpolyposis colorectal cancer. Clin Cancer Res 2004;10(1 Pt 1):191-5.

6. Kim YI. Folate and DNA methylation: a mechanistic link between folate deficiency and colorectal cancer? Cancer Epidemiol Biomarkers Prev 2004;13(4):511-9.

7. Herman JG, Baylin SB. Gene silencing in cancer in association with promoter hypermethylation. N Engl J Med 2003;349(21):2042-54.

8. van Engeland M, Weijenberg MP, Roemen GM, Brink M, de Bruine AP, Goldbohm RA, et al. Effects of dietary folate and alcohol intake on promoter methylation in sporadic colorectal cancer: the Netherlands cohort study on diet and cancer. Cancer Res 2003;63(12):3133-7.

9. van den Donk M, van Engeland M, Pellis L, Witteman BJ, Kok FJ, Keijer J, et al. Dietary folate intake in combination with MTHFR C677T genotype and promoter methylation of tumor suppressor and DNA repair genes in sporadic colorectal adenomas. Cancer Epidemio Biomarkers Prev 2007;16(2):327-33.

10. Ulrich CM. Nutrigenetics in cancer research--folate metabolism and colorectal cancer. $J$ Nutr $2005 ; 135(11): 2698-702$.

11. Moat SJ, Ashfield-Watt PA, Powers HJ, Newcombe RG, McDowell IF. Effect of riboflavin status on the homocysteine-lowering effect of folate in relation to the MTHFR (C677T) genotype. Clin Chem 2003;49(2):295-302.

12. Oyama K, Kawakami K, Maeda K, Ishiguro K, Watanabe G. The association between methylenetetrahydrofolate reductase polymorphism and promoter methylation in proximal colon cancer. Anticancer Res 2004;24(2B):649-54.

13. Chang SC, Lin PC, Lin JK, Yang SH, Wang HS, Fen-Yau Li A. Role of MTHFR polymorphisms and folate levels in different phenotypes of sporadic colorectal cancers. Int J Colorectal Dis 2007;22(5):483-9.

14. Hubner RA, Lubbe S, Chandler I, Houlston RS. MTHFR C677T has differential influence on risk of MSI and MSS colorectal cancer. Hum Mol Genet 2007.

15. Giovannucci E. Alcohol, one-carbon metabolism, and colorectal cancer: recent insights from molecular studies. J Nutr 2004;134(9):2475S-2481S.

16. Mason JB, Choi SW. Effects of alcohol on folate metabolism: implications for carcinogenesis. Alcohol 2005;35(3):235-41.

17. Diergaarde B, Braam H, van Muijen GN, Ligtenberg MJ, Kok FJ, Kampman E. Dietary factors and microsatellite instability in sporadic colon carcinomas. Cancer Epidemiol Biomarkers Prev 2003;12(11 Pt 1):1130-6.

18. Slattery ML, Anderson K, Curtin K, Ma KN, Schaffer D, Samowitz W. Dietary intake and microsatellite instability in colon tumors. Int J Cancer 2001;93(4):601-7.

19. de Vogel S, van Engeland M, Luchtenborg M, de Bruine AP, Roemen GM, Lentjes MH, et al. Dietary folate and APC mutations in sporadic colorectal cancer. J Nutr 2006;136(12):301521.

20. Slattery ML, Curtin K, Sweeney C, Levin TR, Potter J, Wolff RK, et al. Diet and lifestyle factor associations with $\mathrm{CPG}$ island methylator phenotype and $B R A F$ mutations in colon cancer. Int J Cancer 2007;120(3):656-63. 
21. van den Brandt PA, Goldbohm RA, van 't Veer P, Volovics A, Hermus RJ, Sturmans F. A large-scale prospective cohort study on diet and cancer in The Netherlands. J Clin Epidemiol $1990 ; 43(3): 285-95$.

22. Casparie M, Tiebosch AT, Burger G, Blauwgeers $H$, van de Pol A, van Krieken JH, et al. Pathology databanking and biobanking in The Netherlands, a central role for PALGA, the nationwide histopathology and cytopathology data network and archive. Cell Oncol 2007;29(1):19-24

23. Brink M, de Goeij AF, Weijenberg MP, Roemen GM, Lentjes MH, Pachen MM, et al. K-ras oncogene mutations in sporadic colorectal cancer in The Netherlands Cohort Study. Carcinogenesis 2003;24(4):703-10.

24. Herman JG, Graff JR, Myohanen S, Nelkin BD, Baylin SB. Methylation-specific PCR: a novel PCR assay for methylation status of $\mathrm{CpG}$ islands. Proc Natl Acad Sci $U$ S A 1996;93(18):9821-6.

25. Derks S, Lentjes $M H$, Hellebrekers DM, de Bruine AP, Herman JG, van Engeland $M$. Methylation-specific PCR unraveled. Cell Oncol 2004;26(5-6):291-9.

26. Suraweera N, Duval A, Reperant M, Vaury C, Furlan D, Leroy K, et al. Evaluation of tumor microsatellite instability using five quasimonomorphic mononucleotide repeats and pentaplex PCR. Gastroenterology 2002;123(6):1804-11.

27. Sieben NL, Roemen GM, Oosting J, Fleuren GJ, van Engeland M, Prat J. Clonal analysis favours a monoclonal origin for serous borderline tumors with peritoneal implants. J Pathol 2006;210(4):405-11.

28. Nevo table. Dutch food composition table 1986-1987, The Hague, The Netherlands: Voorlichtingsbureau voor de voeding, 1986. 1986.

29. Goldbohm RA, van den Brandt PA, Brants HA, van't Veer P, Al M, Sturmans F, et al. Validation of a dietary questionnaire used in a large-scale prospective cohort study on diet and cancer. Eur J Clin Nutr 1994;48(4):253-65.

30. Goldbohm RA, van 't Veer P, van den Brandt PA, van 't Hof MA, Brants HA, Sturmans F, et al. Reproducibility of a food frequency questionnaire and stability of dietary habits determined from five annually repeated measurements. Eur J Clin Nutr 1995;49(6):420-9.

31. Konings EJ. A validated liquid chromatographic method for determining folates in vegetables, milk powder, liver, and flour. J AOAC Int 1999;82(1):119-27.

32. Konings EJ, Roomans HH, Dorant E, Goldbohm RA, Saris WH, van den Brandt PA. Folate intake of the Dutch population according to newly established liquid chromatography data for foods. Am J Clin Nutr 2001;73(4):765-76.

33. Lin DY WL. The robust inference for the Cox Proportional Hazards Model. JASA 1989;84(408):1074-1078.

34. Schoenfeld D. Partial residuals for the proportional hazards regression models. Biometrika $1982 ; 69(1): 239-241$.

35. Willett W, Stampfer MJ. Total energy intake: implications for epidemiologic analyses. Am J Epidemiol 1986;124(1):17-27.

36. Wacholder S, Gail MH, Pee D, Brookmeyer R. Alternative variance and efficiency calculations for the case-cohort design. Biometrika 1989;76(1):117-23.

37. Watanabe T, Kobunai T, Toda E, Yamamoto Y, Kanazawa T, Kazama Y, et al. Distal colorectal cancers with microsatellite instability (MSI) display distinct gene expression profiles that are different from proximal MSI cancers. Cancer Res 2006;66(20):9804-8.

38. Peltomaki P, Vasen H. Mutations associated with HNPCC predisposition -- Update of ICGHNPCC/INSiGHT mutation database. Dis Markers 2004;20(4-5):269-76.

39. Chaksangchaichot $\mathrm{P}$, Punyarit $\mathrm{P}$, Petmitr S. Novel hMSH2, hMSH6 and hMLH1 gene mutations and microsatellite instability in sporadic colorectal cancer. J Cancer Res Clin Oncol 2007;133(1):65-70.

40. Bariol C, Suter C, Cheong K, Ku SL, Meagher A, Hawkins N, et al. The relationship between hypomethylation and $\mathrm{CpG}$ island methylation in colorectal neoplasia. Am $\mathrm{J}$ Pathol 2003;162(4):1361-71.

41. Frigola J, Sole X, Paz MF, Moreno V, Esteller M, Capella G, et al. Differential DNA hypermethylation and hypomethylation signatures in colorectal cancer. Hum Mol Genet 2005;14(2):319-26. 
42. Deng G, Nguyen A, Tanaka H, Matsuzaki K, Bell I, Mehta KR, et al. Regional hypermethylation and global hypomethylation are associated with altered chromatin conformation and histone acetylation in colorectal cancer. Int J Cancer 2006;118(12):29993005.

43. Rodriguez J, Frigola J, Vendrell E, Risques RA, Fraga MF, Morales C, et al. Chromosomal Instability Correlates with Genome-wide DNA Demethylation in Human Primary Colorectal Cancers. Cancer Res 2006;66(17):8462-9468.

44. Minoo P, Baker K, Goswami R, Chong G, Foulkes WD, Ruszkiewicz AR, et al. Extensive DNA methylation in normal colorectal mucosa in hyperplastic polyposis. Gut 2006;55(10):146774.

45. Kawakami K, Ruszkiewicz A, Bennett G, Moore J, Grieu F, Watanabe G, et al. DNA hypermethylation in the normal colonic mucosa of patients with colorectal cancer. $\mathrm{Br} J$ Cancer 2006;94(4):593-8.

46. Pufulete M, Al-Ghnaniem R, Khushal A, Appleby P, Harris N, Gout S, et al. Effect of folic acid supplementation on genomic DNA methylation in patients with colorectal adenoma. Gut 2005;54(5):648-53.

47. Kim YI. Folate and colorectal cancer: An evidence-based critical review. Mol Nutr Food Res 2007;51(3):267-92.

48. Cole BF, Baron JA, Sandler RS, Haile RW, Ahnen DJ, Bresalier RS, et al. Folic acid for the prevention of colorectal adenomas: a randomized clinical trial. Jama 2007;297(21):2351-9.

49. Kune G, Watson L. Colorectal cancer protective effects and the dietary micronutrients folate, methionine, vitamins B6, B12, C, E, selenium, and lycopene. Nutr Cancer 2006;56(1):11-21.

50. Larsson SC, Giovannucci E, Wolk A. Vitamin b6 intake, alcohol consumption, and colorectal cancer: a longitudinal population-based cohort of women. Gastroenterology 2005;128(7):1830-7.

51. Wei EK, Giovannucci E, Selhub J, Fuchs CS, Hankinson SE, Ma J. Plasma vitamin B6 and the risk of colorectal cancer and adenoma in women. J Natl Cancer Inst 2005;97(9):684-92.

52. Zhang SM, Moore SC, Lin J, Cook NR, Manson JE, Lee IM, et al. Folate, vitamin B6, multivitamin supplements, and colorectal cancer risk in women. $\mathrm{Am} J$ Epidemiol 2006;163(2):108-15.

53. Ishihara J, Otani T, Inoue M, Iwasaki M, Sasazuki S, Tsugane S. Low intake of vitamin B-6 is associated with increased risk of colorectal cancer in Japanese men. $J$ Nutr 2007;137(7):1808-14.

54. Harnack L, Jacobs DR, Jr., Nicodemus K, Lazovich D, Anderson K, Folsom AR. Relationship of folate, vitamin B-6, vitamin B-12, and methionine intake to incidence of colorectal cancers. Nutr Cancer 2002;43(2):152-8.

55. Samowitz WS, Slattery ML, Sweeney C, Herrick J, Wolff RK, Albertsen H. APC mutations and other genetic and epigenetic changes in colon cancer. Mol Cancer Res 2007;5(2):16570 


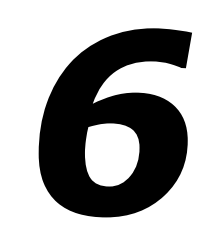

\section{Genetic variants of methyl metabolizing enzymes and epigenetic regulators: associations with promoter CpG island hypermethylation in colorectal cancer}

Stefan de Vogel

Kim AD Wouters Ralph WH Gottschalk

Frederik J van Schooten Anton FPM de Goeij Adriaan $\mathrm{P}$ de Bruïne

R Alexandra Goldbohm Piet $A$ van den Brandt Matty P Weijenberg Manon van Engeland 


\section{Abstract}

Aberrant DNA methylation affects carcinogenesis of colorectal cancer (CRC). Folate metabolizing enzymes may influence the bioavailability of methyl groups whereas DNAand histonemethyltransferases are involved in epigenetic regulation of gene expression.

We studied associations between genetic variants of folate metabolizing enzymes (MTHFR, MTR and MTRR), the DNA methyltransferase DNMT3b, and histone methyltransferases (EHMT1, EHMT2 and PRDM2) with CRC, accounting for the CPG island methylator phenotype (CIMP), MLH1 hypermethylation and microsatellite instability (MSI). Incidence rate ratios (RR) were calculated in case-cohort analyses, with common alleles as reference, among 659 cases and 1,736 subcohort members of the Netherlands Cohort Study on diet and cancer $(n=120,852)$.

Men with the MTHFR 677TT genotype were at decreased CRC risk $(R R=0.49$; $\mathrm{P}=0.01)$, but the $\mathrm{T}$ allele was associated with increased risk in women $(R R=1.39$; $\mathrm{P}=0.02$ ). The $M T R$ 2756GG genotype was associated with increased $\mathrm{CRC}$ risk $(R R=1.58 ; P=0.04)$, and inverse associations were observed among women carrying rare variants of the DNMT3b $\mathrm{C}>\mathrm{T}$ ( $\mathrm{rs} 406193, \mathrm{RR}=0.72 ; \mathrm{P}=0.04$ ) or EHMT2 $\mathrm{G}>\mathrm{A}$ (rs535586, $R R=0.76 ; \quad P=0.05$ ) polymorphisms. Although significantly correlated $(\mathrm{P}<0.001)$, only $41.5 \%$ and $33.3 \%$ of CIMP tumors harbored MLH1 hypermethylation or MSI, respectively. We observed inverse associations between MTR A2756G and CIMP among men ( $R R=0.58 ; P=0.04)$, and between MTRR A66G and MLH1 hypermethylation among women $(R R=0.55 ; P=0.02)$.

In conclusion, genetic variants of MTHFR, MTR, DNMT3b and EHMT2 are associated with CRC risk and rare variants of MTR and MTRR may reduce promoter hypermethylation. Importantly, the incomplete overlap between CIMP, MLH1 hypermethylation and MSI indicates that these related "methylation phenotypes" may not be similar and should be investigated separately. 


\section{Introduction}

Aberrant DNA methylation is an important epigenetic modification which may affect cancer susceptibility (1). Folate metabolizing enzymes are involved in the provision of methyl groups, and the bioavailability of methyl groups is dependent on the activity of these enzymes. Single nucleotide polymorphisms (SNPs) in these genes have been reported to alter enzymatic activity. For example, the C677T and A1298C polymorphisms in the methylenetetrahydrofolate (MTHFR) gene result in reduced enzymatic activity $(2,3)$ and were inversely associated with colorectal cancer (CRC) in several observational studies $(4,5)$. However, it was suggested that subjects having the MTHFR 677TT or 1298CC genotypes were more likely to develop CRC showing a CpG island hypermethylation phenotype $(6,7)$ or microsatellite instability (MSI) (8). Genetic variants of methionine synthase (MTR) have been studied less extensively, but the MTR A2756G SNP was suggested to decrease CRC risk in two studies $(9,10)$. In contrast, it was suggested that some of the rare genetic variants of methionine synthase reductase (MTRR) may be associated with an increased risk of colorectal adenomas (CRA) and carcinomas (11-13).

Whereas the above mentioned one-carbon metabolizing enzymes are involved in the provision of methyl groups, DNA methyltransferases catalyze the transfer of these methyl groups from S-adenosylmethionine into CpG dinucleotides of DNA. The DNA methyltransferase $3 \mathrm{~b}(D N M T 3 b)$ is involved in de novo methylation (14), and may influence epigenetic regulation of gene expression and cancer cell growth. In this respect, experimental research suggested that DNMT3b depletion can reduce aberrant promoter CpG island hypermethylation in cancer cells (15-17), while DNMT3b overexpression initiated promoter hypermethylation of tumor suppressor genes and the formation of colonic miroadenomas (18). In addition, it was observed that expression of DNMT3b was associated with $p 16$ and RASSF1A promoter methylation in non-small cell lung cancer (19), and with a promoter hypermethylator phenotype in breast cancer (20). Several SNPs of the DNMT3b gene have been identified, which may affect catalytic activity of the DNMT3b enzyme. For example, the DNMT3b C>T (rs2424913) polymorphism was found to significantly increase DNTM3b promoter activity, and was associated with an increased risk of lung cancer (21), prostate cancer (22), colorectal polyps including CRAs (23) or with prognosis of head and neck cancer (24). Moreover, subjects with hereditary non-polyposis colorectal cancer (HNPCC) carrying the TT genotype developed CRC at a younger age compared to those homozygous for the wild type DNMT3b CC allele (25). However, the association between the DNMT3b C>T (rs2424913) polymorphism and CRC risk has not previously been investigated.

It has been hypothesized that DNA methyltransferases may only have an effect on the chromatin if histone $\mathrm{H} 3$ lys-9 (H3K9) is first methylated by histone methyltransferases (HMTs; Figure 1), and that DNA methylation may thus depend on the activity of histone methyltransferases (26). Experimental research also indicated that methylation of $\mathrm{H} 3 \mathrm{~K} 9$ and other histones play a critical role in maintaining epigenetic silencing by promoter hypermethylation of genes involved in CRC (27). The retinoblastoma protein $(\mathrm{Rb})$ interacting zinc finger gene (RIZ or PRDM2) is a HMT which may act as a tumor suppressor and PRDM2 frameshift mutations have been observed in CRCs showing microsatellite instability (MSI) (28). 


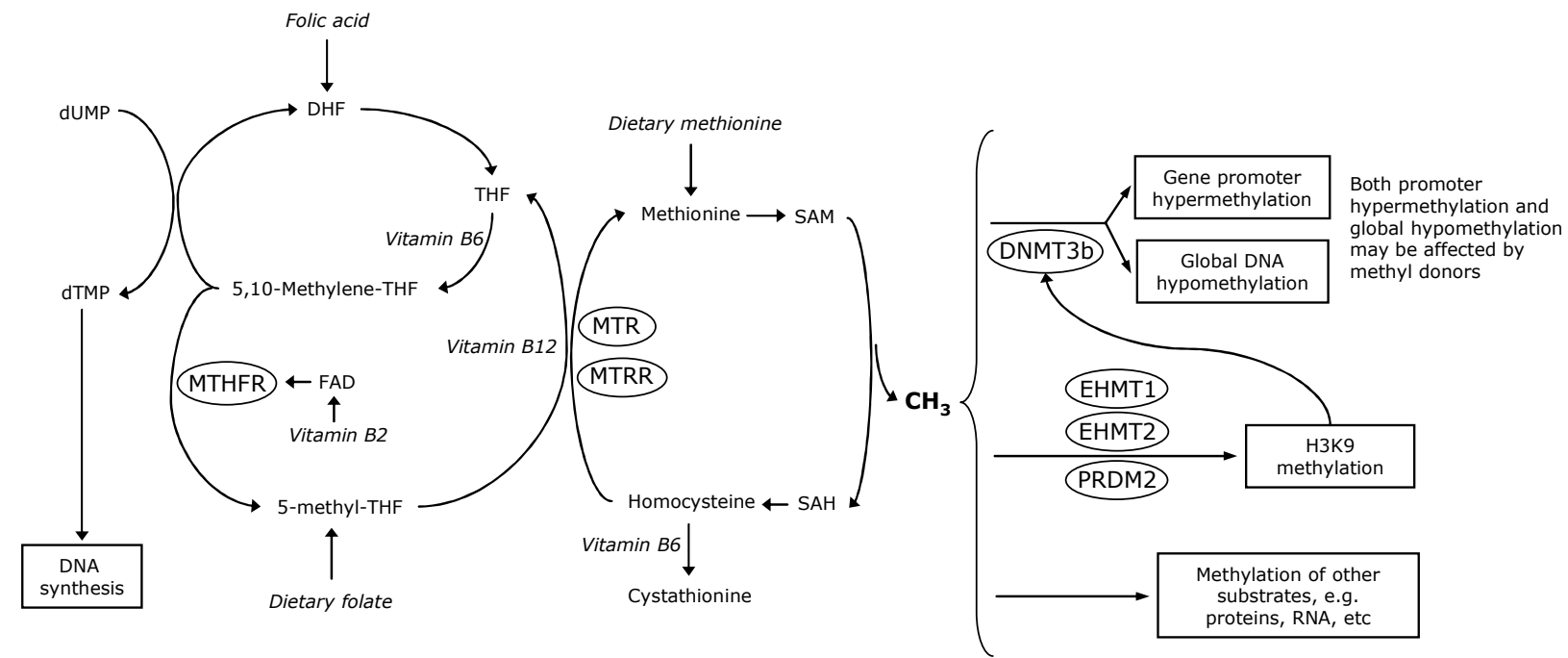

Balance towards increased bioavailability of methyl groups and thereby a potential effect on DNA methylation

Balance towards increased DNA synthesis and thereby a potential effect on DNA stability and/or cell proliferation

\section{Figure 1 Folate metabolizing enzymes, DNA methyltransferases, histone methyl transferases and DNA methylation}

Potential targets of methyl groups are DNA, Iysines (amongst which lysine 9 of Histone 3 (H3K9)), or other substrates e.g. proteins, RNA, etc. DNMT3b activity and promoter CpG island hypermethylation may depend on prior methylation of H3K9. Ovals represent the enzymes of which SNPS are investigated in this study. dUMP: deoxyuridine monophosphate, dTMP: methylene tetrahydrofolate reductase, MTR: methionine synthase, MTRR: methionine synthase reductase, DNMT3b: DNA methyltransferase 3b, PRDM2: PR domain 2, EHMT: euchromatine histone methyltransferase. 
Genetic variation of PRDM2 may be hypothesized to affect its gene activity, and SNPs in PRDM2 were observed to be inversely associated with lung cancer (29). However, an increased risk of breast cancer was suggested (30). Other genes that have been identified as histone methyltransferases are Euchromatin Histone Methyltransferase-1 (EHMT1) and -2 (EHMT2), and genetic variants of these genes were modestly associated with breast cancer risk in a large case-control study (30). However, the potential impact of genetic variants of PRDM2, EHMT1 and EHMT2, have not previously been studied in relation to CRC.

The aim of this study was to determine the occurrence of SNPs in genes encoding folate metabolizing enzymes (MTHFR, MTR and MTRR), the DNA methyltransferase $D N M T 3 b$, and histone methyltransferases (EHMT1, EHMT2 and PRDM2) in a large population-based prospective cohort study in the Netherlands. We estimated associations of these SNPs with overall CRC risk and with CRCs with or without the CpG island methylator phenotype (CIMP), MLH1 hypermethylation or MSI.

\section{Subjects and methods}

\section{Study population and tumour tissue samples}

Tumor material was obtained from incident CRC patients from the Netherlands cohort study (NLCS), which has been described in detail elsewhere (31). Briefly, this prospective cohort study was initiated in September 1986 and includes 58,279 men and 62,573 women aged 55-69 years and free of disease at baseline. The cohort is followed for cancer occurrence by annual record linkage to the Netherlands Cancer Registry (NCR) and to PALGA (Pathologisch Anatomisch Landelijk Geautomatiseerd Archief), a nationwide network and registry of histopathology and cytopathology reports $(32,33)$. At baseline, participants filled out a self administered food frequency questionnaire, by which also information was obtained about age, sex, family history of CRC, smoking behaviour and body mass index (BMI). A subcohort of 5,000 subjects was randomly selected after baseline exposure measurement, to estimate accumulation of person-time in the cohort through biennial follow-up of vital status. Cases with prevalent cancer other than non-melanoma skin cancer were excluded from this subcohort, which left 4,774 men and women eligible for analysis. Tumor material of the CRC patients was collected after approval by the ethical review boards of Maastricht University, the NCR and PALGA. During a follow-up period of 7.3 years after baseline, 734 incident CRC patients were identified who had an available PALGA report of the lesion as well as a sufficient amount of isolated DNA.

\section{Collection of mouth swabs of subcohort members}

Subcohort members still alive in December $2000(n=3,579)$ were contacted and asked to collect mouth swabs. Four cotton swabs in a small non-woven polyethylene envelope were mailed to each subject, including a simple protocol on how to use them. After receipt, the swabs were placed in a falcon tube containing $2.0 \mathrm{ml}$ buffer solution $(100 \mathrm{mM} \mathrm{NaCl}, 10 \mathrm{mM}$ EDTA, $10 \mathrm{mM}$ Tris, Ph 8 with $0.2 \mathrm{mg} / \mathrm{ml}$ proteinase $\mathrm{K}$ and $0.5 \%$ $\mathrm{w} / \mathrm{v}$ SDS). The lysed solution was kept stored at room temperature in the dark. In total, 1,929 subcohort members (54\%) returned the mouth swabs with informed 
consent. The average DNA yield per cotton swab was 0.1-10 $\mu$ g, which corresponded with data from literature (34). In total, DNA could successfully be isolated from 1,829 subcohort members who also had complete follow-up information.

\section{Genotyping analyses}

Nine fragments containing the MTHFR, MTR, MTRR, DNMT3b, EHMT1, EHMT2 and PRDM2 SNPs were amplified, using multiplex polymerase chain reaction (PCR) amplification and single base extension (SBE) reactions as described previously by Knaapen et al (35). Genomic DNA (50 ng) was added to $1 \times$ PCR buffer (Invitrogen, Breda, the Netherlands), $1.75 \mathrm{mM} \mathrm{MgCl}_{2}$ (Invitrogen), $0.4 \mu \mathrm{mol} / \mathrm{L} \mathrm{dNTPs}$ (Amersham Bioscience, Buckinghamshire, England), $100 \mathrm{nM}$ of each primer (Eurogentec, Maastricht, The Netherlands) and $0.25 \mathrm{U}$ Platinum Taq (Invitrogen) in a final volume of $10 \mu \mathrm{l}$. PCR conditions were as follows: $3 \mathrm{~min}$ at $94^{\circ} \mathrm{C}, 35 \mathrm{cycles}$ of $30 \mathrm{sec}$ at $94{ }^{\circ} \mathrm{C}, 30$ sec at $62{ }^{\circ} \mathrm{C}$ and $30 \mathrm{sec}$ at $72{ }^{\circ} \mathrm{C}$, and a final extension for 5 minutes at $72{ }^{\circ} \mathrm{C}$ and 4 minutes at $20^{\circ} \mathrm{C}$. To degrade excess PCR primers and dNTPs, $5 \mu$ multiplex PCR product was incubated with $2 \mu$ EXO-SAP IT (Amersham Bioscience) at $37^{\circ} \mathrm{C}$ for 15 minutes followed by $80^{\circ} \mathrm{C}$ for 15 minutes to deactivate the enzyme. The multiplex SBE reaction was performed using a SNaPShot multiplex kit as described by the manufacturer (Applied Biosystems, Foster City, CA, USA). SBE primers were designed to bind immediately adjacent $5^{\prime}$ to the SNP of interest with a template specific part of 20 to $33 \mathrm{bp}$ and a Tm of $60^{\circ} \mathrm{C}$. Rs-numbers of the SNPs and primer sequences are shown in Supplementary Table 1.

During thermal cycling, the primers are extended at their $3^{\prime}$ end with a single dideoxyribonucleoside triphosphate labelled with a distinct fluorophore, revealing the genotype of the SNP. SBE was performed using 25 cycles of $96^{\circ} \mathrm{C}$ for $10 \mathrm{~s}$ and $60{ }^{\circ} \mathrm{C}$ for $30 \mathrm{~s}$. Following cycling, the reaction was treated with $1 \mathrm{U}$ Shrimp Alkaline Phosphatase (Amersham Bioscience) at $37^{\circ} \mathrm{C}$ for $1 \mathrm{~h}$ to degrade the unincorporated dideoxynucleotide triphosphates, followed by enzyme deactivation at $75^{\circ} \mathrm{C}$ for $15 \mathrm{~min}$. One $\mu \mathrm{l}$ of SBE product was mixed with $13 \mu \mathrm{l}$ of Hi-Di formamide (Applied Biosystems) and $0.4 \mu \mathrm{l}$ of Genescan-120 size standard (Applied Biosystems), subsequently denatured at $95^{\circ} \mathrm{C}$ for 5 min and then analyzed on an ABI Prism 3100 genetic analyzer using Genemapper Analysis software (version 4.0).

To validate the genotype data, we sequenced every fragment containing a specific SNP in a subset of 30 samples including 10 CRC cases, 10 female and 10 male subcohort members with mouth swabs. Sequencing was performed using the BigDye ßTerminater v1.1 cycle sequencing kit, following the manufacturer's recommendations using the ABI 3700 genetic analyzer. The sequencing results were similar to the SNaPShot results for all but one $(99.6 \%)$ of the 9 SNPs within these 30 samples. Reproducibility of the SNaPShot analysis was established by subjecting 93 samples of which 31 CRC cases, 31 female and 31 male subcohort members with mouth swabs, twice to the complete SNaPShot analysis procedure, from multiplex PCR of genomic DNA to the genetic analysis of the samples. We observed that the analyses could be reproduced in $99.5 \%$ of these cases. 


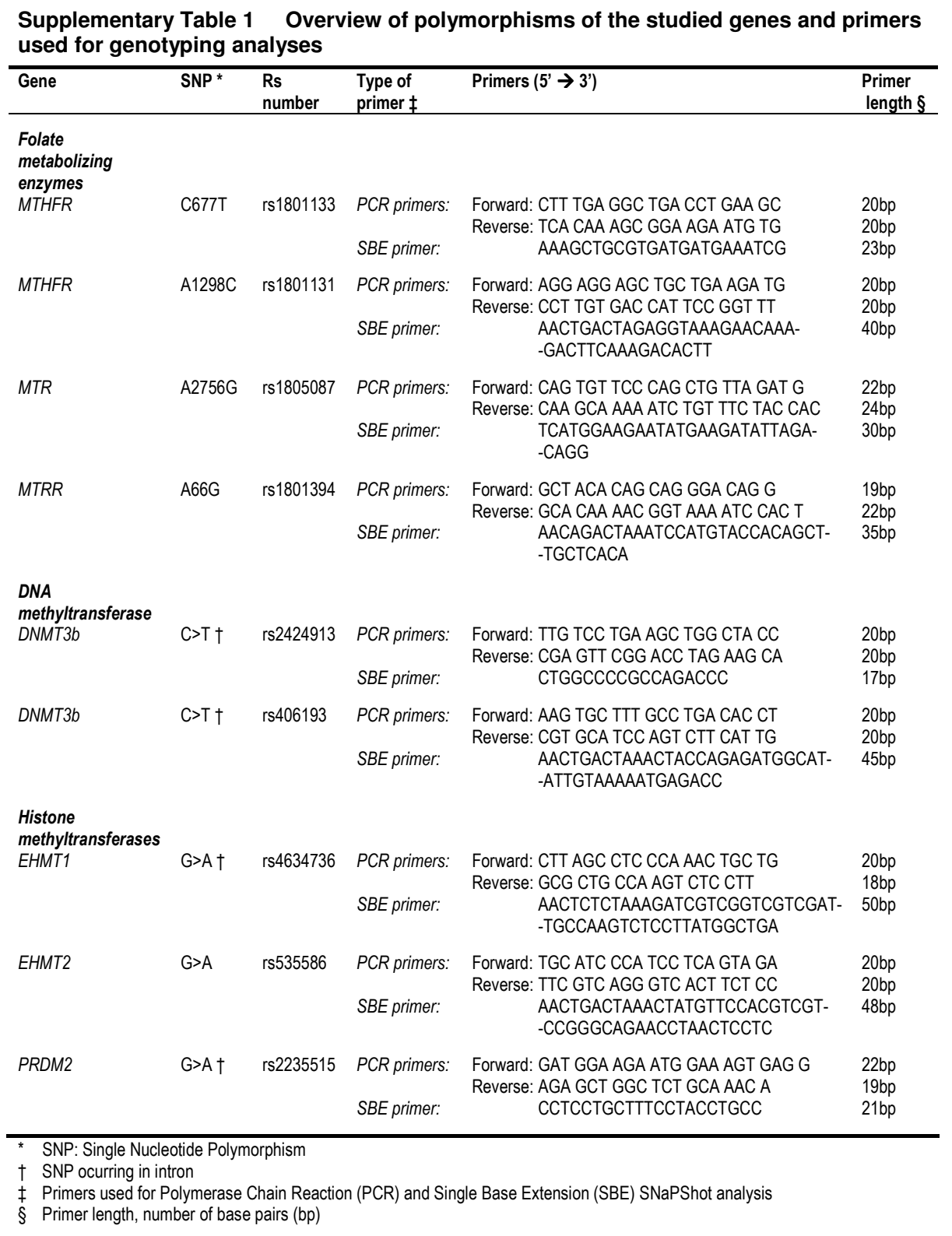

\section{Promoter methylation analyses}

The CpG island methylator phenotype (CIMP) was defined by promoter hypermethylation of at least 3 out of 5 methylation markers (CACNA1G, IGF2, NEUROG1, RUNX3 and SOCS1), as suggested by Weisenberger et al (36). DNA methylation in the CPG islands of these five CIMP markers and of the MLH1 gene was determined by Methylation Specific PCR (MSP) (37). Bisulfite modification was carried out on 500ng DNA using a commercially available kit (Zymo Research). To facilitate 
MSP analysis on DNA retrieved from formalin-fixed, paraffin-embedded tissue, DNA was first amplified with flanking PCR primers that amplify bisulfite modified DNA but do not preferentially amplify methylated or unmethylated DNA.

The resulting fragment was used as a template for the MSP-reaction $(38,39)$. All PCRs were performed with controls for unmethylated alleles (DNA from normal lymphocytes), methylated alleles (normal lymphocyte DNA treated in vitro with SssI methyltransferase (New England Biolabs)) and a control without DNA. Ten $\mu$ l of each MSP reaction was directly loaded onto nondenaturing $6 \%$ polyacrylamide gels, stained with ethidium bromide and visualized under UV illumination. The MSP analyses were successful of $81 \%, 79 \%, 79 \%, 90 \%, 83 \%$ and $93 \%$ out of the 734 patients for CACNA1G, IGF2, NEUROG1, RUNX3, SOCS1 and MLH1, respectively.

\section{Microsatellite instability}

MSI was determined by a pentaplex PCR, using the MSI markers BAT-26, BAT-25, NR$21, N R-22$ and NR-24, as described in detail by Suraweera et al (40). MSI analyses were successful on $662(90 \%)$ out of the 734 available samples.

\section{Statistical analyses}

Data analyses were conducted overall, and for men and women separately. The prevalence of the genotypes and minor allele frequencies (MAF) of the SNPs were calculated for subcohort members and CRC cases. Chi square tests were used to test differences in prevalence between CRC cases and subcohort members who did not develop CRC. The Hardy-Weinberg equilibrium was tested among subcohort members to evaluate whether for each SNP, the individual alleles combined into the observed genotypes in a random manner. Although this subcohort was a random sample of the total cohort, and thus selection would not be expected, the DNA samples were collected from individuals still alive several years after baseline. If survival of these subjects was due to presence of specific genotypes, this may bias the estimated associations.

However, since genetic status is unknown of the remaining subcohort members it is impossible to compare survival between genotypes, and we therefore alternatively compared mean age between genotypes of each gene.

The overlap between the three methylation endpoints, i.e. CIMP, MLH1 hypermethylation and MSI, was compared and tested by Chi-square tests. Cox proportional hazards regression models were used to estimate age-adjusted incidence rate ratios (RR) and $95 \%$ confidence intervals (CI) taking homozygotes for common alleles as reference. Analyses were performed overall, and stratified by CIMP status, MLH1 hypermethylation and MSI, allowing us to compare the effects between the recently defined CIMP phenotype (36), the "classic" methylation marker MLH1 and MSI, and to account for a potential incomplete overlap that may exist between related molecular phenotypes (41). Since two SNPs were determined for MTHFR and DNMT3b, we estimated RRs for combinations of genotypes within these genes. In addition, RRs for combinations of genotypes per functional group were estimated (i.e. based on the number of rare alleles in any of the folate metabolizing enzymes MTHFR, MTR and $M T R R$, or in any of the histone methyltransferases EHMT1, EHMT2 and PRDM2), or the combination of all the studied genes. Standard errors (SE) of the RRs were estimated using the robust Huber-White sandwich estimator to account for additional variance 
introduced by sampling from the cohort (42). The proportional hazards assumption was tested using the scaled Schoenfeld residuals (43). Multivariate-adjusted analyses were additionally conducted including the co-variates dietary folate, vitamin B2, vitamin B6, methionine, alcohol, energy intake, family history of CRC, smoking behaviour and body mass index. Interactions with sex were tested for each of the SNPs. Statistical analyses were performed with the Stata statistical software package (version 10).

\section{Results}

The overall and gender-specific prevalences of genotypes were calculated and compared between subcohort members and CRC cases. We observed that the rare MTHFR 677TT variant occurred more often in subcohort members than in cases, and that this difference was present among men (prevalences in subcohort and cases were $9.7 \%$ and $5.0 \%$, respectively). Prevalences of other genotypes did not significantly differ between subcohort members and cases (Table 1). The distribution of the MTHFR A1298C, MTRR A66G and DNMT3b C>T (rs406193) genotypes deviated from the Hardy-Weinberg equilibrium $(P<0.05)$. However, mean age was similar between genotypes of any of the SNPs, suggesting that there was no survivorship effect due to genetic status.

Overall, subjects with the heterozygous MTHFR 677CT genotype were at modestly increased CRC risk compared to participants with the common CC genotype $(R R=1.23, P=0.04$, Table 2). Similarly, positive associations existed among women with this genotype $(R R=1.43, P=0.02)$, and for the occurrence of the rare $T$ allele (i.e. the combination of the $C T$ and $T T$ genotypes compared to $C C, R R=1.39, P=0.02$ ). 
Table 1 Prevalence of genotypes of subcohort members and colorectal cancer patients in the Netherlands Cohort Study

\begin{tabular}{|c|c|c|c|c|c|c|c|c|}
\hline \multirow[b]{2}{*}{ Gene and SNP * } & \multirow[b]{2}{*}{ dbSNP number } & \multirow[b]{2}{*}{$\begin{array}{c}\text { Genotype } \\
\text { (MAF) } \ddagger\end{array}$} & \multicolumn{2}{|c|}{ Men and women } & \multicolumn{2}{|c|}{ Men } & \multicolumn{2}{|c|}{ Women } \\
\hline & & & $\begin{array}{c}\text { Subcohort } \\
\text { (HWE) } \S\end{array}$ & CRC cases & $\begin{array}{c}\text { Subcohort } \\
\text { (HWE) } \S\end{array}$ & CRC cases & $\begin{array}{c}\text { Subcohort } \\
\text { (HWE) } \S\end{array}$ & CRC cases \\
\hline \multirow[t]{4}{*}{ MTHFR C677T } & rs1801133 & CC & $876(48.9 \%)$ & $318(46.2 \%)$ & $409(45.4 \%)$ & $179(46.8 \%)$ & $467(52.3 \%)$ & $139(45.3 \%)$ \\
\hline & & CT & $750(41.8 \%)$ & $320(46.4 \%)$ & $405(44.9 \%)$ & $184(48.2 \%)$ & $345(38.7 \%)$ & $136(44.3 \%)$ \\
\hline & & TT & $167(9.3 \%)$ & $51(7.4 \%)$ & $87(9.7 \%)$ & $19(5.0 \%)$ & $80(9.0 \%)$ & $32(10.4 \%)$ \\
\hline & & $(0.30)$ & $(0.72)$ & Tा & $(0.36)$ & $\pi$ & $(0.16)$ & \\
\hline \multirow[t]{3}{*}{ MTHFR A1298C } & rs1801131 & $\mathrm{AA}$ & $735(41.6 \%)$ & $299(43.7 \%)$ & $345(39.3 \%)$ & $167(43.8 \%)$ & $390(43.9 \%)$ & $132(43.6 \%)$ \\
\hline & & AC & $774(43.8 \%)$ & $275(40.2 \%)$ & $423(48.2 \%)$ & $166(43.6 \%)$ & $351(39.5 \%)$ & $109(36.0 \%)$ \\
\hline & & CC & $258(14.6 \%)$ & $110(16.1 \%)$ & $110(12.5 \%)$ & $48(12.6 \%)$ & $148(16.6 \%)$ & $62(20.4 \%)$ \\
\hline \multirow[t]{3}{*}{ MTR A2756G } & rs1805087 & AA & $1190(65.9 \%)$ & $449(64.5 \%)$ & $589(65.1 \%)$ & $257(66.4 \%)$ & $601(66.8 \%)$ & $192(62.1 \%)$ \\
\hline & & AG & $543(30.1 \%)$ & $204(29.3 \%)$ & $281(31.0 \%)$ & $108(27.9 \%)$ & $262(29.1 \%)$ & $96(31.1 \%)$ \\
\hline & & $G G$ & $72(4.0 \%)$ & $43(6.2 \%)$ & $35(3.9 \%)$ & $22(5.7 \%)$ & $37(4.1 \%)$ & $21(6.8 \%)$ \\
\hline \multirow{3}{*}{ MTRR A66G } & rs1801394 & AA & $367(20.4 \%)$ & $136(19.5 \%)$ & $193(21.4 \%)$ & $65(16.7 \%)$ & $\frac{0.12)}{174(19.4 \%)}$ & $71(23.0 \%)$ \\
\hline & & $A G$ & $833(46.4 \%)$ & $338(48.3 \%)$ & $399(44.2 \%)$ & $196(50.2 \%)$ & $434(48.5 \%)$ & $142(45.9 \%)$ \\
\hline & & GG & $597(33.2 \%)$ & $225(32.2 \%)$ & $310(34.4 \%)$ & $129(33.1 \%)$ & $287(32.1 \%)$ & $96(31.1 \%)$ \\
\hline \multirow{3}{*}{ DNMT3b C>T $\dagger$} & rs2424913 & CC & $597(32.9 \%)$ & $240(34.1 \%)$ & $303(33.4 \%)$ & $132(33.9 \%)$ & $\begin{array}{c}(0.01) \\
294(32.5 \%)\end{array}$ & $108(34.4 \%)$ \\
\hline & & CT & $895(49.5 \%)$ & $348(49.5 \%)$ & $449(49.6 \%)$ & $184(47.3 \%)$ & $446(49.4 \%)$ & $164(52.2 \%)$ \\
\hline & & TT & $318(17.6 \%)$ & $115(16.4 \%)$ & $154(17.0 \%)$ & $73(18.8 \%)$ & $164(18.2 \%)$ & $42(13.4 \%)$ \\
\hline \multirow{4}{*}{ DNMT3b C>T $\dagger$} & 5406193 & $\frac{(0.4 C)}{c C}$ & $\frac{(0.50)}{1331(74.3 \%)}$ & $528(756 \%)$ & $\frac{10.01)}{686(76.7 \%)}$ & $291(746 \%)$ & $\frac{10.02)}{645(71.9 \%}$ & $237(76.9 \%)$ \\
\hline & & CT & $415(23.1 \%)$ & $152(21.8 \%)$ & $190(21.2 \%)$ & $88(22.6 \%)$ & $225(25.1 \%)$ & $64(20.8 \%)$ \\
\hline & & TT & $46(2.6 \%)$ & $18(2.6 \%)$ & $19(2.1 \%)$ & $11(2.8 \%)$ & $27(3.0 \%)$ & $7(2.3 \%)$ \\
\hline & & $(0.14)$ & $\begin{array}{c}(0.05) \\
(0.05)\end{array}$ & & $(0.18)$ & & $(0.18)$ & \\
\hline \multirow[t]{4}{*}{ EHMT1 G>A $\dagger$} & rs4634736 & GG & $1444(80.6 \%)$ & $568(81.7 \%)$ & $730(81.4 \%)$ & $320(83.1 \%)$ & $714(79.8 \%)$ & $248(80.0 \%)$ \\
\hline & & GA & $334(18.6 \%)$ & $121(17.4 \%)$ & $163(18.2 \%)$ & $64(16.6 \%)$ & $171(19.1 \%)$ & $57(18.4 \%)$ \\
\hline & & $\mathrm{AA}$ & $14(0.8 \%)$ & $6(0.9 \%)$ & $4(0.4 \%)$ & $1(0.3 \%)$ & $10(1.1 \%)$ & $5(1.6 \%)$ \\
\hline & & $(0.10)$ & $(0.27)$ & & $\begin{array}{c}\left.\begin{array}{c}4 \\
(0.41)\end{array}\right) \\
(0.11)\end{array}$ & & $(0.95)$ & \\
\hline \multirow[t]{3}{*}{ EHMT2 G>A } & rs535586 & GG & $755(42.2 \%)$ & $297(42.9 \%)$ & $390(43.3 \%)$ & $155(40.3 \%)$ & $365(41.2 \%)$ & $142(46.3 \%)$ \\
\hline & & GA & $810(45.3 \%)$ & $311(44.9 \%)$ & $414(45.9 \%)$ & $185(48.0 \%)$ & $396(44.6 \%)$ & $126(41.0 \%)$ \\
\hline & & AA & $223(12.5 \%)$ & $84(12.2 \%)$ & $97(10.8 \%)$ & $45(11.7 \%)$ & $126(14.2 \%)$ & $39(12.7 \%)$ \\
\hline \multirow{4}{*}{ PRDM2 G>A $\dagger$} & rs2235515 & $\frac{(.35)}{G G}$ & $\frac{(0.80)}{1065(59.0 \%)}$ & $377(55,7 \%)$ & $\begin{array}{c}(0.41) \\
527(58.5 \%)\end{array}$ & $210(56.0 \%)$ & $\begin{array}{c}(0.27) \\
538(596 \%)\end{array}$ & $167(553 \%)$ \\
\hline & & $\mathrm{GA}$ & $640(35.5 \%)$ & $262(38.7 \%)$ & $320(35.5 \%)$ & $141(37.6 \%)$ & $320(35.4 \%)$ & $121(40.1 \%)$ \\
\hline & & $\mathrm{AA}$ & $99(5.5 \%)$ & $38(5.6 \%)$ & $54(6.0 \%)$ & $24(6.4 \%)$ & $45(5.0 \%)$ & $14(4.6 \%)$ \\
\hline & & $(0.23)$ & $(0.82)$ & & $(0.56)$ & & $(0.77)$ & \\
\hline
\end{tabular}

\section{SNP:Single Nudleolide Polymorphism}

SNP occurring in an intron of the gene
MAF: Minor Allele Frequency among subcohort members (men and women combined)

$P$-value for test for Hardy-Weinberg equilibrium (HWE), based on the distribution of genotypes among subcohort members

$P$-value $<0.05$ for the difference in genotype frequencies between CRC cases and subcohort members who did not develop CRC 
Table 2 Associations of SNPs in folate metabolizing enzymes and epigenetic regulators with CRC risk

\begin{tabular}{|c|c|c|c|c|c|c|c|c|c|c|c|c|}
\hline \multirow[b]{2}{*}{ Gene and SNP * } & \multirow[b]{2}{*}{$\begin{array}{l}\text { dbSNP } \\
\text { number }\end{array}$} & \multirow[b]{2}{*}{ Genotype } & \multicolumn{3}{|c|}{ Men and women } & \multicolumn{3}{|c|}{ Men } & \multicolumn{3}{|c|}{ Women } & \multirow{2}{*}{$\begin{array}{c}\begin{array}{c}\text { Interaction } \\
\text { with sex }\end{array} \\
P\end{array}$} \\
\hline & & & $\mathbf{N}^{\dagger}$ & $\operatorname{RR}(95 \% \mathrm{Cl})^{\ddagger}$ & $P$ & $\mathbf{N}$ & $\operatorname{RR}(95 \% \mathrm{Cl})^{\S}$ & $P$ & $\mathrm{~N}$ & $\mathrm{RR}(95 \% \mathrm{Cl})^{\S}$ & $P$ & \\
\hline MTHFR C677T & rs1801133 & $\begin{array}{l}\text { CC } \\
C T \\
T T \\
C T+T T \text { vs CC }\end{array}$ & $\begin{array}{l}318 \\
320 \\
51 \\
371\end{array}$ & $\begin{array}{l}1.00 \\
1.23(1.02-1.50) \\
0.80(0.56-1.15) \\
1.15(0.95-1.39)\end{array}$ & $\begin{array}{l}0.04 \\
0.23 \\
0.15\end{array}$ & $\begin{array}{l}179 \\
184 \\
19 \\
203\end{array}$ & $\begin{array}{l}1.00 \\
1.10(0.84-1.43) \\
0.49(0.28-0.85) \\
0.98(0.76-1.27)\end{array}$ & $\begin{array}{l}0.49 \\
0.01 \\
0.89\end{array}$ & $\begin{array}{l}139 \\
136 \\
32 \\
168\end{array}$ & $\begin{array}{l}1.00 \\
1.43(1.07-1.91) \\
1.26(0.78-2.05) \\
1.39(1.06-1.83)\end{array}$ & $\begin{array}{l}0.02 \\
0.34 \\
0.02\end{array}$ & 0.03 \\
\hline MTHFR A1298C & rs1801131 & $\begin{array}{l}\mathrm{AA} \\
\mathrm{AC} \\
\mathrm{CC} \\
\mathrm{AC}+\mathrm{CC} \text { vs } \mathrm{AA}\end{array}$ & $\begin{array}{l}299 \\
275 \\
110 \\
385\end{array}$ & $\begin{array}{l}1.00 \\
0.89(0.72-1.09) \\
1.05(0.79-1.38) \\
0.93(0.77-1.12)\end{array}$ & $\begin{array}{l}0.26 \\
0.74 \\
0.45\end{array}$ & $\begin{array}{l}167 \\
166 \\
48 \\
214\end{array}$ & $\begin{array}{l}1.00 \\
0.81(0.62-1.07) \\
0.89(0.59-1.35) \\
0.83(0.64-1.07)\end{array}$ & $\begin{array}{l}0.14 \\
0.58 \\
0.15\end{array}$ & $\begin{array}{l}132 \\
109 \\
62 \\
171\end{array}$ & $\begin{array}{l}1.00 \\
1.00(0.73-1.35) \\
1.23(0.85-1.78) \\
1.07(0.81-1.41)\end{array}$ & $\begin{array}{l}0.98 \\
0.28 \\
0.64\end{array}$ & 0.42 \\
\hline MTR A2756G & rs1805087 & $\begin{array}{l}A A \\
A G \\
G G \\
A G+G G \text { vs } A A\end{array}$ & $\begin{array}{l}449 \\
204 \\
43 \\
247\end{array}$ & $\begin{array}{l}1.00 \\
1.03(0.84-1.27) \\
1.58(1.03-2.43) \\
1.10(0.90-1.33)\end{array}$ & $\begin{array}{l}0.77 \\
0.04 \\
0.35\end{array}$ & $\begin{array}{l}257 \\
108 \\
22 \\
130\end{array}$ & $\begin{array}{l}1.00 \\
0.95(0.72-1.26) \\
1.45(0.79-2.66) \\
1.01(0.77-1.32)\end{array}$ & $\begin{array}{l}0.73 \\
0.23 \\
0.94\end{array}$ & $\begin{array}{l}192 \\
96 \\
21 \\
117\end{array}$ & $\begin{array}{l}1.00 \\
1.14(0.85-1.54) \\
1.76(0.97-3.21) \\
1.22(0.92-1.62)\end{array}$ & $\begin{array}{l}0.38 \\
0.06 \\
0.17\end{array}$ & 0.64 \\
\hline MTRR A66G & rs1801394 & $\begin{array}{l}A A \\
A G \\
G G \\
A G+G G \text { vs } A A\end{array}$ & $\begin{array}{l}136 \\
338 \\
225 \\
563\end{array}$ & $\begin{array}{l}1.00 \\
1.08(0.85-1.39) \\
1.03(0.79-1.34) \\
1.06(0.84-1.34)\end{array}$ & $\begin{array}{l}0.53 \\
0.83 \\
0.62\end{array}$ & $\begin{array}{l}65 \\
196 \\
129 \\
325\end{array}$ & $\begin{array}{l}1.00 \\
1.36(0.96-1.92) \\
1.23(0.85-1.78) \\
1.30(0.94-1.81)\end{array}$ & $\begin{array}{l}0.09 \\
0.27 \\
0.11\end{array}$ & $\begin{array}{l}71 \\
142 \\
96 \\
238\end{array}$ & $\begin{array}{l}1.00 \\
0.83(0.59-1.18) \\
0.85(0.58-1.24) \\
0.84(0.60-1.16)\end{array}$ & $\begin{array}{l}0.31 \\
0.39 \\
0.29\end{array}$ & 0.15 \\
\hline$D N M T 3 b C>T$ & rs2424913 & $\begin{array}{l}\text { CC } \\
\mathrm{CT} \\
\mathrm{TT} \\
\mathrm{CT}+\mathrm{TT} \text { vs CC }\end{array}$ & $\begin{array}{l}240 \\
348 \\
115 \\
463\end{array}$ & $\begin{array}{l}1.00 \\
0.95(0.78-1.17) \\
0.90(0.68-1.19) \\
0.94(0.77-1.14)\end{array}$ & $\begin{array}{l}0.66 \\
0.46 \\
0.54\end{array}$ & $\begin{array}{l}132 \\
184 \\
73 \\
257\end{array}$ & $\begin{array}{l}1.00 \\
0.91(0.68-1.20) \\
1.00(0.69-1.45) \\
0.93(0.71-1.22)\end{array}$ & $\begin{array}{l}0.50 \\
0.99 \\
0.60\end{array}$ & $\begin{array}{l}108 \\
164 \\
42 \\
206\end{array}$ & $\begin{array}{l}1.00 \\
1.01(0.75-1.36) \\
0.76(0.50-1.16) \\
0.95(0.71-1.26)\end{array}$ & $\begin{array}{l}0.94 \\
0.20 \\
0.72\end{array}$ & 0.37 \\
\hline$D N M T 3 b C>T$ & rs406193 & $\begin{array}{l}\mathrm{CC} \\
\mathrm{CT} \\
\mathrm{TT} \\
\mathrm{CT}+\mathrm{TT} \text { vs CC }\end{array}$ & $\begin{array}{l}528 \\
152 \\
18 \\
170\end{array}$ & $\begin{array}{l}1.00 \\
0.91(0.73-1.14) \\
1.05(0.59-1.87) \\
0.93(0.75-1.15)\end{array}$ & $\begin{array}{l}0.43 \\
0.87 \\
0.49\end{array}$ & $\begin{array}{l}291 \\
88 \\
11 \\
99\end{array}$ & $\begin{array}{l}1.00 \\
1.13(0.83-1.54) \\
1.32(0.59-2.95) \\
1.15(0.86-1.54)\end{array}$ & $\begin{array}{l}0.43 \\
0.50 \\
0.36\end{array}$ & $\begin{array}{l}237 \\
64 \\
7 \\
71\end{array}$ & $\begin{array}{l}1.00 \\
0.71(0.51-0.99) \\
0.72(0.52-0.99)\end{array}$ & $\begin{array}{l}0.05 \\
- \\
0.04\end{array}$ & 0.10 \\
\hline EHMT1 $\mathrm{G}>\mathrm{A}$ & rs4634736 & $\begin{array}{l}\text { GG } \\
G A \\
\text { AA } \\
\text { GA+AA vs GG }\end{array}$ & $\begin{array}{l}568 \\
121 \\
6 \\
127\end{array}$ & $\begin{array}{l}1.00 \\
0.93(0.73-1.18) \\
0.93(0.73-1.18)\end{array}$ & $\begin{array}{l}0.55 \\
- \\
0.55\end{array}$ & $\begin{array}{l}320 \\
64 \\
1 \\
65\end{array}$ & $\begin{array}{l}1.00 \\
0.92(0.66-1.28) \\
0.89(0.64-1.24)\end{array}$ & $\begin{array}{l}0.62 \\
- \\
0.49\end{array}$ & $\begin{array}{l}248 \\
57 \\
5 \\
62\end{array}$ & $\begin{array}{l}1.00 \\
0.95(0.67-1.34) \\
0.98(0.70-1.37)\end{array}$ & $\begin{array}{l}0.76 \\
- \\
0.90\end{array}$ & 0.41 \\
\hline EHMT2 G>A & rs535586 & $\begin{array}{l}\text { GG } \\
G A \\
\text { AA } \\
\text { GA+AA vs GG }\end{array}$ & $\begin{array}{l}297 \\
311 \\
84 \\
395\end{array}$ & $\begin{array}{l}1.00 \\
0.92(0.76-1.13) \\
1.01(0.74-1.37) \\
0.94(0.78-1.14)\end{array}$ & $\begin{array}{l}0.44 \\
0.95 \\
0.53\end{array}$ & $\begin{array}{l}155 \\
185 \\
45 \\
230\end{array}$ & $\begin{array}{l}1.00 \\
1.10(0.84-1.44) \\
1.17(0.76-1.80) \\
1.12(0.86-1.44)\end{array}$ & $\begin{array}{l}0.48 \\
0.47 \\
0.41\end{array}$ & $\begin{array}{l}142 \\
126 \\
39 \\
165\end{array}$ & $\begin{array}{l}1.00 \\
0.74(0.55-0.99) \\
0.84(0.55-1.27) \\
0.76(0.58-1.01)\end{array}$ & $\begin{array}{l}0.05 \\
0.44 \\
0.05\end{array}$ & 0.13 \\
\hline$P R D M 2 \mathrm{G}>\mathrm{A}$ & rs2235515 & $\begin{array}{l}\text { GG } \\
G A \\
A A \\
G A+A A \text { vs GG }\end{array}$ & $\begin{array}{l}377 \\
262 \\
38 \\
300\end{array}$ & $\begin{array}{l}1.00 \\
1.14(0.93-1.38) \\
1.09(0.72-1.66) \\
1.13(0.94-1.37)\end{array}$ & $\begin{array}{l}0.20 \\
0.67 \\
0.20\end{array}$ & $\begin{array}{l}210 \\
141 \\
24 \\
165\end{array}$ & $\begin{array}{l}1.00 \\
1.09(0.83-1.43) \\
1.02(0.60-1.75) \\
1.08(0.83-1.40)\end{array}$ & $\begin{array}{l}0.54 \\
0.93 \\
0.57\end{array}$ & $\begin{array}{l}167 \\
121 \\
14 \\
135\end{array}$ & $\begin{array}{l}1.00 \\
1.20(0.90-1.60) \\
1.20(0.63-2.29) \\
1.20(0.91-1.58)\end{array}$ & $\begin{array}{l}0.21 \\
0.58 \\
0.20\end{array}$ & 0.85 \\
\hline
\end{tabular}

SNP: Single Nucleotide Polymorphism
Number of cases. Subgroups of 10 or less cases were considered too small for precise estimates and were therefore omitted from the table Adjusted for age and sex 
Conversely, we observed that men homozygous for the MTHFR 677TT genotype were at reduced $C R C$ risk $(R R=0.49, P=0.01)$. There was a significant interaction between sex and MTHFR C677T genotypes $(P=0.03)$. Whereas MTHFR A1298C was not associated with CRC, we observed a positive association between the MTR 2756GG genotype and $C R C(R R=1.58, P=0.04)$ particularly among women $(R R=1.76, P=0.06)$. Among men, the MTR $2756 \mathrm{GG}$ genotype was associated with a non-significant increase of $C R C$ risk $(R R=1.45, P=0.23)$. MTRR A66G genotypes were not associated with overall CRC.

Among women, the rare alleles of DNMT3b C>T (rs406193) and EHMT2 G>A (rs535586) were inversely associated with $\mathrm{CRC}(\mathrm{RR}=0.72, P=0.04$ and $\mathrm{RR}=0.76$, $P=0.05$, respectively), but such associations were not observed among men. No associations were observed between individual genotypes of the remaining genes and overall CRC risk. Combining MTHFR and DNMT3b genotypes, genotypes per functional group or genotypes of all studied genes did not reveal any clear associations with CRC. Multivariate-adjusted analyses resulted in similar findings compared to age-adjusted analyses (data not shown).

In total, $167(27.7 \%)$ out of the 603 CRCs with available CIMP analyses showed the CIMP phenotype (Table 3 and Figure 2), with no significant difference between men and women (data not shown). As reported previously for MLH1 hypermethylation, MSI and BRAF mutations (41), the overlap between CIMP, MLH1 hypermethylation and MSI was also incomplete. Although statistically significant $\left(P_{\text {chi square }}<0.001\right), 41.5 \%$ of the CRCs with CIMP showed MLH1 methylation, whereas only $33.3 \%$ harbored MSI.

Table 3 Frequency of CRCs harboring CIMP and overlap with MLH1 promoter hypermethylation and MSI

\begin{tabular}{|c|c|c|c|c|}
\hline & \multirow[t]{2}{*}{$\begin{array}{l}\text { Frequency of } \\
\text { molecular } \\
\text { phenotype } \mathrm{N}(\%)\end{array}$} & \multicolumn{2}{|c|}{ CIMP } & \multirow[t]{2}{*}{$P$-value * } \\
\hline & & CIMP+ & CIMP. & \\
\hline \multicolumn{5}{|l|}{ CIMP } \\
\hline CIMP+ & $167 \quad(27.7)$ & - & - & - \\
\hline CIMP- & $436 \quad(72.3)$ & - & - & \\
\hline \multicolumn{5}{|c|}{ MLH1 promoter methylation } \\
\hline Methylated & $152 \quad(22.1)$ & $68 \quad(41.5)$ & $(14.0)$ & $<0.001$ \\
\hline Unmethylated & $534 \quad(77.9)$ & $96 \quad(58.5)$ & $363(86.0)$ & \\
\hline \multicolumn{5}{|c|}{ Microsatellite instability } \\
\hline MSI & $84 \quad(12.7)$ & $52(33.3)$ & $17 \quad(4.2)$ & $<0.001$ \\
\hline MSS & $578 \quad(87.3)$ & $104(67.7)$ & $390 \quad(95.8)$ & \\
\hline
\end{tabular}

MTHFR C677T polymorphisms were not associated with any of the methylation endpoints among men (Table 4). However, we observed that women carrying the rare allele of MTHFR C677T were at significantly increased risk of developing a tumor without CIMP ( $\left.\mathrm{CIMP}^{-}, \mathrm{RR}=1.40 ; \mathrm{P}=0.04\right)$, without $M L H 1$ hypermethylation $(\mathrm{RR}=1.49$; $\mathrm{P}=0.01)$ or without $\mathrm{MSI}(\mathrm{RR}=1.36 ; \mathrm{P}=0.04)$, but also those with $\mathrm{CIMP}\left(\mathrm{CIMP}^{+}\right.$, $\mathrm{RR}=1.65 ; \mathrm{P}=0.04$, Table 5). Among men the MTHFR $\mathrm{A} 1298 \mathrm{C}$ polymorphism was inversely associated with CRCs without $\operatorname{CIMP}(R R=0.72 ; \mathrm{P}=0.03)$. 


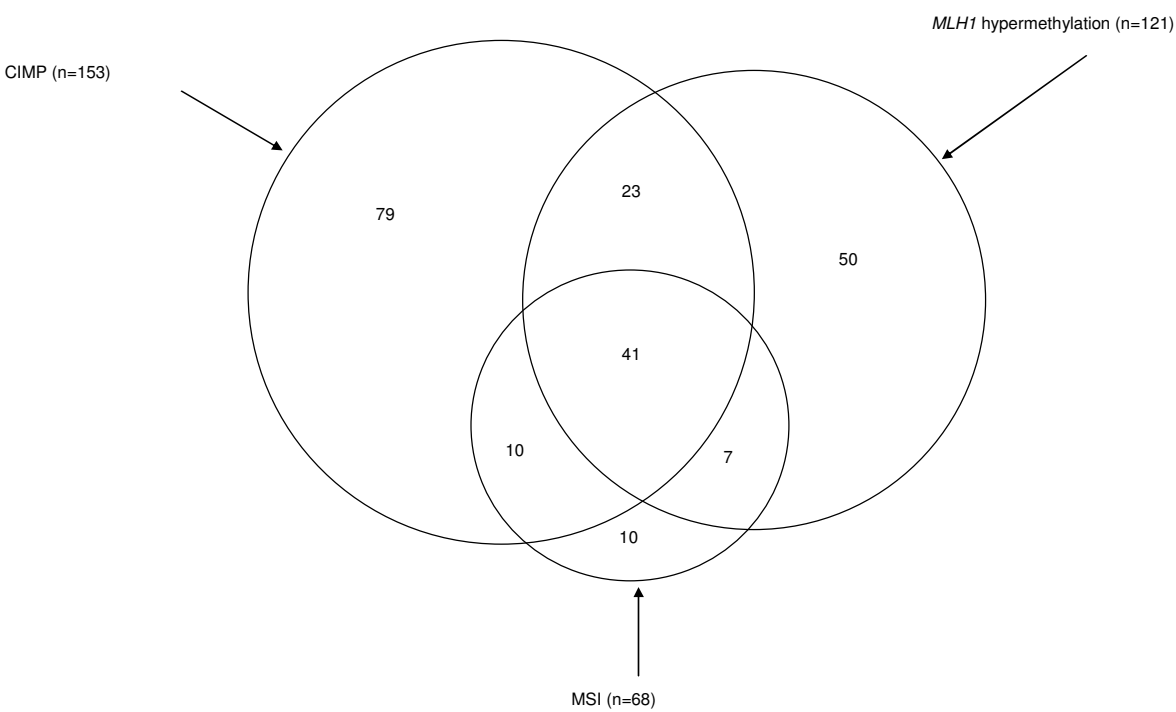

Figure 2 Overlap between CIMP, MLH1 hypermethylation and MSI in CRCs showing at least one of these three aberrations

In total, there were $n=271$ CRCs harboring at least one aberration. Numbers are based on CRCs with complete analyses of all three molecular characteristics ( $n=547 \mathrm{CRCs}$ ). The sizes of the different areas in this figure may not exactly reflect the numbers of the applicable subsets.

Inverse associations were also observed between MTR A2756G and CIMP ${ }^{+}$among men $(\mathrm{RR}=0.58 ; \mathrm{P}=0.04)$, and between MTRR A66G and MLH1 hypermethylation among women ( $R R=0.55 ; P=0.02)$.

The DNMT3b C>T (rs406193) SNP was associated with decreased risks of CRCs without CIMP ( $R R=0.67 ; P=0.04)$, CRCs without $M S I(R R=0.70 ; P=0.04)$, and a nonsignificant decreased risk of CRCs without $M L H 1$ hypermethylation $(R R=0.73 ; P=0.09)$ among women. However, although not statistically significant, RRs were also decreased for CRCs harboring CIMP or MLH1 hypermethylation. Similarly, EHMT2 G>A (rs535586) was inversely associated CRCs without $M L H 1$ methylation $(R R=0.73), C R C s$ without MSI $(R R=0.73)$ or non-significantly with $C R C s$ without $C I M P(R R=0.75)$ in women.

Conversely, we observed a positive association $(R R=1.99)$ of EHMT2 $\mathrm{G}>\mathrm{A}$ with MLH1 hypermethylation among men. 
Table 4 Associations of SNPs in folate metabolizing enzymes and epigenetic regulators with CRC risk according to methylation status of the tumor among men

\begin{tabular}{|c|c|c|c|c|c|c|c|c|c|c|c|c|c|}
\hline \multirow[b]{3}{*}{ Gene and SNP* } & \multirow[b]{3}{*}{ Genotype } & \multicolumn{4}{|c|}{ CpG Island Methylator Phenotype (CIMP) ब } & \multicolumn{4}{|c|}{ MLH1 promoter hypermethylation } & \multicolumn{4}{|c|}{ Microsatellite instability (MSI) } \\
\hline & & \multicolumn{2}{|r|}{ CIMP+ } & \multicolumn{2}{|c|}{ CIMP- } & \multicolumn{2}{|r|}{ Methylated } & \multicolumn{2}{|c|}{ Unmethylated } & \multicolumn{2}{|r|}{ MSI } & \multicolumn{2}{|r|}{ No MSI } \\
\hline & & $\mathbf{N} \neq$ & $\operatorname{RR}(95 \% \mathrm{Cl}) \S$ & $\mathrm{N}$ & $\operatorname{RR}(95 \% \mathrm{Cl}) \S$ & $\mathrm{N}$ & $\operatorname{RR}(95 \% \mathrm{Cl}) \S$ & $\mathrm{N}$ & $\operatorname{RR}(95 \% \mathrm{Cl}) \S$ & $\mathrm{N}$ & $\operatorname{RR}(95 \% \mathrm{Cl}) \S$ & $\mathbf{N}$ & $\operatorname{RR}(95 \% \mathrm{Cl}) \S$ \\
\hline MTHFR C677T & $\mathrm{CC}$ & 43 & ref. & 103 & ref. & 32 & ref. & 143 & ref. & 21 & ref. & 145 & \\
\hline$(\mathrm{rs} 1801133)^{\dagger}$ & $\mathrm{CT}+\mathrm{TT}$ & 40 & $0.81(0.51-1.28)$ & 135 & $1.14(0.84-1.54)$ & 41 & $1.11(0.68-1.81)$ & 153 & $0.93(0.70-1.22)$ & 20 & $0.83(0.44-1.58)$ & 166 & $0.99(0.75-1.30)$ \\
\hline MTHFR A $1298 C$ & AA & 30 & ref. & 112 & ref. & 32 & ref. & 132 & ref. & 16 & & 139 & \\
\hline (rs1801131) & $A C+C C$ & 54 & $1.16(0.72-1.87)$ & 125 & $0.72(0.53-0.97)$ & 40 & $0.81(0.49-1.32)$ & 165 & $0.81(0.61-1.07)$ & 24 & $0.97(0.50-1.88)$ & 173 & $0.80(0.61-1.06)$ \\
\hline MTR A2756G & AA & 66 & ref. & 153 & ref. & 49 & ref. & 199 & & 25 & & 209 & \\
\hline (rs1805087) & $A G+G G$ & 19 & $0.58(0.34-0.99)$ & 87 & $1.14(0.83-1.55)$ & 24 & $0.98(0.58-1.65)$ & 100 & $1.01(0.75-1.35)$ & 16 & $1.31(0.68-2.51)$ & 107 & $1.02(0.77-1.36)$ \\
\hline MTRR A66G & AA & 10 & ref. & 45 & ref. & 12 & ref. & 49 & ref. & 5 & ref. & 56 & ref. \\
\hline (rs1801394) & $A G+G G$ & 75 & - & 197 & $1.14(0.79-1.66)$ & 61 & $1.32(0.69-2.52)$ & 252 & $1.34(0.93-1.92)$ & 36 & & 262 & $1.22(0.87-1.72)$ \\
\hline$D N M T 3 b C>T$ & CC & 29 & ref. & 81 & ref. & 31 & ref. & 95 & ref. & 17 & ref. & 101 & \\
\hline (rs2424913) & $\mathrm{CT}+\mathrm{TT}$ & 56 & $0.92(0.60-1.49)$ & 161 & $0.95(0.69-1.30)$ & 42 & $0.65(0.39-1.06)$ & 205 & $1.03(0.77-1.38)$ & 24 & $0.66(0.35-1.28)$ & 216 & $1.03(0.77-1.36)$ \\
\hline$D N M T 3 b C>T$ & $\mathrm{CC}$ & 59 & ref. & 182 & & 54 & & 223 & & 30 & & 239 & \\
\hline (rs406193) & $\mathrm{CT}+\mathrm{TT}$ & 26 & $1.49(0.90-2.45)$ & 60 & $1.11(0.79-1.57)$ & 19 & $1.19(0.68-2.08)$ & 78 & $1.18(0.86-1.62)$ & 11 & $1.25(0.61-2.56)$ & 79 & $1.12(0.82-1.53)$ \\
\hline$E H M T 1 \mathrm{G}>\mathrm{A}$ & GG & 74 & ref. & 197 & ref. & 57 & ref. & 253 & Ref. & 36 & ref. & 259 & \\
\hline (rs4634736) & $G A+A A$ & 11 & $0.65(0.34-1.26)$ & 43 & $0.96(0.65-1.40)$ & 16 & $1.23(0.69-2.22)$ & 46 & $0.84(0.58-1.21)$ & 4 & & 57 & $0.96(0.68-1.36)$ \\
\hline EHMT2 $\mathrm{G}>\mathrm{A}$ & GG & 34 & ref. & 98 & ref. & 20 & ref. & 130 & Ref. & 15 & & 124 & \\
\hline (rs535586) & $G A+A A$ & 50 & $1.11(0.69-1.76)$ & 143 & $1.10(0.81-1.48)$ & 53 & $1.99(1.16-3.41)$ & 168 & $0.97(0.73-1.28)$ & 26 & $1.30(0.67-2.51)$ & 190 & $1.15(0.88-1.52)$ \\
\hline PRDM2 $\mathrm{G}>\mathrm{A}$ & GG & 46 & ref. & 126 & ref. & 41 & ref. & 160 & Ref. & 47 & ref. & 166 & ref. \\
\hline (rs2235515) & $G A+A A$ & 36 & $1.07(0.67-1.71)$ & 109 & $1.19(0.88-1.60)$ & 31 & $1.04(0.63-1.71)$ & 130 & $1.11(0.84-1.47)$ & 34 & $0.73(0.37-1.44)$ & 140 & 1.16 (0.88-1.52) \\
\hline
\end{tabular}
(1.07)

dbSNP number

Number of cases. Subgroups of $\leq 10$ cases were considered too small for precise estimates and were therefore omitted from the table Age-adjusted incidence rate ratios (95\% Confidence Interval)

If CIMP+: $\geq 3$ out of 5 CIMP markers methylated; CIMP-: $0-2$ out of 5 CIMP markers methylated 
Table 5 Associations of SNPs in folate metabolizing enzymes and epigenetic regulators with CRC risk according to methylation status of the tumor among women

\begin{tabular}{|c|c|c|c|c|c|c|c|c|c|c|c|c|c|}
\hline \multirow[b]{3}{*}{ Gene and SNP* } & \multirow[b]{3}{*}{ Genotype } & \multicolumn{4}{|c|}{ CpG Island Methylator Phenotype (CIMP) " } & \multicolumn{4}{|c|}{ MLH1 promoter hypermethylation } & \multicolumn{4}{|c|}{ Microsatellite instability (MSI) } \\
\hline & & & CIMP+ & & CIMP- & & Methylated & & methylated & & MSI & & No MSI \\
\hline & & $\mathbf{N} \ddagger$ & RR $(95 \% \mathrm{Cl}) \S$ & $\mathbf{N}$ & $\operatorname{RR}(95 \% \mathrm{Cl})$ & $\mathbf{N}$ & $\operatorname{RR}(95 \% \mathrm{Cl})$ & $\mathbf{N}$ & $\operatorname{RR}(95 \% \mathrm{Cl})$ & $\mathrm{N}$ & $\operatorname{RR}(95 \% \mathrm{CI})$ & $\mathrm{N}$ & $\operatorname{RR}(95 \% \mathrm{Cl})$ \\
\hline MTHFR C677T & $\mathrm{CC}$ & 33 & ref. & 82 & ref. & 41 & ref. & 94 & ref. & 18 & ref. & 115 & \\
\hline$(\mathrm{rs} 1801133) \dagger$ & $\mathrm{CT}+\mathrm{TT}$ & 47 & $1.65(1.02-2.65)$ & 100 & $1.40(1.01-1.94)$ & 37 & $1.03(0.64-1.65)$ & 121 & $1.49(1.09-2.03)$ & 23 & $1.49(0.78-2.84)$ & 136 & $1.36(1.02-1.82)$ \\
\hline MTHFR A1298C & AA & 34 & ref. & 80 & ref. & 32 & ref. & 92 & ref. & 22 & ref. & 102 & ref. \\
\hline (rs1801131) & $A C+C C$ & 46 & $1.12(0.70-1.80)$ & 99 & $1.01(0.73-1.41)$ & 45 & $1.15(0.71-1.85)$ & 120 & $1.08(0.79-1.48)$ & 19 & $0.73(0.38-1.39)$ & 146 & $1.18(0.87-1.59)$ \\
\hline $\begin{array}{l}\text { MTR A2756G } \\
\text { (rs1805087) }\end{array}$ & $\begin{array}{l}A A \\
A G+G G\end{array}$ & $\begin{array}{l}54 \\
26\end{array}$ & $\begin{array}{l}\text { ref. } \\
0.96(0.59-1.58)\end{array}$ & $\begin{array}{c}115 \\
70\end{array}$ & $\begin{array}{l}\text { ref. } \\
1.22(0.87-1.71)\end{array}$ & $\begin{array}{l}47 \\
31\end{array}$ & $\begin{array}{l}\text { ref. } \\
1.32(0.82-2.13)\end{array}$ & $\begin{array}{c}137 \\
60\end{array}$ & $\begin{array}{l}\text { ref. } \\
1.17(0.85-2.61)\end{array}$ & $\begin{array}{l}25 \\
16\end{array}$ & $\begin{array}{l}\text { ref. } \\
1.28(0.67-2.45)\end{array}$ & $\begin{array}{c}156 \\
98\end{array}$ & $\begin{array}{l}\text { ref. } \\
1.26(0.93-1.70)\end{array}$ \\
\hline $\begin{array}{l}\text { MTRR A66G } \\
\text { (rs1801394) }\end{array}$ & $\begin{array}{l}A A \\
A G+G G\end{array}$ & $\begin{array}{l}16 \\
64\end{array}$ & $\begin{array}{l}\text { ref. } \\
1.00(0.56-1.79)\end{array}$ & $\begin{array}{c}46 \\
139\end{array}$ & $\begin{array}{l}\text { ref. } \\
0.75(0.51-1.11)\end{array}$ & $\begin{array}{l}24 \\
53\end{array}$ & $\begin{array}{l}\text { ref. } \\
0.55(0.33-0.92)\end{array}$ & $\begin{array}{c}44 \\
252\end{array}$ & $\begin{array}{l}\text { ref. } \\
0.99(0.68-1.46)\end{array}$ & $\begin{array}{l}11 \\
29\end{array}$ & $\begin{array}{l}\text { ref. } \\
0.66(0.32-1.37)\end{array}$ & $\begin{array}{c}58 \\
196\end{array}$ & $\begin{array}{l}\text { ref. } \\
0.84(0.59-1.20)\end{array}$ \\
\hline $\begin{array}{l}\text { DNMT3b C>T } \\
\text { (rs2424913) }\end{array}$ & $\begin{array}{l}\mathrm{CC} \\
\mathrm{CT}+\mathrm{TT}\end{array}$ & $\begin{array}{l}23 \\
57\end{array}$ & $\begin{array}{l}\text { ref. } \\
1.24(0.74-2.06)\end{array}$ & $\begin{array}{c}66 \\
121\end{array}$ & $\begin{array}{l}\text { ref. } \\
0.91(0.65-1.27)\end{array}$ & $\begin{array}{l}23 \\
55\end{array}$ & $\begin{array}{l}\text { ref. } \\
1.18(0.71-1.97)\end{array}$ & $\begin{array}{c}80 \\
141\end{array}$ & $\begin{array}{l}\text { ref. } \\
0.88 \text { (0.64-1.21) }\end{array}$ & $\begin{array}{l}10 \\
31\end{array}$ & ref. & $\begin{array}{c}92 \\
165\end{array}$ & $\begin{array}{l}\text { ref. } \\
0.89(0.66-1.21)\end{array}$ \\
\hline $\begin{array}{l}\text { DNMT3b C>T } \\
\text { (rs406193) }\end{array}$ & $\begin{array}{l}\mathrm{CC} \\
\mathrm{CT}+\mathrm{TT}\end{array}$ & $\begin{array}{l}61 \\
19\end{array}$ & $\begin{array}{l}\text { ref. } \\
0.74(0.43-1.29)\end{array}$ & $\begin{array}{c}145 \\
40\end{array}$ & $\begin{array}{l}\text { ref. } \\
0.67(0.45-0.98)\end{array}$ & $\begin{array}{l}60 \\
17\end{array}$ & $\begin{array}{l}\text { ref. } \\
0.69(0.39-1.21)\end{array}$ & $\begin{array}{c}167 \\
51\end{array}$ & $\begin{array}{l}\text { ref. } \\
0.73(0.51-1.05)\end{array}$ & $\begin{array}{l}30 \\
10\end{array}$ & ref. & $\begin{array}{c}196 \\
57\end{array}$ & $\begin{array}{l}\text { ref. } \\
0.70(0.50-0.98)\end{array}$ \\
\hline $\begin{array}{l}\text { EHMT1 G>A } \\
\text { (rs4634736) }\end{array}$ & $\begin{array}{l}\text { GG } \\
\text { GA+AA }\end{array}$ & $\begin{array}{l}69 \\
11\end{array}$ & $\begin{array}{l}\text { ref. } \\
0.62(0.32-1.21)\end{array}$ & $\begin{array}{l}142 \\
43\end{array}$ & $\begin{array}{l}\text { ref. } \\
1.19(0.81-1.75)\end{array}$ & $\begin{array}{l}62 \\
15\end{array}$ & $\begin{array}{l}\text { ref. } \\
1.01(0.56-1.82)\end{array}$ & $\begin{array}{l}175 \\
44\end{array}$ & $\begin{array}{l}\text { ref. } \\
0.98(0.67-1.44)\end{array}$ & $\begin{array}{c}37 \\
3\end{array}$ & ref. & $\begin{array}{c}199 \\
56\end{array}$ & $\begin{array}{l}\text { ref. } \\
1.10(0.78-1.57)\end{array}$ \\
\hline $\begin{array}{l}\text { EHMT2 G>A } \\
\text { (rs535586) }\end{array}$ & $\begin{array}{l}\text { GG } \\
\text { GA+AA }\end{array}$ & $\begin{array}{l}35 \\
44\end{array}$ & $\begin{array}{l}\text { ref. } \\
0.82(0.51-1.32)\end{array}$ & $\begin{array}{l}86 \\
143\end{array}$ & $\begin{array}{l}\text { ref. } \\
0.75(0.54-1.04)\end{array}$ & $\begin{array}{l}35 \\
42\end{array}$ & $\begin{array}{l}\text { ref. } \\
0.80(0.50-1.28)\end{array}$ & $\begin{array}{l}102 \\
114\end{array}$ & $\begin{array}{l}\text { ref. } \\
0.73(0.54-1.00)\end{array}$ & $\begin{array}{l}15 \\
25\end{array}$ & $\begin{array}{l}\text { ref. } \\
1.07(0.56-2.07)\end{array}$ & $\begin{array}{l}119 \\
132\end{array}$ & $\begin{array}{l}\text { ref. } \\
0.73(0.54-0.98)\end{array}$ \\
\hline $\begin{array}{l}\text { PRDM2 G>A } \\
\text { (rs2235515) }\end{array}$ & $\begin{array}{l}G G \\
G A+A A\end{array}$ & $\begin{array}{l}49 \\
31\end{array}$ & $\begin{array}{l}\text { ref. } \\
0.94(0.58-1.51)\end{array}$ & $\begin{array}{c}99 \\
109\end{array}$ & $\begin{array}{l}\text { ref. } \\
1.22(0.87-1.69)\end{array}$ & $\begin{array}{l}39 \\
37\end{array}$ & $\begin{array}{l}\text { ref. } \\
1.41(0.88-2.26)\end{array}$ & $\begin{array}{c}122 \\
91\end{array}$ & $\begin{array}{l}\text { ref. } \\
1.11(0.81-1.51)\end{array}$ & $\begin{array}{l}21 \\
20\end{array}$ & $\begin{array}{l}\text { ref. } \\
1.41(0.75-2.66)\end{array}$ & $\begin{array}{l}137 \\
111\end{array}$ & $\begin{array}{l}\text { ref. } \\
1.20(0.90-1.61)\end{array}$ \\
\hline
\end{tabular}

SNP: Single Nucleotide Polymorphism

Number of cases. Subgroups of $\leq 10$ cases were considered too small for precise estimates and were therefore omitted from the table

Age-adjusted incidence rate ratios $(95 \%$ Confidence Interval)

$\geq 3$ out of 5 CIMP markers methylated

If CIMP+: $\geq 3$ out of 5 CIMP markers methylated; CIMP-: $0-2$ out of 5 CIMP markers methylated 


\section{Discussion}

Here we studied associations between SNPs in folate metabolizing enzymes, a DNA methyltransferase and histone methyltransferases with CRC risk, accounting for related methylation phenotypes in a large prospective cohort study in the Netherlands. We observed that MTHFR C677T may have opposite effects in men and women, and that MTR A2756G potentially increases CRC risk. Also, genetic variants of DNMT3b and EHMT2 may reduce CRC risk among women. Regarding hypermethylation phenotypes, we observed that MTR and MTRR rare variants were inversely associated with CIMP in men and $M L H 1$ hypermethylation in women, respectively, possibly by lowering methyl group availability. Although methylation-associated characteristics were significantly related, the overlap between CIMP and MLH1 hypermethylation or MSI was limited.

The MTHFR C677T and A1298C polymorphisms have previously been investigated and were generally inversely associated with CRC risk $(4,5,12,44,45)$, or with CRA recurrence (46). Conversely, associations with increased CRC risk (47-49), CRA risk $(50)$, or increased risk of CRA recurrence $(51,52)$ have been observed as well. Analyses were stratified by sex in some studies, and positive associations with CRC were reported among men for MTHFR C677T (47) and A1298C $(48,50)$. In addition, similar to our study, the MTHFR C677T polymorphism has been observed to be associated with increased CRC risk among women, but not among men (48). MTHFR polymorphisms may reduce enzymatic activity and thereby decrease the pool of 5methyltetrahydrofolate. The resulting lower availability of methyl groups may lead to global DNA hypomethylation (53). It may also be associated with increased promoter hypermethylation in CRC (7), with CIMP (6), or with MSI $(8,54,55)$ which is highly correlated with CIMP in CRC (36). Although these two opposite methylation patterns may develop independently of one another, global DNA hypomethylation and gene promoter hypermethylation are observed concurrently in CRC (56-58). However, it is currently unknown to what extent alterations in methyl group metabolism influence this imbalance in the distribution of cytosine methylation, and neither do we know to what extent this influences colorectal carcinogenesis. Moreover, methyl groups may have different targets, e.g. DNA, RNA or proteins (Figure 1), and the relative contribution of methyl groups to either of these targets is unknown.

Although in our study MTHFR C677T tended to increase overall CRC risk among women, this effect could not be explained by a distinct positive association with CIMP only. Among men on the other hand, MTHFR C677T reduced overall CRC risk and MTHFR A1298C was inversely associated with CRCs without CIMP. A decreased pool of 5-methyl tetrahydrofolate by MTHFR polymorphisms may be associated with an increased or normal pool of 5,10-methylenene tetrahydrofolate which optimizes DNA synthesis. However, this may have dual consequences for carcinogenesis since increased DNA synthesis possibly prevents DNA instability and thereby protects against carcinogenesis, but may also increase cell proliferation in tumors. Nonetheless, we hypothesize that MTHFR may act as a switch being able to shift the balance between DNA methylation and DNA synthesis (Figure 1), both of which may have distinct consequences for carcinogenesis. Our observations suggest that MTHFR polymorphisms, albeit in different directions, may influence CRC risk in both men and women but that a change in promoter hypermethylation, as measured by CIMP or 
MLH1 hypermethylation, may not be the primary contributor to carcinogenesis in these individuals.

Among subjects in our study population, the MTR A2756G polymorphism was associated with increased CRC risk. Genetic variants of MTR were not associated with CRC in a number of previous studies $(12,59,60)$. Modest risk reductions among MTR 2756GG homozygotes were found in one CRA study (9) and in one CRC study (10), whereas also non-significant increased risks were observed between this SNP and CRA (11) or CRC (13). SNPs in MTR were associated with lower plasma homocysteine (tHcy) concentrations (61), suggesting lower catalytic activity of the MTR enzyme and lower availability of methyl groups. Interestingly, we observed that the MTR A2756G SNP was associated with reduced risk of CRCs with CIMP among men.

It was previously observed that the MTRR A66G SNP may be inversely associated with CRA recurrence (46), but with increased CRC risk (13). In addition, other SNPs in MTRR were associated with an increased risk of CRA (11) and CRC (12). We did not observe an association with overall CRC risk in our study, but MTRR A66G was associated with reduced risk of CRCs with $M L H 1$ hypermethylation among women. Since the MTRR A66G SNP may also lead to reduced catalytic activity of the MTRR enzyme (62), our data suggest that it may result in decreased promoter hypermethylation in CRC similar to MTR A2756G, which is involved in the same metabolic conversion in the one-carbon metabolism.

The CIMP phenotype has not uniquely been defined, since various sets of promoters have previously been used with different cut-off values (63). In order to investigate an optimal set of markers for CIMP, Weisenberger et al (36) screened 195 CpG island methylation markers, and proposed a robust new panel of 5 markers to define CIMP in CRC. This new set has been successfully validated in a large group of incident CRC patients (64), and we have used these new markers in our study. However, we have shown that the overlap between CIMP and MLH1 or MSI may be incomplete. It has also been suggested that CIMP may consist of three molecular subtypes based on presence or absence of MSI, BRAF, KRAS or p53 mutations (65), but these characteristics are not mutually exclusive. In addition, we previously observed incomplete overlap between MLH1 hypermethylation or -expression, MSI and $B R A F$ mutations (41). The current study suggests that lower enzymatic activity of folate metabolizing enzymes MTR and MTRR is inversely associated with either CIMP or MLH1 hypermethylation. In view of these observations, it remains important to investigate associations with CIMP and other methylation endpoints separately.

The DNMT3b C>T (rs2424913) SNP was not associated with CRC risk. However, an increased risk of CRC could be expected since this polymorphism increases enzymatic activity of DNMT3b (21), and DNMT3b overexpression was associated with increased promoter hypermethylation in different types of cancers $(15-17,19,20)$. Moreover, positive associations were observed with colorectal polyps and early onset of CRC in HNPCC patients $(23,25)$ and several other cancers $(21,22,24)$. Other genetic variants of DNMT3b that have been identified are the $-283 \mathrm{~T}>\mathrm{C}$ and $-579 \mathrm{G}>\mathrm{T}$ polymorphisms, of which the latter was associated with reduced CRC risk (66). In addition, lung cancer risk was reduced for occurrence of the rare alleles of each of these SNPs (67), which was contrary to the increased lung cancer risk associated with DNMT3b C>T (rs2424913) observed by Shen et al (21). Interestingly, enzymatic activity of DNMT3b was decreased when the rare allele of $-283 T>C$ was present (67). Apparently, different 
polymorphisms in DNMT3b may have opposite effects and individuals may be more susceptible to carcinogenesis with higher DNMT3b enzymatic activity $(21-23,25)$, whereas decreased activity may protect against carcinogenesis $(66,67)$. While a similar but weak inverse association was previously observed with breast cancer for the DNMT3b C>T (rs406193) polymorphism (30), we observed an inverse association with CRC among women. However, this protective effect was not substantially different between CRCs with or without CIMP, MLH1 hypermethylation or MSI.

Regarding the histone methyltransferases, we observed an inverse association between EHMT2 G>A (rs535586) and CRC risk among women. A significant positive association was observed with breast cancer although the RR was small for that particular polymorphism (30). These observations seem contradictive, but may nonetheless suggest that this EHMT2 polymorphism affects carcinogenesis of different cancer types. In our study, it was associated with increased risk of CRCs with MLH1 hypermethylation in men and a decreased risk of those without MLH1 hypermethylation among women. However, like for the other genes studied here, it lacks a biological explanation why an effect on methylation would be different for men and women. Moreover, it is currently unknown to which extent SNPs in histone methyltransferases such as EHMT2 lead to altered enzymatic activity. Obviously, the exact role of EHMT2 in colorectal carcinogenesis needs further investigation in the future.

In conclusion, genetic variants of methyl metabolism enzymes or epigenetic regulators may affect colorectal carcinogenesis and our observations suggest that reduced enzymatic activity of some folate metabolizing enzymes may result in decreased gene promoter hypermethylation in CRC. In view of this, it would be interesting to study whether methyl donor intake affects promoter hypermethylation and the potential modifying effect of polymorphisms in folate metabolizing enzymes, DNA methyltransferases and histone methyltransferases. We observed that the overlap of CpG island hypermethylation markers and associated characterstics may be incomplete, indicating that these characteristics should be considered separately when studying potential causes of a "methylation phenotype" in CRC. 


\section{References}

1. Herman JG, Baylin SB. Gene silencing in cancer in association with promoter hypermethylation. N Engl J Med 2003;349(21):2042-54.

2. Frosst $P$, Blom HJ, Milos R, Goyette $P$, Sheppard $C A$, Matthews RG, et al. A candidate genetic risk factor for vascular disease: a common mutation in methylenetetrahydrofolate reductase. Nat Genet 1995;10(1):111-3.

3. van der Put NM, Gabreels F, Stevens EM, Smeitink JA, Trijbels FJ, Eskes TK, et al. A second common mutation in the methylenetetrahydrofolate reductase gene: an additional risk factor for neural-tube defects? Am J Hum Genet 1998;62(5):1044-51.

4. Huang $Y$, Han S, Li Y, Mao Y, Xie Y. Different roles of MTHFR C677T and A1298C polymorphisms in colorectal adenoma and colorectal cancer: a meta-analysis. J Hum Genet 2007;52(1):73-85.

5. Hubner RA, Houlston RS. MTHFR C677T and colorectal cancer risk: A meta-analysis of 25 populations. Int J Cancer 2007;120(5):1027-35.

6. Curtin K, Slattery ML, Ulrich CM, Bigler J, Levin TR, Wolff RK, et al. Genetic polymorphisms in one-carbon metabolism: associations with CpG island methylator phenotype (CIMP) in colon cancer and the modifying effects of diet. Carcinogenesis 2007;28(8):1672-9.

7. Oyama K, Kawakami K, Maeda K, Ishiguro K, Watanabe G. The association between methylenetetrahydrofolate reductase poly-morphism and promoter methylation in proximal colon cancer. Anticancer Res 2004;24(2B):649-54.

8. Hubner RA, Lubbe S, Chandler I, Houlston RS. MTHFR C677T has differential influence on risk of MSI and MSS colorectal cancer. Hum Mol Genet 2007;16(9):1072-7.

9. Chen J, Giovannucci E, Hankinson SE, Ma J, Willett WC, Spiegelman D, et al. A prospective study of methylenetetrahydrofolate reductase and methionine synthase gene polymorphisms, and risk of colorectal adenoma. Carcinogenesis 1998;19(12):2129-32.

10. Ma J, Stampfer MJ, Christensen B, Giovannucci E, Hunter DJ, Chen J, et al. A polymorphism of the methionine synthase gene: association with plasma folate, vitamin B12, homocyst(e)ine, and colorectal cancer risk. Cancer Epidemiol Biomarkers Prev $1999 ; 8(9): 825-9$.

11. Hazra A, Wu K, Kraft P, Fuchs CS, Giovannucci EL, Hunter DJ. Twenty-four nonsynonymous polymorphisms in the one-carbon metabolic pathway and risk of colorectal adenoma in the Nurses' Health Study. Carcinogenesis 2007;28(7):1510-9.

12. Koushik A, Kraft P, Fuchs CS, Hankinson SE, Willett WC, Giovannucci EL, et al. Nonsynonymous polymorphisms in genes in the one-carbon metabolism pathway and associations with colorectal cancer. Cancer Epidemiol Biomarkers Prev 2006;15(12):240817.

13. Le Marchand L, Donlon T, Hankin JH, Kolonel LN, Wilkens LR, Seifried A. B-vitamin intake, metabolic genes, and colorectal cancer risk (United States). Cancer Causes Control $2002 ; 13(3): 239-48$.

14. Okano M, Bell DW, Haber DA, Li E. DNA methyltransferases Dnmt3a and Dnmt3b are essential for de novo methylation and mammalian development. Cell 1999;99(3):247-57.

15. Beaulieu N, Morin S, Chute IC, Robert MF, Nguyen H, MacLeod AR. An essential role for DNA methyltransferase DNMT3B in cancer cell survival. J Biol Chem 2002;277(31):2817681.

16. Jacinto FV, Ballestar E, Ropero S, Esteller M. Discovery of epigenetically silenced genes by methylated DNA immunoprecipitation in colon cancer cells. Cancer Res 2007;67(24):11481-6.

17. Wang J, Bhutani M, Pathak AK, Lang W, Ren $\mathrm{H}$, Jelinek J, et al. Delta DNMT3B variants regulate DNA methylation in a promoter-specific manner. Cancer Res 2007;67(22):1064752.

18. Linhart HG, Lin H, Yamada $Y$, Moran E, Steine EJ, Gokhale S, et al. Dnmt3b promotes tumorigenesis in vivo by gene-specific de novo methylation and transcriptional silencing. Genes Dev 2007;21(23):3110-22.

19. Wang J, Walsh G, Liu DD, Lee JJ, Mao L. Expression of Delta DNMT3B variants and its association with promoter methylation of 16 and RASSF1A in primary non-small cell lung cancer. Cancer Res 2006;66(17):8361-6. 
20. Roll JD, Rivenbark AG, Jones WD, Coleman WB. DNMT3b overexpression contributes to a hypermethylator phenotype in human breast cancer cell lines. Mol Cancer 2008; 7:15.

21. Shen H, Wang L, Spitz MR, Hong WK, Mao L, Wei Q. A novel polymorphism in human cytosine DNA-methyltransferase-3B promoter is associated with an increased risk of lung cancer. Cancer Res 2002;62(17):4992-5.

22. Singal R, Das PM, Manoharan M, Reis IM, Schlesselman JJ. Polymorphisms in the DNA methyltransferase 3b gene and prostate cancer risk. Oncol Rep 2005;14(2):569-73.

23. Jung AY, Poole EM, Bigler J, Whitton J, Potter JD, Ulrich CM. DNA methyltransferase and alcohol dehydrogenase: gene-nutrient interactions in relation to risk of colorectal polyps. Cancer Epidemiol Biomarkers Prev 2008;17(2):330-8.

24. Wang L, Rodriguez M, Kim ES, Xu Y, Bekele N, El-Naggar AK, et al. A novel C/T polymorphism in the core promoter of human de novo cytosine DNA methyltransferase 3 B6 is associated with prognosis in head and neck cancer. Int J Oncol 2004;25(4):993-9.

25. Jones JS, Amos CI, Pande M, Gu X, Chen J, Campos IM, et al. DNMT3b polymorphism and hereditary nonpolyposis colorectal cancer age of onset. Cancer Epidemiol Biomarkers Prev 2006;15(5):886-91.

26. Tamaru H, Selker EU. A histone H3 methyltransferase controls DNA methylation in Neurospora crassa. Nature 2001;414(6861):277-83.

27. Kondo $\mathrm{Y}$, Shen L, Issa JP. Critical role of histone methylation in tumor suppressor gene silencing in colorectal cancer. Mol Cell Biol 2003;23(1):206-15.

28. Chadwick RB, Jiang GL, Bennington GA, Yuan B, Johnson CK, Stevens MW, et al. Candidate tumor suppressor RIZ is frequently involved in colorectal carcinogenesis. Proc Natl Acad Sci U S A 2000;97(6):2662-7.

29. Yoon KA, Park S, Hwangbo B, Shin HD, Cheong HS, Shin HR, et al. Genetic polymorphisms in the Rb-binding zinc finger gene RIZ and the risk of lung cancer. Carcinogenesis 2007;28(9):1971-7.

30. Cebrian A, Pharoah PD, Ahmed S, Ropero S, Fraga MF, Smith PL, et al. Genetic variants in epigenetic genes and breast cancer risk. Carcinogenesis 2006;27(8):1661-9.

31. van den Brandt PA, Goldbohm RA, van 't Veer P, Volovics A, Hermus RJ, Sturmans F. A large-scale prospective cohort study on diet and cancer in The Netherlands. J Clin Epidemiol $1990 ; 43(3): 285-95$.

32. Van den Brandt PA, Schouten LJ, Goldbohm RA, Dorant E, Hunen PM. Development of a record linkage protocol for use in the Dutch Cancer Registry for Epidemiological Research. Int J Epidemiol 1990;19(3):553-8.

33. Casparie M, Tiebosch AT, Burger G, Blauwgeers $H$, van de Pol A, van Krieken JH, et al. Pathology databanking and biobanking in The Netherlands, a central role for PALGA, the nationwide histopathology and cytopathology data network and archive. Cell Oncol 2007;29(1):19-24.

34. Meulenbelt I, Droog S, Trommelen GJ, Boomsma DI, Slagboom PE. High-yield noninvasive human genomic DNA isolation method for genetic studies in geographically dispersed families and populations. Am J Hum Genet 1995;57(5):1252-4.

35. Knaapen AM, Ketelslegers HB, Gottschalk RW, Janssen RG, Paulussen AD, Smeets HJ, et al. Simultaneous genotyping of nine polymorphisms in xenobiotic-metabolizing enzymes by multiplex PCR amplification and single base extension. Clin Chem 2004;50(9):1664-8.

36. Weisenberger DJ, Siegmund KD, Campan M, Young J, Long TI, Faasse MA, et al. CpG island methylator phenotype underlies sporadic microsatellite instability and is tightly associated with BRAF mutation in colorectal cancer. Nat Genet 2006;38(7):787-93.

37. Herman JG, Graff JR, Myohanen S, Nelkin BD, Baylin SB. Methylation-specific PCR: a novel PCR assay for methylation status of $\mathrm{CPG}$ islands. Proc Natl Acad Sci $U$ S A 1996;93(18):9821-6.

38. van Engeland M, Weijenberg MP, Roemen GM, Brink M, de Bruine AP, Goldbohm RA, et al. Effects of dietary folate and alcohol intake on promoter methylation in sporadic colorectal cancer: the Netherlands cohort study on diet and cancer. Cancer Res 2003;63(12):3133-7.

39. Derks S, Lentjes MH, Hellebrekers DM, de Bruine AP, Herman JG, van Engeland M. Methylation-specific PCR unraveled. Cell Oncol 2004;26(5-6):291-9. 
40. Suraweera N, Duval A, Reperant M, Vaury C, Furlan D, Leroy K, et al. Evaluation of tumor microsatellite instability using five quasimonomorphic mononucleotide repeats and pentaplex PCR. Gastroenterology 2002;123(6):1804-11.

41. de Vogel S, Bongaerts BW, Wouters KA, Kester AD, Schouten LJ, de Goeij AF, et al. Associations of dietary methyl donor intake with $M L H 1$ promoter hypermethylation and related molecular phenotypes in sporadic colorectal cancer. Carcinogenesis 2008;29(9):1765-73.

42. Lin DY WL. The robust inference for the Cox Proportional Hazards Model. JASA 1989;84(408):1074-1078.

43. Schoenfeld D. Partial residuals for the proportional hazards regression models. Biometrika 1982;69(1):239-241.

44. Sharp L, Little J, Brockton NT, Cotton SC, Masson LF, Haites NE, et al. Polymorphisms in the methylenetetrahydrofolate reductase (MTHFR) gene, intakes of folate and related $B$ vitamins and colorectal cancer: a case-control study in a population with relatively low folate intake. Br J Nutr 2008;99(2):379-89.

45. Murtaugh MA, Curtin K, Sweeney C, Wolff RK, Holubkov R, Caan BJ, et al. Dietary intake of folate and co-factors in folate metabolism, MTHFR polymorphisms, and reduced rectal cancer. Cancer Causes Control 2007;18(2):153-63.

46. Hubner RA, Muir KR, Liu JF, Sellick GS, Logan RF, Grainge M, et al. Folate metabolism polymorphisms influence risk of colorectal adenoma recurrence. Cancer Epidemiol Biomarkers Prev 2006;15(9):1607-13.

47. Heijmans BT, Boer JM, Suchiman HE, Cornelisse CJ, Westendorp RG, Kromhout D, et al. A common variant of the methylenetetrahydrofolate reductase gene (1p36) is associated with an increased risk of cancer. Cancer Res 2003;63(6):1249-53.

48. Lightfoot TJ, Barrett JH, Bishop T, Northwood EL, Smith G, Wilkie MJ, et al. Methylene tetrahydrofolate reductase genotype modifies the chemopreventive effect of folate in colorectal adenoma, but not colorectal cancer. Cancer Epidemiol Biomarkers Prev 2008;17(9):2421-30.

49. Ryan BM, Molloy AM, McManus R, Arfin Q, Kelleher D, Scott JM, et al. The methylenetetrahydrofolate reductase (MTHFR) gene in colorectal cancer: role in tumor development and significance of allelic loss in tumor progression. Int $\mathrm{J}$ Gastrointest Cancer 2001;30(3):105-11.

50. Mitrou PN, Watson MA, Loktionov AS, Cardwell C, Gunter MJ, Atkin WS, et al. MTHFR (C677T and A1298C) polymorphisms and risk of sporadic distal colorectal adenoma in the UK Flexible Sigmoidoscopy Screening Trial (United Kingdom). Cancer Causes Control 2006;17(6):793-801.

51. Martinez ME, Thompson P, Jacobs ET, Giovannucci E, Jiang R, Klimecki W, et al. Dietary factors and biomarkers involved in the methylenetetrahydrofolate reductase genotypecolorectal adenoma pathway. Gastroenterology 2006;131(6):1706-16.

52. Murphy G, Sansbury LB, Cross AJ, Stolzenberg-Solomon R, Laiyemo A, Albert PS, et al. Folate and MTHFR: risk of adenoma recurrence in the Polyp Prevention Trial. Cancer Causes Control 2008;19(7):751-8.

53. Friso S, Choi SW, Girelli D, Mason JB, Dolnikowski GG, Bagley PJ, et al. A common mutation in the 5,10-methylenetetrahydrofolate reductase gene affects genomic DNA methylation through an interaction with folate status. Proc Natl Acad Sci U S A 2002;99(8):5606-11.

54. Chang SC, Lin PC, Lin JK, Yang SH, Wang HS, Fen-Yau Li A. Role of MTHFR polymorphisms and folate levels in different phenotypes of sporadic colorectal cancers. Int $J$ Colorectal Dis 2007;22(5):483-9.

55. Clarizia AD, Bastos-Rodrigues L, Pena HB, Anacleto C, Rossi B, Soares FA, et al. Relationship of the methylenetetrahydrofolate reductase C677T polymorphism with microsatellite instability and promoter hypermethylation in sporadic colorectal cancer. Genet Mol Res 2006;5(2):315-22.

56. Ehrlich M. Cancer-linked DNA hypomethylation and its relationship to hypermethylation. Curr Top Microbiol Immunol 2006;310:251-74.

57. Bariol C, Suter C, Cheong K, Ku SL, Meagher A, Hawkins N, et al. The relationship between hypomethylation and $\mathrm{CPG}$ island methylation in colorectal neoplasia. Am $\mathrm{J}$ Pathol 2003;162(4):1361-71. 
58. Frigola J, Sole X, Paz MF, Moreno V, Esteller M, Capella G, et al. Differential DNA hypermethylation and hypomethylation signatures in colorectal cancer. Hum Mol Genet 2005;14(2):319-26.

59. Theodoratou E, Farrington SM, Tenesa A, McNeill G, Cetnarskyj R, Barnetson RA, et al. Dietary vitamin b6 intake and the risk of colorectal cancer. Cancer Epidemiol Biomarkers Prev 2008;17(1):171-82.

60. Ulrich CM, Curtin K, Potter JD, Bigler J, Caan B, Slattery ML. Polymorphisms in the reduced folate carrier, thymidylate synthase, or methionine synthase and risk of colon cancer. Cancer Epidemiol Biomarkers Prev 2005;14(11 Pt 1):2509-16.

61. Chen J, Stampfer MJ, Ma J, Selhub J, Malinow MR, Hennekens $\mathrm{CH}$, et al. Influence of a methionine synthase (D919G) polymorphism on plasma homocysteine and folate levels and relation to risk of myocardial infarction. Atherosclerosis 2001;154(3):667-72.

62. Gaughan DJ, Kluijtmans LA, Barbaux S, McMaster D, Young IS, Yarnell JW, et al. The methionine synthase reductase (MTRR) A66G polymorphism is a novel genetic determinant of plasma homocysteine concentrations. Atherosclerosis 2001;157(2):451-6.

63. Teodoridis JM, Hardie C, Brown R. CpG island methylator phenotype (CIMP) in cancer: Causes and implications. Cancer Lett 2008;268(2):177-86.

64. Ogino S, Kawasaki T, Kirkner GJ, Kraft P, Loda M, Fuchs CS. Evaluation of markers for CpG island methylator phenotype (CIMP) in colorectal cancer by a large population-based sample. J Mol Diagn 2007;9(3):305-14.

65. Shen L, Toyota $M$, Kondo $Y$, Lin $E$, Zhang L, Guo $Y$, et al. Integrated genetic and epigenetic analysis identifies three different subclasses of colon cancer. Proc Natl Acad Sci $U S A$ 2007;104(47):18654-9.

66. Hong YS, Lee HJ, You CH, Roh MS, Kwak JY, Lee MJ, et al. DNMT3b 39179GT polymorphism and the risk of adenocarcinoma of the colon in Koreans. Biochem Genet 2007;45(3-4):15563.

67. Lee SJ, Jeon HS, Jang JS, Park SH, Lee GY, Lee BH, et al. DNMT3B polymorphisms and risk of primary lung cancer. Carcinogenesis $2005 ; 26(2): 403-9$ 


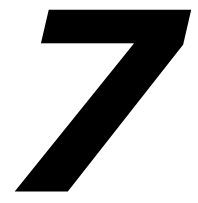

\section{Dietary methyl donors, methyl metabolizing enzymes and epigenetic regulators: diet- gene interactions and promoter CpG island hypermethylation in colorectal cancer}

Stefan de Vogel

Kim AD Wouters Ralph WH Gottschalk Frederik J van Schooten Anton FPM de Goeij Adriaan $\mathrm{P}$ de Bruïne R Alexandra Goldbohm Piet A van den Brandt Manon van Engeland Matty P Weijenberg 


\section{Abstract}

Methyl group intake may influence DNA methylation during carcinogenesis and this effect is possibly modulated by genetic variation in methyl metabolizing enzymes or methyltransferases.

Here, we studied associations of dietary folate, methionine, vitamins B2 and B6 with colorectal cancer (CRC) risk among genotypes of folate metabolizing enzymes (MTHFR, MTR and MTRR), DNA methyltransferase DNMT3b, and histone methyltransferases EHMT1, EHMT2 and PRDM2. Incidence rate ratios (RR) were calculated in case-cohort analyses over tertiles of intake among 609 cases and 1,663 subcohort members of the Netherlands Cohort Study on diet and cancer $(n=120,852)$.

Methionine intake was associated with reduced CRC risk among subjects carrying common variants of both of the rs2424913 and rs406193 C>T polymorphisms in DNMT3b (highest versus lowest tertile: $\mathrm{RR}=0.44 ; P_{\text {trend }}=0.05$ ). Vitamin $\mathrm{B} 2$ was inversely associated with CRC among individuals with the MTHFR 677CC genotype $\left(\mathrm{RR}=0.66 ; P_{\text {trend }}=0.08\right)$, while a strong inverse association was observed when $\leq 1$ rare allele occurred in the combination of folate metabolizing enzymes MTHFR, MTR and MTRR $\left(R R=0.30 ; P_{\text {trend }}=0.005\right)$. Folate or vitamin B6 were not inversely associated with CRC, neither did we observe associations between methyl donor intake and the CpG island methylator phenotype (CIMP).

In conclusion, MTHFR and DNMT3b polymorphisms may modulate the bioavailability of dietary methyl group donors and thereby affect colorectal carcinogenesis. The effect of methyl donors on CRC may be more pronounced if folate metabolizing enzymes or DNA methyltransferases are left unaffected by rare variants of their encoding polymorphic genes. Combining genotypes may reveal diet associations with CRC and should be considered in association studies. 


\section{Introduction}

In the preceding manuscript by de Vogel et al (part 1), associations were investigated between genetic variants of folate metabolizing enzymes, a DNA methyltransferase and histone methyltransferases with sporadic colorectal cancer (CRC) risk, accounting for the CpG island methylator phenotype (CIMP), MLH1 hypermethylation or microsatellite instability (MSI) within the Netherlands Cohort Study on diet and cancer (NLCS). In the present study, we investigate associations between dietary methyl donor intake and these endpoints within the same genotypes among subjects of the NLCS.

CRC may arise through several distinct molecular pathways, which are based on the presence or absence of for example CpG island promoter hypermethylation or specific types of DNA instability. CRCs showing the CpG island methylator phenotype (CIMP) are characterized by frequent hypermethylation of promoter CpG islands (1), which is associated with silencing of tumor suppressor and DNA repair genes thereby contributing to carcinogenesis (2). However, although chromomal instability (CIN) or microsatellite instability (MSI) may be two alternative mechanisms in CRC, CpG island promoter methylation may be associated with both MSI and with specific patterns of chromosomal aberrations in CIN CRCs (3), suggesting that these phenotypes are not mutually exclusive.

Folate and methionine are dietary methyl group donors and may influence DNA methylation, whereas vitamins B2 and B6 may modulate the bioavailability of methyl groups $(4,5)$. A low folate status, which is likely to reflect low dietary folate intake, may decrease genomic DNA methylation $(6,7)$, whereas folate supplementation resulted in increased global DNA methylation in the colonic mucosa (8). Although it may be hypothesized that adequate methyl donor intake also reduces CpG island promoter hypermethylation, the association with gene promoter hypermethylation in CRC was only weak (9), while no inverse associations with CIMP were observed among incident colon cancer patients of a large population-based case-control study (10). High vitamin B6 intake was even suggested to be associated with increased MLH1 promoter methylation in CRC (11) while folate supplementation may increase promoter hypermethylation of multiple genes in colorectal mucosa (12). Apparently, the precise effect of methyl group bioavailability on gene promoter hypermethylation is still unclear and should be investigated further. High alcohol consumption, which reduces the bioavailability of folate, has been reported to be associated with DNA hypomethylation $(13,14)$, and increased risk of CRCs harboring promoter hypermethylation-associated MSI (15). Notably, high alcohol intake was associated with increased risk of CRCs harboring MSI whereas no association was observed with CIMP in the same study population $(10,16)$, suggesting that an effect on these related hypermethylationassociated phenotypes may not be similar. Moreover, we have previously observed that the overlap between CIMP and MSI may be incomplete (part1), which underscores the need to investigate these related endpoints separately.

The effect of methyl donor intake on DNA methylation may be modified by genetic variants of folate metabolizing enzymes, which may influence enzymatic activity and thereby the bioavailability of methyl groups. In the accompanying article in this issue (part1), we observed that the methionine synthase (MTR) A2756G polymorphism was associated with decreased risk of CRCs harboring CIMP among men, and that women with the methionine synthase reductase (MTRR) A66G polymorphism were at reduced 
risk of developing $\mathrm{CRC}$ harboring $\mathrm{MLH1}$ hypermethylation. Furthermore, DNA methyltransferases (DNMTs) and histone methyltransferases (HMTs) are other enzymes involved in epigenetic regulation of gene expression which may modify the effect of methyl donor intake on DNA methylation in CRC. We previously observed inverse associations of DNMT3b C>T (rs406193) and the HMT EHMT2 G>A (rs535586) with CRC among women (part 1). However, whether the effect of methyl donor intake is modified by these DNMT and HMT polymorphisms has not previously been studied in relation to $\mathrm{CRC}$.

Here, we aimed to investigate associations between dietary folate, methionine, vitamins $\mathrm{B} 2$ and $\mathrm{B} 6$ with overall $\mathrm{CRC}$, and risk of CRCs harboring CIMP, MLH1 hypermethylation or MSI, accounting for the occurrence of any, or combinations of polymorphisms in folate metabolizing enzymes MTHFR, MTR and MTRR, the DNA methyltransferase $D N M T 3 b$, and histone methyltransferases EHMT1, EHMT2 and PRDM2 in the Netherlands Cohort Study on diet and cancer.

\section{Subjects and methods}

\section{Study population}

The participants of this study were incident CRC patients from the Netherlands Cohort Study on diet and cancer (NLCS), which has been described in detail elsewhere (17). Briefly, this prospective cohort study was initiated in September 1986 and includes 58,279 men and 62,573 women aged 55-69 years and free of disease at baseline. The cohort is followed for cancer occurrence by annual record linkage to the Netherlands Cancer Registry (NCR) and to PALGA (Pathologisch Anatomisch Landelijk Geautomatiseerd Archief), a nationwide network and registry of histopathology and cytopathology reports $(18,19)$. A subcohort of 5,000 subjects was randomly selected after baseline exposure measurement, to estimate accumulation of person-time in the cohort through biennial follow-up of vital status. Cases with prevalent cancer other than non-melanoma skin cancer were excluded from this subcohort, which left 4,774 men and women eligible for analysis.

\section{Food frequency questionnaire}

At baseline, participants filled out a self-administered, 150-item semi-quantitative food frequency questionnaire (FFQ), which concentrated on habitual consumption of food and beverages during the year preceding the start of the study, and also contained questions about age, sex, body weight and -length, smoking status and family history of CRC. Daily mean nutrient intakes were calculated as the cumulated product of the frequencies and portion sizes of all food items and their tabulated nutrient contents from the Dutch Food Composition Table (NEVO table, 1986) (20). The questionnaire was validated through comparison with a 9-day diet record (21). Reproducibility and stability of dietary habits were determined by five annually repeated measurements (22). In order to minimize observer bias in coding and interpretation of the data, questionnaire data were key-entered twice for all incident cases in the cohort and for all subcohort members in a blinded manner with respect to case/subcohort status. 
Folate data were derived from a validated liquid chromatography trienzyme method (23) used to analyze the 125 most important Dutch foods contributing to folate intake (24). Dietary supplement data were also obtained via the food frequency questionnaire. However, the use of B-vitamin supplements was low (7\%) and folic acid was generally not included in these supplements in the Netherlands in the late 1980s. Therefore, folic acid supplement use most likely plays a very minor role in our study population, and supplement use was not further accounted for in the analyses.

\section{Sample collection}

Subcohort members still alive in December $2000(n=3,579)$ were contacted and asked to collect mouth swabs, of whom 1,929 (54\%) responded and returned the mouth swab with informed consent. In total, DNA could successfully be isolated of 1,829 subcohort members who also had complete follow-up information (part 1).

Tumor material of the CRC patients was collected after approval by the ethical review boards of Maastricht University, the NCR and PALGA. During a follow-up period of 7.3 years after baseline, 734 incident CRC patients were identified who had an available PALGA report of the lesion as well as a sufficient amount of isolated DNA needed for molecular analyses.

\section{Genotyping analyses}

MTHFR, MTR, MTRR, DNMT3b, EHMT1, EHMT2 and PRDM2 genotypes were determined using multiplex polymerase chain reaction (PCR) amplification and single base extension (SBE) reactions as described previously (25) (part1). Genotype data were validated by sequencing of fragments containing specific SNPs, which were similar to the SNaPShot results for all but one (99.6\%) of the 9 SNPs within a subset of 30 samples (part 1). Reproducibility of the SNaPShot analysis was established among 93 samples and we observed that the analyses could be reproduced in $99.5 \%$ of these cases (part 1). In total, genotyping analyses were successful from 1,736 subcohort members and 659 CRC patients.

\section{Promoter methylation analyses}

The CpG island methylator phenotype (CIMP) was defined by promoter hypermethylation of at least 3 out of 5 methylation markers (CACNA1G, IGF2, NEUROG1, RUNX3 and SOCS1), as suggested by Weisenberger et al (1). Hypermethylation of the CpG islands of these five CIMP markers and of the MLH1 gene was determined by Methylation Specific PCR (MSP) (26), and described in detail in (part 1). The MSP analyses were successful of $81 \%, 79 \%, 79 \%, 90 \%, 83 \%$ and $93 \%$ out of the 734 patients for CACNA1G, IGF2, NEUROG1, RUNX3, SOCS1 and MLH1, respectively.

\section{Microsatellite instability}

MSI was determined by a pentaplex PCR, using the MSI markers BAT-26, BAT-25, NR21, NR-22 and NR-24, as described in detail by Suraweera et al (27). MSI analyses were successful on $662(90 \%)$ out of the 734 available samples. 


\section{Statistical analyses}

Cox proportional hazards regression models were used to estimate multivariateadjusted incidence rate ratios (RR) and corresponding $95 \%$ confidence intervals (CI) over tertiles of dietary folate, methionine, vitamins B2 and B6, using the lowest tertiles as reference. Tests for dose response trends over the tertiles of intake were estimated by fitting the ordinal exposure variables as continuous variables and evaluated using the Wald test. Standard errors of the RR were estimated using the robust Huber-White sandwich estimator to account for additional variance introduced by sampling from the cohort (28). The proportional hazards assumption was tested using the scaled Schoenfeld residuals (29), and by fitting the main determinants as time-dependent variables. The dietary variables were adjusted for total energy intake by calculating nutrient residuals from the regression of nutrient intake on total energy intake, as described by Willett et al (30).

The analyses were stratified according to genetic status of individuals, i.e. among those homozygous to common genetic variants and among subjects carrying rare alleles. Interactions were tested between dietary folate, methionine, vitamins B2 and B6, and each of the genetic variants. Associations between dietary factors and CRC were also estimated for combinations of genotypes per functional group (i.e. based on the number of rare alleles in any of the folate metabolizing enzymes MTHFR, MTR and $M T R R$, in the DNA methyltransferase $D N M T 3 b$, or in any of the histone methyltransferases EHMT1, EHMT2 and PRDM2.

To investigate whether dietary methyl donors have an effect on promoter hypermethylation in CRC, associations of folate, methionine, vitamins B2 and B6 with the CIMP phenotype were estimated. The associations with MLH1 hypermethylation and MSI were reported previously (31). Furthermore, it was investigated whether these effects would be modified by genetic status by estimating the associations with methylation endpoints within genotypes of folate metabolizing enzymes, DNMT3b and histone methyltransferases.

All models included the co-variates dietary folate, methionine, vitamin B2 and B6, and were additionally adjusted for age, sex, family history of CRC, smoking status, body mass index (BMI), alcohol consumption and energy intake. After excluding subjects with missing information on these covariates or subjects who only partly filled out the questionnaire, 1,663 subcohort members and 609 CRC cases remained for statistical analyses. All analyses were performed with the Stata statistical software package (version 10).

\section{Results}

CRC risk was estimated over tertiles of folate intake, methionine, vitamins B2 and B6 among subjects homozygous for common wild type alleles and among carriers of the rare allele. Folate or methionine intakes were not associated with CRC within either common homozygotes or within heterozygotes and rare homozygotes of any of the genotypes (Table 1). 
However, we observed a non-significant inverse association between vitamin B2 intake and CRC risk among subjects with the MTHFR 677CC common genotype (RR for the highest versus the lowest tertile of intake $=0.66, P_{\text {trend }}=0.08$, Table 2 ), and a significant inverse association among subjects with the common GG genotype of PRDM2 G>A (rs2235515, RR=0.67, $P_{\text {trend }}=0.05$ ). In addition, vitamin B2 was associated with reduced CRC risk in individuals carrying the variant allele of DNMT3b C>T (rs2424913, $\left.\mathrm{RR}=0.69, P_{\text {trend }}=0.05\right)$. These associations for vitamin B2 were even more pronounced among men (RRs were $0.44,0.56$ and 0.55 for MTHFR 677CC, PRDM2 GG (rs2235515) and DNMT3b TT (rs2424913), respectively), but were not observed among women (data not shown).

Conversely, subjects in the third tertile of vitamin B6 intake were at increased CRC risk when they carried the rare allele of DNMT3b C $>$ T ( $r$ 406193, RR=1.90, $\left.P_{\text {trend }}=0.04\right)$, or the common allele of PRDM2 G>A ( $\mathrm{rs} 2235515, \mathrm{RR}=1.49, P_{\text {trend }}=0.03$ ). However, interactions between these dietary factors and genotypes were not statistically significant. 
Table 1 Intake of folate and methionine and CRC risk stratified by genetic status

\begin{tabular}{|c|c|c|c|c|c|c|c|c|c|}
\hline \multirow{3}{*}{$\begin{array}{c}\text { Gene and SNP } \\
\text { (rs number, MAF) * }\end{array}$} & \multirow{3}{*}{$\begin{array}{c}\text { Tertile } \\
\text { of intake }\end{array}$} & \multicolumn{4}{|c|}{ Folate $\dagger$} & \multicolumn{4}{|c|}{ Methionine $\ddagger$} \\
\hline & & \multicolumn{2}{|c|}{ Common homozygotes } & \multicolumn{2}{|c|}{$\begin{array}{l}\text { Heterozygotes and } \\
\text { rare homozygotes }\end{array}$} & \multicolumn{2}{|c|}{ Common homozygotes } & \multicolumn{2}{|c|}{$\begin{array}{c}\text { Heterozygotes and } \\
\text { rare homozygotes }\end{array}$} \\
\hline & & $\mathrm{N} \S$ & $\operatorname{RR}(95 \% \mathrm{Cl}) \uparrow$ & $\mathrm{N}$ & $\operatorname{RR}(95 \% \mathrm{Cl})$ & $\mathbf{N}$ & $\operatorname{RR}(95 \% \mathrm{Cl})$ & $\mathrm{N}$ & $\operatorname{RR}(95 \% \mathrm{Cl})$ \\
\hline & 1 & 90 & ref. & 133 & ref. & 86 & ref. & 123 & ref. \\
\hline \multirow{3}{*}{$(\mathrm{rs} 1801133,0.30)$} & 2 & 83 & $0.80(0.52-1.21)$ & 78 & $0.51(0.35-0.75)$ & 101 & $1.43(0.96-2.13)$ & 101 & $0.84(0.57-1.24)$ \\
\hline & 3 & 100 & $1.22(0.81-1.85)$ & 123 & $0.82(0.56-1.21)$ & 86 & $0.92(0.61-1.41)$ & 110 & $1.08(0.70-1.67)$ \\
\hline & $P_{\text {trend }}$ * & & $0.28^{\circ}-x$ & & 0.30 & & 0.63 & & 0.90 \\
\hline MTHFR A1298C & 1 & 103 & ref. & 116 & ref. & 95 & ref. & 113 & ref. \\
\hline \multirow{2}{*}{$(\mathrm{rs} 1801131,0.37)$} & 2 & 72 & $0.61(0.40-0.92)$ & 89 & $0.73(0.50-1.07)$ & 85 & $1.00(0.65-1.54)$ & 115 & $1.14(0.80-1.64)$ \\
\hline & $\begin{array}{l}3 \\
P_{\text {trend }}\end{array}$ & 98 & $\begin{array}{l}1.03(0.68-1.56) \\
0.97\end{array}$ & 124 & $\begin{array}{l}1.02(0.69-1.51) \\
0.86\end{array}$ & 93 & $\begin{array}{l}1.02(0.65-1.60) \\
0.99\end{array}$ & 101 & $\begin{array}{l}0.92(0.62-1.38) \\
0.58\end{array}$ \\
\hline MTR A2756G & 1 & 136 & ref. & 89 & ref. & 128 & ref. & 83 & ref. \\
\hline \multirow{2}{*}{ (rs1805087, 0.19) } & 2 & 107 & $0.55(0.39-0.79)$ & 57 & $0.84(0.53-1.33)$ & 141 & $1.22(0.87-1.71)$ & 62 & $0.87(0.55-1.38)$ \\
\hline & $\begin{array}{l}3 \\
P_{\text {tend }}\end{array}$ & 154 & $\begin{array}{l}0.99(0.70-1.39) \\
0.90\end{array}$ & 71 & $\begin{array}{l}0.94(0.57-1.54) \\
0.83\end{array}$ & 128 & $\begin{array}{l}1.03(0.71-1.48) \\
0.98\end{array}$ & 72 & $\begin{array}{l}0.94(0.57-1.54) \\
0.69\end{array}$ \\
\hline MTRR A66G & 1 & 56 & ref. & 172 & ref. & 49 & ref. & 164 & ref. \\
\hline \multirow{2}{*}{ (rs1801394, 0.56) } & 2 & 24 & $0.29(0.14-0.59)$ & 140 & $0.78(0.58-1.05)$ & 38 & $1.00(0.52-1.93)$ & 165 & $1.08(0.80-1.46)$ \\
\hline & $\begin{array}{l}3 \\
P_{\text {trend }}\end{array}$ & 49 & $\begin{array}{l}0.62(0.32-1.22) \\
0.23\end{array}$ & 177 & $\begin{array}{l}1.06(0.78-1.45) \\
0.69\end{array}$ & 42 & $\begin{array}{l}1.22(0.53-2.78) \\
0.94\end{array}$ & 160 & $\begin{array}{l}0.96(0.70-1.33) \\
0.72\end{array}$ \\
\hline DNMT3b C>T & 1 & 89 & ref. & 139 & ref. & 84 & ref. & 129 & ref. \\
\hline \multirow[t]{3}{*}{$(\mathrm{rs} 2424913,0.42)$} & 2 & 60 & $0.60(0.38-0.95)$ & 106 & $0.70(0.49-0.99)$ & 61 & $0.61(0.37-1.00)$ & 144 & $1.37(0.99-1.90)$ \\
\hline & 3 & 68 & $0.73(0.44-1.20)$ & 159 & $1.12(0.80-1.57)$ & 72 & $0.66(0.39-1.11)$ & 131 & $1.20(0.83-1.74)$ \\
\hline & $P_{\text {trend }}$ & & 0.20 & & 0.40 & & & & 0.43 \\
\hline DNMT3b C>T & 1 & 170 & ref. & 56 & ref. & 162 & ref. & 49 & ref. \\
\hline \multirow[t]{3}{*}{ (rs406193, 0.14) } & 2 & 123 & $0.67(0.48-0.93)$ & 41 & $0.56(0.32-0.98)$ & 157 & $1.10(0.80-1.51)$ & 46 & $1.05(0.60-1.82)$ \\
\hline & 3 & 175 & $1.04(0.75-1.44)$ & 51 & $0.72(0.39-1.31)$ & 149 & $0.91(0.64-1.28)$ & 53 & $1.43(0.78-2.59)$ \\
\hline & $P_{\text {trend }}$ & & 0.72 & & 0.34 & & 0.45 & & 0.32 \\
\hline EHMT1 $\mathrm{G}>\mathrm{A}$ & 1 & 187 & ref. & 38 & ref. & 172 & ref. & 39 & ref. \\
\hline \multirow[t]{2}{*}{ (rs4634736, 0.10) } & 2 & 129 & $0.62(0.45-0.84)$ & 34 & $0.95(0.49-1.82)$ & 167 & $1.09(0.81-1.48)$ & 35 & $1.12(0.57-2.22)$ \\
\hline & $\begin{array}{l}3 \\
P_{\text {tend }}\end{array}$ & 186 & $\begin{array}{l}0.99(0.73-1.35) \\
0.97\end{array}$ & 40 & $\begin{array}{l}0.97(0.48-1.97) \\
0.90\end{array}$ & 163 & $\begin{array}{l}0.95(0.69-1.32) \\
0.58\end{array}$ & 38 & $\begin{array}{l}1.24(0.54-2.86) \\
0.63\end{array}$ \\
\hline \multirow{4}{*}{ (rs535586, 0.35) } & 1 & 103 & ref. & 122 & ref. & 89 & ref. & 122 & \\
\hline & 2 & 73 & $0.55(0.35-0.84)$ & 89 & $0.73(0.50-1.05)$ & 83 & $1.17(0.76-1.81)$ & 119 & $0.99(0.69-1.42)$ \\
\hline & 3 & 89 & $0.88(0.57-1.35)$ & 135 & $1.09(0.76-1.59)$ & 93 & $1.24(0.80-1.91)$ & 105 & $0.80(0.53-1.22)$ \\
\hline & $P_{\text {trend }}$ & & 0.50 & & 0.59 & & 0.48 & & 0.25 \\
\hline \multirow{4}{*}{$(\mathrm{rs} 2235515,0.23)$} & 1 & & ref. & 106 & ref. & 120 & ref. & 85 & \\
\hline & 2 & 93 & $0.67(0.46-0.96)$ & 65 & $0.61(0.39-0.96)$ & 107 & $0.95(0.66-1.35)$ & 90 & $1.29(0.83-2.01)$ \\
\hline & 3 & 121 & $0.95(0.65-1.39)$ & 95 & $0.93(0.61-1.43)$ & 103 & $0.97(0.65-1.43)$ & 91 & $1.02(0.64-1.64)$ \\
\hline & $P_{\text {trend }}$ & & 0.81 & & 0.86 & & 0.69 & & 0.91 \\
\hline
\end{tabular}

Among subcohort members within tertiles: median folate intake: 162,200 and $255 \mu \mathrm{g} / \mathrm{day} ;$ accumulated time at risk: 4131,4091 and 4093 person years

RRs based on a model containing the variables folate, methionine, vitamin B2, vitamin B6, and further adjusted for age, sex, family history of colorectal cancer, body mass index, smoking status, alcohol consumption and total ** $P$-value for linear trend. 
Table 2 Intake of vitamins B2 and B6 and CRC risk stratified by genetic status

\begin{tabular}{|c|c|c|c|c|c|c|c|c|c|}
\hline \multirow{3}{*}{$\begin{array}{l}\text { Gene and SNP } \\
\text { (rs number, MAF) * }\end{array}$} & \multirow{3}{*}{$\begin{array}{l}\text { Tertile } \\
\text { of intake }\end{array}$} & \multicolumn{4}{|c|}{ Vitamin B2† } & \multicolumn{4}{|c|}{ Vitamin B6 $\ddagger$} \\
\hline & & \multicolumn{2}{|r|}{$\begin{array}{c}\text { Common } \\
\text { homozygotes }\end{array}$} & \multicolumn{2}{|c|}{$\begin{array}{l}\text { Heterozygotes and } \\
\text { rare homozygotes }\end{array}$} & \multicolumn{2}{|r|}{$\begin{array}{c}\text { Common } \\
\text { homozygotes }\end{array}$} & \multicolumn{2}{|c|}{$\begin{array}{l}\text { Heterozygotes and } \\
\text { rare homozygotes }\end{array}$} \\
\hline & & $\mathrm{N} \S$ & $\operatorname{RR}(95 \% \mathrm{Cl}) \rrbracket$ & $\mathbf{N}$ & RR $(95 \% \mathrm{Cl})$ & $\mathbf{N}$ & $\mathrm{RR}(95 \% \mathrm{Cl})$ & $\mathrm{N}$ & $\operatorname{RR}(95 \% \mathrm{Cl})$ \\
\hline MTHFR C677T & 1 & 103 & ref. & 117 & ref. & 81 & ref. & 105 & ref. \\
\hline \multirow[t]{3}{*}{ (rs1801133, 0.30) } & 2 & 92 & $0.80(0.54-1.17)$ & 112 & $1.02(0.70-1.49)$ & 96 & $1.24(0.85-1.83)$ & 111 & $1.11(0.76-1.61)$ \\
\hline & 3 & 78 & $0.66(0.42-1.04)$ & 105 & $0.89(0.58-1.35)$ & 96 & $1.50(0.98-2.28)$ & 118 & $1.05(0.69-1.61)$ \\
\hline & $P_{\text {trend }} * \star$ & & 0.08 & & 0.54 & & 0.12 & & 0.63 \\
\hline MTHFR A $1298 \mathrm{C}$ & 1 & 100 & ref. & 118 & ref. & 90 & ref. & 98 & ref. \\
\hline \multirow[t]{3}{*}{ (rs1801131, 0.37) } & 2 & 87 & $0.72(0.47-1.09)$ & 116 & $1.06(0.75-1.49)$ & 87 & $1.11(0.74-1.66)$ & 116 & $1.16(0.81-1.68)$ \\
\hline & 3 & 86 & $0.76(0.48-1.19)$ & 95 & $0.85(0.57-1.27)$ & 96 & $1.19(0.77-1.85)$ & 115 & $1.23(0.82-1.85)$ \\
\hline & $P_{\text {trend }}$ & & 0.29 & & 0.42 & & 0.53 & & 0.35 \\
\hline MTR A2756G & 1 & 133 & ref. & 88 & ref. & 115 & ref. & 74 & ref. \\
\hline \multirow[t]{3}{*}{ (rs1805087, 0.19) } & 2 & 137 & $0.95(0.68-1.31)$ & 68 & $0.85(0.54-1.34)$ & 145 & $1.33(0.95-1.86)$ & 64 & $0.91(0.58-1.44)$ \\
\hline & 3 & 127 & $0.81(0.56-1.17)$ & 61 & $0.87(0.53-1.44)$ & 137 & $1.17(0.80-1.72)$ & 79 & $1.31(0.84-2.05)$ \\
\hline & $P_{\text {trend }}$ & & 0.30 & & 0.52 & & 0.49 & & 0.22 \\
\hline MTRR A66G & 1 & 49 & ref. & 174 & ref. & 39 & ref. & 153 & ref. \\
\hline \multirow[t]{3}{*}{$(\mathrm{rs} 1801394,0.56)$} & 2 & 44 & $0.78(0.39-1.56)$ & 162 & $0.93(0.70-1.25)$ & 43 & $1.48(0.80-2.74)$ & 165 & $1.03(0.76-1.38)$ \\
\hline & 3 & 36 & $0.59(0.27-1.32)$ & 153 & $0.89(0.65-1.23)$ & 47 & $1.49(0.74-3.00)$ & 171 & $1.11(0.80-1.53)$ \\
\hline & $P_{\text {trend }}$ & & 0.12 & & 0.56 & & 0.19 & & 0.55 \\
\hline DNMT3b C>T & 1 & 79 & ref. & 146 & ref. & 68 & ref. & 125 & ref. \\
\hline \multirow[t]{3}{*}{ (rs2424913, 0.42) } & 2 & 72 & $1.03(0.64-1.69)$ & 135 & $0.84(0.61-1.15)$ & 71 & $1.60(0.96-2.67)$ & 138 & $1.04(0.76-1.42)$ \\
\hline & 3 & 66 & $1.07(0.63-1.82)$ & 123 & $0.69(0.48-0.99)$ & 78 & $1.42(0.85-2.37)$ & 141 & $1.18(0.82-1.70)$ \\
\hline & $P_{\text {trend }}$ & & 0.81 & & 0.05 & & 0.21 & & 0.44 \\
\hline DNMT3b C>T & 1 & 171 & ref. & 52 & ref. & 145 & ref. & 45 & ref. \\
\hline \multirow[t]{3}{*}{ (rs406193, 0.14) } & 2 & 151 & $0.86(0.63-1.17)$ & 53 & $0.86(0.50-1.48)$ & 163 & $1.12(0.83-1.52)$ & 45 & $1.28(0.70-1.36)$ \\
\hline & 3 & 146 & $0.84(0.59-1.19)$ & 43 & $0.66(0.37-1.19)$ & 160 & $1.12(0.80-1.58)$ & 58 & $1.90(1.00-3.60)$ \\
\hline & $P_{\text {trend }}$ & & 0.33 & & 0.20 & & 0.60 & & 0.04 \\
\hline EHMT1 $\mathrm{G}>\mathrm{A}$ & 1 & 180 & ref. & 42 & ref. & 161 & ref. & 30 & ref. \\
\hline \multirow[t]{3}{*}{ (rs4634736, 0.10) } & 2 & 165 & $0.93(0.69-1.25)$ & 40 & $0.94(0.49-1.82)$ & 169 & $1.07(0.80-1.44)$ & 38 & $1.33(0.68-2.5$ \\
\hline & 3 & 157 & $0.85(0.62-1.18)$ & 30 & $0.69(0.32-1.50)$ & 172 & $1.15(0.84-1.58)$ & 44 & $1.52(0.71-3.26$ \\
\hline & $P_{\text {trend }}$ & & 0.38 & & 0.38 & & 0.40 & & 0.29 \\
\hline EHMT2 $\mathrm{G}>\mathrm{A}$ & 1 & 98 & ref. & 125 & ref. & 81 & ref. & 108 & ref. \\
\hline \multirow[t]{2}{*}{ (rs535586, 0.35) } & 2 & 88 & $0.93(0.62-2.38)$ & 116 & $0.85(0.59-1.21)$ & 85 & $0.98(0.65-1.48)$ & 123 & $1.25(0.88-1.78)$ \\
\hline & $\begin{array}{l}3 \\
P\end{array}$ & 79 & $0.85(0.54-1.34)$ & 105 & $0.75(0.50-1.12)$ & 99 & $1.17(0.75-1.83)$ & 115 & $1.25(0.85-1.86)$ \\
\hline & $\begin{array}{l}P_{\text {tre }} \\
1\end{array}$ & 123 & $\begin{array}{l}0.53 \\
\text { ref. }\end{array}$ & 95 & $\begin{array}{l}0.21 \\
\text { ref. }\end{array}$ & 101 & $\begin{array}{l}0.45 \\
\text { ref. }\end{array}$ & 83 & $\begin{array}{l}0.30 \\
\text { ref. }\end{array}$ \\
\hline \multirow[t]{3}{*}{ (rs2235515, 0.23) } & 2 & 113 & $0.84(0.59-1.19)$ & 84 & $0.94(0.62-1.44)$ & 105 & $1.31(0.92-1.88)$ & 99 & $0.95(0.63-1.42)$ \\
\hline & 3 & 94 & $0.67(0.44-1.00)$ & 87 & $1.02(0.65-1.60)$ & 124 & $1.49(1.00-2.22)$ & 84 & $0.89(0.56-1.41)$ \\
\hline & $P_{\text {trend }}$ & & 0.05 & & 0.88 & & 0.03 & & 0.41 \\
\hline
\end{tabular}

SNP: Single Nucleotide Polymorphism, MAF: Minor Allele Frequency among subcohort members

$\dagger$ Among subcohort members within tertiles: median vitamin B2 intake: 1.19, 1.50 and $1.84 \mathrm{mg} /$ day; accumulated time at risk: 4116,4109 and 4090 person years

$\ddagger$ Among subcohort members within tertiles: median vitamin B6 intake: 1.20,1.44 and $1.70 \mathrm{mg} /$ day; accumulated time at risk: 4125,4118 and 4073 person years

$\S$ Number of colorectal cancer cases

T RRs based on a model containing the variables folate, methionine, vitamin B2, vitamin B6, and further adjusted for age, sex, family history of

colorectal cancer, body mass index, smoking status, alcohol consumption and total energy intake

** $P$-value for linear trend.

We also investigated the associations between methyl donor intake and CRC risk according to the number of rare alleles within each functional group (i.e. folate metabolizing enzymes, DNMT3b and histon methyltransferases). It appeared that methionine was inversely associated with CRC if subjects were homozygous to both of the common variants of DNMT3b rs2424913 and rs406193 C>T SNPs $(R R=0.44$, $P_{\text {trend }}=0.05$, Table 3). 
Table 3 Dietary folate, methionine, vitamins B2 and B6 and CRC risk for combinations of genotypes in folate metabolizing enzymes, DNA methyltransferase $3 \mathrm{~b}$ or histone methyltransferases

\begin{tabular}{|c|c|c|c|c|c|c|c|}
\hline & \multirow{3}{*}{$\begin{array}{l}\text { Tertile } \\
\text { of intake }\end{array}$} & \multicolumn{6}{|c|}{ Folate metabolizing enzymes } \\
\hline & & \multicolumn{2}{|r|}{$\leq 1^{*}$} & \multicolumn{2}{|c|}{2} & \multicolumn{2}{|r|}{$\geq 3$} \\
\hline & & $\mathrm{N}$ & $\operatorname{RR}(95 \% \mathrm{Cl})$ & $\mathrm{N}$ & $\mathrm{RR}(95 \% \mathrm{Cl})$ & $\mathrm{N}$ & $\mathrm{RR}(95 \% \mathrm{Cl})$ \\
\hline \multirow[t]{4}{*}{ Folate } & 1 & 41 & ref. & 95 & ref. & 83 & ref. \\
\hline & 2 & 32 & $0.52(0.24-1.14)$ & 66 & $0.56(0.37-0.86)$ & 61 & $0.76(0.44-1.31)$ \\
\hline & 3 & 42 & $1.23(0.58-2.63)$ & 102 & $0.91(0.60-1.40)$ & 75 & $0.89(0.51-1.54)$ \\
\hline & $P_{\text {trend }}$ & & 0.51 & & 0.97 & & 0.66 \\
\hline \multirow[t]{4}{*}{ Methionine } & 1 & 40 & ref. & 85 & ref. & 81 & ref. \\
\hline & 2 & 41 & $1.50(0.70-3.21)$ & 89 & $1.24(0.82-1.90)$ & 70 & $0.73(0.44-1.21)$ \\
\hline & 3 & 34 & $0.99(0.38-2.53)$ & 89 & $1.06(0.68-1.65)$ & 68 & $0.70(0.40-1.24)$ \\
\hline & $P_{\text {trend }}$ & & 0.90 & & 0.90 & & 0.18 \\
\hline \multirow{4}{*}{ Vitamin B2 } & 1 & 43 & ref. & 91 & ref. & 83 & ref. \\
\hline & 2 & 40 & $0.76(0.37-1.54)$ & 90 & $0.95(0.63-1.43)$ & 71 & $0.94(0.58-1.53)$ \\
\hline & 3 & 32 & $0.30(0.11-0.81)$ & 82 & $0.88(0.55-1.39)$ & 65 & $1.05(0.61-1.80)$ \\
\hline & $P_{\text {trend }}$ & & 0.005 & & 0.96 & & 0.87 \\
\hline \multirow[t]{7}{*}{ Vitamin B6 } & 1 & 31 & ref. & 83 & ref. & 71 & ref. \\
\hline & 2 & 46 & $0.94(0.94-4.03)$ & 88 & $1.05(0.70-1.56)$ & 69 & $1.07(0.63-1.80)$ \\
\hline & 3 & 38 & $2.32(1.00-5.36)$ & 92 & $1.06(0.68-1.65)$ & 79 & $1.39(0.80-2.42)$ \\
\hline & $P_{\text {trend }}$ & & 0.07 & & 1.00 & & 0.21 \\
\hline & & \multicolumn{6}{|c|}{ DNA methyltransferase 3b (DNMT3b) } \\
\hline & \multirow{2}{*}{$\begin{array}{l}\text { Tertile } \\
\text { of intake }\end{array}$} & & 0 & & 1 & & 2 \\
\hline & & $\mathbf{N}$ & $\mathrm{RR}(95 \% \mathrm{Cl})$ & $\mathbf{N}$ & $\mathrm{RR}(95 \% \mathrm{Cl})$ & $\mathbf{N}$ & $\mathrm{RR}(95 \% \mathrm{Cl})$ \\
\hline \multirow[t]{4}{*}{ Folate } & 1 & 53 & ref. & 151 & ref. & 22 & ref. \\
\hline & 2 & 37 & $0.72(0.39-1.35)$ & 107 & $0.63(0.45-0.89)$ & 20 & $0.67(0.27-1.67)$ \\
\hline & 3 & 39 & $0.76(0.39-1.48)$ & 163 & $1.10(0.78-1.55)$ & 23 & $0.78(0.31-1.93)$ \\
\hline & $P_{\text {trend }}$ & & 0.37 & & 0.54 & & 0.79 \\
\hline \multirow{4}{*}{ Methionine } & 1 & 53 & Ref. & 137 & ref. & 20 & ref. \\
\hline & 2 & 37 & $0.74(0.37-1.47)$ & 142 & $1.18(0.85-1.63)$ & 24 & $1.71(0.77-3.79)$ \\
\hline & 3 & 39 & $0.44(0.21-0.94)$ & 142 & $1.12(0.79-1.60)$ & 21 & $1.48(0.56-3.90)$ \\
\hline & $P_{\text {trend }}$ & & 0.05 & & 0.66 & & 0.47 \\
\hline \multirow[t]{4}{*}{ Vitamin B2 } & 1 & 47 & Ref. & 154 & ref. & 22 & ref. \\
\hline & 2 & 41 & $1.09(0.56-2.12)$ & 137 & $0.78(0.57-1.08)$ & 25 & $1.30(0.57-2.98)$ \\
\hline & 3 & 41 & $1.52(0.71-3.22)$ & 130 & $0.72(0.50-1.05)$ & 18 & $0.79(0.29-1.74)$ \\
\hline & $P_{\text {trend }}$ & & 0.36 & & 0.10 & & 0.41 \\
\hline \multirow[t]{7}{*}{ Vitamin B6 } & 1 & 42 & Ref. & 127 & ref. & 21 & ref. \\
\hline & 2 & 42 & $1.80(0.88-3.70)$ & 147 & $1.13(0.83-1.54)$ & 18 & $0.98(0.37-2.57)$ \\
\hline & 3 & 45 & $1.37(0.68-2.75)$ & 147 & $1.15(0.81-1.63)$ & 26 & $2.12(0.79-5.72)$ \\
\hline & $P_{\text {trend }}$ & & 0.44 & & 0.46 & & 0.18 \\
\hline & & \multicolumn{6}{|c|}{ Histone methyltransferases } \\
\hline & \multirow{2}{*}{$\begin{array}{l}\text { Tertile } \\
\text { of intake }\end{array}$} & & 0 & & 1 & & $\geq 2$ \\
\hline & & $\mathbf{N}$ & $\mathrm{RR}(95 \% \mathrm{Cl})$ & $\mathbf{N}$ & $\mathrm{RR}(95 \% \mathrm{Cl})$ & $\mathbf{N}$ & $\mathrm{RR}(95 \% \mathrm{Cl})$ \\
\hline Folate & 1 & 43 & Ref. & 103 & ref. & 72 & ref. \\
\hline & 2 & 30 & $0.47(0.24-0.90)$ & 76 & $0.72(0.47-1.10)$ & 51 & $0.71(0.43-1.17)$ \\
\hline & 3 & 44 & $0.91(0.46-1.80)$ & 90 & $0.92(0.61-1.39)$ & 78 & $1.11(0.67-1.85)$ \\
\hline & $P_{\text {trend }}$ & & 0.64 & & 0.69 & & 0.65 \\
\hline Methionine & 1 & 41 & ref. & 93 & ref. & 68 & ref. \\
\hline & 2 & 35 & $1.03(0.51-2.06)$ & 89 & $1.08(0.71-1.64)$ & 70 & $1.12(0.68-1.85)$ \\
\hline & 3 & 41 & $1.14(0.58-2.23)$ & 87 & $1.12(0.71-1.76)$ & 63 & $0.77(0.44-1.35)$ \\
\hline & $P_{\text {trend }}$ & & 0.80 & & 0.76 & & 0.34 \\
\hline Vitamin B2 & 1 & 45 & ref. & 96 & ref. & 75 & ref. \\
\hline & 2 & 37 & $0.71(0.37-1.37)$ & 94 & $0.94(0.63-1.40)$ & 64 & $0.81(0.50-1.30)$ \\
\hline & 3 & 35 & $0.55(0.26-1.13)$ & 79 & $0.86(0.54-1.37)$ & 62 & $0.78(0.47-1.31)$ \\
\hline & $P_{\text {trend }}$ & & 0.22 & & 0.45 & & 0.49 \\
\hline Vitamin B6 & 1 & 36 & ref. & 85 & ref. & 60 & ref. \\
\hline & 2 & 29 & $0.85(0.44-1.64)$ & 100 & $1.38(0.94-2.04)$ & 73 & $1.11(0.68-1.79)$ \\
\hline & 3 & 52 & $1.69(0.79-3.60)$ & 84 & $1.01(0.66-1.55)$ & 68 & $1.39(0.81-2.39)$ \\
\hline & $P_{\text {trend }}$ & & 0.10 & & 0.93 & & 0.34 \\
\hline
\end{tabular}

* Number of variant alleles (i.e. heterozygotes or homozygotes for the rare allele) 
Moreover, relatively high vitamin B2 intake was associated with reduced CRC risk in subjects with less than one SNP in folate metabolizing enzymes $(R R=0.30$, $P_{\text {trend }}=0.005$ ).

With respect to $\mathrm{CpG}$ island promoter hypermethylation, we observed no overall associations between folate, methionine, vitamins B2 or B6 with CIMP (Table 4). Moreover, there were no clear associations between methyl donor intake and CIMP, MLH1 hypermethylation or MSI when accounting for genetic status of individuals (data not shown).

Table 4 Associations of folate, methionine, vitamins B2 and B6 with CIMP in CRC *

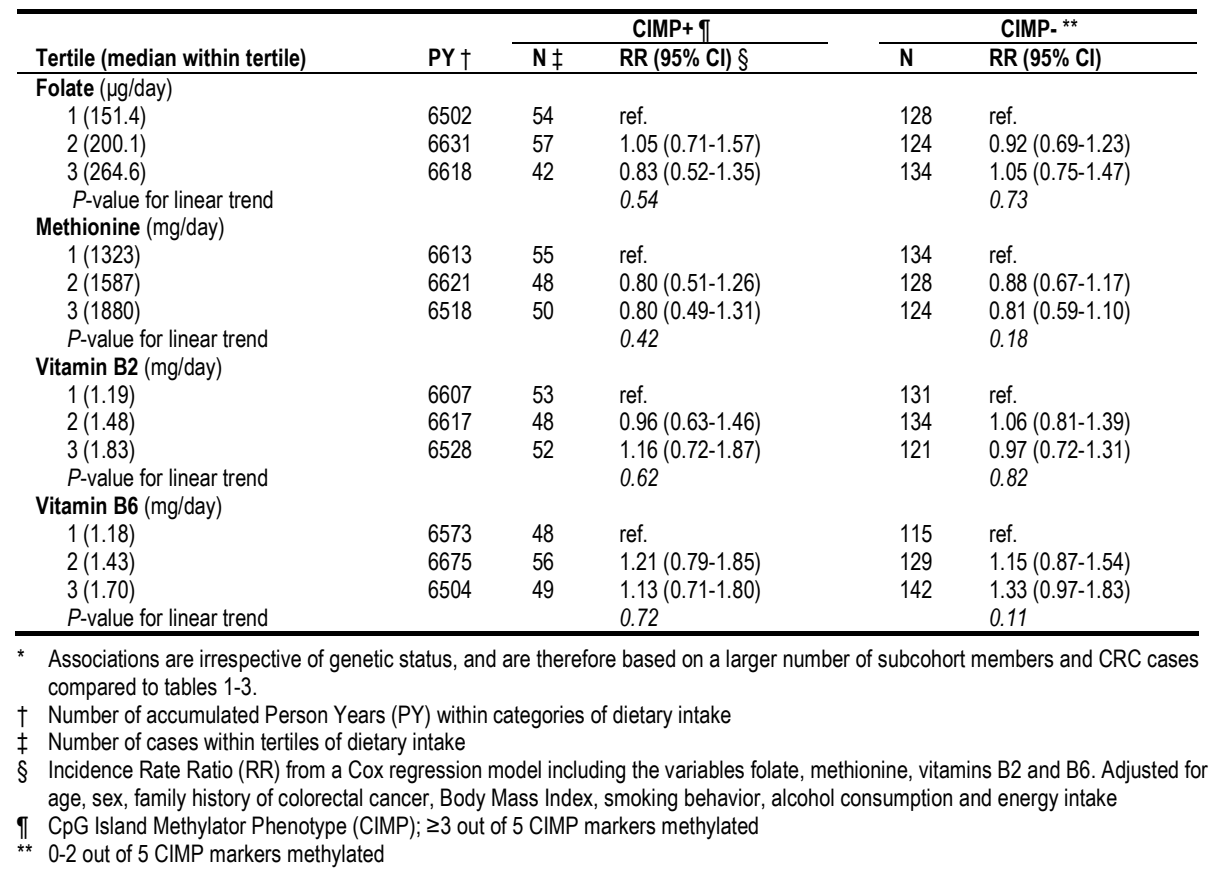

\section{Discussion}

In the current prospective case-cohort study among incident CRC cases, we observed no associations between dietary folate and CRC risk when accounting for genetic variants of folate metabolizing enzymes, DNA methyltransferases or histone methyltransferases. However, relatively high methionine intake may protect against CRC if enzymatic activity of DNMT3b is not affected by two C>T SNPs in its encoding gene. In addition, subjects with high vitamin B2 intake may be at reduced CRC risk in combination with optimal MTHFR activity in those homozygous for the common 677CC variant, the common PRDM2 GG (rs2235515) genotype and among those with the variant allele of DNMT3b C>T (rs2424913), and these associations were most pronounced among men. High vitamin B2 intake may reduce CRC risk among individuals carrying $\leq 1$ rare allele in the combination of any of the folate metabolizing 
enzymes MTHFR, MTR or MTRR. There were no associations with the CIMP phenotype or within strata of the studied genotypes.

It has been suggested that the MTHFR C677T polymorphism reduces binding of the MTHFR enzyme to its cofactor flavin adenine dinucleotide (FAD), a metabolite of vitamin B2, resulting in loss of enzymatic activity to approximately $30 \%$ when compared to wild types $(32,33)$. The potentially resulting reduced bioavailability of methyl groups may induce DNA hypomethylation in for example blood cells $(34,35)$ or CPG island promoter hypermethylation in CRC (36-38). We observed an inverse association between vitamin B2 and CRC risk, predominantly among men homozygous for the MTHFR 677CC variant, suggesting that vitamin B2 may maximize the catalytic activity of MTHFR when binding to FAD is optimal. Similarly, it was recently observed that high vitamin B2 plasma concentrations, in combination with MTHFR 677CC or CT genotypes, may reduce risk of CRA recurrence, whereas such an inverse association was not observed among individuals with the MTHFR 677TT variant (39). We also observed a strong inverse association between vitamin B2 and CRC risk in individuals carrying $\leq 1$ variant allele out of the four studied SNPs of folate metabolizing enzymes, suggesting that the combination of common wild-type genotypes, which possibly results in higher bioavailability of methyl groups, protects against CRC in these people. However, we did not observe an association between methyl donor intake and CRC characterized by CIMP.

In addition to a potential protective effect of vitamin B2 among subjects with the MTHFR 677CC genotype and associated optimal enzymatic MTHFR activity, vitamin B2 may also reduce CRC risk among subjects carrying variant alleles of the DNMT3b C>T (rs2424913) polymorphism. Interestingly, enzymatic activity of DNMT3b is significantly increased among individuals with this polymorphism (40), and it may be hypothesized that normal or increased metabolic activity these enzymes may protect against CRC. Possibly, this may also be true for the histone methyltransferase PRDM2 since high vitamin B2 intake reduced CRC risk in the common GG variant. However, the consequence of the PRDM2 G>A (rs2235515) polymorphism for the PRDM2 enzyme has not previously been studied. Nevertheless, although PRDM2 G>A (rs2235515) was not directly associated with CRC (part 1 ), the association of vitamin B2 for wild-type carriers in the current study underscores its potential role in methyl metabolism and colorectal carcinogenesis.

Our study suggests that relatively high methionine intake may protect against CRC if enzymatic DNMT3b activity is not affected by two polymorphisms. Increased DNMT3b activity by the DNMT3b rs2424913 C>T polymorphism was associated with increased risks of various types of cancer (40-42). Moreover, it was associated with increased risk of CRA in individuals with low folate and methionine intakes (43), suggesting a nutrient-gene interaction in colorectal carcinogenesis. In view of the function of the DNMT3b enzyme of incorporating methyl groups into DNA, an interaction between methionine intake, DNMT3b polymorphisms and CpG island hypermethylation may be expected, but we did not clearly observe associations between methyl donor intake and CIMP, MLH1 hypermethylation or MSI when accounting for DNMT3b genotypes.

Interestingly, the potential protective effects of vitamin B2 or methionine may only be present among individuals with $\leq 1$ polymorphism in folate metabolizing enzymes or among those with common wild-type genotypes of DNMT3b, respectively. This suggests that the occurrence of only one polymorphism is compensated for, but that 
the combination of several polymorphic genes may lead to disruption of a particular metabolic or regulatory function and to the abolishment of beneficial effects of nutrients. Moreover, these data indicate that a gene-nutrient interaction may be present and that combining genotypes is important to reveal associations of dietary factors with cancer risk. Such an approach has not been followed in previous studies investigating associations between genetic factors and cancer risk, and we recommend that combinations of genotypes are considered in future studies.

Although MTHFR C677T may be associated with increased promoter hypermethylation in CRC (36-38), and DNMT3b expression (which is increased by the DNMT3b C>T rs2424913 polymorphism) with increased risk of promoter hypermethylation in lung cancer (44) and breast cancer (45), we did not observe associations of folate, methionine, vitamins B2 or B6 with risk of CRC with CIMP. Moreover, associations between methyl donor intake and CIMP in CRC were not observed in a previous study (10), and an association of one-carbon SNPs with CIMP was only observed for the MTHFR A1298C polymorphism (36). However, these previous studies, as well as our study, may have lacked adequate power to demonstrate such associations, and particularly our study had relatively low numbers of cases within subgroups of genetic variants and methylation endpoints combined. Nonetheless, the effect of methyl donor intake on gene promoter hypermethylation may indeed be weak, and to demonstrate whether such an effect is modified by genetic variability of the methyl metabolism requires studies with large numbers of cases.

In conclusion, the present study suggests that a potential protective effect of vitamin B2 and methionine intakes depends on genetic variants of folate metabolizing enzymes and a DNA methyltransferase in CRC. Combining genotypes is a logical approach of investigating multiple genes and may reveal associations of dietary methyl donors and CRC. However, larger studies are needed to investigate a potential interaction between dietary methyl donor intake, genetic variation of folate metabolizing enzymes and epigenetic regulators, and methylation endpoints in CRC with more precision. 


\section{References}

1. Weisenberger DJ, Siegmund KD, Campan M, Young J, Long TI, Faasse MA, et al. CpG island methylator phenotype underlies sporadic microsatellite instability and is tightly associated with BRAF mutation in colorectal cancer. Nat Genet 2006;38(7):787-93.

2. Herman JG, Baylin SB. Gene silencing in cancer in association with promoter hypermethylation. N Engl J Med 2003;349(21):2042-54.

3. Derks S, Postma C, Carvalho B, van den Bosch SM, Moerkerk PT, Herman JG, et al. Integrated analysis of chromosomal, microsatellite and epigenetic instability in colorectal cancer identifies specific associations between promoter methylation of pivotal tumor suppressor and DNA repair genes and specific chromosomal alterations. Carcinogenesis $2008 ; 29(2): 434-9$.

4. Kim YI. Nutritional epigenetics: impact of folate deficiency on DNA methylation and colon cancer susceptibility. J Nutr 2005;135(11):2703-9.

5. Ulrich CM. Nutrigenetics in cancer research--folate metabolism and colorectal cancer. $J$ Nutr 2005;135(11):2698-702.

6. Kim YI. Folate and DNA methylation: a mechanistic link between folate deficiency and colorectal cancer? Cancer Epidemiol Biomarkers Prev 2004;13(4):511-9.

7. Pufulete M, Al-Ghnaniem R, Rennie JA, Appleby P, Harris N, Gout S, et al. Influence of folate status on genomic DNA methylation in colonic mucosa of subjects without colorectal adenoma or cancer. Br J Cancer 2005;92(5):838-42.

8. Pufulete M, Al-Ghnaniem R, Khushal A, Appleby P, Harris N, Gout S, et al. Effect of folic acid supplementation on genomic DNA methylation in patients with colorectal adenoma. Gut 2005;54(5):648-53.

9. van Engeland M, Weijenberg MP, Roemen GM, Brink M, de Bruine AP, Goldbohm RA, et al. Effects of dietary folate and alcohol intake on promoter methylation in sporadic colorecta cancer: the Netherlands cohort study on diet and cancer. Cancer Res 2003;63(12):3133-7.

10. Slattery ML, Curtin K, Sweeney C, Levin TR, Potter J, Wolff RK, et al. Diet and lifestyle factor associations with $\mathrm{CpG}$ island methylator phenotype and $B R A F$ mutations in colon cancer. Int J Cancer 2007;120(3):656-63.

11. de Vogel S, Bongaerts BW, Wouters KA, Kester AD, Schouten LJ, de Goeij AF, et al. Associations of dietary methyl donor intake with $M L H 1$ promoter hypermethylation and related molecular phenotypes in sporadic colorectal cancer. Carcinogenesis 2008, Mar 13; doi:10.1093/carcin/bgn074.

12. van den Donk M, Pellis L, Crott JW, van Engeland M, Friederich $P$, Nagengast FM, et al. Folic acid and vitamin B-12 supplementation does not favorably influence uracil incorporation and promoter methylation in rectal mucosa DNA of subjects with previous colorectal adenomas. J Nutr 2007;137(9):2114-20.

13. Giovannucci E. Alcohol, one-carbon metabolism, and colorectal cancer: recent insights from molecular studies. J Nutr 2004;134(9):2475S-2481S.

14. Mason JB, Choi SW. Effects of alcohol on folate metabolism: implications for carcinogenesis. Alcohol 2005;35(3):235-41.

15. Diergaarde B, Braam H, van Muijen GN, Ligtenberg MJ, Kok FJ, Kampman E. Dietary factors and microsatellite instability in sporadic colon carcinomas. Cancer Epidemiol Biomarkers Prev 2003;12(11 Pt 1):1130-6.

16. Slattery ML, Anderson K, Curtin K, Ma KN, Schaffer D, Samowitz W. Dietary intake and microsatellite instability in colon tumors. Int J Cancer 2001;93(4):601-7.

17. van den Brandt PA, Goldbohm RA, van 't Veer P, Volovics A, Hermus RJ, Sturmans F. A large-scale prospective cohort study on diet and cancer in The Netherlands. J Clin Epidemiol $1990 ; 43(3): 285-95$.

18. Van den Brandt PA, Schouten $\sqcup$, Goldbohm RA, Dorant E, Hunen PM. Development of a record linkage protocol for use in the Dutch Cancer Registry for Epidemiological Research. Int J Epidemiol 1990;19(3):553-8.

19. Casparie M, Tiebosch AT, Burger G, Blauwgeers $H$, van de Pol A, van Krieken JH, et al. Pathology databanking and biobanking in The Netherlands, a central role for PALGA, the nationwide histopathology and cytopathology data network and archive. Cell Oncol 2007;29(1):19-24. 
20. Nevo table. Dutch food composition table 1986-1987, The Hague, The Netherlands: Voorlichtingsbureau voor de voeding, 1986. 1986.

21. Goldbohm RA, van den Brandt PA, Brants HA, van't Veer P, Al M, Sturmans F, et al. Validation of a dietary questionnaire used in a large-scale prospective cohort study on diet and cancer. Eur J Clin Nutr 1994;48(4):253-65.

22. Goldbohm RA, van 't Veer P, van den Brandt PA, van 't Hof MA, Brants HA, Sturmans F, et al. Reproducibility of a food frequency questionnaire and stability of dietary habits determined from five annually repeated measurements. Eur J Clin Nutr 1995;49(6):420-9.

23. Konings EJ. A validated liquid chromatographic method for determining folates in vegetables, milk powder, liver, and flour. J AOAC Int 1999;82(1):119-27.

24. Konings EJ, Roomans HH, Dorant E, Goldbohm RA, Saris WH, van den Brandt PA. Folate intake of the Dutch population according to newly established liquid chromatography data for foods. Am J Clin Nutr 2001;73(4):765-76.

25. Knaapen AM, Ketelslegers HB, Gottschalk RW, Janssen RG, Paulussen AD, Smeets HJ, et al. Simultaneous genotyping of nine polymorphisms in xenobiotic-metabolizing enzymes by multiplex PCR amplification and single base extension. Clin Chem 2004;50(9):1664-8.

26. Herman JG, Graff JR, Myohanen S, Nelkin BD, Baylin SB. Methylation-specific PCR: a novel PCR assay for methylation status of CPG islands. Proc Natl Acad Sci U S A 1996;93(18):9821-6.

27. Suraweera N, Duval A, Reperant M, Vaury C, Furlan D, Leroy K, et al. Evaluation of tumor microsatellite instability using five quasimonomorphic mononucleotide repeats and pentaplex PCR. Gastroenterology 2002;123(6):1804-11.

28. Lin D, Wei L. The robust inference for the Cox Proportional Hazards Model. JASA 1989;84(408):1074-1078.

29. Schoenfeld D. Partial residuals for the proportional hazards regression models. Biometrika $1982 ; 69(1): 239-241$.

30. Willett W, Stampfer MJ. Total energy intake: implications for epidemiologic analyses. Am J Epidemiol 1986;124(1):17-27.

31. de Vogel S, Bongaerts BW, Wouters KA, Kester AD, Schouten $L$, de Goeij AF, et al. Associations of dietary methyl donor intake with MLH1 promoter hypermethylation and related molecular phenotypes in sporadic colorectal cancer. Carcinogenesis 2008;29(9):1765-73.

32. Yamada K, Chen Z, Rozen R, Matthews RG. Effects of common polymorphisms on the properties of recombinant human methylenetetrahydrofolate reductase. Proc Natl Acad Sci U S A 2001;98(26):14853-8.

33. Frosst P, Blom HJ, Milos R, Goyette P, Sheppard CA, Matthews RG, et al. A candidate genetic risk factor for vascular disease: a common mutation in methylenetetrahydrofolate reductase. Nat Genet 1995;10(1):111-3.

34. Friso S, Choi SW, Girelli D, Mason JB, Dolnikowski GG, Bagley PJ, et al. A common mutation in the 5,10-methylenetetrahydrofolate reductase gene affects genomic DNA methylation through an interaction with folate status. Proc Natl Acad Sci U S A 2002;99(8):5606-11.

35. Stern LL, Mason JB, Selhub J, Choi SW. Genomic DNA hypomethylation, a characteristic of most cancers, is present in peripheral leukocytes of individuals who are homozygous for the C677T polymorphism in the methylenetetrahydrofolate reductase gene. Cancer Epidemiol Biomarkers Prev 2000;9(8):849-53.

36. Curtin K, Slattery ML, Ulrich CM, Bigler J, Levin TR, Wolff RK, et al. Genetic polymorphisms in one-carbon metabolism: associations with $\mathrm{CpG}$ island methylator phenotype (CIMP) in colon cancer and the modifying effects of diet. Carcinogenesis 2007;28(8):1672-9.

37. Mokarram P, Naghibalhossaini F, Saberi Firoozi M, Hosseini SV, Izadpanah A, Salahi H, et al. Methylenetetrahydrofolate reductase C677T genotype affects promoter methylation of tumor-specific genes in sporadic colorectal cancer through an interaction with folate/vitamin B(12) status. World J Gastroenterol 2008;14(23):3662-71.

38. Oyama K, Kawakami K, Maeda K, Ishiguro K, Watanabe G. The association between methylenetetrahydrofolate reductase polymorphism and promoter methylation in proximal colon cancer. Anticancer Res 2004;24(2B):649-54.

39. Figueiredo JC, Levine AJ, Grau MV, Midttun O, Ueland PM, Ahnen DJ, et al. Vitamins B2, B6, and $\mathrm{B} 12$ and risk of new colorectal adenomas in a randomized trial of aspirin use and folic acid supplementation. Cancer Epidemiol Biomarkers Prev 2008;17(8):2136-45. 
40. Shen H, Wang L, Spitz MR, Hong WK, Mao L, Wei Q. A novel polymorphism in human cytosine DNA-methyltransferase-3B promoter is associated with an increased risk of lung cancer. Cancer Res 2002;62(17):4992-5.

41. Singal R, Das PM, Manoharan M, Reis IM, Schlesselman JJ. Polymorphisms in the DNA methyltransferase 3b gene and prostate cancer risk. Oncol Rep 2005;14(2):569-73.

42. Wang L, Rodriguez $M$, Kim ES, Xu Y, Bekele N, El-Naggar AK, et al. A novel C/T polymorphism in the core promoter of human de novo cytosine DNA methyltransferase 3B6 is associated with prognosis in head and neck cancer. Int J Oncol 2004;25(4):993-9.

43. Jung AY, Poole EM, Bigler J, Whitton J, Potter JD, Ulrich CM. DNA methyltransferase and alcohol dehydrogenase: gene-nutrient interactions in relation to risk of colorectal polyps. Cancer Epidemiol Biomarkers Prev 2008;17(2):330-8.

44. Wang J, Walsh G, Liu DD, Lee JJ, Mao L. Expression of Delta DNMT3B variants and its association with promoter methylation of $\mathrm{p} 16$ and RASSF1A in primary non-small cell lung cancer. Cancer Res 2006;66(17):8361-6.

45. Roll JD, Rivenbark AG, Jones WD, Coleman WB. DNMT3b overexpression contributes to a hypermethylator phenotype in human breast cancer cell lines. Mol Cancer 2008;7:15. 


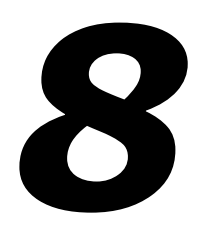

Epilogue 
The main aim of the current study was to investigate associations between dietary methyl donor intake and colorectal cancer risk, accounting for gene mutations and gene promoter hypermethylation in the tumor, and for genetic variants of enzymes involved in methyl group metabolism and epigenetic regulation. In this epilogue, I will briefly discuss the main findings of the study and relate these to the currently debated potential dual role of folate in colorectal carcinogenesis. Finally, I propose some recommendations for public health and future research.

\section{Main findings}

The findings of this study (Figure 1) suggest that in colorectal carcinogenesis, MGMT hypermethylation may succeed $A P C$ mutations but precedes KRAS mutations, and that tumors with MGMT hypermethylation may develop distinctly from those showing MLH1 hypermethylation (chapter 2 ).

Although we did not observe an association between dietary folate and colorectal cancer, methionine and vitamin B2 were associated with reduced proximal colon cancer risk among men and women, respectively. Conversely, vitamin B6 intake was associated with increased colorectal cancer risk, being most pronounced for rectal cancer among women (chapter 3).

Predominantly among men, folate intake was associated with increased risk of colorectal tumors harboring APC mutations (chapter 4) or BRAF mutations (chapter 5), suggesting that folate may enhance the growth of such lesions.

Occurrence of polymorphisms in methyl metabolizing enzymes MTHFR and MTR, the DNA methyltransferase $3 \mathrm{~b}(D N M T 3 b)$ and histone methyltransferase EHMT2 were associated with overall colorectal cancer risk. Our study suggested that MTR and MTRR polymorphisms may reduce the risk of colorectal tumors with a promoter hypermethylation phenotype (chapter 6 ).

A protective effect of methionine and vitamin B2 against colorectal cancer appeared to be more pronounced if no polymorphisms occurred in DNMT3b, or when $\leq 1$ rare allele occurred in the combination of methyl metabolizing enzymes MTHFR, $M T R$ and $M T R R$, respectively. We therefore concluded that a protective effect of dietary methyl donors may be stronger if methyl metabolizing enzymes and DNA methyltransferases are left unaffected by polymorphisms in their encoding genes (chapter 7). 
Exposure: methyl donors and genetic variants Main findings

\section{Chapter 2}

- MGMT hypermethylation associated with G:C>A:T mutatons in KRAS, but not in $A P C$

- MLH1 hypermethylation associated with BRAF mutations, but inversely with $A P C$ truncating and KRAS activating mutations

Concurrent MGMT and $M L H 1$ hypermethylation was rare

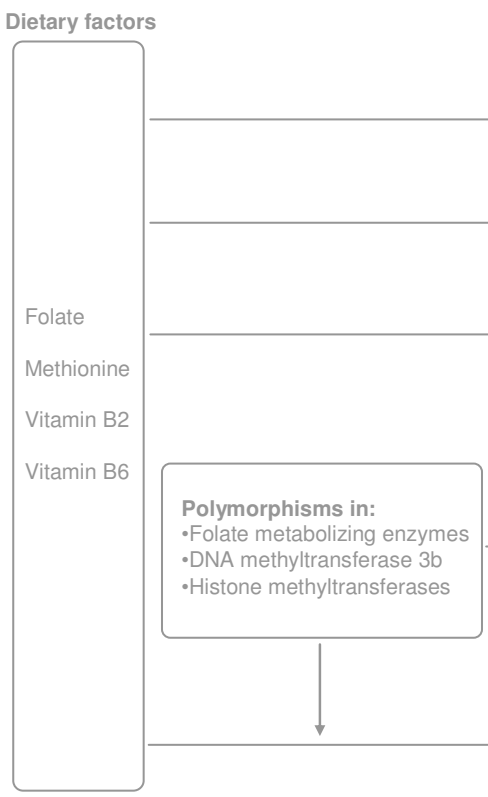

\section{Chapter 3}

- No association of folate intake with overall colorectal cancer

- Inverse associations methionine and vitamin B2 with proximal colon cancer

in men and women, respectively

- Vitamin B6 associated with increased colorectal cancer risk

being most pronounced for rectal cancer among women

Chapter 4

- Folate associated with $A P C$ mutations among men

Chapter 5

- Folate associated with BRAF mutations, predominantly among men

- Folate associated with $B R A F$ mutations, predominantly among men
- Vitamin $B 6$ associated with $M L H 1$ methylation, predominantly among men

Chapter 6

\section{Overall colorectal cancer}

- MTHFR C677T: inverse association in men: positive association in women

- MTR A2756G: associated with increased colorectal cancer risk

- DNMT3b C>T (rs406913) and EHMT2 G>A: inverse associations with

colorectal cancer in women

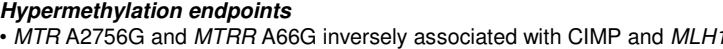

among men and women, respectively

\section{Chapter 7}

Overall colorectal cancer

- Inverse association methionine in subjects without DNMT3b polymorphisms

- Inverse association vitamin B2 in subjects with MTHFR 677CC genotype

combination of MTHFR, MTR and MTRR
Endpoints: colorectal carcinoma subgroups based on molecular analyses

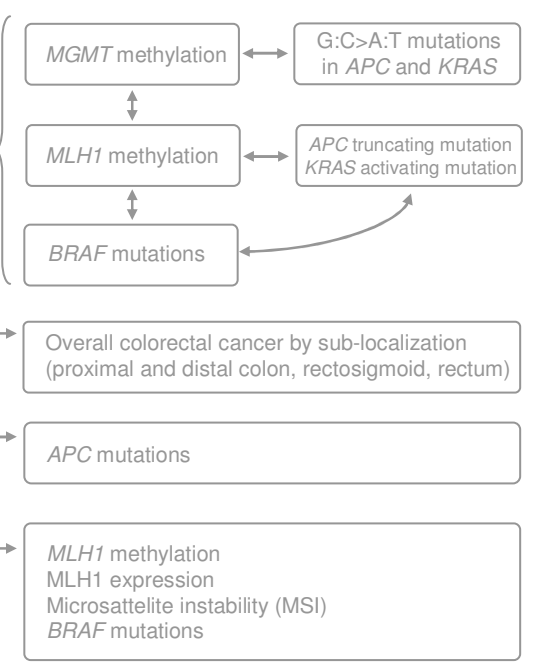

BRAF mutations

$\longrightarrow \begin{array}{ll}\text { CpG island methylator phenotype (CIMP) } \\ \text { MLH1 methylation } \\ M S I\end{array}$

Figure 1 Overview of the main findings 


\section{Correlation between hypermethylation-associated tumor characteristics}

Concurrent hypermethylation of MLH1 and MGMT was rare in our study, and associations with related molecular aberrations suggested that these colorectal cancers may develop through distinct pathways (chapter 2). In addition, we observed that MLH1 hypermethylation was significantly correlated with MSI, BRAF mutations and CIMP (chapters 2,5 and 6). However, the overlap between these characteristics was incomplete, which raises the question whether colorectal cancers with MLH1 hypermethylation, those with MSI, BRAF mutations or CIMP actually develop through one distinct hypermethylation-associated pathway.

In sporadic colorectal cancer, MLH1 hypermethylation is the predominant cause of MSI (1-3). However, germline mutations or loss of expression of other mismatch repair genes may also contribute to MSI, and MLH1 hypermethylation was observed in only $60 \%$ of colorectal carcinomas with MSI in a large population-based study $(n=1,061)$ (4). Moreover, although MSI and CIN are considered as two alternative mechanisms in colorectal cancer (5), CpG island promoter methylation may be associated with both MSI and with specific patterns of chromosomal aberrations in CIN colorectal cancers (6). This potential overlap suggests that a hypermethylation phenotype may, at least in part, develop independently from both types of DNA instability. Furthermore, tumors with different molecular aberrations may not be equally sensitive to environmental factors and genetic variation. This uncertainty prompted us to study the associations of methyl donor intake with CIMP and the related molecular characteristics MLH1 hypermethylation, MSI and BRAF mutations separately.

\section{Dietary methyl donors and promoter hypermethylation in colorectal cancer}

Associations with overall colorectal cancer risk

The a priori hypothesis was that adequate intakes of methyl donors (folate and methionine) or nutrients that are involved in folate metabolism (vitamins B2 and B6) may prevent CPG island promoter hypermethylation in colorectal cancer, which was based on limited and preliminary evidence from literature (7). To test this hypothesis, we first studied associations of these dietary factors with overall colorectal cancer (chapter 3). We observed inverse associations between intakes of methionine and vitamin B2 with tumors in the proximal colon, but folate was not associated with colorectal cancer risk. Vitamin B6 was associated with an unexpected increased overall colorectal cancer risk, and the positive association was particularly strong with rectal tumors among women.

The reason why dietary methyl donors would have a site-specific effect in colorectal cancer remains unclear. Possibly, molecular characteristics differ between sub-sites, for example the observation that gene promoter hypermethylation may occur more often in proximal colon cancer and among women $(4,8,9)$. Although in our study, the majority of the tumors with MLH1 hypermethylation (54\%) and CIMP (60\%) 
occurred in the proximal colon, we did not observe that methionine and vitamin B2 were associated with promoter hypermethylation (chapters 5 and 7). Furthermore, it lacks a biological explanation why hypermethylation would occur more often in the proximal colon. Possibly, the increasing thickness of bowel contents and a decreasing speed of passage through the colorectum moving from proximal colon to rectum may not equally influence molecular aberrations in colorectal carcinogenesis.

Although it has previously been observed that hypermethylation may occur more often in women than in men, the associations of our study did not clearly differ between the sexes. In addition, $M L H 1$ hypermethylation tended to occur only slightly more often in women than in men, while the occurrence of CIMP was similar. One interesting previous observation was that men may have higher folate requirement than women (10). In this respect, it is conceivable that high folate intake would be more protective against colorectal cancer in men than in women, because men in the lowest reference quintile might more often have insufficient folate intake. However, this is only speculative, and our data did not indicate that men with high folate intake, or of the other studied nutrients, were systematically at lower risk of developing colorectal cancer than women.

\section{Associations with promoter hypermethylation and related characteristics}

We did not observe that high intakes of dietary folate, methionine or vitamin B2 were inversely associated with MLH1 promoter hypermethylation or CIMP (chapters 5 and 7). Conversely, in addition to a positive association with overall risk, vitamin B6 tended to increase the risk of colorectal tumors harboring $M L H 1$ hypermethylation (chapter 5). However, we should be cautious in drawing definite conclusions, since a protective effect of vitamin B6 on colorectal cancer has previously been suggested in several observational studies (11-15). Moreover, we observed a positive association with MLH1 hypermethylation only and not with related molecular characteristics such as CIMP, MSI or BRAF mutations. In addition, the other dietary methyl donors did not seem to have an effect on promoter hypermethylation. However, because a smaller proportion of patients is generally characterized by $M L H 1$ methylation ( $22 \%$ of the cases in our study), this subgroup of patients may have been of inadequate size for precise analyses, and the findings therefore need replication in future studies.

Nevertheless, a true positive association between vitamin B6 and MLH1 hypermethylation may indicate that high bioavailability of methyl groups increases promoter hypermethylation in colorectal cancer, rather than decreasing it. Interestingly, although previous studies suggested only weak inverse, or no associations between dietary methyl donors and hypermethylation in colorectal cancer $(7,16)$, positive associations have been observed between plasma folate levels and promoter hypermethylation in colorectal tumors $(17,18)$. Moreover, in a randomized intervention trial, folate supplementation increased promoter hypermethylation in rectal mucosa of patients with a history of colorectal adenoma (19). These observations indicate that the a priori hypothesis of high methyl donor intake to be inversely associated with promoter hypermethylation may have to be rejected. 


\title{
Polymorphisms in folate metabolizing enzymes and epigenetic regulators
}

\begin{abstract}
Associations with overall colorectal cancer and hypermethylation endpoints
In the current study, we investigated the combinations of dietary methyl donors, genetic variants of folate metabolizing enzymes and methyltransferases, and CpG island promoter hypermethylation in colorectal cancer. In addition to associations between polymorphisms in some folate metabolizing enzymes and colorectal cancer, we observed that genetic variants of the DNA methyltransferase DNMT3b and histone methyltransferase EHMT2, which were not previously investigated in relation to colorectal cancer in a prospective cohort study, were associated with reduced colorectal cancer risk among women. Therefore, it may be concluded that these enzymes potentially play an important role in colorectal cancer.

Moreover, polymorphisms in folate metabolizing enzymes MTR and MTRR were associated with reduced risk of developing colorectal tumors harboring promoter hypermethylation. The occurrence of both of these polymorphisms was associated with lower plasma homocysteine concentrations $(20,21)$, suggesting lower catalytic activity of the MTR and MTRR enzymes. Therefore, this may be a second indication that the resulting lower bioavailability of methyl groups reduces promoter hypermethylation in colorectal cancer, rather than leading to an increase.
\end{abstract}

\section{Interaction between dietary methyl donors and genotypes}

Regarding the dietary methyl group donors, we observed that vitamin B2 and methionine intake were both strongly associated with reduced colorectal cancer risk if the enzymatic activity of folate metabolizing enzymes (for the effect of vitamin B2) and DNMT3b (effect of methionine) was not affected by polymorphisms in their encoding genes. Although interactions were not statistically significant, these findings suggest that the effect of vitamin B2 and methionine may depend on genetic status of folate metabolizing enzymes and a DNA methyltransferase. Importantly, our study demonstrates that not only polymorphisms in separate genes, but also combinations of genotypes should be considered within separate functional metabolic pathways, and that dietary associations with cancer may otherwise remain undetected.

\section{Interpretation of associations}

It is important to realize that polymorphisms in folate metabolizing enzymes and methyltransferases may have different consequences for the change in enzymatic activity. Of the genes that were included in this study, there is evidence that enzymatic activity of the folate metabolizing enzyme MTHFR is substantially reduced in individuals with the C677T or A1298C polymorphisms $(22,23)$. As mentioned above, MTR and MTRR polymorphisms were associated with decreased homocysteine concentration, which is indirect evidence for decreased enzymatic activity. In contrast, DNMT3b activity increased due to the occurrence of a rare genetic variant (24), whereas changes of enzymatic activity of histone methyltransferases due to polymorphisms have not yet been investigated. However, the precise consequences of genetic variants need to be clear for the interpretation of biologically plausible mechanisms in genetic association studies. 
Moreover, other epigenetic changes may contribute to colorectal carcinogenesis. For example, global DNA hypomethylation may play a role in colorectal carcinogenesis, but the relative contribution of global hypomethylation and promoter hypermethylation in carcinogenesis, and the effect of methyl donors, are unknown.

\section{Potential dual role of folate in colorectal carcinogenesis}

\section{Observational studies}

After a considerably long follow up period of 13.3 years after baseline, 2349 colorectal cancer patients were identified in the NLCS. With this large number of cases and thereby high power to demonstrate an effect, the hypothesis that adequate dietary folate intake may protect against colorectal cancer was not supported. Several previous observational studies have been conducted to investigate the effect of folate on colorectal carcinogenesis, but only a part of these studies actually suggested a protective effect (25). Furthermore, when estimating the pooled association of observational studies, it appeared that dietary folate, but not total folate (i.e. the combination of dietary folates and folic acid supplements), was inversely associated with colorectal cancer risk (26). However, in the NLCS, in which we only studied the association of dietary folate, this was not observed.

\section{Intervention trials}

The effect of folic acid has been studied in randomized controlled trials among individuals with a history of colorectal adenoma. Folic acid supplementation of 5 $\mathrm{mg} /$ day for 3 years significantly reduced the number of recurrent adenomas, although a rather small number of patients $(n=94)$ was enrolled in that study $(27)$. However, a larger study $(n=853)$ did not suggest a lower risk of colorectal adenoma recurrence in combination with folic acid supplementation of $0.5 \mathrm{mg} / \mathrm{day}$ during a period of approximately 3 years (28). In another recent trial (the Aspirin/Folate Polyp Prevention Study; $n=987$ ), it was observed that baseline folate levels were inversely associated with colorectal adenoma recurrence among individuals in the placebo group, but not in the folic acid intervention group ( $1 \mathrm{mg} /$ day), suggesting that folic acid supplementation does not have an additional protective effect on colorectal adenoma recurrence (29). Interestingly, the folic acid intervention itself was associated with increased risk of developing advanced lesions after a second follow up (30). This is the first trial suggesting a potential tumor promoting effect of folic acid supplementation in humans.

\section{Animal studies}

Previous animal studies indicated that, in rats with normal colonic mucosa, low folate intake or folate deficiency may increase the formation of colonic neoplasias (31), and that high folate intake suppresses intestinal and colorectal carcinogenesis (32-34). However, folate deficiency has an inhibitory effect, and folic acid supplementation may enhance tumor progression in animals with established neoplasms (33-35). It has therefore been proposed that folate may have a dual role in colorectal carcinogenesis, i.e. that the effect depends on the timing of intervention in the process of colorectal carcinogenesis (36). A possible explanation for the observed increased risk of adenoma 
recurrence in the Aspirin/Folate Polyp Prevention Study (30) may be that undetected small lesions were still present in treated patients, and that folic acid enhanced growth of these lesions (37). However, a dual role of folate in colorectal carcinogenesis is still hypothetical and evidence from human studies is limited to date.

Mechanisms of a dual role

Biological mechanisms of a potential dual role of folate in carcinogenesis have not been well established. It is known that adequate folate levels provide nucleotide precursors for sufficient DNA synthesis, which may prevent DNA instability in normal mucosa but enhance proliferation of neoplastic cells (36). We observed that high dietary folate intake was associated with increased risk of tumors harboring APC mutations (chapter 4) or BRAF mutations (chapter 5). Possibly, these mutations arise early in the carcinogenic process and folate may have resulted in growth advantage of these lesions by ensuring adequate DNA synthesis needed for replicating and proliferating tissues. On the other hand, it is also reasonable to expect that adequate folate intake prevents the introduction of gene mutations and would thereby reduce the risk of tumors with gene mutations. However, previous observational studies addressing the association between folate intake and mutations in colorectal cancer are limited in number and were inconsistent $(16,38-40)$. A recent intervention study suggested that supplementation of folic acid and vitamin B12 in subjects with a history of colorectal adenoma increased uracil mis-incorporation and promoter hypermethylation in rectal mucosa (19), suggesting that a high dosis of folic acid may enhance colorectal carcinogenesis.

\section{Implications for folic acid fortification of foods}

\section{Folic acid versus naturally occurring folates}

Results of animal studies (31-35) and randomized controlled trials in humans $(27,28,30)$ were based on an effect of synthetic folic acid and not of folates that occur naturally in our diet. It is questionable however, whether high intake of dietary folates would have a comparable adverse effect on colorectal carcinogenesis as compared to folic acid, and a potential harmful effect may be attributable to supplemented folic acid. One possible explanation may be that naturally occurring folates, as polyglutamates, first have to be cleaved to monoglutamates by enzymes in the intestinal brush border prior to absorption. Since folic acid is a monoglutamate, it may be absorbed directly without enzymatic conversion and thus may have a higher bioavailability than dietary folates $(36,41)$. Nonetheless, as we mentioned above, we observed that naturally occurring folates may also enhance colorectal carcinogenesis depending on molecular characteristics of the tumor.

Nation-wide fortification of foods with folic acid

Mean daily folate intake in the NLCS was $225 \mu \mathrm{g} / \mathrm{d}$ among men and $199 \mu \mathrm{g} / \mathrm{d}$ among women (chapter 3, table 1). In addition, mean folate intake in the Netherlands was estimated to be $282 \mu \mathrm{g} / \mathrm{d}$ among men and $230 \mu \mathrm{g} / \mathrm{d}$ among women in 1998 (42). The 
Recommended Dietary Allowance (RDA) for folate intake in the Netherlands is $300 \mu \mathrm{g} / \mathrm{d}$ for adult men and women (42).

However, in the US, the RDA for adult men and women is $400 \mu \mathrm{g}$ of folate per day (43), and folate intake is substantially higher than in the Netherlands (44). Due to mandatory fortification in the US, additional folic acid intake has been estimated to be $100-200 \mu \mathrm{g} / \mathrm{d}(4445)$. The increase appeared most pronounced among Caucasians, in whom the median total folate intakes increased from around $330 \mu \mathrm{g} / \mathrm{d}$ to at least 470 $\mu \mathrm{g} / \mathrm{d}$ among men, and from 264-303 $\mu \mathrm{g} / \mathrm{d}$ to 380-535 $\mu \mathrm{g} / \mathrm{d}$ among women, depending on the age category (44). In addition, in a cross-sectional survey it has been estimated that more than half of the US adult population uses dietary supplements, which also contributes to total folate intake (46).

After the introduction of nation-wide folic acid fortification in the US and Canada in 1998 , there has been an increase in colorectal cancer incidence compared to the prefortification period (1986 to 1998) (47). The observation may indicate a potential adverse effect of nation-wide fortification, though causality is not proven in such an ecological study and therefore requires further investigation. With respect to a potential tumor promoting effect of folic acid, mandatory nation-wide fortification of foods with folic acid in the US and Canada is of concern. Therefore, other countries that are currently discussing the potential introduction of a nation-wide folic acid fortification program should be very reserved in deciding to do so, because potential long term adverse effects on a population level can not be overseen at this moment.

\section{Recommendations for public health and future research}

Based on results described in the present thesis and the current debate on folate fortification, I would like to propose the following:

1. This is the first prospective cohort study investigating associations of genetic variability of DNA methyltransferases and histone methyltransferases with colorectal cancer risk, and these findings should be replicated in future studies.

2. The complicated interplay between genetic variability and consequences for methyl group metabolism in colorectal cancer warrants future research which should include measurements of global DNA hypomethylation, gene promoter hypermethylation and enzymatic activity of folate metabolizing enzymes and epigenetic regulators. Moreover, there is a need for large studies in order to investigate the relationship between dietary methyl donors, DNA methylation and genetic variants. In addition, existing data and future studies should preferably be pooled to increase power.

3. Despite the proven favorable effect of sufficient folate status in the prevention of neural tube defects $(48,49)$ and stroke $(50)$, we recommend that nation-wide fortification of foods with folic acid should not be introduced given the current state of knowledge about a possible harmful effect on colorectal carcinogenesis and because future long term public health consequences cannot be overseen at present. 
4. It should be considered to decrease the concentration of folic acid in fortified foods in the US and Canada in order to reduce a potential adverse effect on colorectal carcinogenesis.

5. Patients with a history of colorectal adenoma or carcinoma should not be advised to take supplemental folic acid, and medical staff should be aware of a potential harmful effect.

6. Finally, to increase our understanding about the role of folate in colorectal cancer, future studies should focus on the role of folate in DNA synthesis and methylation in normal colorectal epithelium in addition to colorectal adenomas or carcinomas. This will allow conclusions on timing of events and a potential dual role of folate and other dietary methyl donors. 


\section{References}

1. Arnold CN, Goel A, Compton C, Marcus V, Niedzwiecki D, Dowell JM, et al. Evaluation of microsatellite instability, hMLH1 expression and $h M L H 1$ promoter hypermethylation in defining the MSI phenotype of colorectal cancer. Cancer Biol Ther 2004;3(1):73-8.

2. Herman JG, Umar A, Polyak K, Graff JR, Ahuja N, Issa JP, et al. Incidence and functional consequences of $h M L H 1$ promoter hypermethylation in colorectal carcinoma. Proc Natl Acad Sci U S A 1998;95(12):6870-5.

3. Kuismanen SA, Holmberg MT, Salovaara R, de la Chapelle A, Peltomaki P. Genetic and epigenetic modification of MLH1 accounts for a major share of microsatellite-unstable colorectal cancers. Am J Pathol 2000;156(5):1773-9.

4. Poynter JN, Siegmund KD, Weisenberger DJ, Long TI, Thibodeau SN, Lindor N, et al. Molecular Characterization of MSI-H Colorectal Cancer by MLHI Promoter Methylation, Immunohistochemistry, and Mismatch Repair Germline Mutation Screening. Cancer Epidemiol Biomarkers Prev 2008;17(11):3208-3215.

5. Rajagopalan H, Lengauer C. CIN-ful cancers. Cancer Chemother Pharmacol 2004;54 Suppl 1:S65-8.

6. Derks S, Postma C, Carvalho B, van den Bosch SM, Moerkerk PT, Herman JG, et al. Integrated analysis of chromosomal, microsatellite and epigenetic instability in colorectal cancer identifies specific associations between promoter methylation of pivotal tumor suppressor and DNA repair genes and specific chromosomal alterations. Carcinogenesis 2008;29(2):434-9.

7. van Engeland M, Weijenberg MP, Roemen GM, Brink M, de Bruine AP, Goldbohm RA, et al. Effects of dietary folate and alcohol intake on promoter methylation in sporadic colorectal cancer: the Netherlands cohort study on diet and cancer. Cancer Res 2003;63(12):3133-7.

8. Hawkins N, Norrie M, Cheong K, Mokany E, Ku SL, Meagher A, et al. CpG island methylation in sporadic colorectal cancers and its relationship to microsatellite instability. Gastroenterology 2002;122(5):1376-87.

9. van Rijnsoever M, Grieu F, Elsaleh $H$, Joseph D, Iacopetta B. Characterisation of colorectal cancers showing hypermethylation at multiple CpG islands. Gut 2002;51(6):797-802.

10. Winkels RM, Brouwer IA, Verhoef P, van Oort FV, Durga J, Katan MB. Gender and body size affect the response of erythrocyte folate to folic acid treatment. J Nutr 2008;138(8):145661.

11. Ishihara J, Otani T, Inoue M, Iwasaki M, Sasazuki S, Tsugane S. Low intake of vitamin B-6 is associated with increased risk of colorectal cancer in Japanese men. J Nutr 2007;137(7):1808-14.

12. Kune G, Watson L. Colorectal cancer protective effects and the dietary micronutrients folate, methionine, vitamins B6, B12, C, E, selenium, and lycopene. Nutr Cancer 2006;56(1):11-21.

13. Larsson SC, Giovannucci E, Wolk A. Vitamin b6 intake, alcohol consumption, and colorectal cancer: a longitudinal population-based cohort of women. Gastroenterology $2005 ; 128(7): 1830-7$.

14. Wei EK, Giovannucci E, Selhub J, Fuchs CS, Hankinson SE, Ma J. Plasma vitamin B6 and the risk of colorectal cancer and adenoma in women. J Natl Cancer Inst 2005;97(9):684-92.

15. Zhang SM, Moore SC, Lin J, Cook NR, Manson JE, Lee IM, et al. Folate, vitamin B6, multivitamin supplements, and colorectal cancer risk in women. Am J Epidemiol 2006;163(2):108-15.

16. Slattery ML, Curtin K, Sweeney C, Levin TR, Potter J, Wolff RK, et al. Diet and lifestyle factor associations with $\mathrm{CpG}$ island methylator phenotype and $B R A F$ mutations in colon cancer. Int J Cancer 2007;120(3):656-63.

17. Kawakami K, Ruszkiewicz A, Bennett G, Moore J, Watanabe G, Iacopetta B. The folate pool in colorectal cancers is associated with DNA hypermethylation and with a polymorphism in methylenetetrahydrofolate reductase. Clin Cancer Res 2003;9(16 Pt 1):5860-5.

18. Mokarram P, Naghibalhossaini F, Saberi Firoozi M, Hosseini SV, Izadpanah A, Salahi H, et al. Methylenetetrahydrofolate reductase C677T genotype affects promoter methylation of tumor-specific genes in sporadic colorectal cancer through an interaction with folate/vitamin B(12) status. World J Gastroenterol 2008;14(23):3662-71. 
19. van den Donk M, Pellis L, Crott JW, van Engeland M, Friederich P, Nagengast FM, et al. Folic acid and vitamin B-12 supplementation does not favorably influence uracil incorporation and promoter methylation in rectal mucosa DNA of subjects with previous colorectal adenomas. J Nutr 2007;137(9):2114-20.

20. Chen J, Stampfer MJ, Ma J, Selhub J, Malinow MR, Hennekens CH, et al. Influence of a methionine synthase (D919G) polymorphism on plasma homocysteine and folate levels and relation to risk of myocardial infarction. Atherosclerosis 2001;154(3):667-72.

21. Gaughan DJ, Kluijtmans LA, Barbaux S, McMaster D, Young IS, Yarnell JW, et al. The methionine synthase reductase (MTRR) A66G polymorphism is a novel genetic determinant of plasma homocysteine concentrations. Atherosclerosis 2001;157(2):451-6.

22. Frosst P, Blom HJ, Milos R, Goyette P, Sheppard CA, Matthews RG, et al. A candidate genetic risk factor for vascular disease: a common mutation in methylenetetrahydrofolate reductase. Nat Genet 1995;10(1):111-3.

23. van der Put NM, Gabreels F, Stevens EM, Smeitink JA, Trijbels FJ, Eskes TK, et al. A second common mutation in the methylenetetrahydrofolate reductase gene: an additional risk factor for neural-tube defects? Am J Hum Genet 1998;62(5):1044-51.

24. Shen H, Wang L, Spitz MR, Hong WK, Mao L, Wei Q. A novel polymorphism in human cytosine DNA-methyltransferase-3B promoter is associated with an increased risk of lung cancer. Cancer Res 2002;62(17):4992-5.

25. Bollheimer LC, Buettner R, Kullmann A, Kullmann F. Folate and its preventive potential in colorectal carcinogenesis. How strong is the biological and epidemiological evidence? Crit Rev Oncol Hematol 2005;55(1):13-36.

26. Sanjoaquin MA, Allen N, Couto E, Roddam AW, Key TJ. Folate intake and colorectal cancer risk: a meta-analytical approach. Int J Cancer 2005;113(5):825-8.

27. Jaszewski R, Misra S, Tobi M, Ullah N, Naumoff JA, Kucuk O, et al. Folic acid supplementation inhibits recurrence of colorectal adenomas: a randomized chemoprevention trial. World J Gastroenterol 2008;14(28):4492-8.

28. Logan RF, Grainge MJ, Shepherd VC, Armitage NC, Muir KR. Aspirin and folic acid for the prevention of recurrent colorectal adenomas. Gastroenterology 2008;134(1):29-38.

29. Figueiredo JC, Levine AJ, Grau MV, Barry EL, Ueland PM, Ahnen DJ, et al. Colorectal adenomas in a randomized folate trial: the role of baseline dietary and circulating folate levels. Cancer Epidemiol Biomarkers Prev 2008;17(10):2625-31.

30. Cole BF, Baron JA, Sandler RS, Haile RW, Ahnen DJ, Bresalier RS, et al. Folic acid for the prevention of colorectal adenomas: a randomized clinical trial. Jama 2007;297(21):2351-9.

31. Cravo ML, Mason JB, Dayal Y, Hutchinson M, Smith D, Selhub J, et al. Folate deficiency enhances the development of colonic neoplasia in dimethylhydrazine-treated rats. Cancer Res 1992;52(18):5002-6.

32. Kim YI, Salomon RN, Graeme-Cook F, Choi SW, Smith DE, Dallal GE, et al. Dietary folate protects against the development of macroscopic colonic neoplasia in a dose responsive manner in rats. Gut 1996;39(5):732-40.

33. Song J, Medline A, Mason JB, Gallinger S, Kim YI. Effects of dietary folate on intestinal tumorigenesis in the APCMin mouse. Cancer Res 2000;60(19):5434-40.

34. ong J, Sohn KJ, Medline A, Ash C, Gallinger S, Kim YI. Chemopreventive effects of dietary folate on intestinal polyps in APC+/-Msh2-/- mice. Cancer Res 2000;60(12):3191-9.

35. Le Leu RK, Young GP, McIntosh GH. Folate deficiency reduces the development of colorectal cancer in rats. Carcinogenesis 2000;21(12):2261-5.

36. Kim YI. Folate and colorectal cancer: An evidence-based critical review. Mol Nutr Food Res 2007;51(3):267-92.

37. Ulrich CM, Potter JD. Folate and cancer--timing is everything. Jama 2007;297(21):2408-9.

38. Brink M, Weijenberg MP, de Goeij AF, Roemen GM, Lentjes MH, de Bruine AP, et al. Dietary folate intake and k-ras mutations in sporadic colon and rectal cancer in the Netherlands Cohort Study. Int J Cancer 2004.

39. Martinez ME, Maltzman T, Marshall JR, Einspahr J, Reid ME, Sampliner R, et al. Risk factors for Ki-ras protooncogene mutation in sporadic colorectal adenomas. Cancer Res $1999 ; 59(20): 5181-5$. 
40. Schernhammer ES, Giovannuccci E, Fuchs CS, Ogino S. A Prospective Study of Dietary Folate and Vitamin B and Colon Cancer According to Microsatellite Instability and KRAS Mutational Status. Cancer Epidemiol Biomarkers Prev 2008;17(10):2895-8.

41. Winkels RM, Brouwer IA, Siebelink E, Katan MB, Verhoef P. Bioavailability of food folates is $80 \%$ of that of folic acid. Am J Clin Nutr 2007;85(2):465-73.

42. Health Council of the Netherlands: Dietary Reference Intakes: vitamin B6, folic acid and vitamin B12. The Hague: Health Council of the Netherlands 2003; publication no. 2003/04.

43. Institute of Medicine. Dietary reference intakes for thiamin, riboflavin, niacin, vitamin B6, folate, vitamin B12, pantothenic acid, biotin, and choline. Washington: National Academy Press 2000:196-305.

44. Bentley TG, Willett WC, Weinstein MC, Kuntz KM. Population-level changes in folate intake by age, gender, and race/ethnicity after folic acid fortification. Am J Public Health 2006;96(11):2040-7.

45. Quinlivan EP, Gregory JF, 3rd. Reassessing folic acid consumption patterns in the United States (1999 2004): potential effect on neural tube defects and overexposure to folate. Am J Clin Nutr 2007;86(6):1773-9.

46. Radimer K, Bindewald B, Hughes J, Ervin B, Swanson C, Picciano MF. Dietary supplement use by US adults: data from the National Health and Nutrition Examination Survey, 19992000. Am J Epidemiol 2004;160(4):339-49.

47. Mason JB, Dickstein A, Jacques PF, Haggarty P, Selhub J, Dallal G, et al. A temporal association between folic acid fortification and an increase in colorectal cancer rates may be illuminating important biological principles: a hypothesis. Cancer Epidemiol Biomarkers Prev 2007;16(7):1325-9.

48. Prevention of neural tube defects: results of the Medical Research Council Vitamin Study. MRC Vitamin Study Research Group. Lancet 1991;338(8760):131-7.

49. Czeizel AE, Dudas I. Prevention of the first occurrence of neural-tube defects by periconceptional vitamin supplementation. N Engl J Med 1992;327(26):1832-5.

50. Wang X, Qin X, Demirtas H, Li J, Mao G, Huo Y, et al. Efficacy of folic acid supplementation in stroke prevention: a meta-analysis. Lancet 2007;369(9576):1876-82. 

Summary 
Folate is a B-vitamin that occurs naturally in our diet, but may also exist as folic acid which is the synthetic form of folate used in dietary supplements and fortified foods. Folic acid supplementation has been observed to reduce neural tube defects during embryonic development. In addition, adequate folate intake may possibly contribute to preventing colorectal cancer. However, previous studies have been inconsistent in demonstrating a protective effect, and such inconsistencies may be partially explained by the hypothesis that folate has a dual role in colorectal carcinogenesis, i.e. that it may protect against neoplastic development in normal colorectal mucosa whereas folate supplementation might enhance growth of existing pre-malignant lesions.

During colorectal carcinogenesis, the colorectal epithelium transforms into aberrant crypt foci, through colorectal adenomas, colorectal carcinomas and finally metastasis. Several molecular aberrations are thought to contribute to this process, such as accumulation of gene mutations in the tumor suppressor- and oncogenes $A P C$, $K R A S, P 53$ and BRAF. In addition, promoter hypermethylation of CpG islands is a predominant epigenetic alteration that results in inactivation of transcriptional activity. A distinct subset of colorectal cancers harbours widespread promoter hypermethylation and is referred to as the CpG island methylator phenotype (CIMP). Furthermore, colorectal tumors may harbour microsatellite instability (MSI) - genetic instability characterized by length alterations in repeat sequences - often caused by promoter CPG island hypermethylation of the mismatch repair (MMR) gene MLH1. In colorectal cancer, CIMP has been observed to be associated with MLH1 hypermethylation, MSI and $B R A F$ mutations.

Folate has two important biological functions that are relevant with respect to the process of carcinogenesis. First, since it is essential for the biosynthesis of nucleotide precursors, folate deficiency may result in DNA instability, and possibly the introduction of gene mutations thereby contributing to carcinogenesis. Furthermore, folate is a methyl group donor which may influence DNA methylation such as CpG island promoter hypermethylation or global DNA hypomethylation, both of which are often observed in colorectal cancer. Like folate, methionine is a methyl donor. In addition, vitamins B2, B6 and B12 are involved in folate metabolism as co-factors, and may therefore modulate the bioavailability of methyl groups. Adequate intakes of these nutrients ensure a sufficient supply of methyl groups, and may be hypothesized to prevent aberrant DNA methylation, and thus to protect against colorectal cancer.

In this thesis, we investigated the associations between dietary methyl group donors and of other B-vitamins involved in folate metabolism with colorectal cancer, with or without gene mutations or promoter CpG island hypermethylation. We also studied whether genetic variants of folate metabolizing enzymes and methyltransferases (i.e. enzymes that are involved in incorporation of methyl groups into DNA) modify these associations. In addition, we studied the occurrence and correlations of gene mutations and gene promoter hypermethylation in colorectal carcinomas.

The studies described in this thesis were conducted within the Netherlands Cohort Study on diet and cancer (NLCS), which includes 120,852 men and women who filled out a food frequency questionnaire at baseline in 1986 . The cohort was followedup for cancer incidence and a subcohort of 5,000 subjects was randomly selected after baseline exposure measurement to estimate accumulation of person-time in the cohort through biennial follow-up of vital status. Overall colorectal cancer could be 
investigated among 2,349 cases from a follow-up period of 13.3 years after baseline. Tumor material was collected of colorectal cancer patients identified within the first 7.3 years of follow up after baseline. In total, 734 patients were identified of whom sufficient tumor DNA could be extracted needed for genotyping and other molecular analyses.

In chapter 2, we investigated associations between MGMT promoter methylation and $\mathrm{G}: \mathrm{C}>\mathrm{A}: \mathrm{T}$ mutations in KRAS and $A P C$, and between $M L H 1$ promoter methylation and $A P C, K R A S$ and $B R A F$ mutations. We observed that concurrent hypermethylation of MGMT and MLH1 was rare. MGMT hypermethylation occurred more frequently in tumors with $\mathrm{G}: \mathrm{C}>\mathrm{A}: \mathrm{T}$ KRAS mutations compared to those without these mutations, whereas no such difference was observed for $\mathrm{G}: \mathrm{C}>\mathrm{A}: \mathrm{T}$ mutations in $A P C$. MLH1 hypermethylation was less common in tumors with APC or KRAS mutations, but was positively associated with $B R A F$ mutations. The findings of this study suggest that in colorectal carcinogenesis, MGMT hypermethylation may succeed $A P C$ mutations but precedes KRAS mutations, and that tumors with MGMT hypermethylation may develop distinctly from those showing MLH1 hypermethylation.

The associations between dietary folate, methionine, vitamin B2 and vitamin B6 with overall colorectal cancer risk are presented in chapter 3. Although we did not observe an association between dietary folate and colorectal cancer, higher methionine and vitamin B2 intakes were associated with reduced proximal colon cancer risk among men and women, respectively. Conversely, vitamin B6 intake was associated with increased colorectal cancer risk, being most pronounced for rectal cancer among women.

Whether folate intake is associated with $A P C$ mutations in colorectal cancer was investigated in chapter 4 . Men with relatively high folate intake were at reduced risk of developing tumors without $A P C$ mutations, but folate was positively associated with tumors harbouring $A P C$ mutations. In chapter 5, we investigated the associations between dietary folate, methionine, vitamins B2 and B6 with MLH1 hypermethylation, MLH1 expression, MSI and BRAF mutations. Predominantly among men, folate was associated with increased risk of tumors harbouring $B R A F$ mutations, whereas vitamin B6 was associated with $M L H 1$ hypermethylation. These observations suggest that folate may enhance the growth of lesions harbouring gene mutations, and that vitamin B6 may do so by increasing promoter hypermethylation. Intake of folate, methionine, vitamins B2 and B6 were not associated with CIMP (chapter 7).

Chapter 6 addresses the associations between genetic variants of folate metabolizing enzymes MTHFR, MTR and MTRR, the DNA methyltransferase $3 \mathrm{~b}$ (DNMT3b) and histone methyltransferases PRDM2, EHMT1 and EHMT2 with overall colorectal cancer and with tumors with or without CIMP, MLH1 hypermethylation or MSI. The MTHFR 677TT variant was inversely associated with colorectal cancer risk among men, whereas the rare $T$ allele was associated with increased risk in women. The MTR 2756GG genotype was associated with increased colorectal cancer risk, and inverse associations were observed among women carrying rare variants of the DNMT3b C $>\mathrm{T}$ or EHMT2 G>A polymorphisms. We also observed inverse associations between MTR A2756G and CIMP among men, and between MTRR A66G and MLH1 hypermethylation among women, suggesting that the occurrence of rare variants of these MTR and MTRR polymorphisms may reduce the risk of colorectal tumors with a promoter hypermethylation phenotype. 
Finally, in chapter 7 we investigated whether the association between methyl donor intake with overall colorectal cancer, or with CIMP, MLH1 hypermethylation or MSI, may be modified by the genetic variants. An inverse association of methionine with colorectal cancer appeared to be more pronounced if no rare variants occurred in the polymorphic DNMT3b gene. Similarly, we observed that vitamin B2 was inversely associated with CRC among individuals with the MTHFR 677CC genotype, while a strong inverse association existed when $\leq 1$ rare allele occurred in the combination of methyl metabolizing enzymes MTHFR, MTR and MTRR, respectively. We therefore concluded that dietary methyl donors may be more protective against colorectal carcinogenesis if methyl metabolizing enzymes and DNA methyltransferases are left unaffected by rare variants of their encoding polymorphic genes. In addition, combining genotypes may reveal diet associations with colorectal cancer and should be considered in association studies.

This is the first prospective cohort study investigating associations of genetic variability of DNA methyltransferases and histone methyltransferases with colorectal cancer risk, and these findings should be replicated in future studies. In addition, the complicated interplay between genetic variability and consequences for methyl group metabolism in colorectal cancer warrants future research which should include measurements of global DNA hypomethylation, gene promoter hypermethylation and enzymatic activity of folate metabolizing enzymes and epigenetic regulators. Moreover, there is a need for large studies in order to investigate the relationship between dietary methyl donors, DNA methylation and genetic variants. In addition, existing data and future studies should preferably be pooled to increase power. In view of the hypothesized potential dual role of folate in colorectal carcinogenesis, and given our observations that naturally occurring folates may enhance colorectal tumors with specific molecular characteristics, it should not be recommended to introduce nationwidefortification of foods with folic acid. 


\section{Samenvatting}


Folaat, of vitamine B11 komt voor in onder andere groene groenten, brood, aardappelen, vlees- en zuivelproducten. Naast deze natuurlijke vorm van folaat bestaat er een synthetische en chemisch stabielere variant die gebruikt wordt in supplementen en voor de verrijking van voedingsmiddelen. Hoewel de officiële benaming van deze synthetische variant foliumzuur is, wordt deze term in het Nederlands over het algemeen ook gebruikt voor folaat dat van nature in de voeding voorkomt. Om echter verdere verwarring te voorkomen zal in deze samenvatting de term folaat worden gebruikt voor folaten in de voeding, en foliumzuur voor de synthetische vorm.

$\mathrm{Er}$ zijn sterke aanwijzingen dat adequate folaatinname beschermt tegen neuraalbuisdefecten tijdens de embryonale ontwikkeling, waartoe Noord-Amerika en Canada in 1996 tot landelijke foliumzuurfortificatie van granen en graanproducten overgegaan zijn. Bovendien zou het tevens beschermen tegen dikkedarmkanker. Echter, de resultaten uit verschillende studies naar de relatie tussen folaat en dikkedarmkanker zijn inconsistent gebleken, mogelijk doordat folaat een tweeledige rol speelt bij het ontstaan van dikkedarmkanker. Zo word verondersteld dat het weliswaar beschermt tegen afwijkende weefselgroei in gezond darmepitheel, maar dat het de groei van bestaande neoplasma's juist zou kunnen bevorderen.

De carcinogenese van dikkedarmkanker is een langdurig proces waarbij gezond darmepitheel geleidelijk transformeert in een of meerdere carcinomen. Bepaalde moleculaire afwijkingen dragen waarschijnlijk in belangrijke mate bij aan dit proces, zoals somatische mutaties in de tumorsuppressorgenen en oncogenen $A P C$, $K R A S, P 53$ en $B R A F$. Naast zulke genetische afwijkingen spelen epigenetische veranderingen - afwijkingen in het DNA die niet het gevolg zijn van een verandering in de DNA sequentie - een belangrijke rol. Zo kan genexpressie worden geblokkeerd door hypermethylering van CpG dinucleotiden in promotorregio's van genen. In ongeveer $25 \%$ van de dikkedarmtumoren komt dit type epigenetische verandering aanzienlijk meer voor, en tumoren met dit "methyleringsfenotype" worden daarom in de Engelse wetenschappelijke literatuur aangeduid met "CpG island methylator phenotype" of CIMP. Andere moleculaire afwijkingen die sterk correleren met dit fenotype zijn microsatelliet instabiliteit (MSI), een bepaalde vorm van DNA-instabiliteit die onder andere veroorzaakt wordt door hypermethylering van het DNA-reparatiegen $M L H 1$, en mutaties in het oncogen $B R A F$.

Folaat heeft twee belangrijke functies in het lichaam die ook relevant zijn voor het proces van carcinogenese. Het is enerzijds essentieel voor de synthese van DNA. Folaatdeficiëntie kan DNA-instabiliteit tot gevolg hebben, wat genmutaties zou kunnen induceren. Daarnaast is folaat een donor van methylgroepen en is dus mogelijk van invloed op DNA methylering. Naast folaat is methionine een methyldonor in onze voeding, terwijl de vitaminen B2, B6 en B12 betrokken zijn bij verschillende omzettingen in het folaatmetabolisme. We nemen aan dat voldoende inname van deze nutriënten zorgt voor een adequate toelevering van methylgroepen, wat afwijkingen in DNA methylering en daarmee de carcinogenese van dikkedarmkanker kan voorkomen.

In de studies beschreven in dit proefschrift zijn de associaties onderzocht tussen methylgroepdonoren en andere B-vitaminen uit de voeding en dikkedarmkanker, waarbij specifiek naar de relatie gekeken is met tumoren met of zonder genmutaties of CIMP. Er is tevens onderzocht wat de mogelijk modificerende werking is van een aantal folaat metaboliserende enzymen en methyltransferases (enzymen die zorgen voor het incorporeren van methylgroepen in het DNA). Daarnaast 
onderzochten we het vóórkomen en correlaties tussen promotor hypermethylering en genmutaties in dikkedarmtumoren.

De studies zijn uitgevoerd binnen de Nederlandse Cohort Studie naar voeding en kanker (NLCS). Dit cohort bestaat uit 120.852 mannen en vrouwen die bij aanvang van de studie in 1986 een voedselfrequentievragenlijst ingevuld hebben. Voor het schatten van de opgebouwde persoonstijd is bij aanvang een subcohort geselecteerd van 5.000 willekeurige personen, terwijl het gehele cohort gevolgd wordt voor het optreden van kanker. In de eerste 7,3 jaar na aanvang van de studie waren er 734 patiënten met dikkedarmkanker geregistreerd, van wie tumormateriaal uit pathologielaboratoria was opgevraagd dat tevens voldoende DNA bleek te bevatten voor moleculaire analyses. Gedurende de eerste 13,3 jaar na aanvang van de studie waren er in totaal 2.349 patiënten met dikkedarmkanker geregistreerd die de voedselfrequentievragenlijst volledig ingevuld hadden.

In hoofdstuk 2 onderzochten we de correlatie tussen hypermethylering van DNA-reparatiegenen en mutaties in tumorsuppressorgenen en oncogenen in dikkedarmtumoren. Het $O^{6}$-methylguanine DNA methyltransferase (MGMT)-gen codeert voor een enzym dat alkyl adducten van de 06-positie van guanine verwijdert, waarmee $\mathrm{G}: \mathrm{C}>\mathrm{A}: \mathrm{T}$ mutaties kunnen worden voorkomen. We onderzochten de correlatie tussen MGMT hypermethylering en zulke mutaties in $A P C$ en KRAS, en tussen MLH1 hypermethylering en mutaties (ongeacht het type mutatie) in $A P C, K R A S$ en $B R A F$. Het bleek dat gelijktijdige hypermethylering van MGMT en $M L H 1$ in slechts $10 \%$ van de tumoren voorkwam. MGMT hypermethylering kwam vaker voor in tumoren met $\mathrm{G}: \mathrm{C}>\mathrm{A}: \mathrm{T}$ KRAS mutaties dan in tumoren zonder deze mutaties, terwijl een dergelijk verschil niet bleek te bestaan voor $\mathrm{G}: \mathrm{C}>\mathrm{A}: \mathrm{T}$ mutaties in het $A P C$ gen. $M L H 1$ hypermethylering was geassocieerd met $B R A F$ mutaties, maar kwam juist minder vaak voor in tumoren met $A P C$ - of KRAS mutaties. Deze resultaten zouden erop kunnen wijzen dat MGMT hypermethylering ontstaat na de introductie van APC mutaties, maar voorafgaat aan het ontstaan van KRAS mutaties tijdens de carcinogenese van dikkedarmkanker. Tumoren met MGMT hypermethylering zouden zich via een ander moleculair mechanisme kunnen ontwikkelen dan tumoren met MLH1 hypermethylering.

De associaties tussen innamen van folaat, methionine, vitamines B2 en B6, en dikkedarmkanker staan beschreven in hoofdstuk 3. Folaatinname was niet geassocieerd met dikkedarmkanker. Echter, methionine en vitamine B2 waren geassocieerd met een lager risico op het krijgen van een tumor in het proximale colon onder respectievelijk mannen en vrouwen. Vitamine B6-inname was echter geassocieerd met een hoger risico, van met name rectumtumoren bij vrouwen.

Of folaatinname geassocieerd was met $A P C$ mutaties in dikkedarmkanker is onderzocht in hoofdstuk 4. Mannen met een relatief hoge folaatinname hadden een lager risico op het krijgen van een tumor zonder $A P C$ mutatie, maar een hoger risico op tumoren met $A P C$ mutatie. In hoofdstuk 5 zijn de associaties onderzocht tussen innamen van folaat, methionine, vitaminen B2 en B6, en de gerelateerde moleculaire afwijkingen MLH1 hypermethylering, MLH1 expressie, MSI en BRAF mutaties. Met name onder mannen was folaatinname geassocieerd met verhoogd risico op tumoren met BRAF mutaties, terwijl vitamine B6 met geassocieerd was met MLH1 hypermethylering. Het zou zo kunnen zijn dat folaat de groei van beginnende tumoren met genmutaties als in $A P C$ en $B R A F$ stimuleert, en dat vitamine $\mathrm{B} 6$ dat kan doen door het bevorderen van promotor hypermethylering. Folaat, methionine, vitaminen $B 2$ en B6, waren niet geassocieerd met CIMP (hoofdstuk 7). 
Hoofdstuk 6 beschrijft de associaties tussen genetische varianten van de folaat metaboliserende enzymen MTHFR, MTR en MTRR, het DNA methyltransferase 3b (DNMT3b), en de histonmethyltransferases PRDM2, EHMT1 en EHMT2 enerzijds; en dikkedarmkanker ongeacht moleculaire afwijkingen, of het risico op tumoren met of zonder CIMP, MLH1 hypermethylering of MSI anderzijds. De MTHFR 677TT variant was geassocieerd met lager dikkedarmkankerrisico onder mannen, terwijl het zeldzamere T-allel juist geassocieerd was met verhoogd risico bij vrouwen. Het MTR 2756GG genotype was geassocieerd met een hoger risico, terwijl inverse associaties bestonden onder vrouwen met zeldzame varianten van de DNMT3b C>T en EHMT2 G>A polymorfismen. Verder vonden we inverse associaties tussen MTR A2756G en CIMP onder mannen en tussen MTRR A66G en MLH1 hypermethylering onder vrouwen, wat erop wijst dat het voorkomen van zeldzame varianten van deze MTR en MTRR polymorfismen het risico op dikkedarmtumoren met een "methyleringsfenotype" verlaagt.

Tenslotte is in hoofdstuk 7 onderzocht of de associatie tussen methyldonorinname en dikkedarmkanker met of zonder CIMP, MLH1 hypermethylering of MSI, gemodificeerd wordt door het vóórkomen van de onderzochte genetische varianten. Het bleek dat de mogelijk beschermende werking van methionine tegen dikkedarmkanker sterker was indien er geen zeldzame varianten voorkwamen in het polymorfe DNMT3b gen. Analoog daaraan bestond de inverse associatie tussen vitamine B2 en dikkedarmkanker alleen onder individuen met het MTHFR 677CC genotype, terwijl een sterk invers verband bestond voor diegenen met minder dan 1 zeldzaam allel in de combinatie van de folaat metaboliserende enzymen MTHFR, MTR en MTRR. We concluderen daarom dat een inverse associatie tussen methyldonorinname en dikkedarmkanker sterker zou kunnen zijn in mensen bij wie folaat metaboliserende enzymen en methyltransferases niet zijn aangetast door zeldzame varianten van hun coderende polymorfe genen. Bovendien is blijkbaar het combineren van verschillende genotypen van belang om associaties tussen nutriënten en kankerrisico te kunnen ontdekken.

Dit is de eerste keer dat de associaties tussen genetische varianten van DNA methyltransferases en histonmethyltransferases en dikkedarmkanker zijn onderzocht in een prospectieve cohortstudie. Daarom moeten deze bevindingen in de toekomst worden herhaald, bij voorkeur in grote studies of door het samenvoegen van studies. Daarnaast zijn de exacte consequenties van polymorfismen in folaat metaboliserende enzymen en methyltransferases voor enzymactiviteit lang niet altijd bekend, en is het bovendien de vraag wat de gevolgen zijn voor veranderingen in DNA methylering. In toekomstig onderzoek zou daarom de verandering van enzymactiviteit gemeten moeten worden voor genetische varianten van enzymen in het folaatmetabolisme en methyltransferases, en eventuele veranderingen in DNA methylering. Gegeven de hypothese dat folaat een mogelijk tweeledige rol speelt in de carcinogenese van dikkedarmkanker, en gezien onze observaties dat natuurlijk voorkomend folaat het risico van tumoren met specifieke moleculaire afwijkingen kan verhogen, zou een fortificatieprogramma met foliumzuur op landelijk niveau moeten worden afgeraden. 
Dankwoord 
$\mathrm{Na}$ het opschrijven van een heleboel wetenschap in dit proefschrift, wil ik hier graag iedereen bedanken die betrokken is geweest bij het onderzoek, en mij op wetenschappelijk of persoonlijk vlak gesteund heeft gedurende de afgelopen jaren dat ik in Maastricht gewerkt heb als AIO.

Matty, allereerst zou ik jou als dagelijkse begeleider willen bedanken voor het regelmatige, en altijd heel prettige werkoverleg samen met Manon. Daarnaast kon ik altijd bij je aankloppen voor hulp bij data-analyses, artikelen schrijven, presentaties, noem maar op. Ook ben je persoonlijk betrokken bij mensen wat een heel fijne eigenschap is. Ik heb me bij jou altijd gewaardeerd gevoeld en heb erg veel van je geleerd. Mochten we in de toekomst nog eens samenwerken dan kijk ik daar nu al naar uit. Bedankt voor alles!

Manon, ook jij hartelijk bedankt voor alle begeleiding. Ik heb niet vaak zo'n enthousiast iemand meegemaakt als jij! Als ikzelf twijfelde over aspecten van het onderzoek, kon jij meestal meteen overtuigen dat de resultaten toch echt fantastisch waren. Je enthousiasme werkt aanstekelijk, en vaak liep ik na een bespreking met een heel goed gevoel en hernieuwde energie jouw kamer weer uit.

Piet, hartelijk bedankt voor je fijne hulp, het regelmatige overleg over het project, commentaar op artikelen en je begeleiding bij het schrijven van de inleiding en epiloog van het proefschrift. In de zomer van 2008 reisden wij samen met Matty naar Lyon voor een bezoek aan een symposium over moleculaire epidemiologie. Ons vervoermiddel op weg naar het symposium was de TGV, en onderweg hebben we de opzet van de inleiding van het proefschrift besproken. Blijkbaar gaat dat prima bij 300 $\mathrm{km} / \mathrm{u}$ ! Het afronden van het proefschrift ging met iets lagere snelheid, maar jouw kritische en gestructureerde blik op het onderzoek hebben mij veel geholpen.

Kim, tja, het is eigenlijk simpel. Zonder jou als labanalist had het grootste gedeelte van dit proefschrift er nooit kunnen komen. We hebben echt ontzettend veel gehad aan je betrokkenheid bij het project en je snelle en efficiënte manier van werken. In de periode dat de genotypering gedaan moest worden bleek de gemaakte planning niet haalbaar te zijn. De ontwikkeling en het werkend krijgen van de SnapShot analyse bleek veel meer werk te zijn dan ingeschat. Desondanks werkte jij hard door, en heb je met deze en andere analyses geprobeerd om data betrouwbaar en zo snel mogelijk aan te leveren. En daar mogen we je heel dankbaar voor zijn. Hoewel ik in het begin vrijwel niets afwist van labanalyses, heb jij me wegwijs gemaakt in de wereld van pipetten, PCR, MSP, bisulfietbehandeling, iets "op gel zetten", immuunhistochemie, SnapSHot analyse, en de interpretatie van SNPs. Bij dat laatste moesten grafieken op het computerscherm worden afgelezen totdat we er allebei scheel van werden, wat de moleculair-epidemioloog doet beseffen dat het echte werk in het lab gedaan wordt!

Adriaan, bedankt voor je hulp en advies bij interpretatie van de coupes van P53 expressie en je advies over moleculaire subtypes van dikkedarmtumoren. We hebben elkaar iets beter leren kennen op het AACR congres in Boston, je bent een sociaal mens, en het was leuk daar! Ik wens je heel veel succes met je nieuwe baan in Venlo. 
Ton, je bent erg goed in het precies formuleren en ik heb jouw gedetailleerde commentaar op de artikelen en abstracts gewaardeerd. Dankjewel!

Jim Herman, during the period of your TEFAF professorship in Maastricht, you helped me, Manon and Matty with the paper on methylation and mutations. Thank you very much for your contribution; your new ideas were very helpful.

Leo, ik wil jou hartelijk bedanken voor de samenwerking bij het ontwikkelen van de bootstrapmethode, je hulp en advies bij het programmeren in Stata en databeheer. Gaandeweg zijn we co-auteurs geworden op elkaars artikelen. Ik heb er plezier in gehad en heb prettig met je samengewerkt. Bedankt!

Arnold, jou hulp bij het ontwikkelen van de bootstrapmethode was onmisbaar. Hartelijk bedankt voor je bijdrage, voor de uitleg van de statistische procedure en je suggesties voor het ontwikkelen van een programma.

Martien en Erik, ik heb drie jaar achter elkaar de bijspijkercursus gecoördineerd. Het was fijn om daarbij met jullie samen te werken. Het bedenken van goede examenvragen valt zeker niet mee, maar ik heb er wel veel van geleerd.

Brenda, jij bedankt, bedankt, bedankt voor het delen van zorgen over de juistheid van datasets, interpretatie van resultaten, data-analyses, het over en weer mailen van relevante artikelen, lachen om de kuikentjes in de epi-vijver en andere pluizige beestjes op jouw screensavers, fantaseren over ski- en zomervakanties, je gezelligheid tijdens onze reis naar Stockholm, de talloze keren dat we de slappe lach hadden, het vertellen over thuis, etc, etc, etc. Je was een ontzettend fijne kamergenoot!

Rikkert, toen ik in 2004 in Maastricht kwam wonen kende ik bijna niemand, maar het was een groot genoegen dat jij destijds als ex-studiegenoot/goede vriend bij epi werkte. Het is altijd prettig als je na een aantal jaar weer bij een goede vriend in de buurt woont. Met dat betreft konden we zo verder praten, precies daar waar we een jaar of 4 eerder gebleven waren tijdens een van onze befaamde bier en blues avonden in de binnenlanden van Kenia. Zaken die het leven buiten het werk aangenaam maakten waren de potten squash, Lumière op maandagavond, salades en pasta's bouwen (met een klein biertje, wijn of gewoon verstandig met een glas water), doordeweeks kroegbezoek, of op de bank hangen voor de tv naar een aflevering van "The office" kijken. Ik vond het jammer toen je naar Utrecht verhuisde, maar ik kijk wel terug op een bijzonder leuke tijd!

Yvonne, hartelijk bedankt voor de strakke lay-out van het proefschrift.

Bas, dankzij jouw inspanningen bij het ontwerp van de omslag is het proefschrift er werkelijk fantastisch uit komen te zien. Ik had me geen mooier ontwerp kunnen voorstellen!

Alle collega's van epidemiologie en pathologie, dank jullie wel voor de prettige en collegiale sfeer. Ik heb een fijne tijd gehad op het werk. Toen we onze tweeling Fleurtje en Madelief verloren was dat een moeilijke tijd voor mij en Simone, maar ik heb me 
zeer gesteund gevoeld door alle oprechte reacties en medeleven van een heleboel van jullie. Dit was heel erg waardevol en zal ik niet gauw vergeten, en ik wil jullie daarvoor dan ook ontzettend bedanken.

Zangkoor Catotsh, het zingen op de dinsdagavond was vanaf het begin een voornaam onderdeel van mijn sociale leven in Maastricht. Ik heb altijd veel plezier gehad in het zingen en het begeleiden op piano en gitaar. Bedankt voor alle gezelligheid, en het gaat jullie goed!

Martine de Vogel en Marten Postma, mijn paranimfen. Tine, wat bijzonder dat jij nu naast mij staat als paranimf. Ik geloof niet dat Joris al begrijpt waar het bij de promotie om draait, maar wie weet zit er een grote wetenschapper in dat kleine ventje. Marten, we kennen elkaar sinds de brugklas en hebben al aan heel wat brommers en automobielen gesleuteld en mooie reizen mogen maken. Je bent een van mijn allerbeste vrienden en ik ben trots dat jij paranimf bent.

Lieve Simone, we hebben de afgelopen paar jaar een hoop meegemaakt. Tijdens mijn eerste baan in Amsterdam twijfelde ik of ik mijn carrière als programmeur zou voortzetten of toch het onderzoek in. Jij hebt me gestimuleerd en geleerd om je hart te volgen, en mede dankzij jouw steun ben ik toch gaan doen wat ik het leukste vind. Je bent geweldig! Mijn baan in Maastricht begon toen jij nog twee jaar verder moest werken aan je promotieonderzoek in Wageningen, en halverwege mijn AIO-tijd in Maastricht kreeg jij werk aan de universiteit van Bergen in Noorwegen, zodat we de afgelopen 4 jaar op en neer hebben gereisd tussen Wageningen en Maastricht en later tussen Noorwegen en Maastricht. Ik ben heel blij dat we nu op één plaats wonen samen met onze kleine meid.

Lieve Milou, klein knorretje, wat geef je me veel geluk en rust. Je hebt me met je vier maanden doen beseffen hoe bijzonder en kostbaar het leven is. We gaan er samen met mama wat moois van maken!

Stefan de Vogel

Bergen, april 2009 


\section{Curriculum vitae}




\section{About the author}

Stefan de Vogel was born in Leidschendam in the Netherlands on May 2nd, 1975. After completing Athenaeum at the IJsselcollege, Zwolle in 1995, he started studying Human Nutrition at the Wageningen University. For his first master thesis, Stefan was involved in a randomized controlled trial on iron supplementation and malaria chemoprophylaxis to prevent anaemia in infants in a rural area in Kenya. His second thesis was an epidemiological study to determine the representativeness of subjects in a calibration study among Dutch participants of the European Investigation into Cancer and nutrition (EPIC). He performed work on this thesis at the National Institute of Public Health and the Environment in Bilthoven, the Netherlands. In June 2001, Stefan graduated and started working as a SAS programmer at the pharmaceutical company Chiron BV in Amsterdam. From 2004, he was employed as a PhD student at the departments of Pathology and Epidemiology of the Maastricht University, where he worked on a project entitled: "Epigenetic silencing of caretaker genes as a cause of gatekeeper gene defects in sporadic colorectal cancer: modulation by dietary factors and polymorphisms in methyl donor metabolic enzymes" which resulted in the present thesis. Stefan is currently working as a post-doctoral fellow at the department of Public Health and Primary Health Care of the University of Bergen, Norway, where he continues to work in the field of folate and cancer. 


\section{List of publications}

\section{Abstracts}

- de Vogel S, Wouters KAD, Gottschalk R, van Schooten FJ, de Goeij AFPM, de Bruïne AP, Goldbohm RA, van den Brandt PA, Weijenberg MP, van Engeland M. Genetic variants of folate metabolizing enzymes and epigenetic regulation genes and sporadic colorectal cancer risk. Eur J Cancer 2008 Jul 6(9) Suppl:201. (Symposium "Integrative Molecular Cancer Epidemiology", International Agency for Research on Cancer (IARC), 3-5 July 2008, Lyon, France).

- de Vogel S, Bongaerts BW, Wouters KA, Kester AD, Schouten LJ, de Goeij AF, de Bruïne AP, Goldbohm RA, van den Brandt PA, van Engeland M, Weijenberg MP. Associations of dietary methyl donor intake with $M L H 1$ promoter hypermethylation and related molecular phenotypes in sporadic colorectal cancer. In Abstract book "AACR Advances in colorectal cancer research" (14-16 November 2007, Boston MA, USA).

- de Vogel S, Bongaerts BW, Wouters KA, de Goeij AF, de Bruïne AP, Goldbohm RA, van den Brandt PA, van Engeland M, Weijenberg MP. Dietary folate and vitamin B6 may increase colorectal cancer risk through BRAF mutations and MLH1 promoter methylation. In abstract book WEON:\#26 "Methodologische uitdagingen in cohortonderzoek" (WEON, Maastricht, the Netherlands, June 2007).

- de Vogel S, van Engeland $M$, Luchtenborg $M$, de Bruine AP, Roemen GM, Lentjes $\mathrm{MH}$, Goldbohm RA, van den Brandt PA, de Goeij AF, Weijenberg MP. Dietary folate and $A P C$ mutations in sporadic colorectal cancer: an indication for a distinct pathway of tumor development? Eur J Epidemiology 200621 Suppl;112-3. (Congress of the International Epidemiology Association (IEA) in Utrecht, the Netherlands, June 2006).

Full papers

- de Vogel S, Weijenberg MP, Herman JG, Wouters KAD, de Goeij AFPM, van den Brandt PA, de Bruïne AP, van Engeland M. MGMT and $M L H 1$ promoter methylation versus $A P C, K R A S$ and $B R A F$ gene mutations in colorectal cancer: indications for distinct pathways and sequence of events. Ann Oncol 2009, in press.

- $\quad$ Schouten $\mathrm{J}$, van Dijk BAC, Oosterwijk E, van Engeland M, Hulsbergen-van de Kaa CA, Kiemeney LALM, Goldbohm RA, Kester ADM, de Vogel S, Schalken JA, van den Brandt PA. Alcohol consumption and mutations or promoter hypermethylation of the Von Hippel-Lindau gene in renal cell carcinoma. Cancer Epidemiol Biomarkers Prev 2008 Dec;17(12):3543-50. 
- de Vogel S, Dindore V, van Engeland M, Goldbohm RA, van den Brandt PA, Weijenberg MP. Dietary folate, methionine, riboflavin and vitamin B-6 and risk of sporadic colorectal cancer. J Nutr 2008, Dec;138(12):2372-8.

- de Vogel S, Bongaerts BW, Wouters KAD, Kester ADM, Schouten L, de Goeij AFPM, de Bruïne AP, Goldbohm RA, van den Brandt PA, van Engeland $M$, Weijenberg MP. Associations of dietary methyl donor intake with MLH1 promoter hypermethylation and related molecular phenotypes in sporadic colorectal cancer. Carcinogenesis 2008 Sep;29(9):1765-73.

- $\quad$ van der Valk R, Webers CA, Hendrikse F, de Vogel S, Prins MH, Schouten JS. Predicting intraocular pressure change before initiating therapy: timolol versus latanoprost. Acta Ophthalmol 2008 Jun;86(4):415-8.

- Bongaerts BW, de Goeij AF, de Vogel S, van den Brandt PA, Goldbohm RA, Weijenberg MP. Alcohol consumption and distinct molecular pathways to colorectal cancer. Br J Nutr 2007 Mar;97(3):430-4.

- de Vogel S, van Engeland $M$, Luchtenborg $M$, de Bruine AP, Roemen GM, Lentjes $\mathrm{MH}$, Goldbohm RA, van den Brandt PA, de Goeij AF, Weijenberg MP. Dietary folate and APC mutations in sporadic colorectal cancer. J Nutr 2006 Dec;136(12):301521.

- Verhoef H, West CE, Nzyuko SM, de Vogel S, van der Valk R, Wanga MA, Kuijsten A, Veenemans J, Kok FJ. Intermittent administration of iron and sulfadoxinepyrimethamine to control anaemia in Kenyan children: a randomised controlled trial. Lancet 2002 Sep 21;360(9337):908-14.

\section{Manuscripts submitted for publication}

- de Vogel S, Wouters KAD, Gottschalk RWH, van Schooten FJ, de Goeij AFPM, de Bruïne AP, Goldbohm RA, van den Brandt PA, Weijenberg MP, van Engeland M. Genetic variants of methyl metabolizing enzymes and epigenetic regulators: associations with promoter CpG island hypermethylation in colorectal cancer.

- de Vogel S, Wouters KAD, Gottschalk RWH, van Schooten FJ, de Goeij AFPM, de Bruïne AP, Goldbohm RA, van den Brandt PA, Weijenberg MP, van Engeland $M$. Dietary methyl donors, methyl metabolizing enzymes and epigenetic regulators: diet-gene interactions and promoter $\mathrm{CpG}$ island hypermethylation in colorectal cancer. 